\title{
MODELO COMPUTACIONAL PARA DETERMINAÇÃO DO RISCO ECONÔMICO EM CULTURAS IRRIGADAS
}

\author{
PATRICIA ANGÉLICA ALVES MARQUES
}

Tese apresentada à Escola Superior de Agricultura "Luiz de Queiroz”, Universidade de São Paulo, para obtenção do título de Doutor em Agronomia, Área de Concentração: Irrigação e Drenagem.

\author{
P I R A C I C A B A
}

Estado de São Paulo - Brasil

Julho - 2005 


\title{
MODELO COMPUTACIONAL PARA DETERMINAÇÃO DO RISCO ECONÔMICO EM CULTURAS IRRIGADAS
}

\author{
PATRICIA ANGÉLICA ALVES MARQUES \\ Engenheiro Agrônomo
}

Orientador: Prof. Dr. JOSÉ ANTÔNIO FRIZZONE

Tese apresentada à Escola Superior de Agricultura "Luiz de Queiroz”, Universidade de São Paulo, para obtenção do título de Doutor em Agronomia, Área de Concentração: Irrigação e Drenagem.

\author{
P I R A C I C A B A
}

Estado de São Paulo - Brasil

Julho - 2005 
Dados Internacionais de Catalogação na Publicação (CIP) DIVISÃO DE BIBLIOTECA E DOCUMENTAÇÃO - ESALQ/USP

Marques, Patricia Angélica Alves

Modelo computacional para determinação do risco econômico em culturas irrigidas / Patricia Angélica Alves Marques. - - Piracicaba, 2005.

142 p. : il.

T ese (doutorado) - - Escola Superior de Agricultura Luiz de Queiroz, 2005. Bibliografia.

1. Análise de risco 2. Balanço hídrico 3. Estatística computacional 4. Evapotranspiração 5. Irrigação 6. Planta cultivada 7. Preço agrícola 8. Simulação (Estatística) I. Título

CDD 631.7 
À memória de minha mãe Edina Maria Lafrata Alves e a toda minha família.

Em especial para meu marido Tadeu Alcides Marques pela colaboração prestada e pelos momentos que lhe faltei para concluir esta Tese.

À minha princesa Sarah Alves Marques 


\section{AGRADECIMENTOS}

À Escola Superior de Agricultura “Luiz de Queiroz” ESALQ/USP, pela formação e amizade dos professores, funcionários e companheiros de estudo.

Ao Departamento de Engenharia Rural, pelo apoio e ensino, em especial à Davilmar Aparecida Domingues Collevatti e à Sandra Regina Thompson Silveira Mello.

Ao Prof. Dr. José Antônio Frizzone, pela sua orientação profissional e espiritual, por sua amizade, por seus ensinamentos e pelo encorajamento antes, durante e posteriormente a esta trabalhosa, mas importantíssima fase.

Ao Prof. Dr. Tarlei Arriel Botrel, que desde a minha graduação ajudou-me a traçar meu caminho profissional e minha paz.

À CAPES (Coordenadoria de Apoio à Pesquisa do Estado de São Paulo) pela viabilização do presente projeto.

Ao meu tio Atílio Vidal Lafratta e ao professor Newman Ribeiro Simões que desde minha infância incentivaram o espírito de curiosidade e desejo de aprender.

Aos amigos Prof. Dr. Nelson Barbosa Machado Neto e Amalia Inês Antão que muito me auxiliaram nos momentos mais difíceis.

A todos que direta ou indiretamente contribuíram para a realização deste trabalho. 


\section{SUMÁRIO}

Página

LISTA DE FIGURAS .......................................................................... vii

LISTA DE TABELAS ............................................................................ xi

LISTA DE SÍMBOLOS …......................................................................... xvi

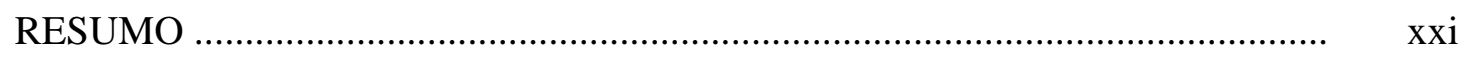

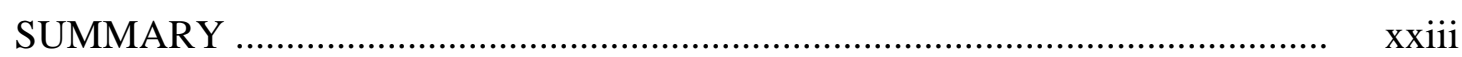

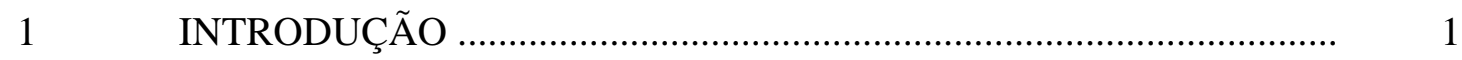

2 REVISÃO DE LITERATURA …................................................... 3

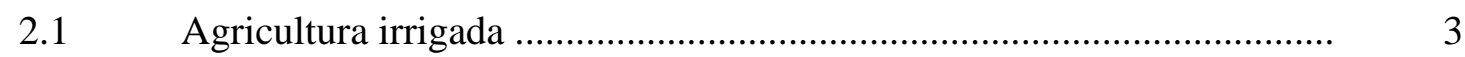

2.2 Seleção do sistema de irrigação ............................................................ 4

2.3 O risco na empresa agrícola .................................................................

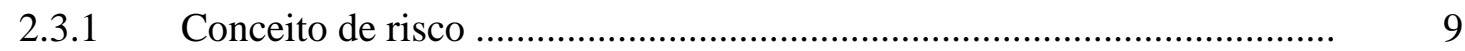

2.3.2 Fatores de risco no planejamento agrícola .............................................. 11

2.4 Análise de risco ................................................................................. 12

2.4.1 Análise de sensibilidade ....................................................................... 13

2.4.2 Simulação de dados ............................................................................. 13

2.4.3 Método de Monte Carlo ........................................................................ 14

2.4.4 Teste de aderência da distribuição simulada ............................................ 16 
2.4.5 O teste de Kolmogorov-Smirnov …................................................... 16

2.5 Projeto de viabilidade econômica de culturas irrigadas ........................... 17

2.5.1 Componentes da viabilidade econômica de culturas irrigadas ................. 18

2.5.2 Custos fixos da irrigação ...................................................................... 18

2.5.3 Custos variáveis da irrigação ..................................................................... 19

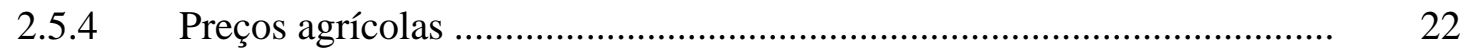

2.5.5 Benefícios da irrigação .......................................................................... 23

$2.6 \quad$ Informática na agricultura .................................................................. 23

$3 \quad$ MATERIAL E MÉTODOS ……….................................................... 26

3.1 Rotina “Características agronômicas do projeto e do solo” ...................... 29

Rotina “Características agronômicas da cultura” ................................... 30

3.3 Rotina “Características do sistema de irrigação” ................................... 31

Rotina “Seleção dos dados climáticos por região” .................................. 32

3.5 Rotina “Cálculo da evapotranspiração de referência (ETo)” .................. 32

3.6 Rotina "Balanço hídrico" ..................................................................... 37

3.7 Rotina "Benefícios brutos da irrigação" ............................................... 40

3.8 Rotina "Custos fixos” "........................................................................... 41

3.8.1 Simulação ..................................................................................... 42

3.8.2 Cálculo das freqüências relativa e acumulada ........................................ 43

3.8.3 Cálculo do custo fixo anual ........................................................................ 44

Rotina “Custos variáveis” ..................................................................... 45

3.9.1 Custo de manutenção ............................................................................. 47

3.9.2 Custo de bombeamento para motor elétrico .............................................. 47 
3.9.2.1 Tarifa convencional ..................................................................... 49

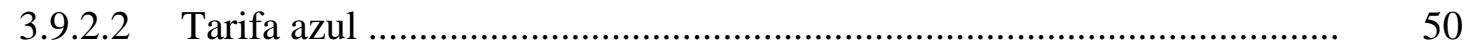

3.9.2.3 Tarifa verde .............................................................................. 52

3.9.3 Custo do bombeamento para motor diesel .............................................. 53

3.9.4 Custo da mão-de-obra …………………................................................ 53

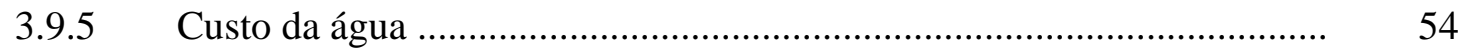

3.10 Rotina "Custo total anual da irrigação” .................................................... 55

3.11 Rotina "Benefícios líquidos anuais da irrigação (BLA)” ........................ 55

3.12 Rotina “Teste de aderência da distribuição de probabilidades do

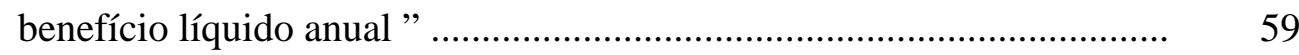

3.13 Rotina “Análise de sensibilidade do benefício líquido anual” ................ 62

3.14 Levantamento de dados para análise do risco econômico ………............. 62

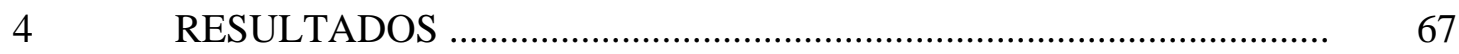

4.1 Apresentação do modelo ................................................................ 67

4.2 Análise econômica e análise de sensibilidade utilizando o modelo ......... 82

4.2.1 Análise econômica e análise de sensibilidade para a cultura de cana-deaçúcar na região de Piracicaba ............................................................. 84

4.2.2 Análise econômica e análise de sensibilidade para a cultura do tomate industrial na região de Piracicaba ......................................................... 92

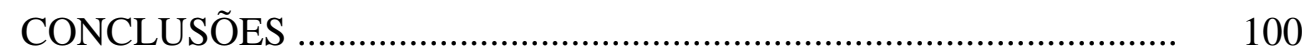

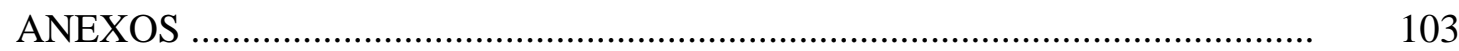

REFERÊNCIAS BIBLIOGRÁFICAS ............................................................. 127 


\section{LISTA DE FIGURAS}

Página

1 Exemplo de risco em duas alternativas de investimento (Fonte: Frizzone \& Silveira, 2000)

2 Fluxograma geral do modelo computacional para determinação do risco econômico em culturas irrigadas

3 Seqüência de rotinas do projeto

4 Fluxograma da rotina de características agronômicas do projeto e solo

5 Fluxograma da rotina de características da cultura ..... 30

6 Fluxograma da rotina de características do sistema de irrigação

7 Fluxograma da rotina de cálculo da evapotranspiração de referência

8 Fluxograma da rotina de balanço hídrico 38

9 Fluxograma da rotina de benefícios brutos da irrigação

10 Fluxograma da rotina de cálculo do custo fixo anual da irrigação 42

11 Fluxograma da rotina de cálculo do custo variável anual da irrigação 46

12 Fluxograma da rotina de cálculo do custo total da irrigação 55

13 Fluxograma da rotina do benefício líquido anual da irrigação (BLA) ... 56

14 Fluxograma da rotina do teste de aderência da distribuição de probabilidades do benefício líquido anual 
15 Tela principal do modelo computacional para determinação do risco econômico em culturas irrigadas ...................................................................... 68

16 Tela para criar novo projeto de viabilidade incluindo risco .............................. 68

$17 \quad$ Tela para acessar projeto já salvo ….................................................................... 69

18 Tela de características agronômicas do projeto .................................................... 69

19 Tela de características agronômicas do solo ....................................................... 70

20 Tela de características agronômicas da cultura: dados da cultura ...................... 71

21 Tela de características agronômicas da cultura: valores de kc, período em dias e profundidade efetiva do sistema radicular ............................................... 71

22 Tela de características do sistema de irrigação ................................................... 72

23 Tela de seleção de dados climáticos por região ................................................ 72

24 Tela de cálculo do balanço hídrico diário ........................................................... 73

25 Tela de cálculo da evapotranspiração de referência .......................................... 74

26 Tela de benefícios brutos da irrigação ................................................................ 74

27 Tela de custos fixos anuais da irrigação ........................................................... $\quad 75$

28 Tela de simulação da taxa de juros ................................................................... 75

29 Tela de simulação da vida útil do sistema de irrigação .................................... 76

30 Tela de custos variáveis anuais da irrigação ...................................................... 77

31 Tela de simulação da taxa de manutenção ........................................................ 77

32 Tela de simulação do preço da água para o cálculo do custo da água .............. 78

33 Tela de simulação do número de horas por hectare e por irrigação para o cálculo do custo da mão-de-obra ..................................................................... $\quad 78$

34 Tela de cálculo do custo do bombeamento ...................................................... 79 
35 Tela do custo total da irrigação ....................................................................... 80

36 Tela do cálculo dos benefícios líquidos e dos coeficientes econômicos .......... 80

37 Tela do teste de aderência da distribuição pelo método de KolmogorovSmirnov

38 Tela da análise de sensibilidade do benefício líquido anual com a variação dos fatores econômicos

39 Distribuição de freqüência obtida por uma simulação do valor de venda do produto para cana-de-açúcar

40 Distribuição de freqüência obtida por uma simulação do valor de venda do produto para tomate industrial

41 Distribuição de freqüência obtida por uma simulação da taxa de juros anual .. 106

42 Distribuição de freqüência obtida por uma simulação da vida útil dos sistemas de irrigação pivô central e deslocamento linear

43 Distribuição de freqüência obtida por uma simulação da vida útil do sistema de irrigação autopropelido

44 Distribuição de freqüência obtida por uma simulação da vida útil do sistema de irrigação aspersão convencional

45 Distribuição de freqüência obtida por uma simulação da taxa de manutenção do sistema de irrigação pivô central

46 Distribuição de freqüência obtida por uma simulação da taxa de manutenção dos sistemas de irrigação deslocamento linear e autopropelido

47 Distribuição de freqüência obtida por uma simulação da taxa de manutenção do sistema de irrigação aspersão convencional

48 Distribuição de freqüência obtida por uma simulação da mão-de-obra para o sistema de irrigação pivô central 
49 Distribuição de freqüência obtida por uma simulação da mão-de-obra para o sistema de irrigação deslocamento linear

50 Distribuição de freqüência obtida por uma simulação da mão-de-obra para o sistema de irrigação autopropelido

51 Distribuição de freqüência obtida por uma simulação da mão-de-obra para o sistema de irrigação aspersão convencional

52 Distribuição de freqüência obtida por uma simulação do preço da água 


\section{LISTA DE TABELAS}

Página

1 Valores médios de eficiência de irrigação, uso de energia e de mão-de-obra dos sistemas de irrigação ..................................................................................... 5

2 Vida útil e custo de manutenção dos sistemas de irrigação ................................ 6

3 Área irrigada, em 1.000 ha, no Brasil por sistema de irrigação no ano de 2001

4 Radiação solar global extraterrestre (Qo em mm de evaporação equivalente por dia) no $15^{\circ}$ dia do mês correspondente, para a Latitude (Lat) do hemisfério Sul

5 Tarifas de energia elétrica do grupo A4, para as modalidades de Tarifa Verde, Tarifa Azul e Tarifa Convencional (16/11/2004)

6 Fatores fixos utilizados para a cultura da cultura da cana-de-açúcar e para a cultura do tomate industrial

7 Características dos sistemas de irrigação utilizados

8 Valores utilizados na simulação por Monte Carlo para os valores de venda da cultura de cana-de-açúcar e da cultura do tomate industrial

9 Valores utilizados na simulação por Monte Carlo para os fatores envolvidos nos custos fixos: vida útil do sistema de irrigação e taxa de juros

10 Valores utilizados na simulação por Monte Carlo para os fatores envolvidos nos custos variáveis: taxa de manutenção do sistema de irrigação, horas de trabalho para irrigação e preço da água 
11 Valores esperados obtidos nos estudos para a cultura da cana-de-açúcar na região de Piracicaba

12 Valores esperados obtidos nos estudos para a cultura do tomate industrial na região de Piracicaba

13 Valores médios da relação B/C para os sistemas de irrigação em função do tipo de motor e de tarifa, para a cultura da cana-de-açúcar na região de Piracicaba

14 Coeficientes médios de risco para os sistemas de irrigação considerando a cultura da cana-de-açúcar na região de Piracicaba

15 Valores médios de probabilidade de benefício líquido anual $>0$ (\%) para os sistemas de irrigação em função do tipo de motor e de tarifa, para a cultura da cana-de-açúcar na região de Piracicaba

16 Valores médios de benefícios líquidos anuais e custos médios anuais advindos do uso da irrigação, para os sistemas de irrigação utilizando motor elétrico na cultura da cana-de-açúcar para a região de Piracicaba

17 Participação percentual dos custos advindos da irrigação no custo total da irrigação da cana-de-açúcar utilizando motor elétrico para Piracicaba

18 Benefícios líquidos anuais e custos médios anuais advindos do uso da irrigação para os sistemas de irrigação utilizando motor diesel para cana-deaçúcar na região de Piracicaba

19 Participação percentual dos custos advindos da irrigação no custo total da irrigação utilizando motor diesel para cana-de-açúcar na região de Piracicaba

20 Custo anual do bombeamento para os sistemas de irrigação em função do tipo de motor e de tarifa para cana-de-açúcar na região de Piracicaba 
21 Análise de sensibilidade do benefício líquido anual, com a variação de $\pm 20 \%$, para os sistemas de irrigação para a cana-de-açúcar na região de Piracicaba

22 Valores médios da relação B/C para os sistemas de irrigação em função do tipo de motor e de tarifa, para a cultura do tomate industrial na região de Piracicaba

23 Coeficientes médios de risco para os sistemas de irrigação considerando a cultura do tomate industrial na região de Piracicaba

24 Valores médios da probabilidade de benefício líquido anual > 0 (\%) para os sistemas de irrigação em função do tipo de motor e de tarifa, para a cultura do tomate industrial na região de Piracicaba

25 Valores médios de benefícios líquidos anuais e custos médios anuais advindos do uso da irrigação, para os sistemas de irrigação utilizando motor elétrico na cultura do tomate industrial para a região de Piracicaba

26 Participação percentual dos custos advindos da irrigação no custo total da irrigação do tomate industrial utilizando motor elétrico para Piracicaba

27 Benefícios líquidos anuais e custos médios anuais advindos do uso da irrigação para os sistemas de irrigação utilizando motor diesel para tomate industrial na região de Piracicaba

28 Participação percentual dos custos advindos da irrigação no custo total da irrigação utilizando motor diesel para tomate industrial na região de Piracicaba

29 Custo do bombeamento para os sistemas de irrigação em função do tipo de motor e de tarifa para tomate industrial na região de Piracicaba

30 Análise de sensibilidade do benefício líquido anual, com a variação de $\pm 20 \%$, para os sistemas de irrigação para o tomate industrial na região de Piracicaba 
31 Índices econômicos obtidos para irrigação da cana-de-açúcar para o pivô central utilizando energia elétrica para os anos estudados

32 Índices econômicos obtidos para irrigação da cana-de-açúcar para o deslocamento linear utilizando energia elétrica, para os anos estudados

33 Índices econômicos obtidos para irrigação da cana-de-açúcar para o autopropelido utilizando energia elétrica, para os anos estudados

34 Índices econômicos obtidos para irrigação da cana-de-açúcar para o pivô central utilizando óleo diesel, para os anos estudados

35 Índices econômicos obtidos para irrigação da cana-de-açúcar para o deslocamento linear utilizando óleo diesel, para os anos estudados

36 Índices econômicos obtidos para irrigação da cana-de-açúcar, para o autopropelido utilizando óleo diesel, para os anos estudados

37 Índices econômicos obtidos para irrigação do tomate industrial para o pivô central utilizando energia elétrica para os anos estudados

38 Índices econômicos obtidos para irrigação do tomate industrial para aspersão convencional utilizando energia elétrica, para os anos estudados

39 Índices econômicos obtidos para irrigação do tomate industrial para o autopropelido utilizando energia elétrica, para os anos estudados

40 Índices econômicos obtidos para irrigação do tomate industrial para o pivô central utilizando óleo diesel, para os anos estudados

41 Índices econômicos obtidos para irrigação do tomate industrial para aspersão convencional utilizando óleo diesel, para os anos estudados

42 Índices econômicos obtidos para irrigação do tomate industrial, para o autopropelido utilizando óleo diesel, para os anos estudados 
43 Análise de sensibilidade do benefício líquido, com variação de -20\% e +20\%, para pivô central em cana-de-açúcar, anos de 2001, 2002, 2003 e 2004

44 Análise de sensibilidade do benefício líquido, com variação de -20\% e +20\%, para autopropelido em cana-de-açúcar, anos de 2001, 2002, 2003 e 2004

45 Análise de sensibilidade do benefício líquido, com variação de -20\% e +20\%, para deslocamento linear em cana-de-açúcar, anos de 2001, 2002, 2003 e 2004

46 Análise de sensibilidade do benefício líquido, com variação de -20\% e +20\%, para pivô central em tomate industrial, anos de 2001, 2002, 2003 e 2004

47 Análise de sensibilidade do benefício líquido, com variação de -20\% e +20\%, para aspersão convencional em tomate industrial, anos de 2001, 2002, 2003 e 2004

48 Análise de sensibilidade do benefício líquido, com variação de -20\% e +20\%, para autopropelido em tomate industrial, anos de 2001, 2002, 2003 e 2004 


\section{LISTA DE SÍMBOLOS}

a - valor mínimo

Alt - alteração no armazenamento de água no solo ( $\mathrm{mm} \mathrm{dia}^{-1}$ )

b - valor máximo

B/C - relação benefício/custo

$\mathrm{Bi}$ - benefício bruto anual da irrigação ( $\left.\mathrm{R} \$ \mathrm{ha}^{-1} \mathrm{ano}^{-1}\right)$

BLA - benefício líquido anual da irrigação $\left(\mathrm{R} \$ \mathrm{ha}^{-1} \mathrm{ano}^{-1}\right)$

Cab - custo anual do bombeamento $\left(\mathrm{R} \$ \mathrm{ha}^{-1} \mathrm{ano}^{-1}\right)$

Cam - custo anual de manutenção ( $\left.\mathrm{R} \$ \mathrm{ha}^{-1} \mathrm{ano}^{-1}\right)$

Camo - custo anual da mão-de-obra ( $\mathrm{R} \$$ ha $\left.^{-1} \mathrm{ano}^{-1}\right)$

Caw - custo anual da água ( $\left.\mathrm{R} \$ \mathrm{ha}^{-1} \mathrm{ano}^{-1}\right)$

$\mathrm{CF}_{\mathrm{a}}$ - custo fixo anual da irrigação $\left(\mathrm{R} \$ \mathrm{ha}^{-1} \mathrm{ano}^{-1}\right)$

Co - custo do óleo diesel na propriedade $\left(\mathrm{R} \$ \mathrm{~L}^{-1}\right)$

$\cos \varphi$ - fator de potência

$\mathrm{Cp}$ - custo de produção independente da irrigação $\left(\mathrm{R} \$ \mathrm{Mg}^{-1}\right)$

Cs - consumo específico do motor diesel $\left(\mathrm{g} \mathrm{cv}^{-1} \mathrm{~h}^{-1}\right)$

$\mathrm{CT}_{\mathrm{a}}$ - custo total anual da irrigação $\left(\mathrm{R} \$ \mathrm{ha}^{-1} \mathrm{ano}^{-1}\right)$

$\mathrm{CV}_{\mathrm{a}}$ - custo variável anual da irrigação $\left(\mathrm{R} \$ \mathrm{ha}^{-1} \mathrm{ano}^{-1}\right)$

CV - coeficiente de variação (\%)

Demanda - demanda contratada $\left(\mathrm{kW} \mathrm{ha}^{-1}\right)$

Df - demanda ocorrida no horário fora de ponta $\left(\mathrm{kW} \mathrm{ha}^{-1}\right)$

dgi - densidade do solo para a camada i $\left(\mathrm{g} \mathrm{cm}^{-3}\right)$

$\mathrm{DM}$ - desvio médio absoluto $\left(\mathrm{R} \$ \mathrm{ha}^{-1} \mathrm{ano}^{-1}\right)$

Dp - demanda ocorrida no horário de ponta (18h às 21h) $\left(\mathrm{kW} \mathrm{ha}^{-1}\right)$ 
DTAi - disponibilidade total de água do solo para a camada i $\left(\mathrm{mm} \mathrm{cm}^{-1}\right)$

DTAj - disponibilidade total de água do solo para a fase fenológica j(mm)

DRAj - disponibilidade real de água do solo para a fase fenológica j(mm)

$\mathrm{e}_{\mathrm{a}}$ - pressão parcial de vapor $(\mathrm{kPa})$

Ea - eficiência de aplicação de água (decimal)

Encargos - encargos pagos relativos a férias, $13^{\circ}$ salário e INSS (\%);

$\mathrm{e}_{\mathrm{s}}$ - pressão de saturação de vapor $(\mathrm{kPa})$

ETc (mensal) - evapotranspiração da cultura acumulada para cada mês (mm mês ${ }^{-1}$ )

ETc - evapotranspiração da cultura $\left(\mathrm{mm} \mathrm{dia}^{-1}\right)$

ETo - evapotranspiração de referência $\left(\mathrm{mm} \mathrm{dia}^{-1}\right)$

$\operatorname{ETm}_{a}$ - Evapotranspiração máxima anual para um ciclo total por ano da cultura $\left(\mathrm{mm} \mathrm{ano}^{-1}\right)$

ETr - Evapotranspiração real diária (mm dia $\left.{ }^{-1}\right)$

$\mathrm{ETr}_{\mathrm{a}}$ - Evapotranspiração real anual para um ciclo total por ano da cultura (mm ano-1)

$\mathrm{E}(\mathrm{X})$ - valor esperado do fator $\left(\mathrm{R} \$ \mathrm{ha}^{-1} \mathrm{ano}^{-1}\right)$

Férias - encargo pago relativo a férias em porcentagem do salário (\%)

f - fator de esgotamento de água do solo FAO (Doorenbos \& Pruitt, 1984)

FCa - faturamento anual de consumo $\left(\mathrm{R} \$ \mathrm{ha}^{-1} \mathrm{ano}^{-1}\right)$

FCm - faturamento mensal de consumo ( $\mathrm{R} \$$ ha $\left.^{-1} \mathrm{mês}^{-1}\right)$

fd - fator de desconto da Portaria 105 DNAEE (\%)

FDa - faturamento anual de demanda ( $\left.\mathrm{R} \$ \mathrm{ha}^{-1} \mathrm{ano}^{-1}\right)$

FDm - faturamento mensal de demanda ( $\left.\mathrm{R} \$ \mathrm{ha}^{-1} \mathrm{mês}^{-1}\right)$

$\mathrm{f}_{\mathrm{i}}$ - freqüência relativa de $\mathrm{Xi}$

$\mathrm{Fi}$ - freqüiência acumulada de Xi

FRC - fator de recuperação de capital (decimal)

$\mathrm{G}$ - fluxo total diário de calor no solo $\left(\mathrm{MJ} \mathrm{m}^{-2} \mathrm{dia}^{-1}\right)$

$\mathrm{H}$ - horas de funcionamento mensal (h ha ${ }^{-1}$ mês $^{-1}$ )

Hd - horas de funcionamento com desconto (21h30 às 6h) (h ha ${ }^{-1}$ mês $^{-1}$ )

$\mathrm{HI}$ - horas de trabalho necessárias por hectare e por irrigação $\left(\mathrm{h} \mathrm{ha}^{-1}\right.$ irrigação $^{-1}$ )

$\mathrm{Hp}$ - horas de funcionamento no horário de ponta (18h às 21h) (h ha ${ }^{-1}$ mês $\left.^{-1}\right)$ 
Hs - horas de funcionamento sem desconto $(\mathrm{Hs}=\mathrm{H}-\mathrm{Hd})\left(\mathrm{h} \mathrm{ha}^{-1}\right.$ mês $\left.^{-1}\right)$

Hsf - horas de funcionamento fora de ponta sem desconto ( $\mathrm{h} \mathrm{ha}^{-1} \mathrm{mês}^{-1}$ )

i - taxa de juros ao ano (decimal)

INSS - encargo pago relativo ao INSS em porcentagem do salário (\%)

ICMS - Imposto sobre circulação de mercadorias e serviços cobrado na região (decimal)

IT - encargo pago relativo ao INSS do $13^{\circ}$ salário em porcentagem do salário (\%)

Kc - coeficiente de cultura

Ky - fator de resposta da cultura para um ciclo total por ano da cultura (Doorenbos \& Kassam, 2000)

Lat - latitude

LBm - lâmina bruta da de irrigação mensal (mm mês $\left.{ }^{-1}\right)$

LLm - lâmina líquida de irrigação mensal ( $\mathrm{mm} \mathrm{mês}^{-1}$ )

m - valor modal

$\mathrm{n}$ - vida útil do equipamento (anos)

$\mathrm{N}$ - número total de observações

$\mathrm{N}(\mathrm{Xi})$ - número de vezes que ocorre Xi

NId - necessidade de irrigação diária (mm)

$\mathrm{P}$ - precipitação diária $\left(\mathrm{mm} \mathrm{dia}{ }^{-1}\right)$

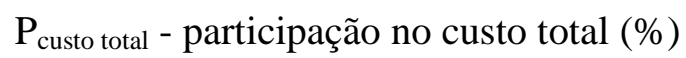

$\mathrm{Pa}$ - preço da água $\left(\mathrm{R} \$ \mathrm{~m}^{-3}\right)$

Pot - potência do motor (cv ha $\left.{ }^{-1}\right)$

$\mathrm{Pp}$ - preço pago ao produtor $\left(\mathrm{R} \$ \mathrm{Mg}^{-1}\right)$

PS - preço de aquisição e instalação do equipamento de irrigação ( $\mathrm{R}$ \$ ha $\left.{ }^{-1}\right)$

$\mathrm{Q}$ - vazão $\left(\mathrm{m}^{3} \mathrm{ha}^{-1} \mathrm{~h}^{-1}\right)$

Qo - radiação solar global extraterrestre (mm de evaporação equivalente dia $^{-1}$ )

r* - valor de referência

$\mathrm{Ri}$ - receita bruta anual com irrigação $\left(\mathrm{R} \$ \mathrm{ha}^{-1} \mathrm{ano}^{-1}\right)$

$\mathrm{Rn}$ - radiação líquida total diária $\left(\mathrm{MJ} \mathrm{m}^{-2} \mathrm{dia}^{-1}\right)$

Rs - receita bruta anual sem irrigação $\left(\mathrm{R} \$ \mathrm{ha}^{-1} \mathrm{ano}^{-1}\right)$

$\mathrm{S}$ - salário mensal ( $\mathrm{R} \$$ mês $\left.^{-1}\right)$ 
$\mathrm{S}$ - declividade da curva de pressão de vapor $\left(\mathrm{kPa}^{\circ} \mathrm{C}^{-1}\right)$

$\mathrm{T}$ - encargo pago relativo ao $13^{\circ}$ salário em porcentagem do salário (\%)

Tarifas - tarifas de energia elétrica de consumo $\left(\mathrm{R} \$ \mathrm{kWh}^{-1}\right)$ e de demanda $\left(\mathrm{R} \$ \mathrm{~kW}^{-1}\right)$

$\mathrm{T}_{3 \mathrm{~d}}$ - temperatura média dos três dias anteriores $\left({ }^{\circ} \mathrm{C}\right)$

TCazsf - tarifa de consumo azul fora de ponta período seco referente aos meses de maio a novembro $\left(\mathrm{R} \$ \mathrm{kWh}^{-1}\right)$

TCazsp - tarifa de consumo azul horário de ponta período seco referente aos meses de maio a novembro $\left(\mathrm{R} \$ \mathrm{kWh}^{-1}\right)$

TCazuf - tarifa de consumo azul fora de ponta período úmido referente aos meses de dezembro a abril $\left(\mathrm{R} \$ \mathrm{kWh}^{-1}\right)$

TCazup - tarifa de consumo azul horário de ponta período úmido referente aos meses de dezembro a abril $\left(\mathrm{R} \$ \mathrm{kWh}^{-1}\right)$

TCc - tarifa de consumo convencional referente ao valor de venda de um kWh de energia consumida $\left(\mathrm{R} \$ \mathrm{kWh}^{-1}\right)$

TCvfs - tarifa de consumo verde fora de ponta no período seco referente aos meses de maio a novembro $\left(\mathrm{R} \$ \mathrm{kWh}^{-1}\right)$

TCvfu - tarifa de consumo verde fora de ponta no período úmido referente aos meses de dezembro a abril $\left(\mathrm{R} \$ \mathrm{kWh}^{-1}\right)$

TCvps - tarifa de consumo verde de ponta no período seco referente aos meses de maio a novembro $\left(\mathrm{R} \$ \mathrm{kWh}^{-1}\right)$

TCvpu - tarifa de consumo verde de ponta no período úmido referente aos meses de dezembro a abril $\left(\mathrm{R} \$ \mathrm{kWh}^{-1}\right)$

Tdem - tarifa de demanda referente ao valor de $1 \mathrm{~kW}$ de potência demandada, que dá o direito à sua utilização pelo período de um mês $\left(\mathrm{R} \$ \mathrm{~kW}^{-1}\right)$

Td - temperatura média diária $\left({ }^{\circ} \mathrm{C}\right)$

Tdazf - tarifa de demanda azul no horário fora de ponta $\left(\mathrm{R} \$ \mathrm{~kW}^{-1}\right)$

Tdazp - tarifa de demanda azul no horário de ponta $\left(\mathrm{R} \$ \mathrm{~kW}^{-1}\right)$

$\mathrm{Tdv}$ - tarifa de demanda verde $\left(\mathrm{R} \$ \mathrm{~kW}^{-1}\right)$

Tm - taxa anual de manutenção (\%)

Tmáx - temperatura máxima média diária $\left({ }^{\circ} \mathrm{C}\right)$ 
Tmín - temperatura mínima média diária $\left({ }^{\circ} \mathrm{C}\right)$

$\mathrm{U}_{2}$ - velocidade do vento $\left(\mathrm{m} \mathrm{s}^{-1}\right)$ a $2 \mathrm{~m}$ de altura da superfície do solo

$\mathrm{Ucc}_{\mathrm{i}}$ - umidade do solo à capacidade de campo para a camada i (\% em massa)

Upmp $_{\mathrm{i}}$ - umidade do solo a ponto de murcha permanente para a camada i (\% em massa)

UR - umidade relativa média (\%)

VR - valor residual do sistema de irrigação $\left(\mathrm{R} \$ \mathrm{ha}^{-1}\right)$

W - fator de ponderação dependente da temperatura

$\mathrm{E}(\mathrm{X})_{\text {custototal- }}$ valor esperado do custo total da irrigação $\left(\mathrm{R} \$ \mathrm{ha}^{-1} \mathrm{ano}^{-1}\right)$

$\mathrm{E}(\mathrm{X})_{\text {fator }}$ - valor esperado do fator estudado $\left(\mathrm{R} \$ \mathrm{ha}^{-1} \mathrm{ano}^{-1}\right)$

$\mathrm{X}_{\mathrm{i}}$ - valor da variável i $\left(\mathrm{R} \$ \mathrm{ha}^{-1} \mathrm{ano}^{-1}\right)$

Xsi - valor simulado para o ano i

Yi - produtividade com irrigação para um ciclo total por ano da cultura ( $\mathrm{Mg} \mathrm{ha}^{-1} \mathrm{ano}^{-1}$ )

Ys - produtividade sem irrigação para um ciclo total por ano da cultura ( $\mathrm{Mg} \mathrm{ha}^{-1} \mathrm{ano}^{-1}$ )

$\mathrm{z}$ - profundidade efetiva do sistema radicular (cm)

$\mathrm{z}_{\mathrm{i}}$ - profundidade de cada camada i (cm)

$\mu$ - média

$\sigma$ - desvio padrão ( $\left.\mathrm{R} \$ \mathrm{ha}^{-1} \mathrm{ano}^{-1}\right)$

$\sigma^{2}-$ variância $\left(\mathrm{R}^{2} \mathrm{ha}^{-1} \mathrm{ano}^{-1}\right)$

$\gamma$ - constante psicrométrica $=0,063 \mathrm{kPa}^{\circ} \mathrm{C}^{-1}$

$\theta \mathrm{CC}_{\mathrm{i}}$ - umidade do solo à capacidade de campo para a camada i (\% em volume)

$\theta \mathrm{pmp}_{\mathrm{i}}$ - umidade do solo a ponto de murcha permanente para a camada i (\% em volume) 


\title{
MODELO COMPUTACIONAL PARA DETERMINAÇÃO DO RISCO ECONÔMICO EM CULTURAS IRRIGADAS
}

\author{
Autora: PATRICIA ANGÉLICA ALVES MARQUES \\ Orientador: Prof. Dr. JOSÉ ANTÔNIO FRIZZONE
}

\section{RESUMO}

As empresas agrícolas atuam sob condições de risco, dessa maneira a utilidade de modelos determinísticos para fins de planejamento torna-se relativamente limitada. Isto implica na necessidade de não se desprezar a aleatoriedade de determinados coeficientes e introduzir o risco na análise do projeto. Com este objetivo, desenvolveu-se uma ferramenta na forma de um Modelo Computacional para Determinação do Risco Econômico em Culturas Irrigadas, para o ambiente Windows XP em linguagem Delphi 7.0, que permite simular situações de implantação e manejo da irrigação e suas conseqüências econômicas sob o horizonte de risco. Esse modelo considera, na forma de um projeto, as características agronômicas pertinentes ao solo, a cultura e ao clima, para estudar, de maneira regional, o armazenamento de água no solo, a evapotranspiração, o desenvolvimento da cultura durante as fases fenológicas e o preço de venda do produto. Para atingir o objetivo o modelo realiza simulações dos parâmetros de preço de venda do produto, taxa de manutenção do sistema de irrigação, horas de trabalho necessárias por hectare e por irrigação realizada, preço da água, vida útil do sistema de irrigação e taxa de juros; as quais são classificadas em classes, sendo: cinco classes para vida útil, taxa de manutenção, horas de trabalho necessárias por 
hectare e por irrigação realizada, preço da água e juros, e 10 classes para o preço de venda do produto. Com esses parâmetros o modelo computacional gera 31.250 valores de benefícios líquidos anuais combinados das classes com suas respectivas probabilidades de ocorrência, permitindo assim um estudo probabilístico dos possíveis resultados da decisão de aquisição do sistema de irrigação. Como resultados essa ferramenta simula e fornece a distribuição de probabilidades dos fatores econômicos e calcula os custos fixos, custos variáveis, custos totais e benefícios líquidos anuais da irrigação. Com os 31.250 valores de benefícios líquidos anuais e suas probabilidades realiza o teste de aderência às funções de densidade de probabilidade normal ou triangular e posteriormente exibe as probabilidades de viabilidade do projeto, a relação benefício/custo, valor esperado de benefício líquido, desvio absoluto, variância, desvio padrão e coeficiente de variação como índices econômicos envolvidos na decisão de irrigar ou não irrigar. Apresenta também uma análise de sensibilidade do benefício líquido anual em função da variação dos fatores econômicos e a participação em porcentagem dos fatores econômicos na formação do custo total da irrigação. Nas análises realizadas sobre a irrigação da cana-de-açúcar para região de Piracicaba, todos os sistemas testados apresentaram relação benefício/custo inferior a um e valores esperados de benefício líquido anual da irrigação negativos, indicando inviabilidade. A utilização do motor diesel apresentou para todos os sistemas, probabilidade nula de ocorrência de benefício líquido anual maior que zero. Dentre os sistemas analisados o pivô central apresentou a maior probabilidade de ocorrência de benefício líquido anual maior que zero $(10,70 \%)$ utilizando energia elétrica. No caso da irrigação do tomate industrial na região de Piracicaba todos os sistemas testados apresentaram viabilidade, isto é, relação benefício/custo sempre maior que um e valores esperados de benefício líquido anual positivos. Dentre eles a aspersão convencional apresentou a maior relação benefício/custo (média de 4,74), o maior valor esperado de benefício líquido anual ( R \$ 1.582,60 ha ${ }^{-1}$ ano $^{-1}$ ) e o menor risco com um desvio padrão de $\mathrm{R} \$ 363,99 \mathrm{ha}^{-1} \mathrm{ano}^{-1}$ 


\title{
COMPUTATIONAL MODEL FOR ECONOMICAL RISK DETERMINATION IN IRRIGATED CULTURES
}

\author{
Author: PATRICIA ANGÉLICA ALVES MARQUES \\ Adviser: Prof. Dr. JOSÉ ANTÔNIO FRIZZONE
}

\section{SUMMARY}

The agricultural companies were submitted to risky conditions, so the utility of deterministic models to planning is relatively limited. That implies in not despise the randomness of some coefficients and to introduce them in the project analysis. As a proposal of this work a Computational model for risk determination in irrigated cultures was elaborated for Windows $\mathrm{XP}^{\circledR}$ in Delphi 7.0 language, that allow the simulation of implanting and managing irrigations projects and their economical consequences under the risk conditions. This model considers, in a project form, the agronomical characteristics of the soil, of the culture and of the climate, to study, regionally, the water storage in the soil, the evapotranspiration, the culture development during the phenological phases and the selling price of the product. To reach its objectives the model accomplishes simulations in the selling price of the product, maintaining cost of the irrigation system, hours of needed work by hectare and per irrigation, water cost, useful life of the system and the welfare taxes, that were classified in classes as: five for useful live, maintain tax, hours of needed work by hectare and per irrigation, water cost and welfare taxes; and ten for selling price. With those parameters the model generated 31,250 values of annual combined liquid profits of the classes with their respective 
probability of occurrence, allowing a probabilistic study of the possible results in the acquisition of an irrigation system, e.g., the probability of the project viability. This tool, as its results, simulates and displays the economical factor probability and calculates the variable and the non variable costs, total costs and annual profits of irrigation. With the 31,250 values of annual profits and their probabilities, it realizes the adherence test to the density functions of normal or triangular probability and exhibits the project viability probabilities, cost/profit relation, expected value of liquid profit, absolute deviance, variance, standard deviation and coefficient of variation as economical indexes involved in the decision of or not of to irrigate. It also presents a sensibility analysis of the annual profit as a function of the economical variation factors and the participation, in percentage, of those factors in the total cost of the irrigation. In the analysis of sugarcane irrigation in the Piracicaba region, all tested systems showed a cost/profit relation inferior to one and expected annual irrigation profit values negative indicating the inviability. The use of a diesel motor, for any system, showed the null probability of the annual profit to be higher then zero. Among the tested systems the center pivot showed the highest probability of annual liquid profits higher then zero (10.7\%) using electrical energy. In the case of tomato culture for industry under irrigation, in the Piracicaba region, all systems were viable, e.g., the relation cost/profit ever higher then one and expected values of annual liquid profits positive. Among them the conventional aspersion showed the higher relation between cost/profit with a mean of 4.74, the highest expected value of annual liquid profit of $\mathrm{R} \$ 1,582.60 \mathrm{ha}^{-1}$ year $^{-1}$ and with the lower risk with standard deviation of R\$ $363.99 \mathrm{ha}^{-1}$ year $^{-1}$. 


\section{INTRODUÇÃO}

A irrigação é uma das mais importantes tecnologias empregadas para aumentar a produtividade e permitir maior eficiência e estabilidade na produção agrícola. A sua adoção deve ser baseada na viabilidade técnica e econômica do projeto, obtida por meio da análise detalhada e cuidadosa dos fatores climáticos, agronômicos e econômicos envolvidos. A análise do projeto permite identificar as possibilidades econômicas decorridas do investimento e permitir ao tomador de decisão selecionar de forma racional a alternativa mais viável.

A irrigação pode ajudar os agricultores reduzindo ou eliminando as perdas causadas pelo déficit hídrico, porém os riscos econômicos permanecem. Na agricultura irrigada, uma produção eficiente e rentável deve constituir o principal objetivo econômico, buscando sempre receitas maiores que os custos. Desta maneira é importante conhecer o grau de risco envolvido na aquisição de novas tecnologias. Estes riscos são decorrentes de incertezas econômicas proporcionadas pela variação do preço de venda do produto, taxa de juros, custos da água, vida útil do sistema de irrigação e taxa de manutenção ocorrida com o manejo do sistema de irrigação, bem como variação na produtividade. Empregando-se tecnologias de simulação por computador voltadas às decisões no planejamento dos projetos de irrigação, a produção agrícola pode ser avaliada por intermédio da análise de probabilidade da viabilidade dos projetos de irrigação. Com dados locais climáticos e econômicos é possível simular qual será a viabilidade econômica da agricultura irrigada, o risco envolvido, a influência dos fatores estudados na composição do custo e a análise de sensibilidade do benefício líquido anual em função da variação dos fatores estudados. 
Considerando-se o desenvolvimento da informática nos projetos de irrigação e a necessidade da determinação da viabilidade da agricultura irrigada em sua fase de projeto, o presente trabalho teve como objetivo o desenvolvimento de uma ferramenta na forma de um modelo computacional para determinação do risco econômico em culturas irrigadas, para o ambiente Windows XP em linguagem Delphi 7.0, que permite simular os fatores que promovem o risco na aquisição de um sistema de irrigação e observar suas conseqüências econômicas sob o horizonte de risco. Este modelo apresentará os fatores econômicos para a tomada de decisão (relação benefício/custo, valor esperado de benefício líquido, desvio absoluto, desvio padrão, variância e coeficiente de variação), a viabilidade do projeto e uma análise de sensibilidade dos fatores envolvidos. Possibilitará assim, que a decisão de investir ou não em um sistema de irrigação seja baseada em valores probabilísticos que representem as possíveis conseqüências dessa decisão. 


\section{REVISÃO DE LITERATURA}

\subsection{Agricultura irrigada}

A irrigação é uma alternativa que visa aumento da produtividade das culturas, porém, apenas com um planejamento racional da agricultura irrigada, baseado em um projeto bem elaborado, é que os benefícios advindos da irrigação poderão ser obtidos (Castro et al., 2002). Devido às características estruturais dos projetos de irrigação e com o aumento gradativo das áreas cultivadas, é necessária uma programação visando melhor alocação dos recursos, buscando-se uma produção eficiente e rentável (Rodriguez, 1990; Frizzone et al., 1997; Gentil, 2000).

A irrigação justifica-se como recurso tecnológico indispensável ao aumento da produtividade das culturas em regiões onde a insuficiência ou má distribuição das chuvas inviabiliza a exploração agrícola. Entretanto a viabilidade econômica é um fator indispensável para sua adoção entre os agricultores (Frizzone et al., 1994; Bastos et al., 2000). De acordo com Christofidis (2002) a importância da agricultura irrigada pode ser vista pelos dados da superfície agrícola mundial, colhida no ano de 2000, correspondendo a uma área da ordem de 1,5 bilhões de hectares. Desta área, cerca de 275 milhões estavam sob de irrigação. A superfície produtiva agrícola sob sequeiro, em torno de 1,225 bilhões de hectares, foi responsável por 58\% do total colhido, enquanto a superfície agrícola irrigada, correspondente a 18\% da área total sob produção agrícola, possibilitou cerca de $42 \%$ do total colhido. 


\subsection{Seleção do sistema de irrigação}

Qualquer sistema de irrigação tem por objetivo final a reposição da quantidade de água requerida a toda área irrigada, procurando manter elevados os níveis de eficiência e uniformidade, sem comprometer a qualidade dos recursos naturais, e ao menor custo possível. Não existe um sistema de irrigação ideal, capaz de atender a esses objetivos em todas as condições. Em outras palavras, deve haver um sistema de irrigação mais adequado para cada condição. O problema consiste em se identificar a aptidão de cada sistema às condições específicas consideradas e, por meio de uma análise técnica e econômica criteriosa, definir o sistema mais recomendável (Scaloppi, 1985; Marouelli \& Silva, 1998). Para tanto, devem-se conhecer as principais características de cada sistema, e as implicações resultantes de sua utilização para atender aos objetivos propostos. Vários fatores determinam a escolha de um sistema, entre os quais o clima, o solo, a topografia, a disponibilidade e a qualidade de recursos hídricos, cultura e o consumo de energia. O consumo de energia elétrica depende da quantidade de água a ser aplicada, da energia hidráulica exigida pelo sistema de irrigação e da eficiência total do sistema de bombeamento (Scaloppi, 1985; Srivastava et al., 2003; Zocoler, 2003).

Existem basicamente quatro formas de aplicação de água, que caracterizam os principais sistemas de irrigação: superfície, aspersão, localizada e subsuperfície. Devido as suas características técnicas e hidráulicas, acarretam diferentes acréscimos nos custos de produção (Rezende et al., 1999). As Tabelas 1 e 2, adaptadas de Marouelli \& Silva (1998) e Christofidis (2002), mostram algumas características dos principais sistemas de irrigação. A Tabela 3, adaptada de Christofidis (2002), apresenta as áreas irrigadas e os sistemas de irrigação utilizados para as regiões do Brasil no ano de 2001. 
Tabela 1. Valores médios de eficiência de irrigação, uso de energia e de mão-de-obra dos sistemas de irrigação

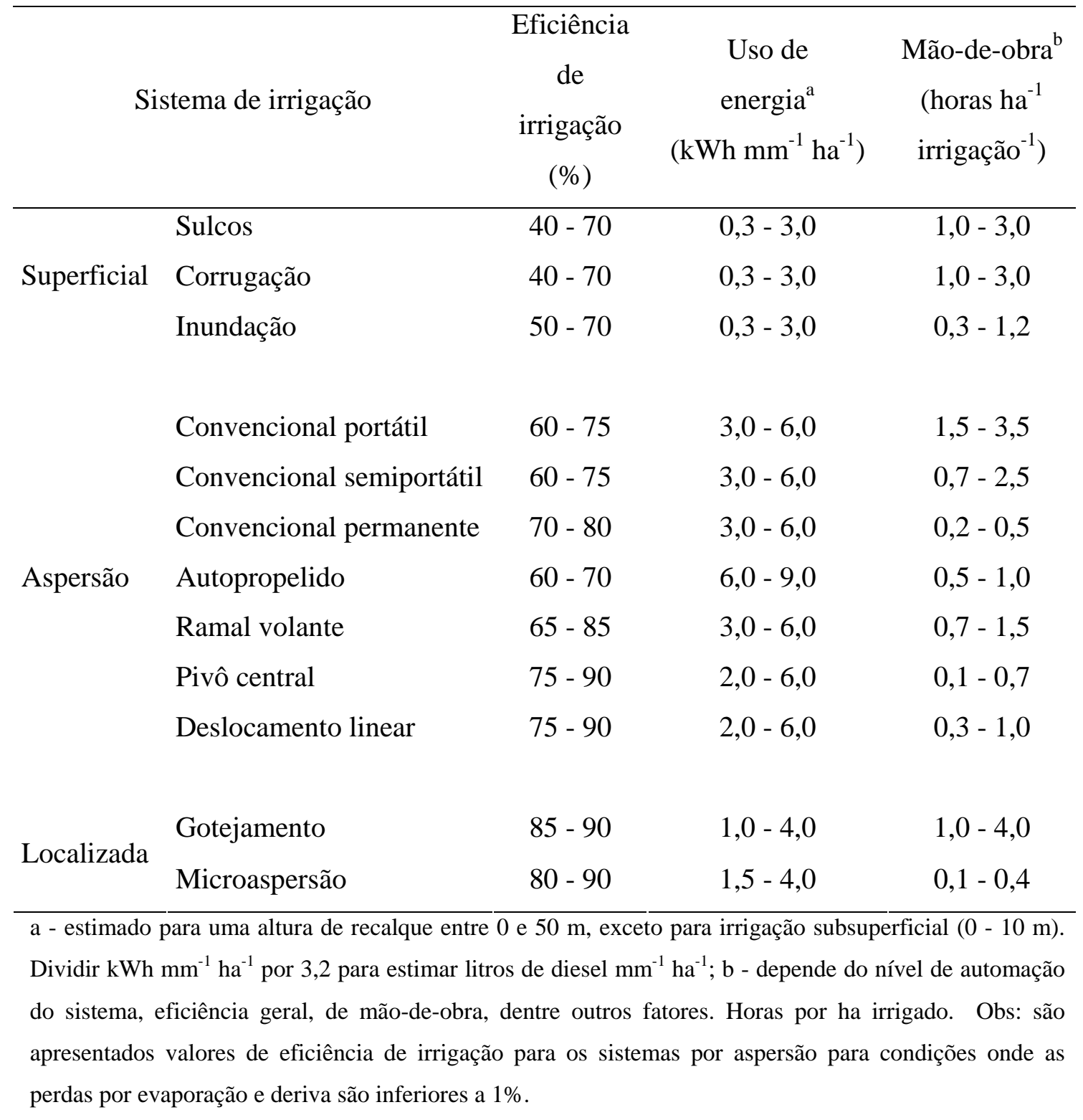

Fonte: Marouelli \& Silva (1998); Christofidis (2002) 
Tabela 2. Vida útil e custo de manutenção dos sistemas de irrigação

\begin{tabular}{lcc}
\hline Sistemas e componentes & Vida útil (anos) & $\begin{array}{c}\text { Manutenção anual } \\
\text { (\%valor inicial) }\end{array}$ \\
\hline Aspersão & $10-15$ & $1,0-4,0$ \\
Convencional portátil & $10-18$ & $1,5-3,0$ \\
Convencional semiportátil & $15-25$ & $0,5-2,0$ \\
Convencional permanente & $8-12$ & $5,0-7,0$ \\
Autopropelido & $10-15$ & $1,0-3,0$ \\
Ramal volante & $12-18$ & $4,0-6,0$ \\
Pivô central & $12-18$ & $5,0-7,0$ \\
Deslocamento linear & & \\
& & $2,0-4,0$ \\
Localizada & $10-15$ & $1,0-3,0$ \\
Gotejamento & $10-15$ & \\
Microaspersão & &
\end{tabular}

Fonte: Marouelli \& Silva (1998)

Tabela 3. Área irrigada, em 1.000 ha, no Brasil por sistema de irrigação no ano de 2001

\begin{tabular}{lcccccc}
\hline \multicolumn{1}{c}{ Sistema de Irrigação } & Norte & Nordeste & Sudeste & Sul & $\begin{array}{c}\text { Centro- } \\
\text { Oeste }\end{array}$ & Brasil \\
\hline Superfície & 50,18 & 155,64 & 208,74 & 152,92 & 6,52 & $\begin{array}{c}574,01 \\
(27,5 \%) \\
\text { Aspersão convencional }\end{array}$ \\
& 6,06 & 242,51 & 245,77 & 82,06 & 39,03 & $\begin{array}{c}615,42 \\
(29,4 \%)\end{array}$ \\
Pivô central & 1,41 & 122,01 & 362,62 & 0,50 & 165,01 & 651,55 \\
& & & & & & $(31,2 \%)$ \\
Localizada & 1,69 & 138,42 & 83,39 & 18,72 & 6,20 & 248,41 \\
& & & & & & $(11,9 \%)$ \\
\hline
\end{tabular}

Fonte: Christofidis (2002) 
Rezende et al. (1999) estudaram a viabilidade econômica da irrigação complementar em citros no Paraná e concluíram que não é economicamente viável irrigar citros com aspersão convencional devido ao seu alto consumo de energia. A irrigação por microaspersão é viável em algumas situações e a irrigação por gotejamento mostrou-se de maior viabilidade econômica. Bonomo et al. (1999) compararam os custos de diferentes sistemas de irrigação para a cafeicultura do cerrado de Minas Gerais e observaram que os sistemas por pivô central apresentaram os menores custos totais. Em relação aos custos variáveis, os sistemas por autopropelido superaram os demais nos gastos com energia elétrica. Os sistemas de gotejamento apresentaram os maiores custos fixos. Frizzone et al. (2001) estudaram a viabilidade econômica da irrigação suplementar da cana-de-açúcar para a região Norte do Estado de São Paulo utilizando árvore de decisão e concluíram que a irrigação suplementar promoveu aumento dos valores esperados de benefícios líquidos por hectare de área cultivada.

\subsection{0 risco na empresa agrícola}

As oportunidades de aperfeiçoamento requerem investimentos geralmente em montante maior do que o disponível no orçamento. Isto caracteriza um dilema no momento de decidir quando, quanto, como e onde investir, já que o que se visa é a otimização da alocação eficiente dos recursos (Moreira, 1981; Alberton, 1996). Como as empresas agrícolas atuam sob condições de risco, a utilidade de modelos determinísticos para fins de planejamento torna-se relativamente limitada. Isto implica na necessidade de não se desprezar, na maioria das vezes, a aleatoriedade de determinados coeficientes e introduzir este risco na análise do projeto (Dias, 1996).

Na avaliação de investimentos produtivos, a abordagem determinística baseia-se em informações tidas como certas. Em conseqüência, produz um único valor para as medidas de decisão e não inclui estimativa quantitativa do risco. A abordagem probabilística produz, como resultado, uma distribuição de probabilidades das medidas de mérito, quantificando o risco de todo investimento (Franke \& Dorfman, 1998). 
Mendes \& Larson (1982) explicam que as pressuposições da teoria da firma, de que os produtores têm perfeito conhecimento do valor das variáveis que afetam os processos de suas atividades e fazem decisões objetivando a maximização do benefício líquido, têm recebido diversas críticas. Essas pressuposições implicam não estocasticidade das variáveis, e que o único critério para a seleção de uma alternativa é o seu retorno esperado - modelo determinístico. Contudo, dado o ambiente de risco de produção e de mercado em que os agricultores operam, o critério da teoria clássica não auxilia muito as decisões do produtor. Conseqüentemente, isto sugere o uso de modelos alternativos, estocásticos, que explicitamente incorporem risco. De acordo com Porto et al. (1982) a introdução do risco proporciona aos agricultores informações econômicas adicionais sobre novas tecnologias geradas pela pesquisa. Estas informações não se referem somente à rentabilidade de uma determinada tecnologia, mas também ao risco que o agricultor estará correndo na sua adoção.

Garcia \& Ruas (1981) afirmaram que existe evidência da aversão a risco, por parte dos agricultores, e é pouco provável que se conheça perfeitamente o resultado final de uma atividade que é, na maioria dos casos, fortemente afetada por condições aleatórias de clima. A partir desta constatação, tem-se tentado introduzir considerações com respeito ao risco nas análises de tomada de decisão na agricultura.

Vários autores utilizaram a inclusão do risco no estudo da otimização agrícola. Porto et al. (1982) estudaram a rentabilidade e o risco em um experimento de interações de alternativas tecnológicas com arroz irrigado. Mattos (1984) avaliou a lucratividade e o risco na produção de alimentos para o Estado de São Paulo utilizando o valor presente anualizado. Noronha \& Latapia (1988) avaliaram os custos agrícolas do Estado de São Paulo sob condições de risco utilizando a simulação por Monte Carlo. Franke \& Dorfman (1998) estudaram a viabilidade da cultura do milho irrigado por aspersão utilizando a inclusão do risco. Por intermédio da simulação, utilizando série de 10 anos de dados meteorológicos diários, concluíram que a irrigação, na cultura do milho, apresenta viabilidade numa ampla gama de combinações de épocas de semeadura, níveis de manejo e níveis de risco para as condições locais de Missões e Planalto Médio no Rio Grande do Sul. 


\subsubsection{Conceito de risco}

Uma das mais importantes características da atividade agropecuária é o elevado risco ao qual ela está sujeita. Por isto, todo modelo matemático efetuado para estudo de planos de produção que visem aumentar a rentabilidade das unidades de produção agropecuárias devem, a rigor, incluir o risco na sua formulação (Silva Neto \& Stulp, 2000; Pizzol, 2002). A variável risco tem sido utilizada para permitir mais realismo às análises, quando se tenta compreender melhor a complexidade do ambiente em que os agricultores tomam suas decisões (Moreira, 1981).

Knight ${ }^{1}$ citado por Araújo (1997) define risco como a situação onde eventuais resultados obedecem a uma distribuição de probabilidade conhecida. Do contrário, caso não sejam conhecidos os valores dessa probabilidade, diz-se que o problema de decisão envolve incerteza. Reilly (1994) define risco de duas formas bastante simples e imediatas. Risco significa incertezas sobre futuros eventos ou ainda risco é a possibilidade de ocorrência de um evento adverso. Já Frizzone (2005) define risco como uma estimativa do grau de incerteza que se tem com respeito à obtenção dos resultados futuros desejados.

Decisões tomadas sob risco são aquelas em que o analista modela o problema de decisão em termos de resultados futuros possíveis conhecidos. Dessa maneira o risco existe quando o tomador de decisões pode basear-se em probabilidades objetivas para estimar diferentes resultados, de modo que sua expectativa se baseia em dados históricos e, portanto, a decisão é tomada a partir de estimativas julgadas aceitáveis pelo tomador de decisões (Franke \& Dorfman, 1998; Pizzol, 2002).

Uma maneira de se medir o risco é colocá-lo em termos de distribuição de probabilidade dos futuros retornos do investimento. Quanto menor a dispersão da distribuição de probabilidade, menor o risco. Assim quando se introduz o risco na análise de investimento, não se pode mais dizer que duas alternativas com o mesmo benefício líquido anual sejam economicamente equivalentes. A melhor alternativa é a

\footnotetext{
${ }^{1}$ KNIGHT, F.H. Risk, uncertainly and profit. Houghton: Milflin, 1921.
} 
que apresenta menor possibilidade de variação, por exemplo, a alternativa B (Figura 1) apresenta menor possibilidade de variação que a alternativa A, apesar de ambas apresentarem o mesmo valor presente líquido médio (Frizzone \& Silveira, 2000; Frizzone, 2005).

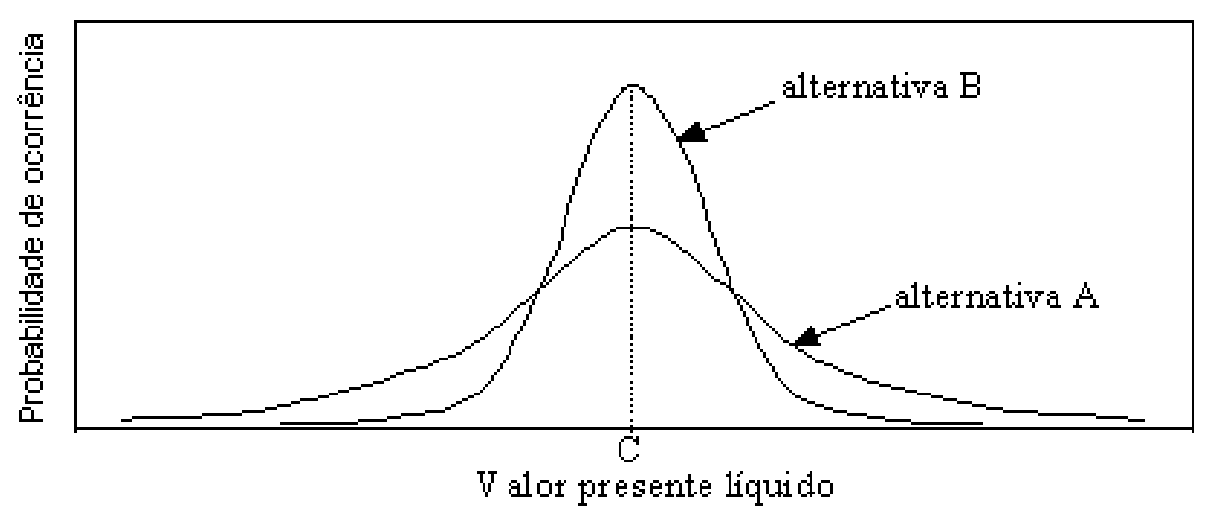

Figura 1 - Exemplo de risco em duas alternativas de investimento (Fonte: Frizzone \& Silveira, 2000)

A situação de risco pressupõe o conhecimento de um número suficiente de valores observados do dado em questão, flutuando à volta de um valor médio central, de maneira a tornar possível uma estimativa da probabilidade de ocorrência desse valor central entre limites calculados. Just \& Pope (2003) complementam que a maioria dos estudos sobre o risco na agricultura evidencia o suprimento total (usualmente medido por unidade de área) responsável por mudanças na variabilidade de preços e/ou produtividade.

Reis \& Pongibove (1997) consideraram em seu estudo do risco em planejamento agropecuário que todas as atividades consideradas estão, na prática, sujeitas à variabilidade que pode ser definida a partir de probabilidades estimadas de maneira subjetiva a partir de dados fornecidos pelo agricultor, associadas às séries históricas disponíveis. Kim \& Chavas (2003) estudaram a relação entre mudanças tecnológicas e o risco agrícola para a cultura do milho e concluíram que o progresso tecnológico contribui para reduzir os riscos em relação à produtividade. 


\subsubsection{Fatores de risco no planejamento agrícola}

No setor agrícola o conhecimento exato dos coeficientes dos rendimentos das várias atividades constitui um problema, pois a produção e até a utilização dos fatores são fortemente dependentes da chuva, da temperatura e de vários outros fatores não controláveis (Dias, 1996; Pereira et al., 2002). Noronha \& Latapia (1988) consideraram como a essência do risco a obtenção de estimativas que não correspondem à realidade da agricultura, quando se pressupõe coeficientes não aleatórios de produção. Franke \& Dorfman (1998) comentaram que a média dos valores observados geralmente não espelha a realidade, sendo que os fenômenos ficam melhor caracterizados pela análise da freqüência.

A condução de análises que considerem o risco na agricultura é dificultada pela raridade de dados, com dimensão suficiente para caracterizar uma distribuição de probabilidade (Garcia \& Ruas, 1981; Just \& Pope, 2003). A situação da informação incompleta do produtor, relativamente aos meios a empregar e aos resultados a obter, faz com que o processo decisório, na agricultura, seja sempre limitado pela insegurança. Em razão disso, os economistas têm-se preocupado em desenvolver modelos que incorporem situações de incerteza (Moreira, 1981). A maioria dos agricultores são aversos ao risco; assim, os tomadores de decisão são negativamente afetados pela variância das receitas tanto em curto quanto em longo prazo (Pizzol, 2002; Kim \& Chavas, 2003). Gómez-Limón et al. (2003), estudando os coeficientes de aversão ao risco pelos agricultores de uma área irrigada do Norte da Espanha, observaram que a aversão ao risco está presente em todas as decisões de manejo na agricultura, gerando como resultado a incerteza dos preços, da produtividade e dos recursos. Os riscos da adoção de uma agricultura irrigada devem ser criteriosamente estudados e analisados, objetivando-se sempre que os incrementos nas receitas sejam maiores que nos custos (Pickren, 1986; Silva et al., 2003). 
As diferentes formas que os riscos podem ocorrer traduzem-se em riscos de preços e riscos de rendimento. O risco tende a atuar como um impedimento na adoção de práticas mais avançadas, assim como no uso eficiente dos recursos. Os riscos de preços surgem, principalmente, devido ao interstício que existe entre o ponto, no tempo, em que o agricultor toma suas decisões de produção e o ponto, no tempo, em que obtém o produto. Como tal, os preços dos insumos são conhecidos com certeza enquanto, em relação aos preços dos produtos, os agricultores têm que formular expectativas a respeito do seu comportamento futuro. Os riscos de rendimentos surgem principalmente devido a variações nas condições climáticas e incidência de pragas e doenças. Se o agricultor buscar reduzir a variabilidade de sua renda, em seus planos de produção, irá selecionar produtos e processos de produção que apresentem a mais baixa variabilidade (Pareton $\&$ Cumming, 1990; Lemos, 1995). Outro fator de risco da agricultura regional é a flutuação de preços de mercado causada por variações de demanda, por políticas governamentais, ou pela concentração da comercialização dos produtos em mãos de um pequeno grupo de atravessadores (Mendes \& Larson, 1982; Lemos, 1995; Medeiros, 2003).

\subsection{Análise do risco}

Frizzone \& Silveira (2000) comentaram que muitas técnicas têm sido utilizadas para o tratamento de problemas risco em projetos de investimento. Várias dessas técnicas, por serem muito simplificadas ou excessivamente teóricas, têm resultado em informações insuficientes para as decisões ou necessitando de dados difíceis de serem obtidos. Consideraram como técnicas úteis, para serem aplicadas com sucesso para resolver problemas de risco na avaliação de alternativas de investimento, a análise de sensibilidade e a simulação de risco. A primeira representa um tratamento essencialmente prático e a segunda um tratamento mais complexo. 


\subsubsection{Análise de sensibilidade}

A análise de sensibilidade é uma técnica muito utilizada para análise de projetos de investimento, pois permite medir o efeito produzido na rentabilidade do investimento pela variação dos dados de entrada. A sensibilidade pode ser examinada para inúmeras variáveis como: taxa de juros, preço de venda, vida útil do projeto, custos, receitas e outros (Frizzone \& Silveira, 2000). Fazer uma análise de sensibilidade é medir em que magnitude uma alteração prefixada em um ou mais fatores do projeto altera o resultado final, ou seja, faz-se o teste do modelo de projeção para se determinar quais são os elementos mais relevantes para a decisão de investimento analisada. Procedendo-se desse modo com os diversos parâmetros do projeto será possível selecionar aqueles mais sensíveis em termos de influência na análise (Noronha \& Latapia, 1988; Frizzone, 2005).

\subsubsection{Simulação de dados}

Os modelos de simulação são ferramentas de grande importância no estudo do processo de tomada de decisão, uma vez que possibilitam considerar um grande número de fatores, o que seria impossível em experimentos convencionais em razão dos altos custos e do longo tempo demandado para a obtenção de resultados de pesquisa. A utilização de modelos permite, portanto, uma economia de tempo, recursos financeiros e humanos (Freitas et al., 2001; Iglesias et al., 2003). Permite também a simulação de vários cenários e estimar a repercussão dos diferentes cursos de ação sobre os sistemas de produção (Medeiros, 2003).

Simulação é a representação dinâmica de um sistema mediante um modelo, o qual é, por natureza, em grande parte matemático. Por sistema entende-se um conjunto de componentes e variáveis que se interrelacionam, formando um corpo único (Frizzone \& Silveira, 2000; Frizzone, 2005). Para a descrição do sistema é necessário que a variação de seus elementos possam ser preditos, pelo menos, em termos de distribuição 
de probabilidades (Hillier \& Lieberman, 1988). A simulação de dados permite o cálculo de diferentes combinações que probabilisticamente podem ocorrer, obtendo-se como resultado não um valor determinista, mas uma distribuição de freqüências, sendo o risco traduzido em números pela variância (Brunelli, 1990; Pareton \& Cumming, 1990; Dias, 1996 e Frizzone \& Silveira, 2000). Noronha \& Latapia (1988) concluíram que a utilização do método de Monte Carlo foi viável e útil como meio de introduzir o risco na tomada de decisão das instituições ligadas ao setor e dos agricultores.

Iglesias et al. (2003) estudaram as conseqüências econômicas das secas no setor da irrigação, por meio de modelagem e simulação. Observaram que a seca impôs altos custos aos agricultores, mas observaram também que os agricultores apresentaram custos exagerados devido à alocação excessiva de água para irrigação. Maya (2003), estudando a viabilidade da pastagem irrigada por meio de simulações determinísticas e estocásticas, observaram que a análise de risco apontou o sistema irrigado como inviável economicamente para as condições de Piracicaba.

\subsubsection{Método de Monte Carlo}

Uma técnica de simulação muito usada é o método de Monte Carlo, que se baseia na comparação de números randômicos com uma determinada função densidade de probabilidade acumulada, ou seja, a partir de um número aleatório o método permite a geração de outros possíveis valores para o referido evento. Esse método obtém como resultado uma distribuição de freqüências dos valores simulados (Porto et. al., 1985; Maya, 2003). Bissera (1994) comentou que o método foi criado por Hertz ${ }^{2}$ e ampliado posteriormente por técnicos do Banco Mundial.

\footnotetext{
${ }^{2}$ HERTZ, D.B Risk analysis in capital investment. Harvard Business Review, v.42, n.95, p.95-106, 1964.
} 
De acordo com Noronha (1983) o método de Monte Carlo consiste em construir e simular modelos matemáticos por meio de recursos estatísticos. Baseia-se no fato de que a freqüência relativa de ocorrência do acontecimento de certo fenômeno se aproxima da probabilidade matemática de ocorrência do mesmo fenômeno, quando a experiência é repetida um grande número de vezes. Este método pode ser aplicado aos casos em que a análise matemática exata seria intratável ou excessivamente trabalhosa.

Admitindo que a distribuição de um coeficiente técnico seja triangular, basta conhecer o valor mínimo, o valor modal e o valor máximo para que se possa estabelecer a distribuição da freqüência deste coeficiente técnico. Esta distribuição é bastante utilizada quando não se dispõe de muitas informações sobre as variáveis. Uma vez individualizada a distribuição de probabilidade, a próxima etapa do processo de simulação é a seleção, ao acaso, de um valor para cada uma das variáveis dentro das distribuições preestabelecidas. Para associar um número aleatório à distribuição de probabilidade de cada variável, são utilizados números gerados a partir de uma distribuição uniforme no intervalo fechado de 0 a 1 (Noronha \& Latapia, 1988).

Neves (1984) explicou que a distribuição triangular permite uma boa flexibilidade quanto ao tipo de assimetria, o que se pode considerar uma característica positiva para a estimação subjetiva de distribuição.

A técnica de simulação de Monte Carlo foi empregada em estudos de análise de risco em avaliação de investimento em projetos e de custo de produção em Porto et al. (1985); Azevedo Filho (1988); Brunelli (1990); Bissera (1994) e Dias (1996). Sousa (1999) também utilizou a técnica de simulação por Monte Carlo para valores de evapotranspiração de referência (ETo) e déficit de evapotranspiração a partir de dados históricos, para a previsão de fenômenos meteorológicos. Andrade Júnior et al. (2001) utilizaram este método para estudar a viabilidade da irrigação sob risco climático e econômico. 


\subsubsection{Teste de aderência da distribuição simulada}

Grande parte da estatística foi desenvolvida sob a suposição de normalidade das variáveis, o que permite o uso da média como medida adequada de tendência central. Entretanto, existem casos em que a suposição de que as variáveis seguem uma distribuição normal não é razoável, ou não encontra respaldo na realidade, o que acontece com muitas variáveis econômicas (Kroll, 2001). Dessa maneira um problema que surgiu desde que foram propostas as distribuições de valores, foi identificar o tipo de distribuição mais adequada para uma determinada amostra de dados. Quando se ajusta uma distribuição de probabilidade a um conjunto de dados, trabalha-se com a hipótese de que a distribuição representaria adequadamente aquele conjunto de informações. Assim, torna-se necessário a utilização de testes estatísticos para aceitar ou não essa hipótese. O nível de significância do teste refere-se à probabilidade de se rejeitar a hipótese, sendo comum adotar-se níveis de 0,05 (5\%) ou 0,01 (1\%). Dentre os testes estatísticos são largamente utilizados o teste do qui-quadrado e o teste de KolmogorovSmirnov (Assis et al., 1996; Kroll, 2001; Bautista, 2002).

\subsubsection{O teste de Kolmogorov-Smirnov}

O teste de Kolmogorov-Smirnov é um teste não-paramétrico, utilizado para se testar a hipótese de diversas distribuições. O princípio deste teste baseia-se na comparação da curva de freqüência cumulativa dos dados, como função de distribuição teórica em hipótese. Quando duas curvas se sobrepõem, a estatística do teste é calculada pela máxima diferença entre ambas. A magnitude da diferença estabelece-se, probabilisticamente, segundo a lei de probabilidades dessa estatística, que se encontra tabelada (Kroll, 2001). Segundo Campos (1983) este teste foi desenvolvido para adaptação de uma específica e bem conhecida distribuição Fo(X), a dados provenientes de uma distribuição desconhecida $\mathrm{Fn}(\mathrm{X})$, ou seja, é um teste baseado na proximidade da função de distribuição empírica $(F n(X))$ e a função de distribuição hipotética $(F o(X))$. 
O teste de Kolmogorov-Smirnov para uma amostra é um teste de aderência, isto é, diz respeito ao grau de concordância entre a distribuição de um conjunto de valores observados e determinada distribuição teórica especifica. Determina se os valores da amostra podem ser, razoavelmente, considerados como provenientes de uma população como aquela de distribuição teórica (Siegel, 1975). Sua vantagem é que pode ser aplicado, sem restrição, para pequenas amostras. Além disso, trata as variáveis individualmente, não perdendo informações em decorrência de agrupamentos, como ocorre no caso do teste Qui-quadrado (Siegel, 1975; Campos, 1983; Bautista, 2002).

\subsection{Projeto de viabilidade econômica de culturas irrigadas}

Determinar a viabilidade econômica de um projeto que se inicia é fundamental para seu sucesso. Um projeto é o conjunto de informações internas e/ou externas, coletadas e processadas com o objetivo de analisar uma decisão de investimento. Assim, o projeto é entendido como um modelo que, incorporando informações qualitativas e quantitativas, procura simular a decisão de investir e suas implicações onde a determinação dos valores econômicos é uma parte importante no estudo da viabilidade econômica (Clark et al., 1993; Frizzone \& Silveira, 2000; Silva et al., 2003).

A agricultura irrigada exige alto investimento em obras e aquisição de equipamentos, em transporte, em controle e distribuição de água; além de gastos com energia e mão-de-obra para operação do sistema, que representam importantes custos adicionais, que devem ser pagos pelo incremento de produtividade proporcionado pela irrigação (Rodriguez, 1990; Clark et al., 1993; Frizzone et al., 1997). Assim a irrigação é uma tecnologia que requer investimentos significativos e está associada à utilização intensiva de insumos, tornando importante a análise econômica dos componentes envolvidos no sistema (Pickren, 1986; Silva et al., 2003). Como exemplos podem ser citados: Marques \& Coelho (2003) que estudaram a viabilidade da irrigação da pupunheira para Ilha Solteira - SP variando o custo da água, a vida útil e o tipo de motor utilizado; concluíram que para todas as simulações a irrigação foi viável. 
Pinheiro et al. (2002) e Pinheiro \& Coelho (2003) estudaram a viabilidade econômica da irrigação de pastagens em diferentes regiões do Brasil e concluíram que a irrigação de pastagens no Brasil apresenta rentabilidade variável e assim a tomada de decisão da irrigação da pastagem deve ser realizada estudando-se cada caso e suas características. Blanco et al. (2004) estudando a viabilidade econômica da irrigação da manga para o Estado de São Paulo, observaram que o custo da aquisição do equipamento associado à sua vida útil foi o fator de maior sensibilidade na análise de viabilidade e que a cobrança pela água não inviabilizou a implantação do sistema de irrigação.

\subsubsection{Componentes da viabilidade econômica de culturas irrigadas}

O manejo da irrigação tem potencial para elevar a produção e reduzir o risco associado às flutuações de produção por deficiência hídrica. No entanto, introduz custos adicionais, envolvendo mão-de-obra energia e água, além da aquisição de equipamentos. A análise de custos da irrigação não deve contemplar apenas os custos de implantação e de investimento, mas também outros custos fixos e variáveis calculados por um ano e por unidade de área (Paudyal \& Gupta, 1990; Rodriguez, 1990; Freitas et al., 2001; Silva et al., 2003). Rezende et al. (1999) utilizaram estimativas de custos e de receitas para a avaliação da viabilidade econômica da irrigação do citros no estado do Paraná.

\subsubsection{Custos fixos da irrigação}

Os custos são classificados em fixos, quando não se alteram com a quantidade produzida. São principalmente a depreciação dos componentes do sistema e a remuneração do capital investido (Turra, 1990; Melo, 1993; Pinheiro et al., 2002). A depreciação é o custo necessário para substituir os bens de capital de longa duração, quando eles se tornam inutilizáveis, em decorrência do desgaste físico, ou perdem seu valor com o passar dos anos, devido às inovações tecnológicas e/ou à capacidade de 
gerar receitas (Frizzone, 1999; Frizzone \& Silveira, 2000). A depreciação é baseada no investimento inicial e em uma esperada vida útil do componente. A variabilidade da vida útil esperada pode ocorrer em razão das diferenças de condições físicas de operação, do nível de reparo, operação e manutenção praticada, e do número total de horas que o sistema é usado em cada ano (Marouelli \& Silva, 1998; Bonomo et al., 1999; Silva et al., 2003).

O cálculo do custo fixo pode ser representado pelo custo anual uniforme utilizando o investimento inicial, a vida útil esperada e o valor residual do componente. Utiliza-se o Fator de Recuperação de Capital (FRC), o qual pressupõe a reserva de uma quantidade suficiente de dinheiro em cada ano para possibilitar a reposição do bem em $n$ anos mais os encargos dos juros sobre o capital investido, sendo comum seu uso em engenharia econômica (Matioli et al., 1998; Frizzone \& Silveira, 2000; Marques et al., 2002). Segundo Marouelli \& Silva (1998) os sistemas de irrigação superficiais e subsuperficiais são os que requerem, via de regra, menor investimento inicial, seguidos pelos sistemas por aspersão e gotejamento.

\subsubsection{Custos variáveis da irrigação}

Os custos variáveis são os dispêndios utilizados na operação do sistema, ou seja, combustível, manutenção, insumos, mão-de-obra e energia elétrica (Turra, 1990; Clark et al., 1993; Freitas, 2000; Pinheiro et al., 2002). Entre os custos variáveis de um sistema de irrigação, o consumo de energia destaca-se como um dos principais componentes (Gohring \& Wallender, 1987; Frizzone et al., 1994; Bonomo et al., 1999; Andrade Júnior et al., 2001). Portugual (2001), em uma análise do consumo de energia elétrica na agricultura irrigada, comentou que segundo a Confederação Nacional da Agricultura, o consumo de energia elétrica do setor agrícola é de 4\% do consumo total do país. Acrescentou ainda que a irrigação inadequada pode levar ao consumo excessivo de água e energia. 
O consumo de energia elétrica em sistemas de irrigação está concentrado na instalação de bombeamento, cujo bom desempenho reflete nas características hidráulicas e energéticas da irrigação. Não existe um sistema de irrigação ideal em relação à utilização de energia (Scaloppi, 1985; Paudyal \& Gupta, 1990). De acordo com Scaloppi (1985) os maiores valores de consumo de energia estão associados, em ordem decrescente de consumo, aos seguintes sistemas: autopropelido, pivô central, aspersão, localizada e superficial.

O produtor pode entrar em contato com a concessionária de energia, para solicitar uma tarifa diferenciada para irrigantes no período noturno. Esse desconto varia de acordo com a região, sendo: 90\% para o Nordeste, vale do Jequitinhonha e Polígono das secas em Minas Gerais; 80\% para a região Norte e Centro Oeste e 70\% para as demais regiões (Frizzone, 1999; Portugual, 2001; Pinheiro et al. 2002; Zocoler, 2003; Alves Júnior et al., 2004). A portaria DNAEE 105 de 03 de abril de 1992 definia para o período noturno o horário das 23 h às 5h, porém a resolução da Agência Nacional de Energia Elétrica (ANEEL) 540 de 02 de outubro de 2002 alterou para o período compreendido entre as $21 \mathrm{~h} 30$ e $6 \mathrm{~h}$, ampliando o horário de aplicação de desconto na tarifa. Dessa forma os agricultores passam a ter 2 horas e 30 minutos a mais de tarifa reduzida (Diário Oficial, 2002).

Quando ocorre fator de potência abaixo de 0,92 indica um desequilíbrio no consumo de energia, por uma sub-utilização dos transformadores ou um excesso de pequenos motores elétricos. Isto promoverá uma multa pelo baixo fator de potência. A correção deste fator se faz com a instalação de capacitores colocados nas instalações de bombeamento, de forma que, quando da entrada dos motores os capacitores comecem a funcionar corrigindo estas perdas e elevando o fator de potência (Gentil, 2000).

Os custos com mão-de-obra são influenciados pelas características e pelo grau de automação do sistema de irrigação utilizado, pela quantidade de água aplicada e pelo número de irrigações realizadas (Keller \& Bliesner, 1990). Este custo diz respeito às despesas com salários e encargos sociais para todas as atividades envolvidas na operacionalização do sistema; depende do sistema de irrigação e varia com o nível de automação (Marouelli \& Silva, 1998; Zocoller, 2003). A Tabela 1 apresenta estimativas 
de consumo de mão-de-obra para alguns dos sistemas de irrigação. Rezende et al. (1992) estudaram o efeito do custo da mão-de-obra, da água e das estruturas hidráulicas no custo total da irrigação por sulcos e concluíram que o custo da mão-de-obra apresentou pouca influência no custo total.

O custo de manutenção corresponde aos gastos para manter o sistema de irrigação em condições adequadas de uso, sendo comum estimá-los como um percentual do investimento inicial do equipamento de irrigação (Keller \& Bliesner, 1990; Pinheiro et al., 2002; Maya, 2003). A Tabela 2 apresenta alguns valores de taxa de manutenção para alguns sistemas de irrigação.

A deficiência de água normalmente é o fator mais limitante para a obtenção de produtividade elevada e produtos de boa qualidade, porém o excesso também pode ser prejudicial (Marouelli \& Silva, 1998). Tanto a variabilidade espacial quanto a temporal, da disponibilidade hídrica dos solos, é de suma importância na quantificação das necessidades hídricas dos vegetais (Paudyal \& Gupta, 1990; Alfonsi et al., 1998). No cálculo do custo da água a determinação da evapotranspiração é um problema compartilhado com várias ciências que estudam o sistema solo-planta-atmosfera. Uma maneira muito utilizada para obter a evapotranspiração de referência (ETo) é por meio de métodos de estimativa (Turco \& Fernandes, 2003). O perfeito conhecimento deste processo e sua facilidade de estimativa permitem quantificar as necessidades hídricas, programar a irrigação, prever o desenvolvimento e as safras das culturas (Mota et al., 1989). Medeiros (2002) comentou que a estimativa do consumo de água pelas culturas assume grande destaque quando se busca maximizar a produção e minimizar os custos.

Sobre a cobrança do uso da água, Balsalobre et al. (2003) comentam que esta cobrança tem respaldo legal na Lei Federal nº 9433/97 que, em seu artigo 19, estabelece a água como um bem econômico sujeito à cobrança, e que os recursos financeiros arrecadados serão utilizados em financiamento de programas e intervenções para a recuperação ambiental da bacia hidrográfica onde foram gerados. O código das águas de 1934 já previa a cobrança pelo uso da água. Na assembléia Legislativa de São Paulo tramita, desde 1998, o projeto de lei que regulamenta esta cobrança (PL 20/98), que já foi aprovado pelos 20 comitês das bacias do Estado e pelo Conselho Estadual de 
Recursos Hídricos, tendo recebido propostas de 102 emendas e 2 substitutivos. A cobrança incidirá sobre a utilização da água por qualquer um e para qualquer uso, inclusive sobre os irrigantes, sendo este mais um item que deve ser computado no custo variável da irrigação. Setti (2000) completa que a água é um bem limitado no Brasil, e que passa, portanto, a ser mensurada dentro dos valores da economia. Isso não pode e nem deve levar a condutas que permitam que alguém, por meio de pagamento de um preço, possa usar a água inescrupulosamente. A valoração econômica da água deve levar em conta o preço da conservação, da recuperação e da melhor distribuição deste bem.

\subsubsection{Preços agrícolas}

As estatísticas de preços estão entre as mais úteis em economia, tanto para estudos, como para atuação no mercado. Os estudos sobre preços de maneira geral iniciaram-se por volta da década de 60, porém os estudos sobre a distribuição de preços agrícolas são escassos (Kroll, 2001; Nagaoka et al., 2001). Souza \& Frizzone (2003b) comentam que a oscilação dos preços agrícolas representa um importante fator de risco. Alguns sites disponibilizam on-line os preços agrícolas permitindo o acesso a valores atualizados (Companhia de Abastecimento e Armazéns Gerais do Estado de Pernambuco, 2004; Instituto de Economia Agrícola, 2004a e 2004b; Sociedade de Olericultura do Brasil, 2004). 


\subsubsection{Benefícios da irrigação}

A quantificação da resposta da cultura à disponibilidade de água é um importante fator na estimativa da produção e na análise da viabilidade da irrigação, sendo o fator de resposta da cultura (Ky) um bom indicador para avaliação do efeito déficit hídrico (Arruda \& Grande, 2003). Dessa maneira, a produtividade sem irrigação pode ser estimada por meio do fator de resposta da cultura (Ky) que relaciona a queda do rendimento relativo e o déficit de evapotranspiração relativa. Os valores de Ky para a maioria das culturas são obtidos supondo-se que a relação entre o rendimento relativo (Yr/Ym) e a evapotranspiração relativa (ETr/ETm) é linear e válida para déficits hídricos de até 50\%, ou seja, $1-$ Etr/ETm = 0,5 (Mannocchi \& Mecarelli, 1994; Doorenbos \& Kassam, 2000).

\subsection{Informática na agricultura}

Na medida em que a agricultura passa a se caracterizar mais e mais como um negócio, a ênfase na tecnologia se dá no sentido de permitir o gerenciamento confiável e seguro da produção e um controle mais eficaz sobre a força de trabalho. Neste caso, entre tantas outras técnicas, o uso do computador ocupa um lugar de destaque. Os resultados mais expressivos do uso dos computadores na agricultura têm sido o de facilitar o controle de grandes recursos produtivos por um número reduzido de pessoas e permitir a constituição de um banco de dados para desenvolvimento de estudos e padrões (Oliveira, 1985; Ascough II et al., 1999).

Os avanços da informática permitem o desenvolvimento de "softwares” cada vez mais sofisticados, com grande capacidade de armazenamento de dados e alta velocidade de processamento. Estes programas, que antes só estavam disponíveis em centros de pesquisa, estão agora ao alcance de pessoas com um mínimo de conhecimento em informática (Mota et al., 1989; Ascough II et al., 1999). 
Segundo Baltra (1987) o cálculo computacional abriu um novo e vasto panorama com muitas vias de solução para os problemas da água, sua distribuição e benefício por meio da irrigação. Azevedo Filho (1988) comentou que para apoiar o processo de tomada de decisão há a preocupação de se desenvolver um instrumental analítico que possa auxiliar os tomadores de decisão na realização de sua tarefa, dentro dos limites consistentes com os princípios da racionalidade econômica.

As tecnologias e equipamentos que envolvem a irrigação bem como a consultoria técnica, muitas vezes são de elevado custo para os pequenos e médios produtores brasileiros. Para atenuar este problema, várias pesquisas têm sido desenvolvidas nas principais universidades e em centros nacionais de pesquisa, mediante extensão rural, com a criação de programas de apoio aos produtores, para viabilizar a difusão de tecnologia de forma mais acessível e econômica (Pickren, 1986; Mota et al., 2001). Na área de Irrigação e Drenagem várias pesquisas foram realizadas utilizando a informática. Podem-se citar como exemplos, Gomide (1979) que desenvolveu um programa para cálculo de vários parâmetros de uniformidade, num ensaio de avaliação de aspersores com disposição de pluviômetros em malha onde as rotinas eram introduzidas a partir de cartões perfurados. Azevedo Filho (1988) desenvolveu um programa em Pascal que realiza análise econômica de projetos para uso em DOS de computadores de grande porte. Van Lier \& Dourado Neto (1991) desenvolveram em QuickBasic o programa Bhídrico que permite elaborar o balanço hídrico com variação do Kc e profundidade do sistema radicular da cultura.

Moreira \& Torres Filho (1993) desenvolveram um sistema agroclimático para acompanhamento das culturas irrigadas (S.A.A.C.I.). Hernandez et al. (1995) desenvolveram em Pascal um programa para realizar o balanço hídrico com diversos métodos de determinação de evapotranspiração de referência. Silva Neto \& Stulp (2000) desenvolveram um modelo de programação matemática para otimizar sistemas de produção considerando as tendências dos resultados econômicos das atividades sem deixar de considerar adequadamente as variações aleatórias. Mota et al. (2001) desenvolveram um sistema multimídia para ensino e aprendizado de irrigação em parceria com a Universidade Federal de Viçosa e o Centro de Produções 
Técnicas (CPT). Castro et al. (2002) desenvolveram um sistema computacional para a determinação da lâmina ótima econômica em irrigação pressurizada onde buscam não a máxima produção e sim a obtenção do máximo retorno econômico. Marques et al. (2002) desenvolveram um programa para avaliação econômica da irrigação da pupunha onde é permitida a variação dos fatores que interferem no custo da irrigação gerando curvas comparativas de acréscimo de produção necessário para pagar a irrigação.

Faria et al. (2003) desenvolveram um programa computacional para organização e análise de dados meteorológicos. Srivastava et al. (2003) desenvolveram um software para estimar o valor limiar econômico do custo de investimento da irrigação por gotejamento e compará-la ao custo da irrigação por superfície. O software fornece informações do consumo de energia elétrica e da receita líquida. 


\section{MATERIAL E MÉTODOS}

O desenvolvimento do modelo computacional para determinação do risco econômico em culturas irrigadas foi realizado em três etapas, sendo:

- Etapa 1: desenvolvimento do modelo utilizando-se a linguagem Delphi 7.0, por meio de procedimentos e seqüências lógicas. O fluxograma geral do modelo computacional pode ser visto na Figura 2. O programa é constituído por rotinas seqüenciais (Figura 3), acompanhando passo a passo o estudo do risco econômico por meio de simulações e dos cálculos dos custos e benefícios envolvidos;

- Etapa 2: levantamento de dados agronômicos e econômicos sobre as culturas da canade-açúcar e tomate industrial, por meio de pesquisa em artigos científicos e técnicos, manuais e dados locais;

- Etapa 3: aplicação do modelo para analisar a viabilidade da adoção do sistema de irrigação para as culturas de cana-de-açúcar e tomate industrial, e análise de sensibilidade dos fatores envolvidos utilizando quatro anos consecutivos (2001, 2002, 2003 e 2004) de dados meteorológicos obtidos na estação meteorológica automática do Departamento de Ciências Exatas da Escola Superior de Agricultura “Luiz de Queiroz”, Piracicaba - São Paulo, altitude 546 m, latitude $22^{\circ} 42^{\prime} 30$ ”'S e longitude $47^{\circ} 38^{\prime} 00^{\prime \prime} \mathrm{W}$. 


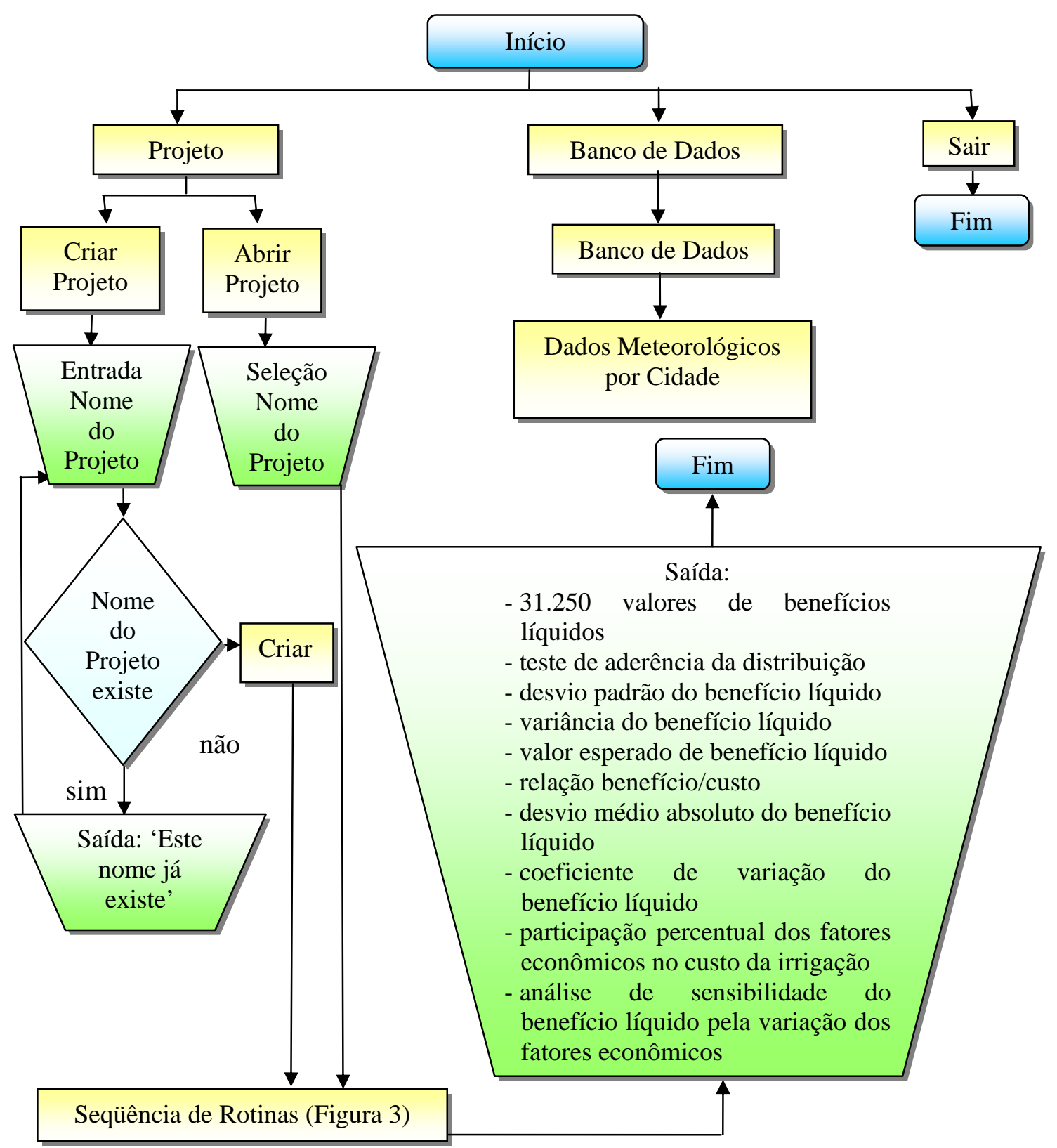

Figura 2 - Fluxograma geral do modelo computacional para determinação do risco econômico em culturas irrigadas 


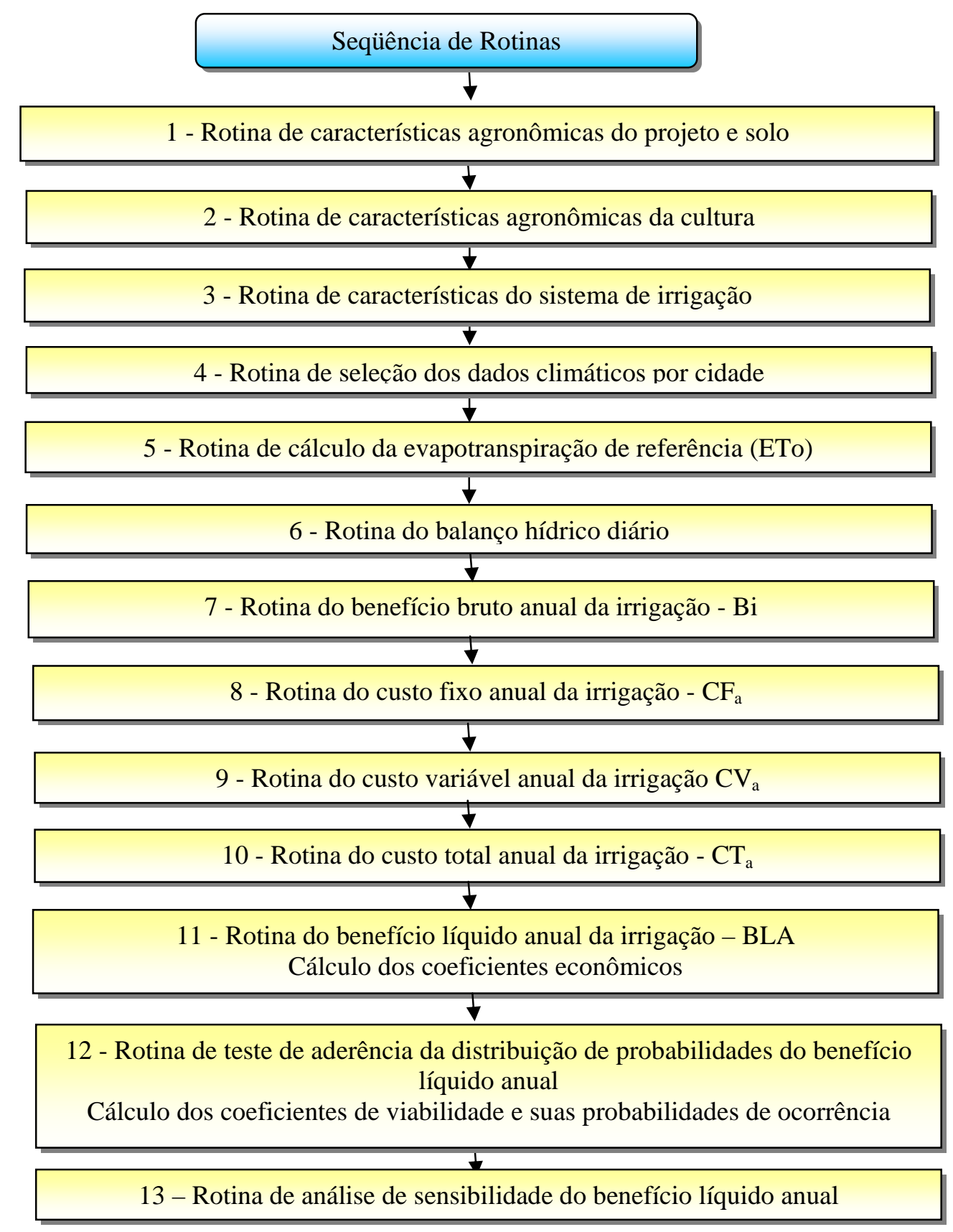

Figura 3 - Seqüência de rotinas do projeto 


\subsection{Rotina "Características agronômicas do projeto e do solo"}

Esta rotina tem por objetivo definir as características do projeto para criação do banco de dados referente ao projeto. Nesta rotina definem-se também as características do solo (Figura 4). Na caracterização do solo são permitidas as entradas de até cinco camadas de solo com seus valores respectivos de profundidade e umidade. Para cada camada i de solo é calculada a disponibilidade total de água pela eq. 1 .

$$
\mathrm{DTA}_{\mathrm{i}}=\frac{\left(\theta \mathrm{cc}_{\mathrm{i}}-\theta \mathrm{pmp}_{\mathrm{i}}\right)}{10} \quad(\mathrm{i}=1, \ldots, 5)
$$

sendo:

$\mathrm{DTA}_{\mathrm{i}}$ - disponibilidade total de água do solo para a camada i $\left(\mathrm{mm} \mathrm{cm}^{-1}\right)$;

$\theta \mathrm{cc}_{\mathrm{i}} \quad$ - umidade do solo à capacidade de campo para a camada i (\% em volume);

$\theta \mathrm{pmp}_{\mathrm{i}}$ - umidade do solo no ponto de murcha permanente para a camada i (\% em volume).

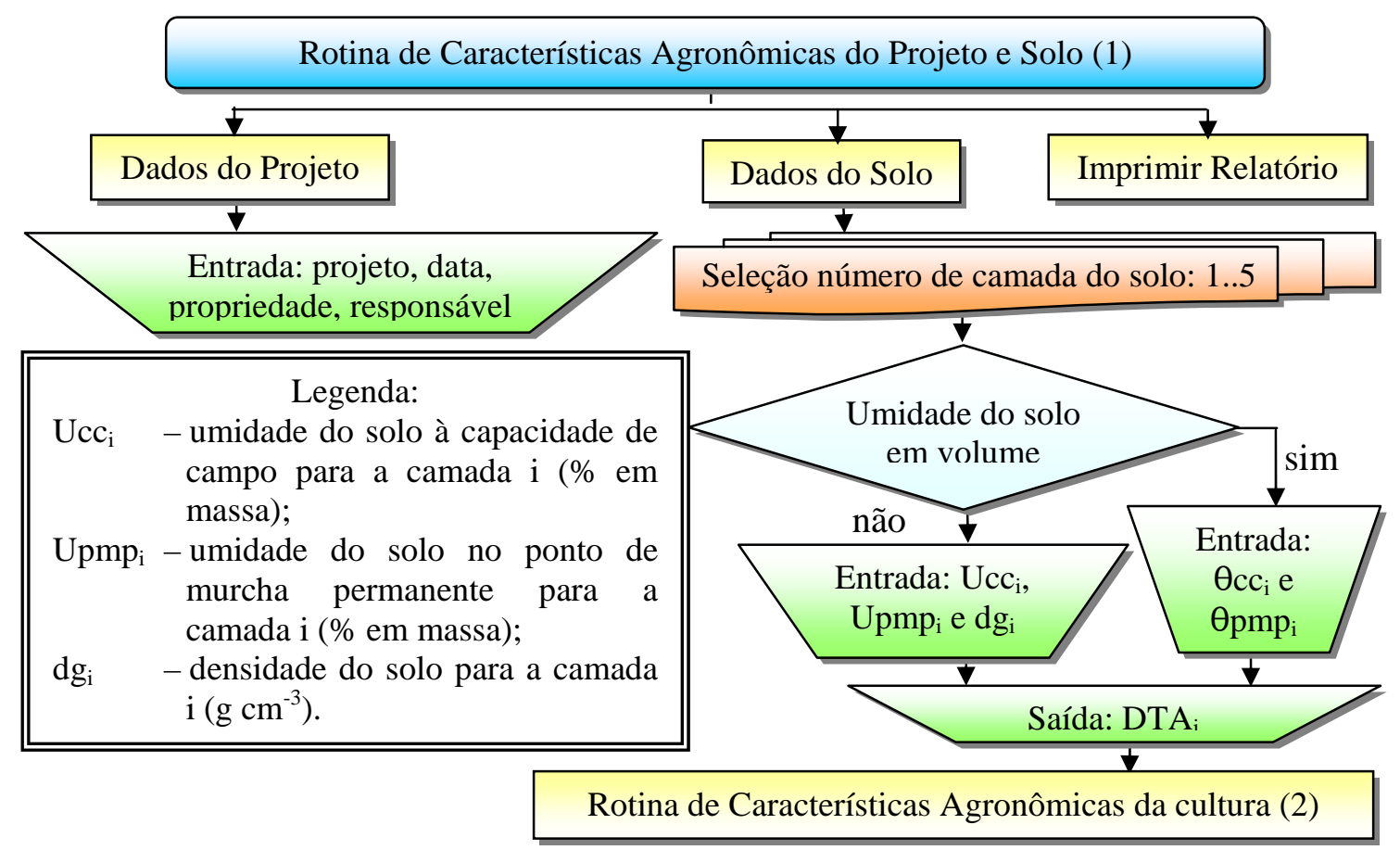

Figura 4 - Fluxograma da rotina de características agronômicas do projeto e solo 


\subsection{Rotina "Características agronômicas da cultura”}

Em função do tipo de solo, profundidade das raízes e tipo de cultura, podem ser definidos limites (máximo e mínimo) do armazenamento de água no solo, dentro dos quais a cultura tem seu desenvolvimento favorecido (Mota et al., 1989; Alfonsi et al., 1998). Esta rotina tem por objetivo definir as características da cultura e suas fases fenológicas para o banco de dados referente ao projeto e a partir destas calcula-se a disponibilidade real de água no solo (DRA), a qual representa a quantidade de água que pode ser armazenada no solo, na camada radicular explorada pelas raízes, disponível para a planta (Figura 5). Nesta rotina é realizado o preenchimento automático da tabela de balanço hídrico, para o ciclo da cultura, com as fases fenológicas e seus respectivos coeficientes de cultura (Kc) e profundidade efetiva do sistema radicular (z).

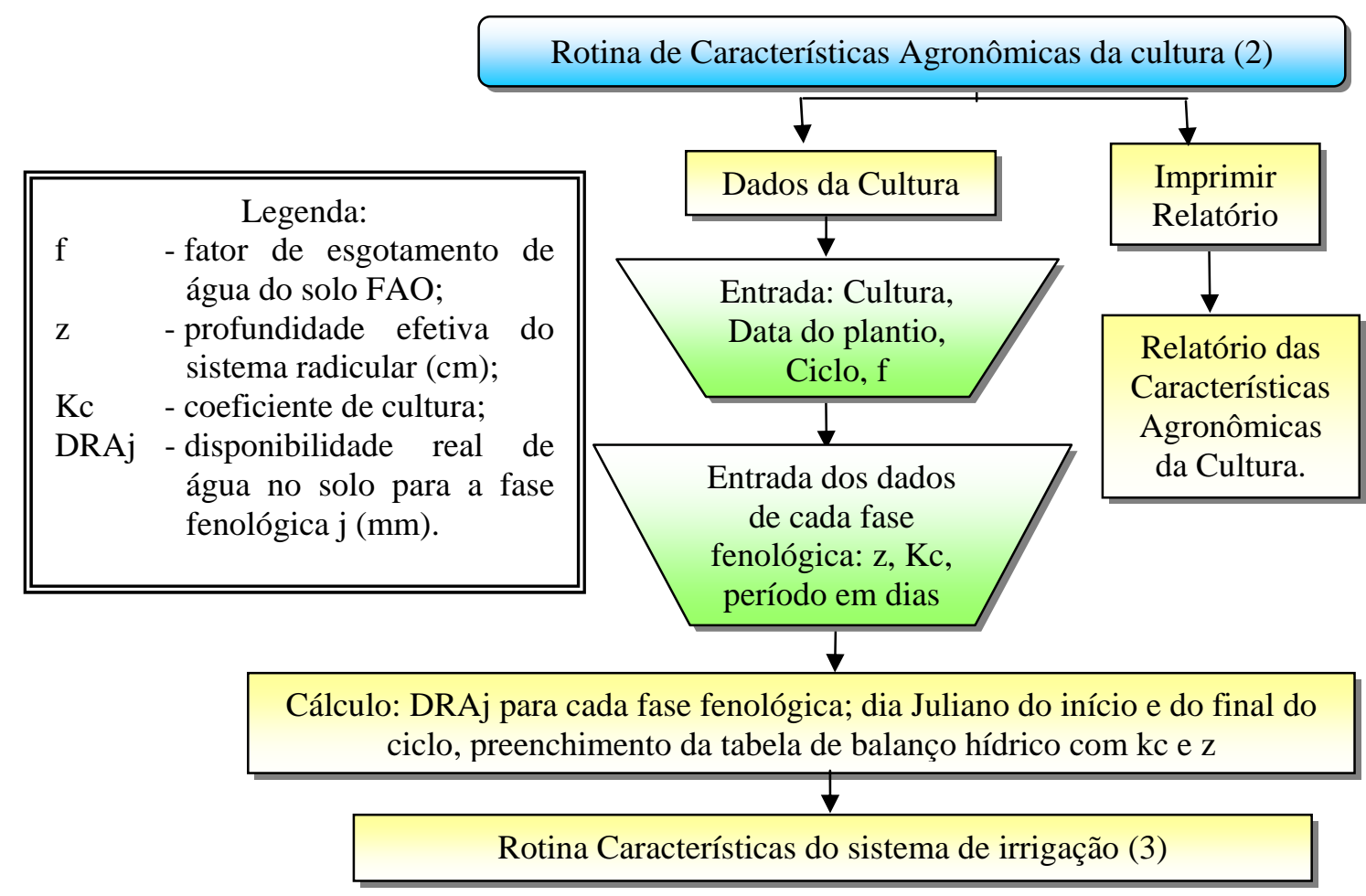

Figura 5 - Fluxograma da rotina de características da cultura 
No cálculo da DRA considera-se a profundidade da camada de solo explorada pelas raízes para cada fase fenológica j e o fator f de esgotamento de água do solo (Doorenbos \& Pruitt, 1984; Alfonsi et al., 1998; Wrege et al., 1999; Franke \& Dorfman, 2000). A disponibilidade total de água do solo na fase fenológica j é calculada pela eq. 2 até a profundidade efetiva do sistema radicular e a disponibilidade real de água para cada fase fenológica j pela eq. 3.

$$
\begin{aligned}
& \operatorname{DTA}_{j}=\sum_{i=1}^{n}\left(D_{i} \cdot z_{i}\right) \\
& \text { DRA }_{j}=\text { DTA }_{j} \cdot f
\end{aligned}
$$

sendo:

$\mathrm{DTA}_{\mathrm{j}}$ - disponibilidade total de água do solo na fase fenológica j (mm);

$\mathrm{Z}_{\mathrm{i}} \quad$ - profundidade de cada camada i de solo $(\mathrm{cm})$;

$\mathrm{DRA}_{\mathrm{j}}$ - disponibilidade real de água do solo para cada fase fenológica j (mm);

f $\quad$ - fator de esgotamento de água do solo (Doorenbos \& Pruitt, 1984).

\subsection{Rotina “Características do sistema de irrigação”}

Nessa rotina são inseridas as características do sistema de irrigação utilizado, necessárias para o prosseguimento dos cálculos (Figura 6).

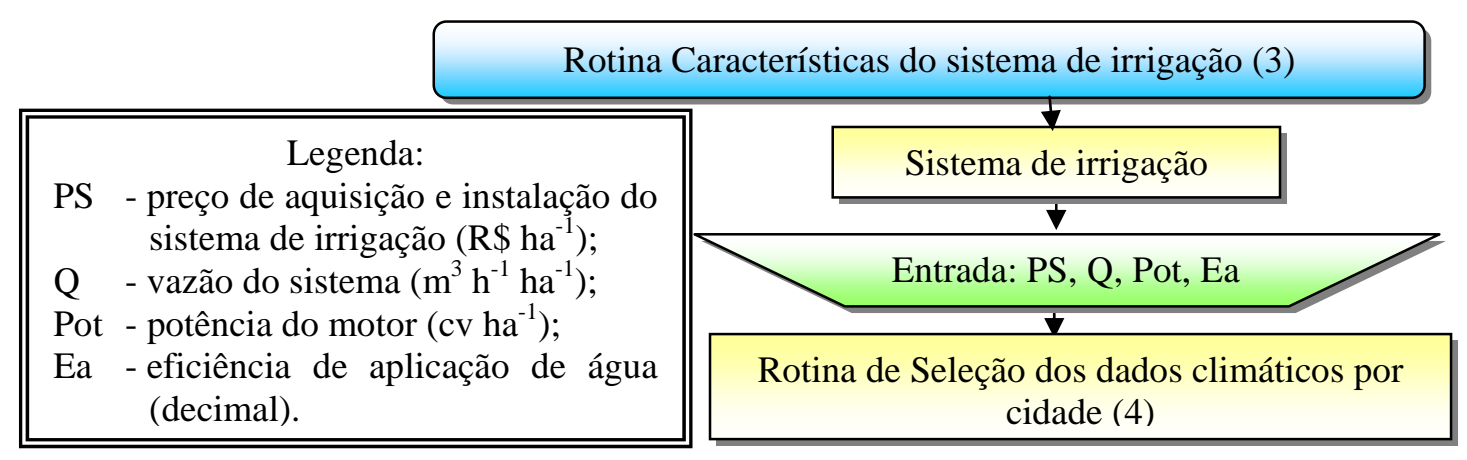

Figura 6 - Fluxograma da rotina de características do sistema de irrigação 


\subsection{Rotina “Seleção dos dados climáticos por região”}

O clima é o fator mais determinante da produção agrícola, condicionando a variabilidade sazonal e interanual da produtividade dos cultivos de uma determinada região (Faria et al., 2003). A análise de registros históricos de dados climáticos permite estimar a evapotranspiração que, juntamente com a capacidade de retenção de água no solo, torna possível estimar o balanço de água na zona radicular das culturas e as demandas totais e diárias de irrigação, seguindo a época de plantio da cultura (Faria et al., 2002). Nesta rotina é selecionada a região para a qual será realizada a análise econômica. Após a confirmação da seleção da região são armazenados os dados de latitude, longitude, altitude e os valores diários de temperatura máxima $\left({ }^{\circ} \mathrm{C}\right)$, temperatura mínima $\left({ }^{\circ} \mathrm{C}\right)$, temperatura média $\left({ }^{\circ} \mathrm{C}\right)$, precipitação $(\mathrm{mm})$, radiação líquida total diária $\left(\mathrm{MJ} \mathrm{m}^{-2} \mathrm{dia}^{-1}\right)$, umidade relativa média (\%) e velocidade média do vento $\left(\mathrm{m} \mathrm{s}^{-1}\right)$ a $2 \mathrm{~m}$ da superfície do solo.

\subsection{Rotina “Cálculo da evapotranspiração de referência (ETo)”}

A ETo é calculada diariamente para posterior uso no balanço hídrico como utilizado em Franke \& Dorfman (2000). Na Figura 7 têm-se o fluxograma geral desta rotina com os métodos utilizados e as variáveis necessárias. Entre os métodos de estimativa da ETo, o método simplificado proposto por Camargo, citado por Pereira et al. (2002), utiliza a temperatura média diária e a latitude do local (eq. 4).

$$
\mathrm{ETo}=0,01 \cdot \mathrm{Qo} \cdot \mathrm{Td}
$$

sendo:

ETo - evapotranspiração de referência $\left(\mathrm{mm} \mathrm{dia}^{-1}\right)$;

Qo - radiação solar global extraterrestre ( $m m$ de evaporação equivalente dia $^{-1}$ ) Tabela 4;

Td - temperatura média diária $\left({ }^{\circ} \mathrm{C}\right)$. 


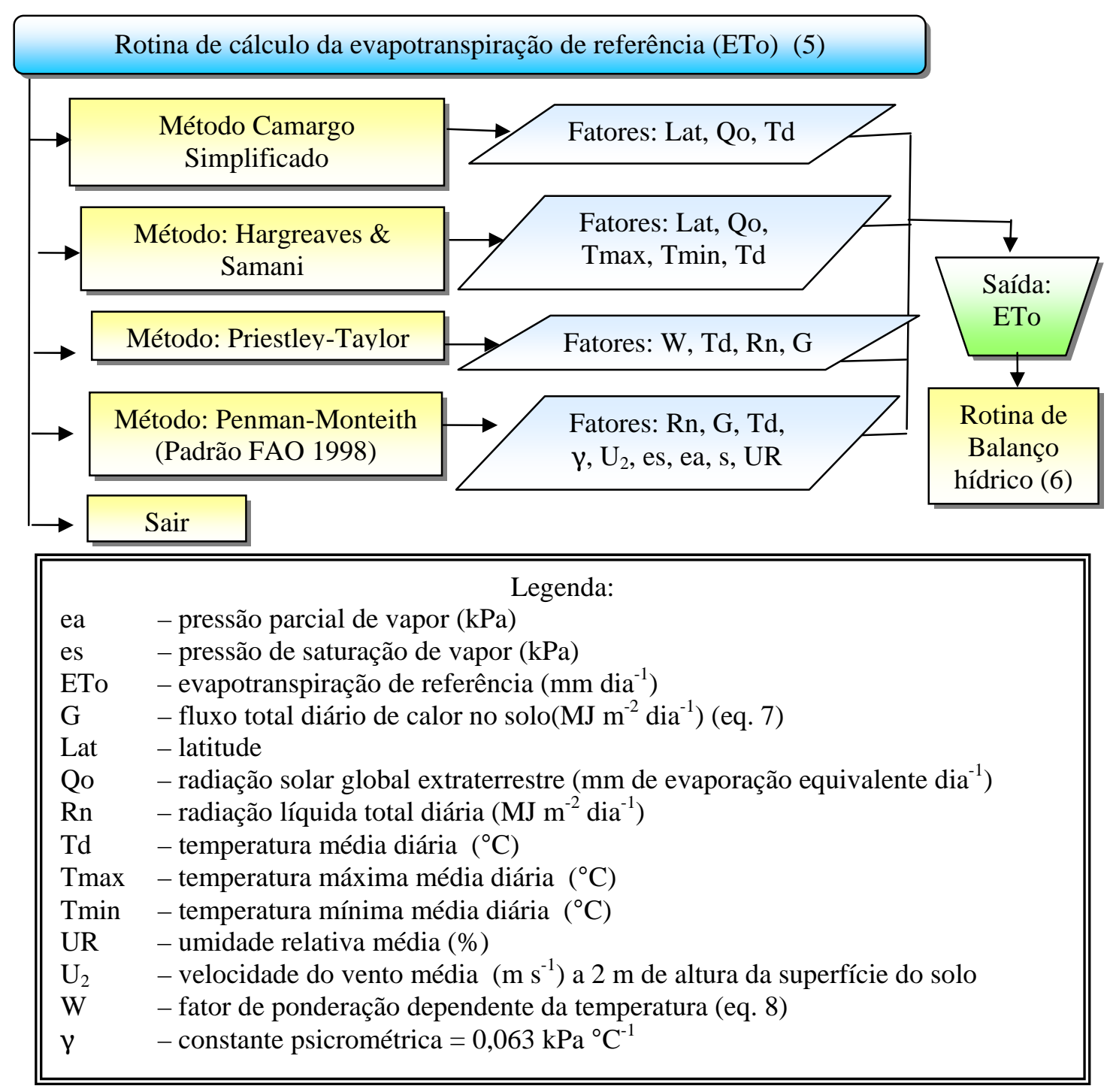

Figura 7 - Fluxograma da rotina de cálculo da evapotranspiração de referência 
Tabela 4. Radiação solar global extraterrestre (Qo em mm de evaporação equivalente por dia) no $15^{\circ}$ dia do mês correspondente, para a Latitude (Lat) do hemisfério Sul

\begin{tabular}{lllllllllllll}
\hline Lat & & & & & \multicolumn{1}{c}{ Mês } & & & & & \\
S & jan & Fev & mar & Abr & mai & jun & jul & ago & set & Out & Nov & dez \\
\hline 0 & 14,5 & 15,0 & 15,2 & 14,7 & 13,9 & 13,4 & 13,5 & 14,2 & 14,9 & 14,9 & 14,6 & 14,3 \\
2 & 14,8 & 15,2 & 15,2 & 14,5 & 13,6 & 13,0 & 13,2 & 14,0 & 14,8 & 15,0 & 14,8 & 14,6 \\
4 & 15,0 & 15,3 & 15,1 & 14,3 & 13,3 & 12,7 & 12,8 & 13,7 & 14,7 & 15,1 & 15,0 & 14,9 \\
6 & 15,3 & 15,4 & 15,1 & 14,1 & 13,0 & 12,6 & 12,5 & 13,5 & 14,6 & 15,1 & 15,2 & 15,1 \\
8 & 15,6 & 15,6 & 15,0 & 14,0 & 12,7 & 12,0 & 12,2 & 13,2 & 14,5 & 15,2 & 15,4 & 15,4 \\
10 & 15,9 & 15,7 & 15,0 & 13,8 & 12,4 & 11,6 & 11,9 & 13,0 & 14,4 & 15,3 & 15,7 & 15,7 \\
12 & 16,1 & 15,8 & 14,9 & 13,5 & 12,0 & 11,2 & 11,5 & 12,7 & 14,2 & 15,3 & 15,8 & 16,0 \\
14 & 16,3 & 15,8 & 14,9 & 13,2 & 11,6 & 10,8 & 11,1 & 12,4 & 14,0 & 15,3 & 15,9 & 16,2 \\
16 & 16,5 & 15,9 & 14,8 & 13,0 & 11,3 & 10,4 & 10,8 & 12,1 & 13,8 & 15,3 & 16,1 & 16,4 \\
18 & 16,7 & 15,9 & 14,7 & 12,7 & 10,9 & 10,0 & 10,4 & 11,8 & 13,7 & 15,3 & 16,2 & 16,7 \\
20 & 16,7 & 16,0 & 14,5 & 12,4 & 10,6 & 9,6 & 10,0 & 11,5 & 13,5 & 15,3 & 16,2 & 16,8 \\
22 & 16,9 & 16,0 & 14,3 & 12,0 & 10,2 & 9,1 & 9,6 & 11,1 & 13,1 & 15,2 & 16,4 & 17,0 \\
24 & 16,9 & 15,9 & 14,1 & 11,7 & 9,8 & 8,6 & 9,1 & 10,7 & 13,1 & 15,1 & 16,5 & 17,1 \\
26 & 17,0 & 15,9 & 13,9 & 11,4 & 9,4 & 8,1 & 8,7 & 10,4 & 12,8 & 15,0 & 16,5 & 17,3 \\
28 & 17,1 & 15,8 & 13,7 & 11,1 & 9,0 & 7,8 & 8,3 & 10,0 & 12,6 & 14,9 & 16,6 & 17,5 \\
30 & 17,2 & 15,7 & 13,5 & 10,8 & 8,5 & 7,4 & 7,8 & 9,6 & 12,2 & 14,7 & 16,7 & 17,6 \\
\hline
\end{tabular}

O método Hargreaves \& Samani citado por Pereira et al. (2002), utiliza na estimava da evapotranspiração as temperaturas média, máxima e mínima diárias (eq. 5).

$$
\text { ETo }=0,0023 \cdot \text { Qo } \cdot(\text { Tmáx }- \text { Tmín })^{0,5} \cdot(\text { Td }+17,8)
$$


sendo:

ETo - evapotranspiração de referência $\left(\mathrm{mm} \mathrm{dia}^{-1}\right)$;

Qo - radiação solar global extraterrestre (mm de evaporação equivalente dia $^{-1}$ );

Tmáx - temperatura máxima diária $\left({ }^{\circ} \mathrm{C}\right)$;

Tmín - temperatura mínima diária $\left({ }^{\circ} \mathrm{C}\right)$;

Td - temperatura média diária $\left({ }^{\circ} \mathrm{C}\right)$.

O método de Priestley-Taylor (Pereira et al., 2002; Medeiros, 2002), inclui no seu cálculo (eq. 6) a radiação líquida total diária, temperatura média diária e o fluxo diário de calor do solo para a estimativa da evapotranspiração de referência.

$$
\mathrm{ETo}=\frac{1,26 \cdot \mathrm{W} \cdot(\mathrm{Rn}-\mathrm{G})}{2,45}
$$

sendo:

ETo - evapotranspiração de referência $\left(\mathrm{mm} \mathrm{dia}^{-1}\right)$;

$\mathrm{Rn}$ - radiação líquida total diária $\left(\mathrm{MJ} \mathrm{m}^{-2} \operatorname{dia}^{-1}\right)$;

G - fluxo total diário de calor no solo ( $\left.\mathrm{MJ} \mathrm{m}^{-2} \mathrm{dia}^{-1}\right)$ (eq. 7);

W - fator de ponderação dependente da temperatura (eq. 8).

$$
\mathrm{G}=0,38 \cdot\left(\mathrm{T}_{\mathrm{d}}-\mathrm{T}_{3 \mathrm{~d}}\right)
$$

$$
\begin{cases}\mathrm{W}=0,407+0,0145 \cdot \mathrm{Td} & \left(0^{\circ} \mathrm{C}<\mathrm{Td}<16^{\circ} \mathrm{C}\right) \\ \mathrm{W}=0,483+0,01 \cdot \mathrm{Td} & \left(16,1^{\circ} \mathrm{C}<\mathrm{Td}<32^{\circ} \mathrm{C}\right)\end{cases}
$$

sendo:

$\mathrm{T}_{\mathrm{d}} \quad$ - temperatura média diária $\left({ }^{\circ} \mathrm{C}\right)$;

$\mathrm{T}_{3 \mathrm{~d}} \quad$ - temperatura média dos três dias anteriores $\left({ }^{\circ} \mathrm{C}\right)$. 
O método Penman-Monteith (eq. 9), preconizado pela FAO e de utilização mundial (Medeiros, 2002; Turco \& Fernandes, 2003), descrito em Doorenbos \& Kassam (2000) e Pereira et al. (2002), considera para a estimativa da evapotranspiração de referência os dados de radiação líquida total diária, fluxo de calor no solo, temperaturas média, mínima e máxima diárias, umidade relativa e velocidade do vento.

$$
\text { ETo }=\frac{0,408 \cdot s \cdot(R n-G)+\frac{\gamma \cdot 900 \cdot U_{2} \cdot\left(e_{s}-e_{a}\right)}{\mathrm{Td}+273}}{s+\gamma \cdot\left(1+0,34 \cdot U_{2}\right)}
$$

sendo:

ETo - evapotranspiração de referência $\left(\mathrm{mm} \mathrm{dia}^{-1}\right)$;

$\mathrm{Rn} \quad$ - radiação líquida total diária $\left(\mathrm{MJ} \mathrm{m}^{-2} \mathrm{dia}^{-1}\right)$;

G - fluxo total diário de calor no solo( $\left.\mathrm{MJ} \mathrm{m}^{-2} \mathrm{dia}^{-1}\right)$ (eq. 07);

Y $\quad$ - constante psicrométrica $=0,063 \mathrm{kPa}^{\circ} \mathrm{C}^{-1}$;

Td - temperatura média diária $\left({ }^{\circ} \mathrm{C}\right)$;

$\mathrm{U}_{2} \quad$ - velocidade do vento $\left(\mathrm{m} \mathrm{s}^{-1}\right)$ a $2 \mathrm{~m}$ de altura da superfície do solo;

$\mathrm{e}_{\mathrm{s}} \quad$ - pressão de saturação de vapor (kPa) (eq. 10);

$\mathrm{e}_{\mathrm{a}} \quad$ - pressão parcial de vapor (kPa) (eq. 11);

s $\quad$ - declividade da curva de pressão de vapor $\left(\mathrm{kPa}^{\circ} \mathrm{C}^{-1}\right)$ (eq. 12).

$$
\mathrm{e}_{\mathrm{S}}=\frac{\left(0,6108 \cdot \mathrm{e}^{\left[\frac{17,27 \cdot \text { Tmáx }}{237,7+\text { Tmáx }}\right]}+0,6108 \cdot \mathrm{e}^{\left[\frac{17,27 \cdot \text { Tmín }}{237,7+\text { Tmín }}\right]}\right)}{2}
$$

$$
\begin{aligned}
& e_{a}=\frac{\left(U R \cdot e_{S}\right)}{100} \\
& s=\frac{4098 \cdot e_{s}}{(T d+237,3)^{2}}
\end{aligned}
$$

sendo: $\quad$ UR a umidade relativa média (\%). 
A escolha do método de estimativa da evapotranspiração de referência depende de uma série de fatores, sendo a mais restritiva a disponibilidade de dados. Outro fator importante é conhecer as condições climáticas para as quais foram desenvolvidos. Dessa maneira o método modificado de Camargo é indicado para regiões de clima úmido com disponibilidade apenas de dados de temperatura média. Já o método de Hargreaves \& Samani adapta-se melhor às regiões de clima seco (semi-árido) necessitando dos dados de temperaturas máxima, mínima e média (Pereira et al., 2002). Quando se dispõe da medida da radiação líquida (Rn) podem-se utilizar os métodos de Priestley-Taylor e Penman-Monteith. O método de Priestley-Taylor é uma simplificação do método de Penman apresentando melhores resultados em climas úmidos (Stone \& Silveira, 1995; Medeiros, 2002). Em regiões onde se dispõem de observações de radiação líquida total diária, temperaturas média, mínima e máxima diárias, umidade relativa e velocidade do vento recomenda-se o uso do método de Penman-Monteith, que avalia os efeitos do clima sobre as necessidades hídricas das culturas, promovendo resultados mais precisos, sendo considerado o método padrão da FAO (Doorenbos \& Pruitt, 1984; Pereira et al., 2002).

\subsection{Rotina "Balanço hídrico"}

Para a estimativa da necessidade de irrigação, faz-se um balanço hídrico diário, considerando-se a época de semeadura e as fases fenológicas da cultura. A somatória dos déficits hídricos diários, referentes a cada mês, correspondem à necessidade mensal de irrigação (Raju \& Kumar, 1999; Frizzone et al., 1994). Utiliza-se como balanço hídrico para irrigação uma adaptação do balanço hídrico climatológico seqüencial visando facilitar sua aplicação (Pereira et al., 2002). O fluxograma é mostrado na Figura 8. 


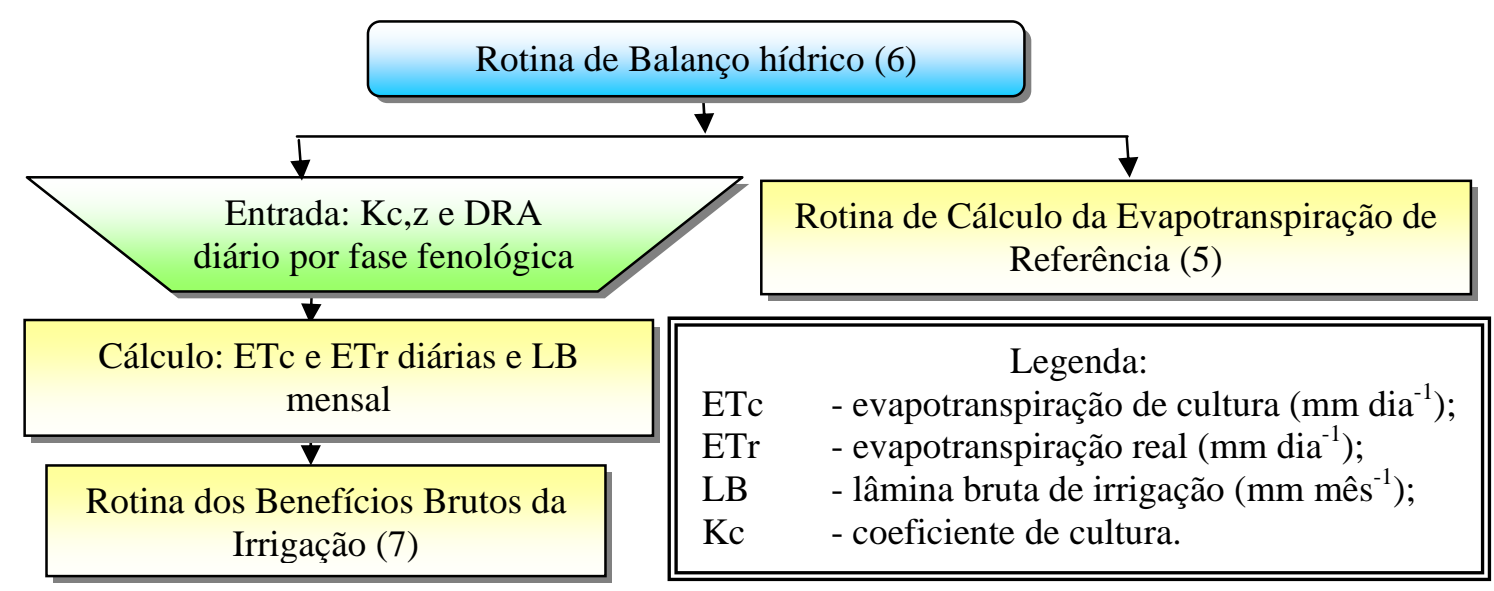

Figura 8 - Fluxograma da rotina de balanço hídrico

A evapotranspiração de cultura (ETc) é a quantidade de água utilizada por uma cultura, em qualquer fase de seu desenvolvimento quando não houver restrição hídrica sendo calculada de acordo com a eq. 13. A evapotranspiração real (ETr) é aquela que realmente ocorre em função da disponibilidade de água no solo nas condições normais de cultivo, sendo menor ou igual a ETc. Seu cálculo (eq. 14) é baseado na alteração no armazenamento de água no solo (Stone \& Silveira, 1995; Pereira et al., 2002).

$\mathrm{ETc}=\mathrm{ETo} \cdot \mathrm{Kc}$

onde:

ETc - evapotranspiração da cultura (mm dia $\left.{ }^{-1}\right)$;

Kc - coeficiente de cultura, varia com as fases fenológicas e também entre espécies e variedades/cultivares (Mota et al., 1989; Doorenbos \& Kassam, 2000).

$$
\left\{\begin{array}{lll}
\text { se } \quad \mathrm{P}-\mathrm{ETc} \geq 0 & \Rightarrow \mathrm{ETr}=\mathrm{ETc} \\
\text { se } \quad \text { Alt } \leq 0 & \Rightarrow & \text { ETc }=\mathrm{P}+\mid \text { Alt } \mid
\end{array}\right.
$$

onde:

ETr - evapotranspiração real diária $\left(\mathrm{mm} \mathrm{dia}^{-1}\right)$;

P - precipitação diária $\left(\mathrm{mm} \mathrm{dia}^{-1}\right)$;

Alt - alteração no armazenamento de água no solo diária (mm dia $\left.{ }^{-1}\right)$. 
Para obter o nível do manejo da irrigação, para otimização dos benefícios econômicos da irrigação, realiza-se um balanço hídrico diário, no qual se estima níveis de extração da capacidade de água disponível no solo e, em conseqüência, quantidades de irrigação, que representam custos de irrigação diferenciados (Franke \& Dorfman, 1998). Dessa maneira, por meio do balanço hídrico do solo calcula-se o déficit hídrico diário, o qual representa a necessidade de irrigação diária. Com estes valores acumulados obtém-se a necessidade de irrigação mensal e a partir desta é calculada a lâmina líquida mensal necessária (eq. 15) e a lâmina bruta mensal (eq. 16).

$$
\begin{aligned}
& \mathrm{LLm}=\sum_{\mathrm{i}=1}^{\mathrm{n}}(\mathrm{NId}) \quad \mathrm{i}=\text { número de dias do mês } \\
& \mathrm{LBm}=\frac{\mathrm{LLm}}{\mathrm{Ea}}
\end{aligned}
$$

em que:

LLm - lâmina líquida de irrigação mensal (mm mês $\left.{ }^{-1}\right)$;

NId - necessidade de irrigação diária (mm);

LBm - lâmina bruta da de irrigação mensal (mm mês ${ }^{-1}$ );

Ea - eficiência de aplicação de água (decimal). 


\subsection{Rotina "Benefícios brutos da irrigação"}

A receita bruta, utilizada em uma análise financeira, é obtida multiplicando-se a produtividade agrícola pelo preço pago ao produtor (Frizzone, 1999; Srivastava et al., 2003). Nessa rotina (Figura 9) são inseridos o preço pago ao produtor, a produtividade sem irrigação e a produtividade com irrigação. A produtividade sem irrigação pode ser estimada por meio do fator de resposta da cultura (Ky) que relaciona a queda do rendimento relativo e o déficit de evapotranspiração relativa (Doorenbos \& Kassam, 2000). Nessa rotina, o Ky refere-se a um ciclo total por ano da cultura (Souza, 2001) e $E r_{a}$ representa o somatório dos ETr diários durante o período de um ciclo da cultura no ano. A estimativa da produtividade pode ser feita pela eq. 17 demonstrada em Mannocchi \& Mecarelli (1994). Com os valores de produtividades calcula-se o benefício bruto da irrigação (eq. 18) que representa o acréscimo de renda oriundo da irrigação (Hatch et al., 1985).

$$
\mathrm{Ys}=\mathrm{Yi} \cdot\left[1-\mathrm{Ky} \cdot\left(1-\frac{\operatorname{ETr}_{\mathrm{a}}}{\operatorname{ETm}_{\mathrm{a}}}\right)\right]
$$

sendo:

Ys - produtividade sem irrigação para um ciclo total por ano da cultura $\left(\mathrm{Mg} \mathrm{ha}^{-1}\right.$ $\left.\mathrm{ano}^{-1}\right)$;

Yi - produtividade com irrigação para um ciclo total por ano da cultura ( $\mathrm{Mg} \mathrm{ha}^{-1}$ $\left.\mathrm{ano}^{-1}\right)$;

Ky - fator de resposta da cultura para um ciclo total por ano da cultura (Doorenbos \& Kassam, 2000);

$\operatorname{ETr}_{\mathrm{a}}$ - evapotranspiração real para um ciclo total por ano da cultura ( $\mathrm{mm} \mathrm{ano}^{-1}$ );

$\mathrm{ETm}_{\mathrm{a}}$ - evapotranspiração máxima para um ciclo total por ano da cultura (mm ano ${ }^{-1}$ ). 


$$
\mathrm{Bi}=(\mathrm{Yi} \cdot \mathrm{Pp})-(\mathrm{Ys} \cdot \mathrm{Pp})
$$

onde:

$\mathrm{Pp}$ - preço pago ao produtor $\left(\mathrm{R} \$ \mathrm{Mg}^{-1}\right)$;

$\mathrm{Bi}$ - benefício bruto anual da irrigação $\left(\mathrm{R} \$ \mathrm{ha}^{-1} \mathrm{ano}^{-1}\right)$.

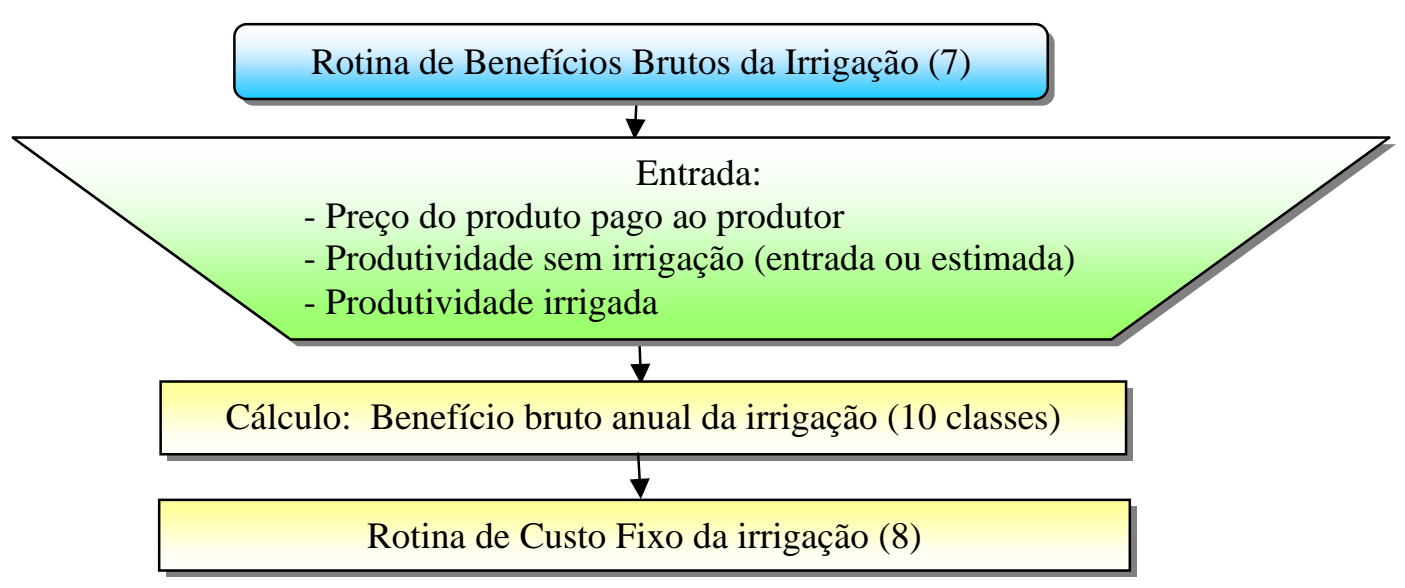

Figura 9 - Fluxograma da rotina de benefícios brutos da irrigação

\subsection{Rotina “Custos fixos”}

O custo total da irrigação pode ser dividido em custos fixos e variáveis. Os custos fixos são aqueles que ocorrem independente do número de horas anuais de operação do sistema de irrigação, incluem a depreciação do sistema e a remuneração do capital investido (Frizzone et al., 1994; Freitas, 2000; Frizzone \& Silveira, 2000). Os custos fixos (Figura 10) são calculados para o período de um ano e por unidade de área (ha) (Mattos, 1984; Turra, 1990; Melo, 1993; Pinheiro \& Coelho, 2003). 


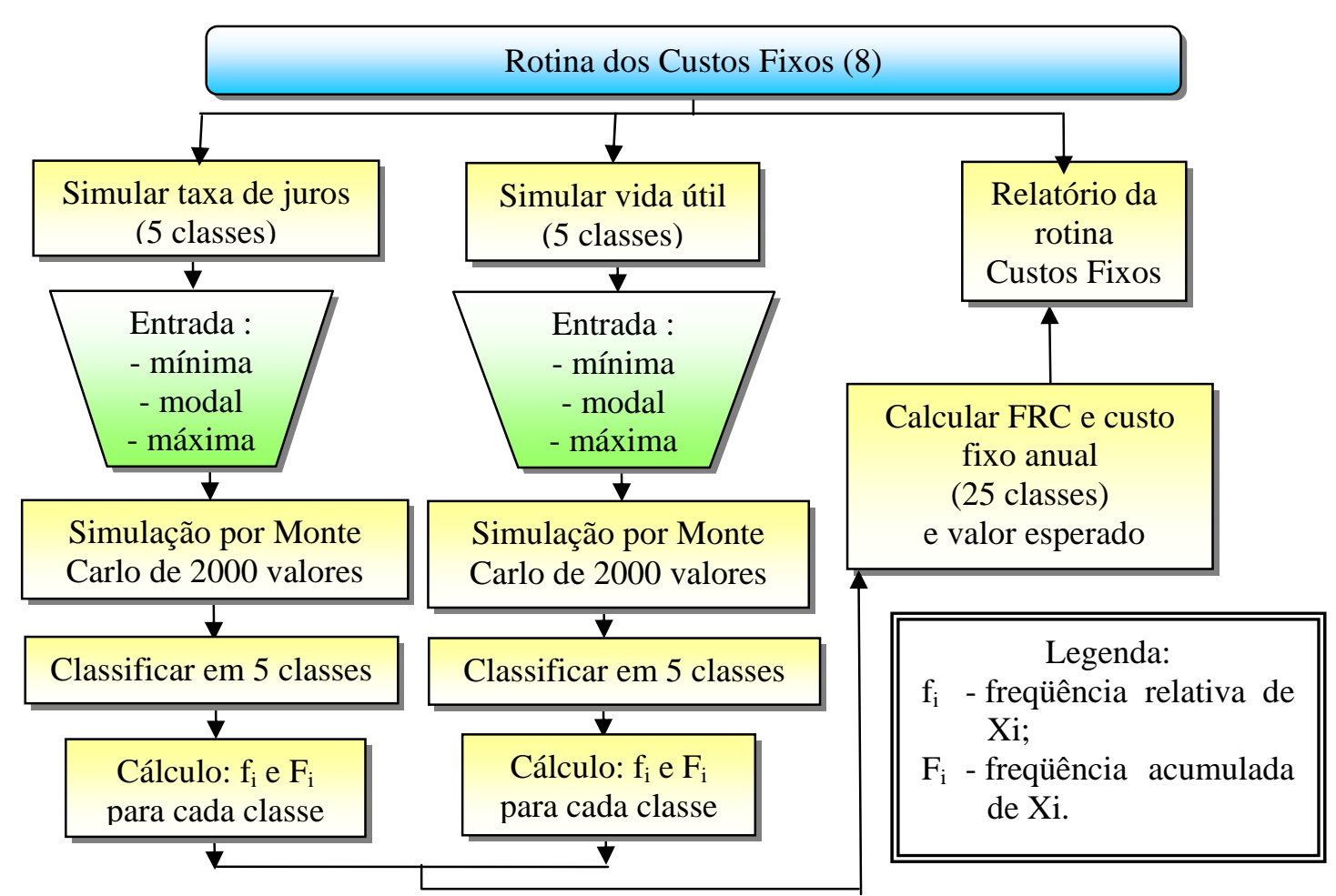

Figura 10 - Fluxograma da rotina de cálculo do custo fixo anual da irrigação

\subsubsection{Simulação}

Com os valores de máximo, modal e mínimo para cada variável realiza-se pelo método de Monte Carlo a simulação dos dados em Distribuição Triangular, gerando-se valores randômicos ( $\mathrm{r}$ entre 0 e 1). Compara-se o valor simulado a um valor de referência r* (eq. 19). Se $r>r^{*}$ obtém-se o valor simulado pela eq. 20, se $r<r^{*}$, obtémse o valor simulado pela eq. 21 e se $r=r^{*}$ obtêm-se o valor simulado pela eq. 22 (Andrade Júnior et al., 2001). Dessa forma obteve-se 2000 valores simulados para cada variável. 


$$
\begin{aligned}
& r *=\frac{(m-a)}{(b-a)} \\
& X s i=b-\sqrt{(1-r) \cdot(b-a) \cdot(b-m)} \\
& X s i=a+\sqrt{r \cdot(b-a) \cdot(b-a)} \\
& X s i=m
\end{aligned}
$$

onde:

r* - valor de referência;

Xsi - valor simulado para o ano i;

a $\quad$ - valor mínimo;

b - valor máximo;

m - valor modal.

\subsubsection{Cálculo das freqüências relativa e acumulada}

A distribuição de freqüência é o resumo tabular de um conjunto de dados brutos arranjados em classes ou categorias onde é determinado o número de elementos pertencentes a cada uma das classes, denominado de freqüência de classe. Este agrupamento permite evidenciar certas propriedades da variável que não seriam possíveis identificar pela simples análise dos dados brutos.

A média aritmética entre os limites de classe é chamada de ponto médio de classe. O número de classes é uma escolha arbitrária que geralmente recai entre 5 e 20. Um número de classe muito pequeno ou extensivo pode ocultar certas propriedades da distribuição de freqüências que seriam evidenciadas com a escolha mais adequada do número de classe (Assis et al., 1996). Dessa maneira utilizam-se 5 classes para as variáveis taxa de juro anual e vida útil do equipamento resultando em 25 valores de custo fixo anual. Com as classes definidas, calculam-se as freqüências relativas $\left(\mathrm{f}_{\mathrm{i}}\right)$, isto é, o número de vezes que os valores contidos na amplitude de classe ocorrem em relação 
ao número total (eq. 23) e as freqüências acumuladas $\left(\mathrm{F}_{\mathrm{i}}\right)$, ou seja, a soma das freqüências relativas ocorridas (eq. 24) para cada classe e estas visualizadas em um histograma que representa graficamente a distribuição de freqüências.

$$
\begin{aligned}
& \mathrm{f}_{\mathrm{i}}=\frac{\mathrm{N}(\mathrm{Xi})}{\mathrm{N}} \quad 0 \leq \mathrm{f}_{\mathrm{i}} \leq 1 \\
& \mathrm{~F}_{\mathrm{i}}=\mathrm{f}_{\mathrm{i}}+\mathrm{F}_{\mathrm{i}-1} \quad 0 \leq \mathrm{F}_{\mathrm{i}} \leq 1
\end{aligned}
$$

onde:

$\mathrm{f}_{\mathrm{i}} \quad$ - freqüência relativa de $\mathrm{Xi}$;

$\mathrm{N}(\mathrm{Xi})$ - número de vezes que ocorre Xi;

$\mathrm{N} \quad$ - número total de observações;

$\mathrm{F}_{\mathrm{i}} \quad$ - freqüência acumulada de Xi.

\subsubsection{Cálculo do custo fixo anual}

Para obtenção dos custos fixos anuais da irrigação emprega-se o custo anual uniforme que considera o valor residual do sistema de irrigação. Neste cálculo utiliza-se o Fator de Recuperação de Capital (FRC) que pressupõe a reserva de uma quantidade suficiente de dinheiro em cada ano para possibilitar a reposição do bem em $\mathrm{n}$ anos mais os encargos dos juros sobre o capital investido (Frizzone \& Silveira, 2000; Marques et al., 2002). O FRC (eq. 25) utiliza as 5 classes de taxas de juros anuais e as 5 classes de valores de vida útil do equipamento, resultando assim em 25 coeficientes. A variabilidade da vida útil esperada pode ocorrer em razão das diferenças de condições físicas de operação, do nível de reparo, operação e manutenção praticada, e do número total de horas que o sistema é usado em cada ano (Bonomo et al., 1999; Silva et al., 2003). Com a eq. 26 obtêm-se os 25 valores de custo fixo anual referentes a este investimento e suas probabilidades de ocorrência. 


$$
\mathrm{FRC}=\frac{\mathrm{i} \cdot(\mathrm{i}+1)^{\mathrm{n}}}{(\mathrm{i}+1)^{\mathrm{n}}-1}
$$

onde:

FRC - fator de recuperação de capital (decimal);

i $\quad$ - taxa de juros ao ano (decimal);

$\mathrm{n} \quad$ - vida útil do equipamento (anos).

$$
\mathrm{CF}_{\mathrm{a}}=\mathrm{FRC} \cdot \mathrm{PS}-\frac{\mathrm{VR} \cdot \mathrm{i}}{(\mathrm{i}+1)^{\mathrm{n}}-1}
$$

onde:

$\mathrm{CF}_{\mathrm{a}}$ - custo fixo anual da irrigação $\left(\mathrm{R} \$ \mathrm{ha}^{-1} \mathrm{ano}^{-1}\right)$;

PS - preço de aquisição e instalação do equipamento de irrigação ( $\left.\mathrm{R} \$ \mathrm{ha}^{-1}\right)$;

VR - valor residual do sistema de irrigação $\left(\mathrm{R} \$ \mathrm{ha}^{-1}\right)$.

\subsection{Rotina "Custos variáveis"}

Os custos variáveis (eq. 27) dependem da operação do sistema de irrigação. No cálculo dos custos variáveis anuais da irrigação, utilizam-se os custos de bombeamento, manutenção, mão-de-obra e custo da água (Andrade Júnior et al., 2001; Frizzone et al., 2001; Marques \& Coelho, 2003). O fluxograma pode ser visto na Figura 11.

$$
\mathrm{CV}_{\mathrm{a}}=\mathrm{Cam}+\mathrm{Cab}+\mathrm{Caw}+\mathrm{Camo}
$$

onde:

$\mathrm{CV}_{\mathrm{a}}$ - custo variável anual $\left(\mathrm{R} \$\right.$ ha $\left.^{-1} \mathrm{ano}^{-1}\right)$;

Cam - custo anual de manutenção $\left(\mathrm{R} \$ \mathrm{ha}^{-1} \mathrm{ano}^{-1}\right)$;

Cab - custo anual de bombeamento $\left(\mathrm{R} \$ \mathrm{ha}^{-1} \mathrm{ano}^{-1}\right)$;

Caw - custo anual da água ( $\left.\mathrm{R} \$ \mathrm{ha}^{-1} \mathrm{ano}^{-1}\right)$;

Camo - custo anual da mão-de-obra ( $\left.\mathrm{R} \$ \mathrm{ha}^{-1} \mathrm{ano}^{-1}\right)$. 


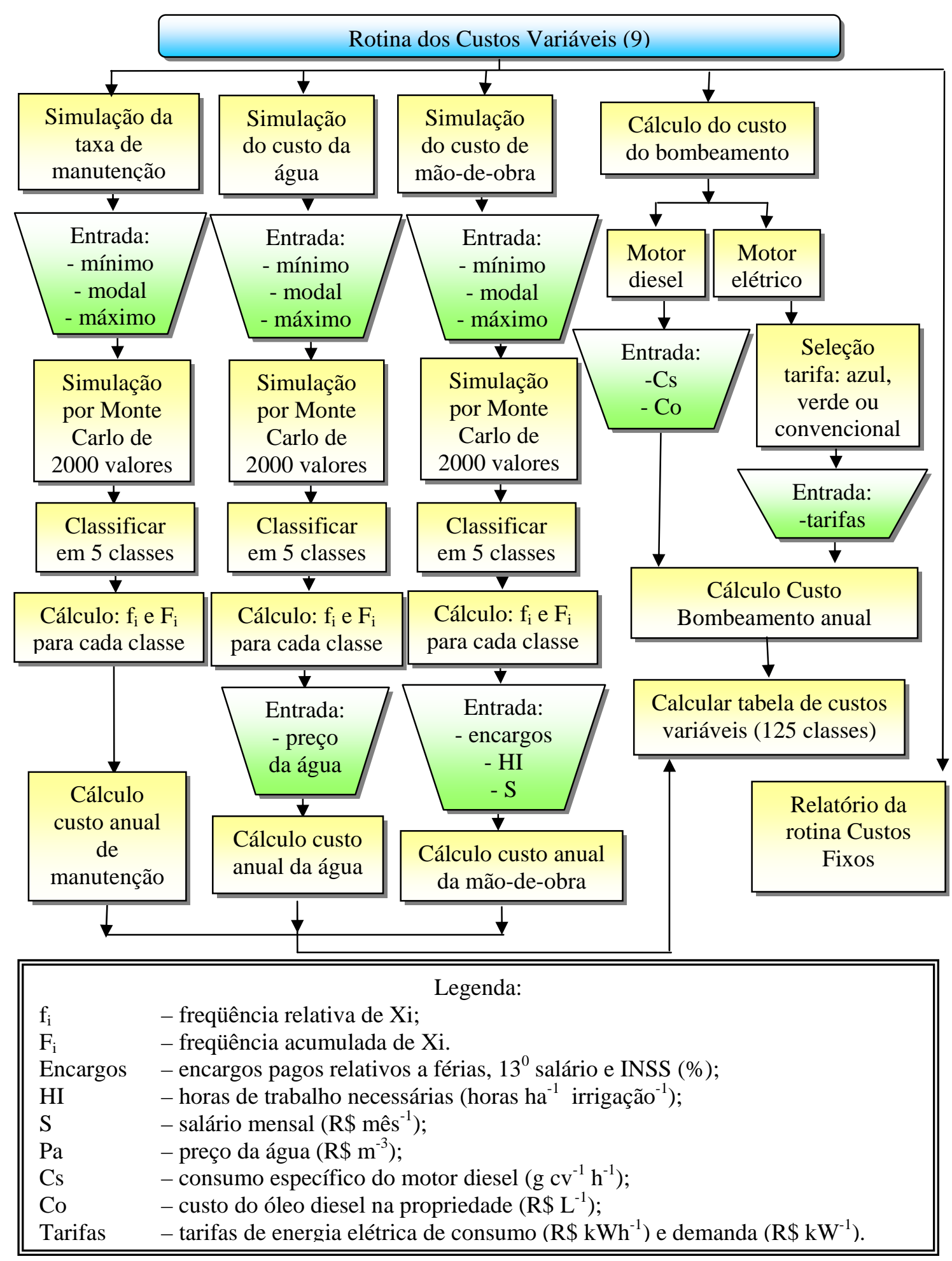

Figura 11 - Fluxograma da rotina de cálculo do custo variável anual da irrigação 


\subsubsection{Custo de manutenção}

O custo de manutenção corresponde ao custo anual necessário para manter o bem capital em condições de uso, varia em função do número de horas anuais de operação (Zocoller, 2003; Blanco et al., 2004). Taxas anuais de manutenção são simuladas e classificadas em 5 classes como descrito nos itens 3.8.1 e 3.8.2 e o custo anual de manutenção calculado pela eq. 28.

$$
\mathrm{Cam}=\frac{\mathrm{Tm} \cdot \mathrm{PS}}{100}
$$

onde: Tm é a taxa anual de manutenção (\%).

\subsubsection{Custo de bombeamento para motor elétrico}

O tipo de motor, elétrico ou a combustão, é um parâmetro de grande efeito sobre os custos. Para o motor elétrico é importante considerar a modalidade de tarifação elétrica (Melo, 1993; Frizzone, 1999; Campana, 2000; Zocoler, 2003). O fornecimento de energia elétrica divide as unidades consumidoras em dois grupos: grupo A e grupo B. O grupo B corresponde às unidades consumidoras com carga instalada igual ou inferior a $50 \mathrm{~kW}$, já as unidades do grupo A, corresponde as unidades com carga instalada superior a $50 \mathrm{~kW}$ e inferior a $2500 \mathrm{~kW}$. Para o grupo A, onde se encontram os irrigantes, existem três tipos de tarifas (convencional, azul e verde) e dois componentes básicos na definição do seu preço: um relativo a demanda de potência, e outro relativo ao consumo de energia (Souza, 2001; Souza \& Frizzone, 2003a). Dessa maneira o custo anual do bombeamento para o motor elétrico (eq. 29) é calculado pela soma do faturamento anual da demanda e o faturamento anual de consumo ajustados pelo fator de potência (Frizzone, 1999; Campana, 2000; Marques et al., 2002) em função do tipo de tarifa horosazonal utilizada, isto é, tarifa convencional, tarifa verde ou tarifa azul (Zocoler, 2003; Alves Júnior et al., 2004). 


$$
\mathrm{Cab}=(\mathrm{FDa}+\mathrm{FCa}) \cdot\left(\frac{0,92}{\cos \varphi}\right) \cdot(1+\mathrm{ICMS})
$$

em que:

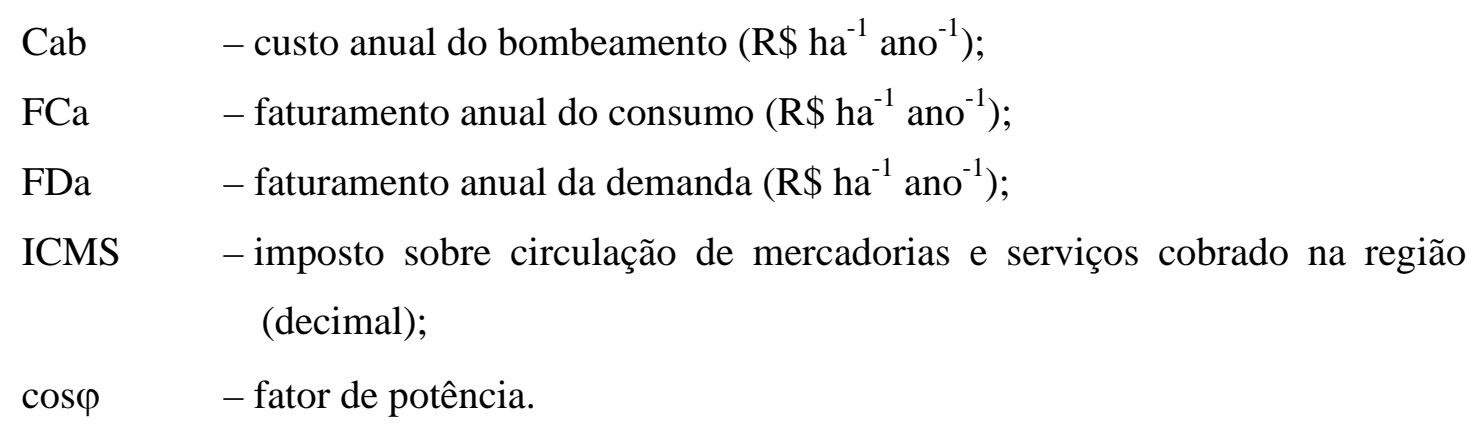

$\mathrm{Na}$ composição dos preços das tarifas horosazonais azul e verde, existem algumas diferenciações que se baseiam na utilização da energia elétrica durante as horas do dia e durante o período do ano. As horas do dia dividem-se em horário de ponta e horário fora de ponta. O horário de ponta corresponde a três horas consecutivas entre as 18h e 21h (Agência Nacional de Energia Elétrica, 2004). O horário fora de ponta corresponde a todos os horários fora dos limites colocados no horário de ponta (Andrade Júnior et al., 2001; Souza \& Frizzone, 2003a; Alves Júnior et al., 2004).

Optou-se por desconsiderar as tarifas de ultrapassagem de carga nos cálculos seguindo o raciocínio de Souza (2001) que considerou que os motores elétricos utilizados em projetos de irrigação são em número reduzido e basicamente são exclusivos para executar o acionamento de bombas hidráulicas e equipamentos destinados à movimentação do sistema de irrigação. Assim, a estimativa da demanda é mais precisa tornando-se pouco provável longos períodos de ultrapassagem de carga durante a utilização do sistema, sendo mais provável a ocorrência de ultrapassagem somente no momento de partida dos motores.

O faturamento mensal da demanda é calculado com a potência da motobomba (eq. 30) e posteriormente calcula-se o faturamento anual da demanda, sendo que nos meses em que não há necessidade de irrigar existe a cobrança de $10 \%$ do valor da demanda (Souza, 2001; Zocoler, 2003). O consumo de energia elétrica depende da quantidade de água a ser aplicada na área irrigada, da energia hidráulica exigida pelo 
sistema de irrigação e da eficiência total do sistema de bombeamento. Seguindo estas considerações, o número de horas de funcionamento mensais de irrigação foi calculado (eq. 31) utilizando a necessidade mensal de água e a capacidade do equipamento (Marques et al., 2002; Srivastava et al., 2003). O faturamento anual do consumo é calculado em função das tarifas e do número de horas de funcionamento, sendo estas divididas em funcionamento no horário fora de ponta (até 21 horas diárias) e funcionamento no horário de ponta (até 3 horas diárias). O funcionamento no horário fora de ponta foi também dividido em horas de funcionamento com desconto especial (até 8,5 horas diárias) e sem desconto (até 12,5 horas diárias).

$$
\text { Demanda }=0,736 \cdot \text { Pot }
$$

sendo:

Demanda - demanda contratada $\left(\mathrm{kW} \mathrm{ha}^{-1}\right)$;

Pot - potência do motor $\left(\mathrm{cv} \mathrm{ha}^{-1}\right)$.

$$
\mathrm{H}=\frac{\mathrm{LBm} \cdot 10}{\mathrm{Q}}
$$

onde:

$\mathrm{H} \quad$ - horas de funcionamento mensal $\left(\mathrm{h} \mathrm{ha}^{-1} \mathrm{mês}^{-1}\right)$;

Q - vazão da motobomba $\left(\mathrm{m}^{3} \mathrm{ha}^{-1} \mathrm{~h}^{-1}\right)$;

LBm - lâmina bruta mensal (mm mês ${ }^{-1}$ ).

\subsubsection{Tarifa convencional}

A tarifa convencional se aplica às unidades consumidoras do Grupo A, atendidas em tensão inferior a $69 \mathrm{kV}$ e demanda menor que 500 kW (Souza, 2001; Agência Nacional de Energia Elétrica, 2004). Para o cálculo dos faturamentos mensais da demanda (eq. 32) e do consumo (eq. 33) da tarifa convencional a tarifas são únicas, isto é, não diferem em relação ao horário do dia ou época do ano. 


$$
\begin{array}{ll}
\mathrm{F} \mathrm{Dm}=(\mathrm{Tdm} \cdot \mathrm{Demanda}) & \Rightarrow \mathrm{FDa}=\sum_{\text {mês }=1}^{12} \mathrm{FDm} \\
\mathrm{FCm}=\mathrm{TCc} \cdot[\mathrm{Hd} \cdot(1-\mathrm{fd})+\mathrm{Hs}] \cdot 0,736 \cdot \mathrm{Pot} \Rightarrow \mathrm{FCa}=\sum_{\text {mês }=1}^{12} \mathrm{FCm}
\end{array}
$$

sendo:

FDm - faturamento mensal de demanda $\left(\mathrm{R} \$ \mathrm{ha}^{-1}\right.$ mês $\left.{ }^{-1}\right)$;

Tdm - tarifa de demanda referente ao valor de $1 \mathrm{~kW}$ de potência demandada, que dá o direito à sua utilização pelo período de um mês $\left(\mathrm{R} \$ \mathrm{~kW}^{-1}\right)$ (Frizzone et al., 1994);

Demanda - demanda contratada $\left(\mathrm{kW} \mathrm{ha}^{-1}\right)$;

FDa - faturamento anual de demanda $\left(\mathrm{R} \$ \mathrm{ha}^{-1} \mathrm{ano}^{-1}\right)$;

FCm - faturamento mensal de consumo ( $\mathrm{R} \$$ ha $^{-1}$ mês $\left.^{-1}\right)$;

TCc - tarifa de consumo convencional referente ao valor de venda de $1 \mathrm{kWh}$ de energia consumida $\left(\mathrm{R} \$ \mathrm{kWh}^{-1}\right)$;

Hd - horas de funcionamento com desconto (21h30 às 6h) (h ha $\left.{ }^{-1} \mathrm{mês}^{-1}\right)$;

Hs $\quad$ - horas de funcionamento sem desconto ( $\mathrm{Hs}=\mathrm{H}-\mathrm{Hd})\left(\mathrm{h} \mathrm{ha}^{-1} \mathrm{mês}^{-1}\right)$;

fd - fator de desconto da Portaria 105 DNAEE (\%) (Pinheiro et al., 2002; Pinheiro \& Coelho, 2003);

FCa - faturamento anual de consumo $\left(\mathrm{R} \$ \mathrm{ha}^{-1} \mathrm{ano}^{-1}\right)$.

\subsubsection{Tarifa azul}

A tarifa azul é aplicada aos consumidores do Grupo A, de forma compulsória para as unidades consumidoras com tensão igual ou superior a $69 \mathrm{kV}$ e unidades consumidoras com tensão inferior a $69 \mathrm{kV}$ com demanda de potência igual ou superior a 500 kW desde que não façam opção pela tarifa verde; é aplicada de forma opcional para as unidades consumidoras atendidas com tensão inferior as $69 \mathrm{kV}$ com demanda de potência entre $50 \mathrm{~kW}$ e $500 \mathrm{~kW}$ (Souza, 2001). O cálculo do faturamento de demanda 
considera o funcionamento no horário de ponta e fora de ponta (eq. 34). Para o cálculo do faturamento de consumo são considerados o horário de funcionamento (ponta e fora de ponta) e o período do ano de funcionamento, para o período úmido (eq. 35) e para o período seco (eq. 36) (Andrade Júnior et al., 2001; Alves Júnior et al., 2004).

$$
\begin{aligned}
& \mathrm{FDm}=[(\text { Tdazp } \cdot \mathrm{Dp})+(\text { Tdazf } \cdot \mathrm{Df})] \Rightarrow \mathrm{FDa}=\sum_{\text {mês }=1}^{12} \mathrm{FDm} \\
& \mathrm{FCm}=\{\text { TCazuf } \cdot[\mathrm{Hd} \cdot(1-\mathrm{fd})+\mathrm{Hsf}]+\mathrm{TCazup} \cdot \mathrm{Hp}\} \cdot 0,736 \cdot \mathrm{Pot} \Rightarrow \mathrm{FCa}=\sum_{\mathrm{mês}=1}^{12} \mathrm{FCm}(35) \\
& \mathrm{FCm}=\{\text { TCazsf } \cdot[\mathrm{Hd} \cdot(1-\mathrm{fd})+\mathrm{Hsf}]+\mathrm{TCazsp} \cdot \mathrm{Hp}\} \cdot 0,736 \cdot \mathrm{Pot} \Rightarrow \mathrm{FCa}=\sum_{\text {mês }=1}^{12} \mathrm{FCm}(36)
\end{aligned}
$$

onde:

Tdazp - tarifa de demanda azul no horário de ponta $\left(\mathrm{R} \$ \mathrm{~kW}^{-1}\right)$;

Tdazf - tarifa de demanda azul no horário fora de ponta $\left(\mathrm{R} \$ \mathrm{~kW}^{-1}\right)$;

Dp - demanda ocorrida no horário de ponta (18h às 21h) $\left(\mathrm{kW} \mathrm{ha}^{-1}\right)$;

Df - demanda ocorrida no horário fora de ponta $\left(\mathrm{kW} \mathrm{ha}^{-1}\right)$;

TCazuf - tarifa de consumo azul fora de ponta período úmido (dezembro a abril) $\left(\mathrm{R} \$ \mathrm{kWh}^{-1}\right)$;

Hsf - horas de funcionamento fora de ponta sem desconto (h ha ${ }^{-1}$ mês $^{-1}$ );

Hp - horas de funcionamento no horário de ponta (18h às 21h) (h ha ${ }^{-1}$ mês $\left.^{-1}\right)$;

TCazup - tarifa de consumo azul horário de ponta período úmido (dezembro a abril) $\left(\mathrm{R} \$ \mathrm{kWh}^{-1}\right)$;

TCazsf - tarifa de consumo azul fora de ponta período seco (maio a novembro) $\left(\mathrm{R} \$ \mathrm{kWh}^{-1}\right)$;

TCazsp - tarifa de consumo azul horário de ponta período seco (maio a novembro) $\left(\mathrm{R} \$ \mathrm{kWh}^{-1}\right)$. 


\subsubsection{Tarifa verde}

A tarifa verde é oferecida em caráter opcional aos consumidores do Grupo A com tensão inferior a $69 \mathrm{kV}$ com demanda a partir de $50 \mathrm{~kW}$ (Souza, 2001). A tarifa verde considera no faturamento da demanda um preço único (eq. 37). No faturamento do consumo, as tarifas são diferenciadas para o horário de funcionamento (ponta e fora de ponta) e a época do ano, sendo período seco (eq. 38) e período úmido (eq. 39) (Andrade Júnior et al., 2001; Alves Júnior et al., 2004).

$$
\begin{aligned}
& \mathrm{FDm}=(\mathrm{Tdv} \cdot \text { Demanda }) \quad \Rightarrow \mathrm{FDa}=\sum_{\text {mês }=1}^{12} \mathrm{FDm} \\
& \mathrm{FCm}=\{\mathrm{TCvfu} \cdot[\mathrm{Hd} \cdot(1-\mathrm{fd})+\mathrm{Hsf}]+\mathrm{TCvpu} \cdot \mathrm{Hp}\} \cdot 0,736 \cdot \mathrm{Pot} \Rightarrow \mathrm{FCa}=\sum_{\text {mês }=1}^{12} \mathrm{FCm}(38) \\
& \mathrm{FCm}=\{\mathrm{TCvfs} \cdot[\mathrm{Hd} \cdot(1-\mathrm{fd})+\mathrm{Hsf}]+\mathrm{TCvps} \cdot \mathrm{Hp}\} \cdot 0,736 \cdot \mathrm{Pot} \Rightarrow \mathrm{FCa}=\sum_{\text {mês }=1}^{12} \mathrm{FCm}(39)
\end{aligned}
$$

sendo:

$\mathrm{Tdv} \quad$ - tarifa de demanda verde $\left(\mathrm{R} \$ \mathrm{~kW}^{-1}\right)$;

Hp - horas de funcionamento no horário de ponta (18h às 21h) (h ha $\left.{ }^{-1} \mathrm{mês}^{-1}\right)$;

Hsf - horas de funcionamento fora de ponta sem desconto $\left(\mathrm{h} \mathrm{ha}^{-1} \mathrm{mês}^{-1}\right)$;

TCvfu - tarifa de consumo verde fora de ponta no período úmido (dezembro a abril) $\left(\mathrm{R} \$ \mathrm{kWh}^{-1}\right)$;

TCvfs - tarifa de consumo verde fora de ponta no período seco (maio a novembro) $\left(\mathrm{R} \$ \mathrm{kWh}^{-1}\right)$;

TCvpu - tarifa de consumo verde de ponta no período úmido (dezembro a abril) $\left(\mathrm{R} \$ \mathrm{kWh}^{-1}\right)$;

TCvps - tarifa de consumo verde de ponta no período seco (maio a novembro) $\left(\mathrm{R} \$ \mathrm{kWh}^{-1}\right)$. 


\subsubsection{Custo do bombeamento para motor diesel}

No motor a diesel não se tem componente de demanda, sendo necessário calcular a potência requerida por hora (cvh) e transformá-la em litros de óleo (Frizzone et al., 1994; Marques et al., 2002; Marques \& Coelho, 2003). O cálculo do custo anual do bombeamento do motor diesel pode ser feito pela na eq. 40 .

$$
\mathrm{Cab}=\mathrm{Co} \cdot \mathrm{Pot} \cdot \mathrm{Cs} \cdot 0,00125 \cdot \sum_{\text {mês }=1}^{12} \mathrm{H}
$$

onde:

Cab - custo anual do bombeamento ( $\left.\mathrm{R} \$ \mathrm{ha}^{-1} \mathrm{ano}^{-1}\right)$;

Co - custo do óleo diesel na propriedade $\left(\mathrm{R} \$ \mathrm{~L}^{-1}\right)$;

Pot - potência do motor (cv ha $\left.{ }^{-1}\right)$;

Cs - consumo específico do motor diesel $\left(\mathrm{g} \mathrm{cv}^{-1} \mathrm{~h}^{-1}\right)$;

$\mathrm{H} \quad$ - horas de funcionamento mensal $\left(\mathrm{h} \mathrm{ha}^{-1} \mathrm{mês}^{-1}\right)$.

\subsubsection{Custo da mão-de-obra}

No cálculo do custo anual da mão-de-obra (eq. 41), considerou o salário médio mensal pago ao trabalho rural, o número de horas de trabalho necessárias por hectare e por irrigação realizada, e os encargos pagos sobre o salário (Marouelli \& Silva, 1998; Frizzone, 1999; Marques et al., 2002; Pinheiro et al., 2002; Maya, 2003). O número horas de trabalho necessárias por hectare e por irrigação realizada foi simulado e classificado em 5 classes como descrito nos itens 3.8.1 e 3.8.2.

$$
\text { Camo }=\sum_{\text {dias irrigados }=1}^{\mathrm{n}}\left\{\frac{\mathrm{S}}{240} \cdot\left[1+\left(\frac{\text { Férias }+\mathrm{T}+\mathrm{INSS}+\mathrm{IT}}{100}\right)\right] \cdot \mathrm{HI}\right\}
$$


onde:

Camo - custo anual da mão-de-obra ( $\left.\mathrm{R} \$ \mathrm{ha}^{-1} \mathrm{ano}^{-1}\right)$;

$\mathrm{S} \quad$ - salário mensal ( $\mathrm{R} \$$ mês $\left.^{-1}\right)$;

240 - horas de trabalho por mês;

Férias - encargo pago relativo a férias em porcentagem do salário (\%);

$\mathrm{T} \quad$ - encargo pago relativo ao $13^{\circ}$ salário em porcentagem do salário (\%);

INSS - encargo pago relativo ao INSS em porcentagem do salário (\%);

IT - encargo pago relativo ao INSS do $13^{\circ}$ salário em porcentagem do salário (\%);

HI - horas de trabalho necessárias por hectare e por irrigação realizada (horas ha-1 irrigação $^{-1}$ ).

\subsubsection{Custo da água}

A cobrança sobre o uso da água incidirá sobre qualquer uso, inclusive irrigantes, sendo este mais um item que deve ser computado nos custos (Nagaoka et al., 2001; Balsalobre et al., 2003). O Custo da água é calculado pela eq. 42 (Rezende et al., 1992; Souza, 2001; Marques \& Coelho, 2003), sendo possível a entrada fixa do preço da água ou a sua simulação e classificação em 5 classes como descrito nos itens 3.8.1 e 3.8.2.

$$
\text { Caw }=\sum_{\text {mês }=1}^{12}\left(\mathrm{LBm}_{\text {mês }} \cdot \mathrm{Pa} \cdot 10\right)
$$

sendo:

Caw - custo anual da água $\left(\mathrm{R} \$ \mathrm{ha}^{-1} \mathrm{ano}^{-1}\right)$;

LBm - lâmina bruta mensal (mm mês ${ }^{-1}$ );

$\mathrm{Pa} \quad$ - preço da água $\left(\mathrm{R} \$ \mathrm{~m}^{-3}\right)$. 


\subsection{Rotina “Custo total anual da irrigação”}

O Custo Total Anual (eq. 43) é obtido pela soma das combinações dos custos fixos anuais (25 classes) e dos custos variáveis anuais (125 classes) resultando em 3.125 valores. O fluxograma pode ser visto na Figura 12.

$$
\mathrm{CT}_{\mathrm{a}}=\mathrm{CF}_{\mathrm{a}}+\mathrm{CV}_{\mathrm{a}}
$$

onde: $\mathrm{CT}_{\mathrm{a}}$ - custo total anual da irrigação $\left(\mathrm{R} \$ \mathrm{ha}^{-1} \mathrm{ano}^{-1}\right)$.

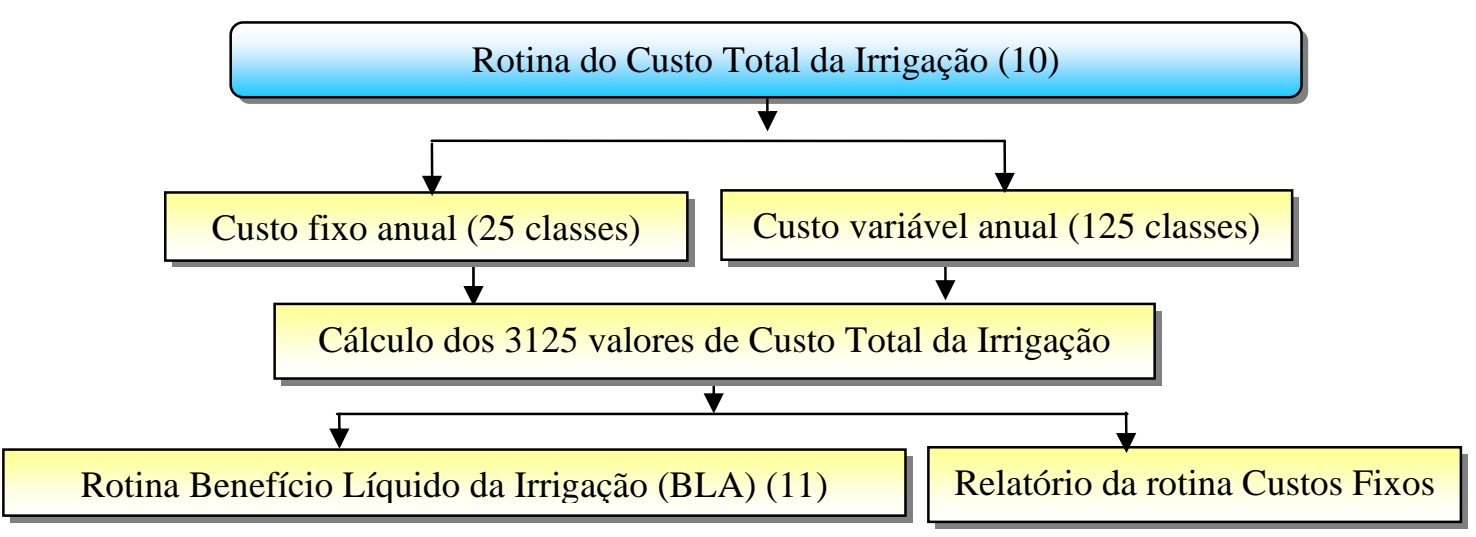

Figura 12 - Fluxograma da rotina de cálculo do custo total da irrigação

\subsection{Rotina "Benefícios líquidos anuais da irrigação (BLA)"}

A agricultura irrigada exige alto investimento que representa importantes custos adicionais, os quais devem ser pagos pelo incremento de produtividade proporcionado pelo fornecimento de água às plantas. Dessa maneira o benefício líquido anual é calculado como a diferença entre a receita líquida com irrigação e a receita líquida sem irrigação, isto é, o benefício líquido anual só terá valor superior a zero quando o incremento de renda bruta devido à irrigação for superior aos custos da irrigação (eq. 44) (Gohring \& Wallender, 1987; Clark et al., 1993; Srivastava et al., 2003). Nesta rotina são apresentados os coeficientes econômicos do projeto, sendo: valor médio ponderado 
de benefício líquido anual do projeto, valor médio ponderado do custo fixo total anual, valor médio ponderado do custo variável total anual, valor médio ponderado do custo total anual, valor médio ponderado do benefício líquido anual, valor médio ponderado da relação benefício/custo, desvio padrão do benefício líquido anual e o coeficiente de variação do benefício líquido. São calculados também a porcentagem de participação no custo total da irrigação dos fatores: custo fixo, custo da mão-de-obra, custo da água, custo do bombeamento e custo de manutenção (Figura 13).

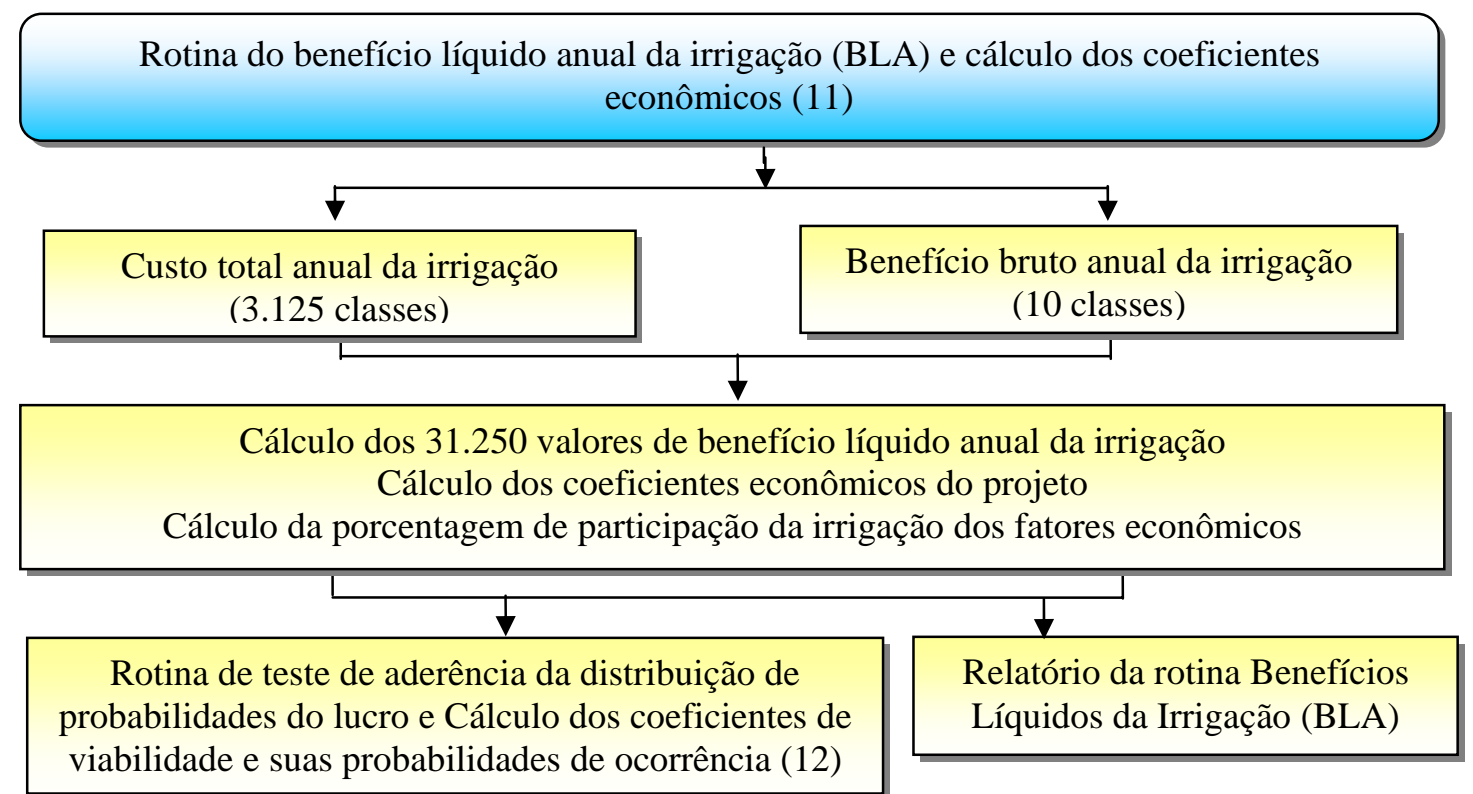

Figura 13 - Fluxograma da rotina do benefício líquido anual da irrigação (BLA)

$$
\mathrm{BLA}=\left(\mathrm{Ri}-\mathrm{Cp} \cdot \mathrm{Yi}-\mathrm{CT}_{\mathrm{a}}\right)-(\mathrm{Rs}-\mathrm{Cp} \cdot \mathrm{Ys})
$$

onde:

BLA - benefício líquido anual da irrigação $\left(\mathrm{R} \$ \mathrm{ha}^{-1} \mathrm{ano}^{-1}\right)$;

$\mathrm{Ri}$ - receita bruta anual com irrigação $\left(\mathrm{R} \$ \mathrm{ha}^{-1} \mathrm{ano}^{-1}\right)$;

$\mathrm{Cp} \quad$ - custo de produção independente da irrigação $\left(\mathrm{R} \$ \mathrm{Mg}^{-1}\right)$;

$\mathrm{Yi}$ - produtividade com irrigação $\left(\mathrm{Mg} \mathrm{ha}^{-1} \mathrm{ano}^{-1}\right)$;

$\mathrm{CT}_{\mathrm{a}}$ - custo total anual da irrigação $\left(\mathrm{R} \$ \mathrm{ha}^{-1} \mathrm{ano}^{-1}\right)$;

Rs - receita bruta anual sem irrigação $\left(\mathrm{R} \$ \mathrm{ha}^{-1} \mathrm{ano}^{-1}\right)$;

Ys - produtividade sem irrigação $\left(\mathrm{Mg} \mathrm{ha}^{-1} \mathrm{ano}^{-1}\right)$. 
A relação benefício/custo (B/C) consiste na razão entre os benefícios anuais e os custos anuais e avalia quanto o projeto remunera por unidade de investimento. Seguindo a regra, um projeto deve apresentar B/C maior que a unidade para que seja viável e, quanto maior esta relação, mais atraente o projeto. A relação B/C é calculada de acordo com a eq. 45 (Clark et al., 1993; Frizzone \& Silveira, 2000).

$$
\mathrm{B} / \mathrm{C}=\frac{\mathrm{Bi}}{\mathrm{CI}}
$$

sendo:

B/C - relação benefício/custo;

$\mathrm{Bi}$ - benefício bruto anual da irrigação $\left(\mathrm{R} \$ \mathrm{ha}^{-1} \mathrm{ano}^{-1}\right)$;

CI - acréscimo no custo anual promovido pelo uso da irrigação ( $\left.\mathrm{R} \$ \mathrm{ha}^{-1} \mathrm{ano}^{-1}\right)$.

O valor médio ponderado, também denominado de valor esperado, mede a tendência central, isto é, o resultado que, na média, espera-se que viesse a ocorrer (Assis et al., 1996; Frizzone \& Silveira, 2000). Nesta rotina o valor esperado é calculado pela eq. 46 para os fatores benefício líquido anual, custo fixo total anual, custo variável total anual, custo total anual e benefício líquido anual.

$$
E(X)=\sum_{i=1}^{31.250}\left(X_{i} \cdot f_{i}\right)
$$

sendo:

$\mathrm{E}(\mathrm{X})$ - valor esperado do fator $\left(\mathrm{R} \$ \mathrm{ha}^{-1} \mathrm{ano}^{-1}\right)$;

$\mathrm{X}_{\mathrm{i}} \quad$ - valor da variável i $\left(\mathrm{R} \$ \mathrm{ha}^{-1} \mathrm{ano}^{-1}\right)$;

$\mathrm{f}_{\mathrm{i}} \quad$ - freqüência relativa da variável Xi. 
Para obter a variabilidade dos resultados de benefícios líquidos anuais obtidos no projeto, ou seja, medir o risco envolvido, utilizam-se como medidas de dispersão a variância, o desvio padrão, o desvio médio absoluto e o coeficiente de variação (Frizzone \& Silveira, 2000). A variância (eq. 47) é a média dos quadrados dos desvios dos resultados de benefícios líquidos em relação ao valor esperado de benefício líquido. O desvio padrão é a raiz quadrada da variância (eq. 48), o cálculo do desvio médio absoluto é feito pela eq. 49 e o cálculo do coeficiente de variação pela eq. 50.

$$
\begin{aligned}
& \sigma^{2}=\sum_{i=1}^{31.250}\left(X_{i}-E(X)\right)^{2} \cdot f_{i} \\
& \sigma=\sqrt{\sigma^{2}} \\
& D M=\sum_{i=1}^{31.250}\left|X_{i}-E(X)\right| \cdot f_{i} \\
& C V=\frac{\sigma}{E(X)} \cdot 100
\end{aligned}
$$

em que:

$\mathrm{\sigma}^{2} \quad$ - variância $\left(\mathrm{R}^{2} \mathrm{ha}^{-1} \mathrm{ano}^{-1}\right)$;

$\sigma \quad$ - desvio padrão $\left(\mathrm{R} \$ \mathrm{ha}^{-1} \mathrm{ano}^{-1}\right)$;

$\mathrm{DM}$ - desvio médio absoluto $\left(\mathrm{R} \$ \mathrm{ha}^{-1} \mathrm{ano}^{-1}\right)$;

CV - coeficiente de variação (\%);

$\mathrm{X}_{\mathrm{i}} \quad$ - valor da variável i $\left(\mathrm{R} \$ \mathrm{ha}^{-1} \mathrm{ano}^{-1}\right)$;

$f_{i} \quad$ - freqüência relativa da variável Xi. 
A porcentagem de participação no custo total da irrigação para os fatores custo fixo, custo da mão-de-obra, custo da água, custo do bombeamento e custo da manutenção é calculada de acordo com a eq. 51.

$$
\mathrm{P}_{\text {custo total }}=\frac{\mathrm{E}(\mathrm{X})}{\mathrm{E}(\mathrm{X})_{\text {custo total }}} \cdot 100
$$

sendo:

$\mathrm{P}_{\text {custo total }} \quad$ - participação no custo total (\%);

$\mathrm{E}(\mathrm{X})_{\text {custototal }}$ - valor esperado do custo total da irrigação $\left(\mathrm{R} \$ \mathrm{ha}^{-1} \mathrm{ano}^{-1}\right)$.

\subsection{Rotina "Teste de aderência da distribuição de probabilidades do benefício líquido anual”}

O teste de Kolmogorov-Smirnov é aplicado para verificar se os valores de uma certa amostra de dados podem ser considerados como provenientes de uma população com distribuição teórica preestabelecida. O teste confronta duas distribuições de freqüência acumuladas (Figura 14) e calcula-se a Dmax; se este valor for maior ou igual ao valor crítico de Dmax (tabelado) a hipótese é rejeitada (Assis et al., 1996; Souza, 2001). Considerou-se para o ajuste as funções de densidades de probabilidades triangular (eq. 52) e normal (eq. 53) adotando-se 5\% de nível de significância, que indica uma confiança de 95\% (Assis et al., 1996; Franke \& Dorfman, 2000). O Dmax utilizado é calculado pela eq. 54 encontrado em Campos (1983) e Souza (2001). Nesta rotina também é calculada a probabilidade de ocorrência de 6 níveis de benefícios líquidos: 0 , 20\% do benefício líquido anual máximo; 40\% do benefício líquido anual máximo; 60\% do benefício líquido anual máximo; 80\% do benefício líquido anual máximo e 100\% do benefício líquido anual máximo, permitindo-se ainda a entrada do valor esperado seguido do cálculo de sua probabilidade de ocorrência. 
Formulário Rotina de teste de aderência da distribuição de probabilidades do benefício líquido anual e cálculo dos coeficientes de viabilidade (12)

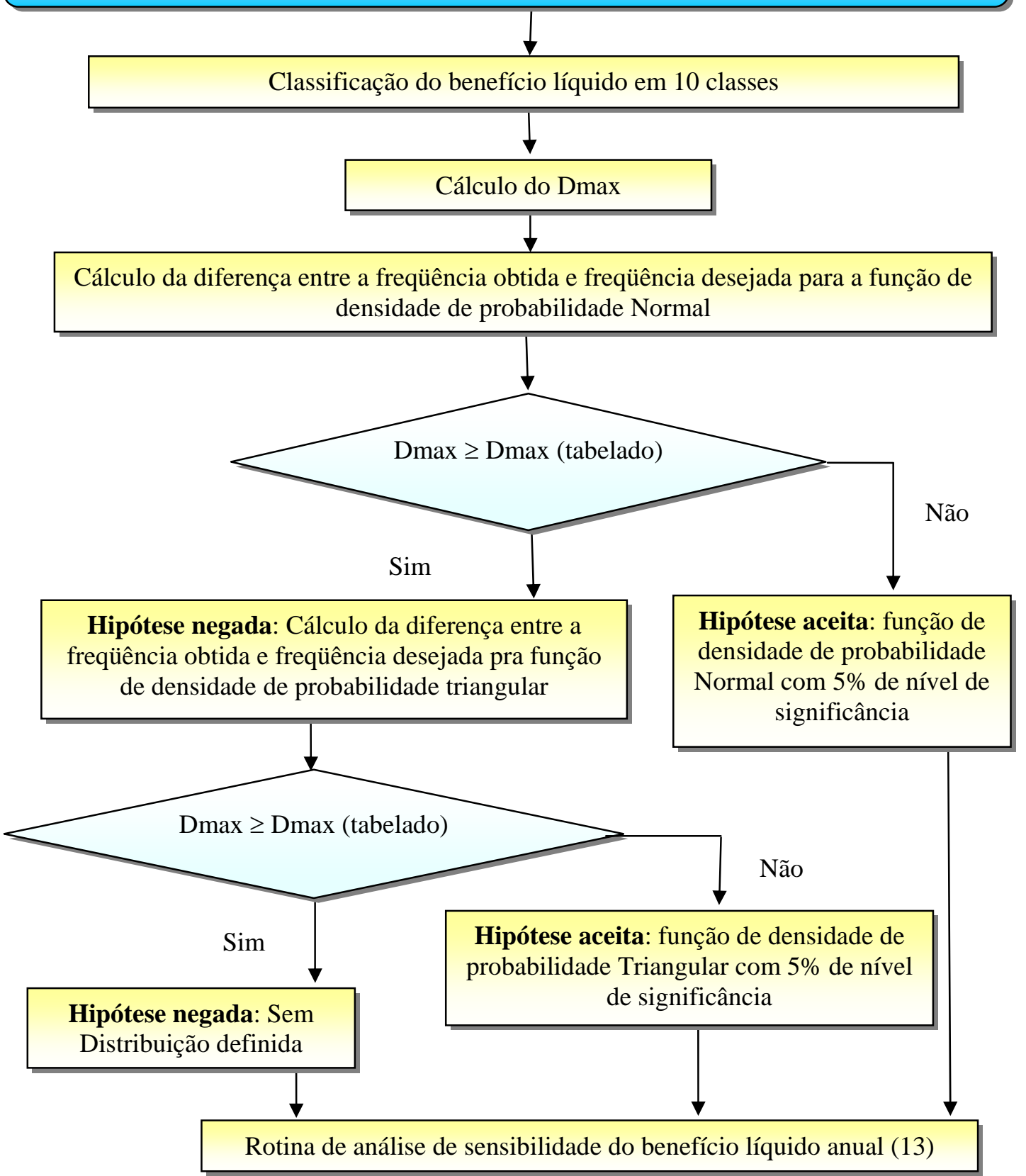

Figura 14 - Fluxograma da rotina do teste de aderência da distribuição de probabilidades do benefício líquido anual 


$$
f(x)= \begin{cases}\frac{2(x-a)}{(b-a) \cdot(m-a)} & \text { para } a \leq x \leq m \\ \frac{2(b-x)}{(b-a) \cdot(b-m)} & \text { para } m<x \leq b \\ 0 & \text { para outros valores de } x\end{cases}
$$

sendo:

$$
\begin{array}{ll}
\text { a } & \text { - valor mínimo; } \\
\text { b } & \text { - valor máximo; } \\
\text { m } & \text { - valor modal. }
\end{array}
$$

$$
f(x)=\frac{1}{\sqrt{2 \pi}} e^{-\frac{1}{2} \cdot\left(\frac{x-\mu}{\sigma}\right)^{2}}
$$

sendo:

$\mu \quad$ - média;

$\sigma \quad$ - desvio padrão.

$$
D \max =\frac{1,37}{\sqrt{N}}
$$

$\mathrm{N}$ - número de elementos da amostra. 


\subsection{Rotina “Análise de sensibilidade do benefício líquido anual”}

Nesta rotina a sensibilidade do benefício líquido anual é examinada pela variação percentual dos fatores: taxa de juros, preço de venda do produto, vida útil, taxa de manutenção, preço da água e horas de trabalho necessárias por hectare e por irrigação realizada. Para cada fator selecionado, são fixados os demais com seu valor modal, e então são calculados 200 valores de benefícios líquidos, os quais são visualizados graficamente em função da variação percentual. São apresentados os valores de variação percentual do benefício líquido anual pela variação de $-20 \%$ e $+20 \%$ dos fatores para cada análise estudada.

\subsection{Levantamento de dados para análise do risco econômico}

As culturas analisadas são a cana-de-açúcar e o tomate industrial, com quatro anos de dados climáticos (2001 a 2004) obtidos na estação meteorológica automática do Departamento de Ciências Exatas da Escola Superior de Agricultura "Luiz de Queiroz", USP, Piracicaba - SP, altitude 546 m, latitude $22^{\circ} 42^{\prime} 30^{\prime \prime}$ S e longitude $47^{\circ} 38$ ’00” $\mathrm{W}$.

São utilizados para a análise de risco do projeto e análise de sensibilidade, os valores citados por Manzan (1980); Melo (1993); Matioli et al. (1998); Faveta (1998); Marouelli \& Silva (1998); Campana (2000); Nagaoka et al. (2001); Pinheiro et al. (2002); Marques \& Coelho (2003); Soares et al. (2003); Companhia Paulista de Força e Luz (2004); Instituto de Economia Agrícola (2004a e 2004b); Sociedade de Olericultura Brasileira (2004); FNP Consultoria \& Comércio (2005).

Para o cálculo do custo de bombeamento com motor elétrico utilizaram-se as tarifas elétricas vigentes no Estado de São Paulo apresentadas na Tabela 5. Para o cálculo do bombeamento com motor diesel considerou-se o valor de venda do óleo diesel de $\mathrm{R} \$ 1,50 \mathrm{~L}^{-1}$ e um consumo específico de $170 \mathrm{~g} \mathrm{cv}^{-1} \mathrm{~h}^{-1}$ (Marques \& Coelho, 2003). O salário mensal utilizado é de $\mathrm{R} \$ 260,00$ mês $^{-1}$. A evapotranspiração de referência foi estimada pelo método de Penman-Montheit. 
Tabela 5. Tarifas de energia elétrica do grupo A4, para as modalidades de Tarifa Verde, Tarifa Azul e Tarifa Convencional (16/11/2004)

\begin{tabular}{|c|c|c|}
\hline & Fatores & Valores \\
\hline \multirow{6}{*}{ Tarifa Verde } & período úmido ponta & 0,88437 \\
\hline & consumo período úmido fora de ponta & 0,09113 \\
\hline & $\left(\mathrm{R} \$ \mathrm{kWh}^{-1}\right)$ período seco ponta & 0,90079 \\
\hline & período seco fora de ponta & 0,10299 \\
\hline & demanda $\left(\mathrm{R} \$ \mathrm{~kW}^{-1}\right)$ & 10,29 \\
\hline & período úmido ponta & 0,1955 \\
\hline \multirow{5}{*}{ Tarifa Azul } & período úmido fora de ponta & 0,09124 \\
\hline & $\left(\mathrm{R} \$ \mathrm{kWh}^{-1}\right)$ período seco ponta & 0,21203 \\
\hline & período seco fora de ponta & 0,10312 \\
\hline & demanda ponta $\left(\mathrm{R} \$ \mathrm{~kW}^{-1}\right)$ & 31,28 \\
\hline & demanda fora de ponta $\left(\mathrm{R} \$ \mathrm{~kW}^{-1}\right)$ & 10,29 \\
\hline \multirow[t]{2}{*}{ Tarifa Convencional } & consumo $\left(\mathrm{R} \$ \mathrm{kWh}^{-1}\right)$ & 0,17491 \\
\hline & demanda $\left(\mathrm{R} \$ \mathrm{~kW}^{-1}\right)$ & 13,00 \\
\hline
\end{tabular}

Fonte: Companhia Paulista de Força e Luz (2004).

Os valores fixos utilizados para as culturas da cana-de-açúcar e do tomate industrial são demonstrados na Tabela 6 e os valores fixos para os sistemas de irrigação utilizados são demonstrados na Tabela 7. Os valores utilizados na simulação de preço de venda das culturas podem ser vistos na Tabela 8. Nas Tabelas 9 e 10 são apresentados, respectivamente, os valores utilizados na simulação para fatores envolvidos nos custos fixos e nos custos variáveis. 
Tabela 6. Fatores fixos utilizados para a cultura da cana-de-açúcar e para a cultura do tomate industrial

\begin{tabular}{llc}
\hline \multicolumn{1}{c}{ Fatores } & Valores \\
\hline \multirow{2}{*}{ cana-de-açúcar } & Produtividade de sequeiro $\left(\mathrm{Mg} \mathrm{ha}^{-1}\right.$ ciclo $\left.^{-1}\right)$ & estimada \\
& Fator de resposta da cultura $(\mathrm{Ky})$ & 1,20 \\
& Produtividade máxima irrigada $\left(\mathrm{Mg} \mathrm{ha}^{-1} \mathrm{ciclo}^{-1}\right)$ & 174 \\
& Custo de produção $\left(\mathrm{R} \$ \mathrm{Mg}^{-1}\right)$ & 18,00 \\
& Ciclo (dias) & 365 \\
& Data de plantio & $15 / 11$ \\
& & \\
& Produtividade de sequeiro $\left(\mathrm{Mg} \mathrm{ha}^{-1} \mathrm{ciclo}^{-1}\right)$ & estimada \\
& Fator de resposta da cultura $\left(\mathrm{Ky}^{-1}\right)$ & 1,05 \\
& Produtividade máxima irrigada $\left(\mathrm{Mg} \mathrm{ha}^{-1}\right.$ ciclo $\left.^{-1}\right)$ & 80 \\
& Custo de produção $\left(\mathrm{R} \$ \mathrm{Mg}^{-1}\right)$ & 105,00 \\
& Ciclo (dias) & 125 \\
& Data de plantio & $25 / 05$ \\
\hline
\end{tabular}

Fonte: Manzan (1980); Matioli et al. (1998); Doorenbos \& Kassam,(2000); Soares et al. (2003); Sociedade de Olericultura Brasileira (2004); FNP Consultoria \& Comércio (2005).

Tabela 7. Características dos sistemas de irrigação utilizados

\begin{tabular}{|c|c|c|c|c|}
\hline \multirow[b]{2}{*}{ Características } & \multicolumn{4}{|c|}{ Sistemas de irrigação } \\
\hline & $\begin{array}{c}\text { Pivô } \\
\text { Central }\end{array}$ & $\begin{array}{l}\text { Deslocamento } \\
\text { Linear }\end{array}$ & Autopropelido & $\begin{array}{c}\text { Aspersão } \\
\text { Convencional }\end{array}$ \\
\hline $\begin{array}{c}\text { Eficiência de aplicação de } \\
\text { água (\%) }\end{array}$ & 80 & 86 & 65 & 70 \\
\hline $\begin{array}{l}\text { Vazão do sistema } \\
\qquad\left(\mathrm{m}^{3} \mathrm{~h}^{-1} \mathrm{ha}^{-1}\right)\end{array}$ & 4,56 & 4,56 & 2,50 & 4,80 \\
\hline Custo de aquisição ( $\left.\mathrm{R} \$ \mathrm{ha}^{-1}\right)$ & $3.000,00$ & $3.500,00$ & $2.000,00$ & $1.500,00$ \\
\hline Potência do motor (cv ha $\left.{ }^{-1}\right)$ & 2,39 & 2,39 & 2,60 & 3,00 \\
\hline
\end{tabular}


Tabela 8. Valores utilizados na simulação por Monte Carlo para os valores de venda da cultura de cana-de-açúcar e da cultura do tomate industrial

\begin{tabular}{ccc}
\hline Parâmetros & & Valor \\
\hline \multirow{2}{*}{ Preço de venda da cana-de-açúcar $\left({\left.\mathrm{R} \$ \mathrm{Mg}^{-1}\right)}\right.$} & Modal & 25,40 \\
& Máximo & 27,90 \\
& & 31,55 \\
Preço de venda do tomate industrial $\left(\mathrm{R} \$ \mathrm{Mg}^{-1}\right)$ & Mínimo & 140,00 \\
& Modal & 160,00 \\
& Máximo & 190,00
\end{tabular}

Fonte: Instituto de Economia Agrícola (2004a e 2004b); Sociedade de Olericultura Brasileira (2004).

Tabela 9. Valores utilizados na simulação por Monte Carlo para os fatores envolvidos nos custos fixos: vida útil do sistema de irrigação e taxa de juros

\begin{tabular}{ccc}
\hline \multicolumn{1}{c}{ Parâmetros } & Valor \\
\hline Vida útil para o pivô central e & Mínimo & 12 \\
deslocamento linear (anos) & Modal & 15 \\
& Máximo & 18 \\
Vida útil para o autopropelido & Mínimo & 8 \\
(anos) & Modal & 10 \\
& Máximo & 12 \\
Vida útil para a aspersão & & 10 \\
convencional (anos) & Mínimo & 12 \\
Taxa de Juros (\% ao ano) & Modal & 15 \\
& Máximo & 3 \\
\hline Fonte: Melo (1993); Matioli et al. (1998); Faveta (1998); Marouelli \& Silva (1998); Campana (2000); \\
Pinheiro et al. (2002); Soares et al. (2003).
\end{tabular}


Tabela 10. Valores utilizados na simulação por Monte Carlo para os fatores envolvidos nos custos variáveis: taxa de manutenção do sistema de irrigação, horas de trabalho para irrigação e preço da água

\begin{tabular}{|c|c|c|}
\hline Parâmetros & & Valor \\
\hline \multirow{3}{*}{ Taxa de manutenção do pivô central (\%) } & Mínimo & 4,0 \\
\hline & Modal & 5,0 \\
\hline & Máximo & 6,0 \\
\hline \multirow{3}{*}{$\begin{array}{l}\text { Taxa de manutenção do deslocamento linear } \\
\text { e autopropelido (\%) }\end{array}$} & Mínimo & 5,0 \\
\hline & Modal & 6,0 \\
\hline & Máximo & 7,0 \\
\hline \multirow{3}{*}{$\begin{array}{c}\text { Taxa de manutenção da aspersão } \\
\text { convencional (\%) }\end{array}$} & Mínimo & 1,0 \\
\hline & Modal & 2,5 \\
\hline & Máximo & 4,0 \\
\hline \multirow{3}{*}{$\begin{array}{l}\text { Horas de trabalho por irrigação para o pivô } \\
\text { central }\left(\mathrm{h} \mathrm{ha}^{-1} \text { irrigação }^{-1}\right)\end{array}$} & Mínimo & 0,1 \\
\hline & Modal & 0,4 \\
\hline & Máximo & 0,7 \\
\hline \multirow{3}{*}{$\begin{array}{l}\text { Horas de trabalho por irrigação para o } \\
\text { autopropelido }\left(\mathrm{h} \mathrm{ha}^{-1} \text { irrigação }^{-1}\right)\end{array}$} & Mínimo & 0,5 \\
\hline & Modal & 0,8 \\
\hline & Máximo & 1,0 \\
\hline \multirow{3}{*}{$\begin{array}{l}\text { Horas de trabalho por irrigação para o } \\
\text { deslocamento linear }\left(\mathrm{h} \mathrm{ha}^{-1} \text { irrigação }{ }^{-1}\right)\end{array}$} & Mínimo & 0,3 \\
\hline & Modal & 0,7 \\
\hline & Máximo & 1,0 \\
\hline \multirow{3}{*}{$\begin{array}{l}\text { Horas de trabalho por irrigação para a } \\
\text { aspersão convencional (h ha }{ }^{-1} \text { irrigação }^{-1} \text { ) }\end{array}$} & Mínimo & 1,5 \\
\hline & Modal & 2,5 \\
\hline & Máximo & 3,5 \\
\hline \multirow{3}{*}{ Preço da água $\left(\mathrm{R} \$ \mathrm{~m}^{-3}\right)$} & Mínimo & 0,00 \\
\hline & Modal & 0,01 \\
\hline & Máximo & 0,03 \\
\hline
\end{tabular}




\section{RESULTADOS E DISCUSSÃO}

Os resultados e discussão são apresentados em duas partes, sendo a primeira parte a apresentação do modelo computacional para a determinação do risco econômico em culturas irrigadas por meio da exibição de suas telas na seqüência de execução dos cálculos. A segunda parte consta de uma análise econômica para a implantação da irrigação para as culturas de cana-de-açúcar e tomate industrial na região de Piracicaba, com estudos de viabilidade econômica, dos custos envolvidos e análise de sensibilidade dos fatores econômicos simulados.

\subsection{Apresentação do modelo}

No modelo computacional para determinação do risco econômico em culturas irrigadas os dados são salvos em um banco de dados interno do programa, para serem acessados e alterados a qualquer momento pelo usuário. O modelo consta de 19.116 linhas de programação e 18 tabelas interligadas. As telas que seguem (Figuras 15 a 38) exibem valores relativos à análise econômica da irrigação da cana-de-açúcar para a região de Piracicaba. A tela principal (Figura 15) oferece as opções do projeto e nas Figuras 16 e 17 podem ser vistas as telas de criação de um novo projeto e a de abertura de um projeto existente, respectivamente. Após a abertura do arquivo é apresentada a tela de caracterização agronômica do projeto e do solo, onde são inseridos os dados do projeto que identificam o banco de dados para o controle das demais telas (Figura 18). Em seguida são preenchidos os dados referentes ao solo, para posterior cálculo do armazenamento de água no solo (Figura 19). 


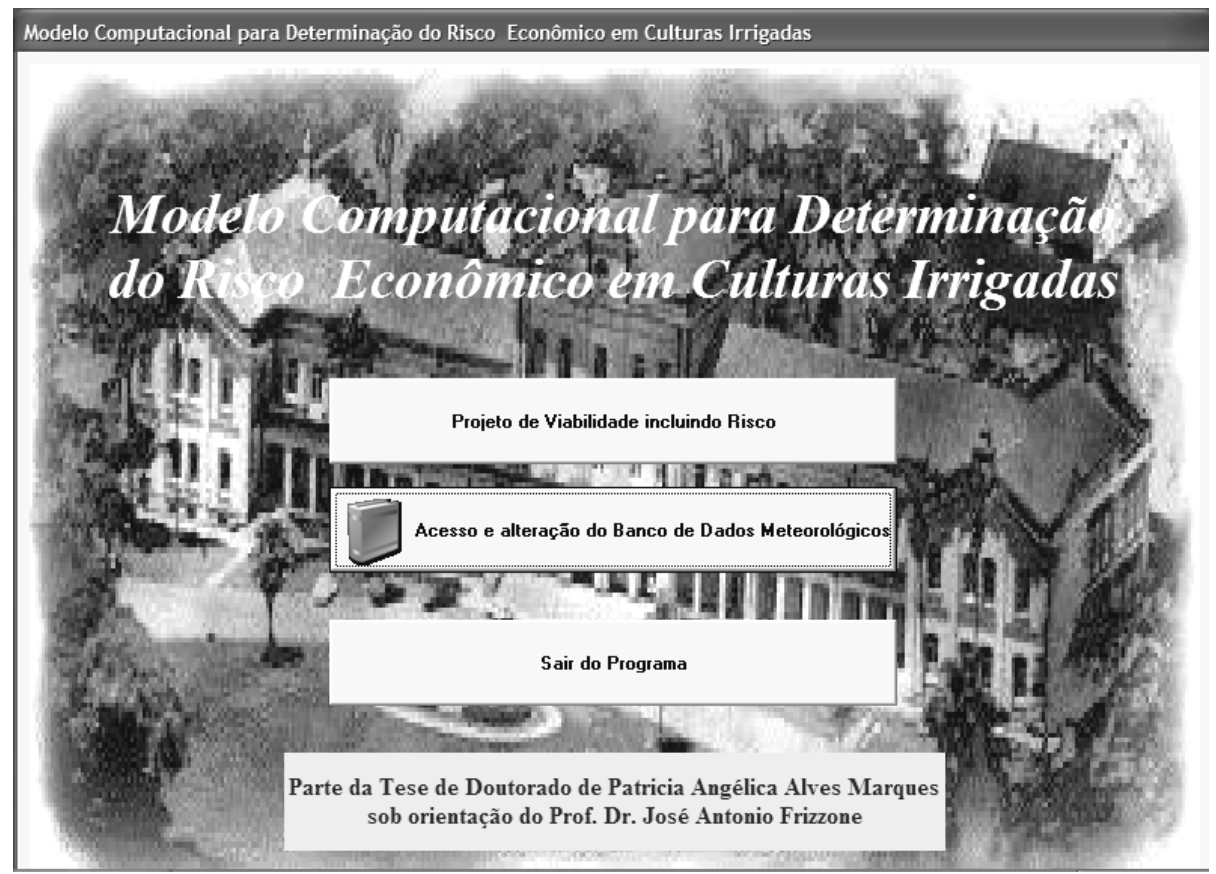

Figura 15 - Tela principal do modelo computacional para determinação do risco econômico em culturas irrigadas

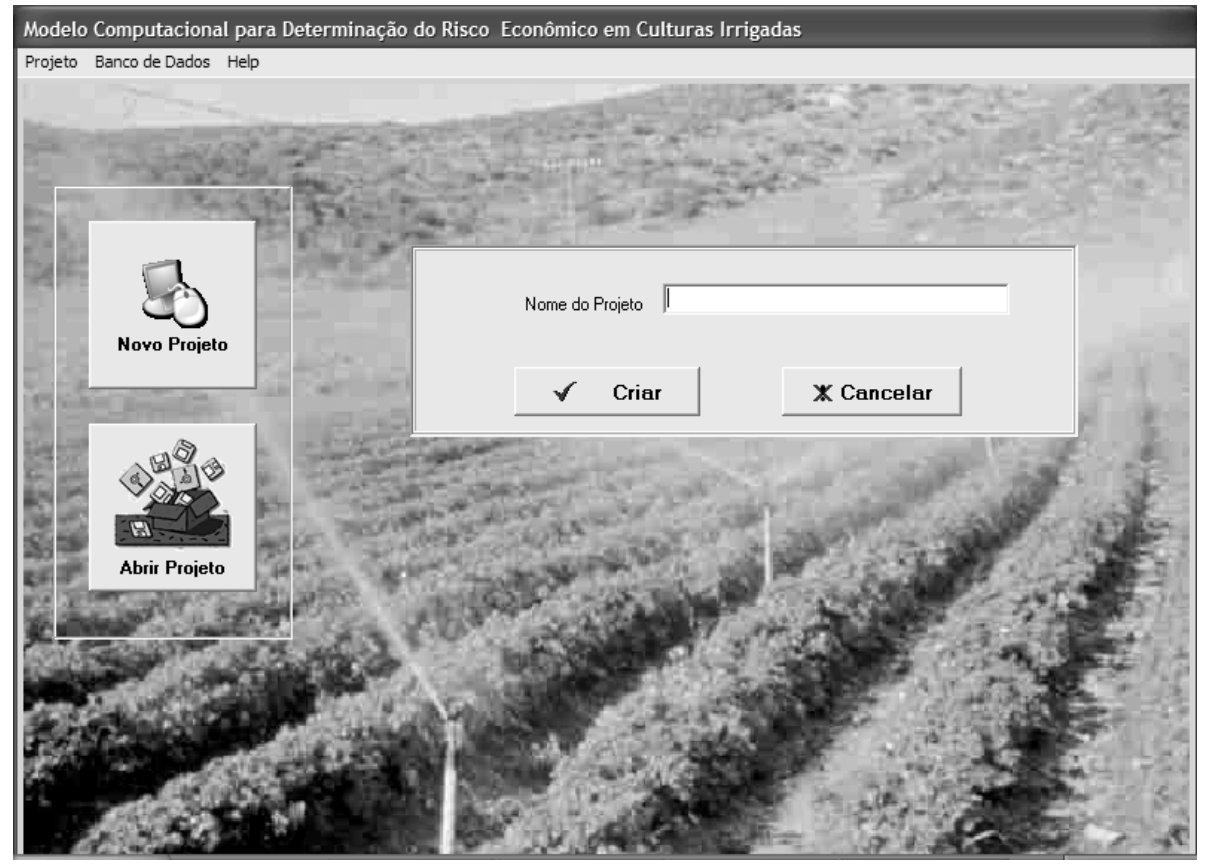

Figura 16 - Tela para criar novo projeto de viabilidade incluindo risco 


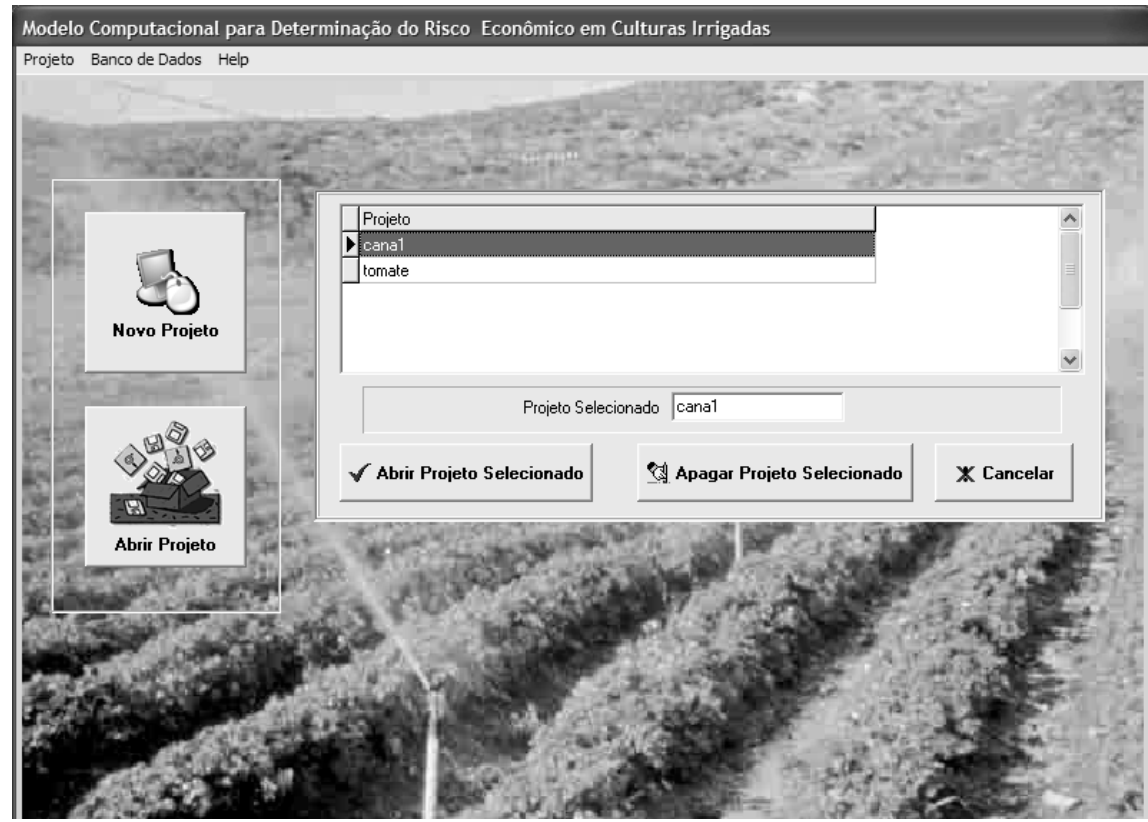

Figura 17 - Tela para acessar projeto já salvo

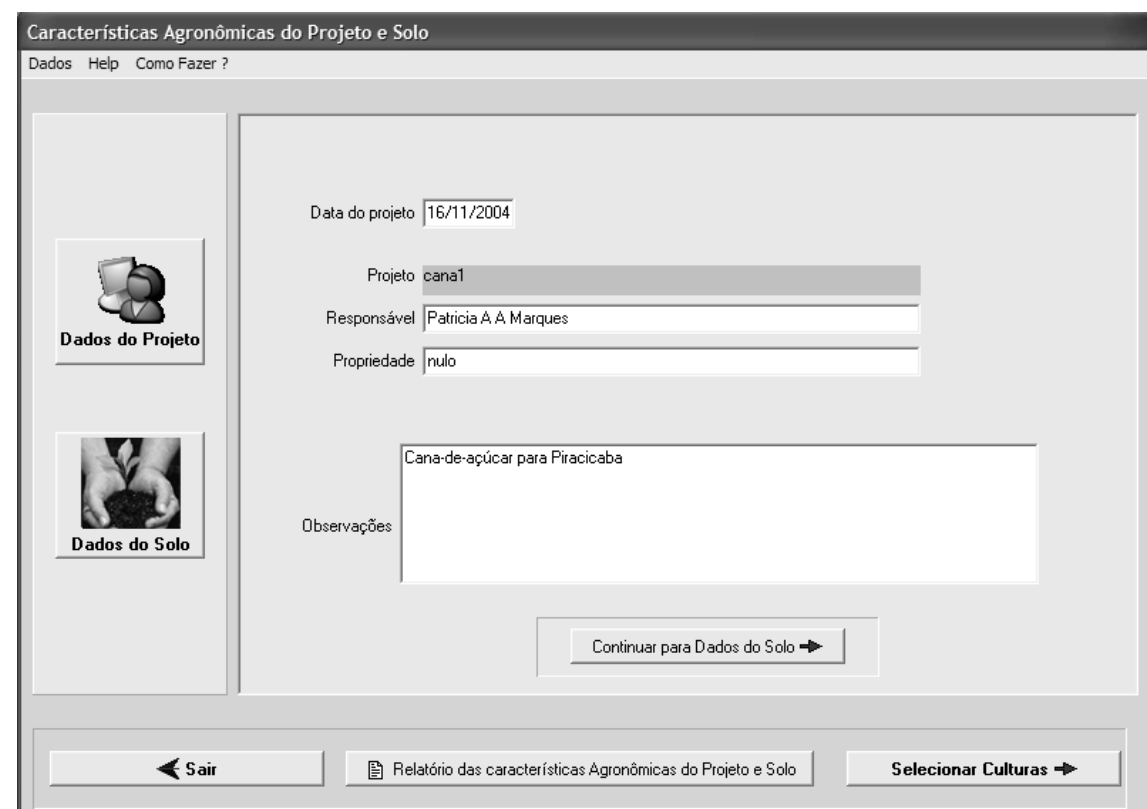

Figura 18 - Tela de características agronômicas do projeto 


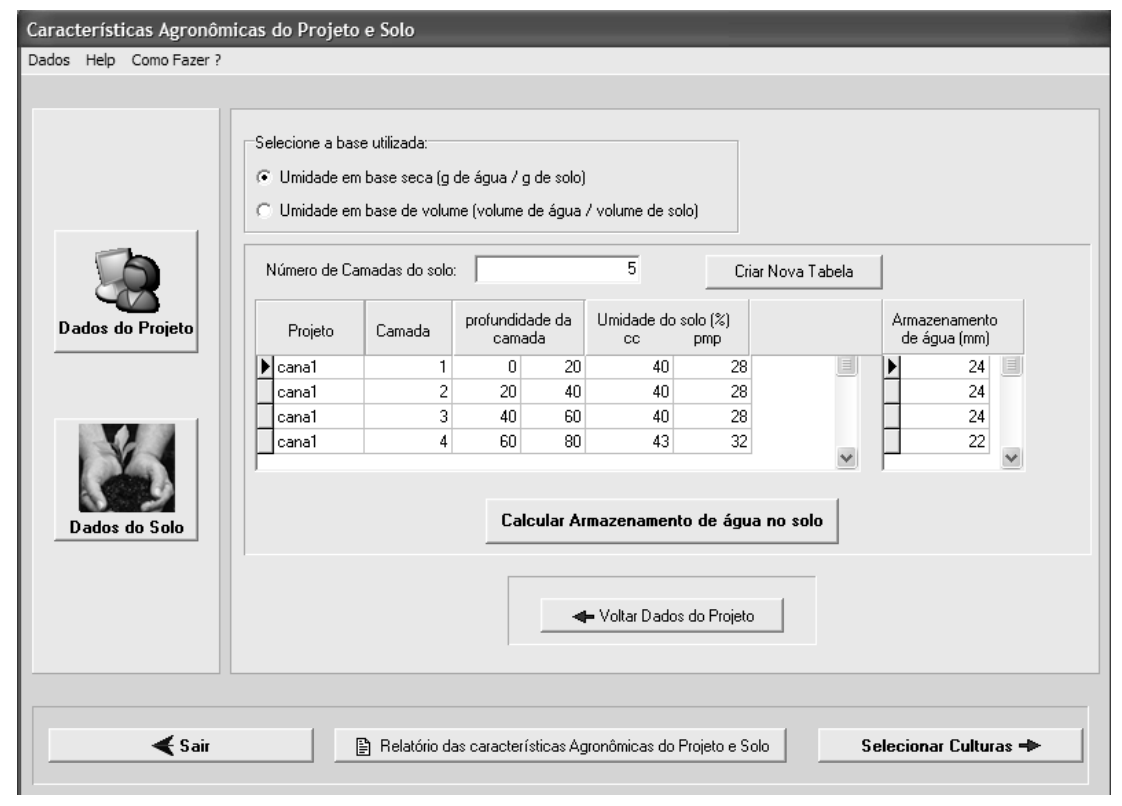

Figura 19 - Tela de características agronômicas do solo

A próxima tela consta das informações agronômicas da cultura, onde os dados da cultura são inseridos sendo: cultura, fator f de esgotamento de água do solo FAO, data do plantio e ciclo da cultura (Figura 20). Em seguida, para a criação da tabela de balanço hídrico é necessário o preenchimento dos valores correspondentes a cada fase fenológica (Kc, período em dias e profundidade do sistema radicular) conforme se apresenta na Figura 21.

Depois de definidas as características agronômicas da cultura, são necessárias as características do sistema de irrigação para posteriores cálculos de custo fixo anual, lâmina bruta de irrigação e custos de bombeamento (Figura 22). Após essa caracterização, os dados climáticos são selecionados por cidade em um banco de dados previamente preenchido (Figura 23). Nessa tela é criada uma tabela auxiliar vinculada ao projeto com os dados climáticos, para posterior cálculo da estimativa da evapotranspiração de referência. 


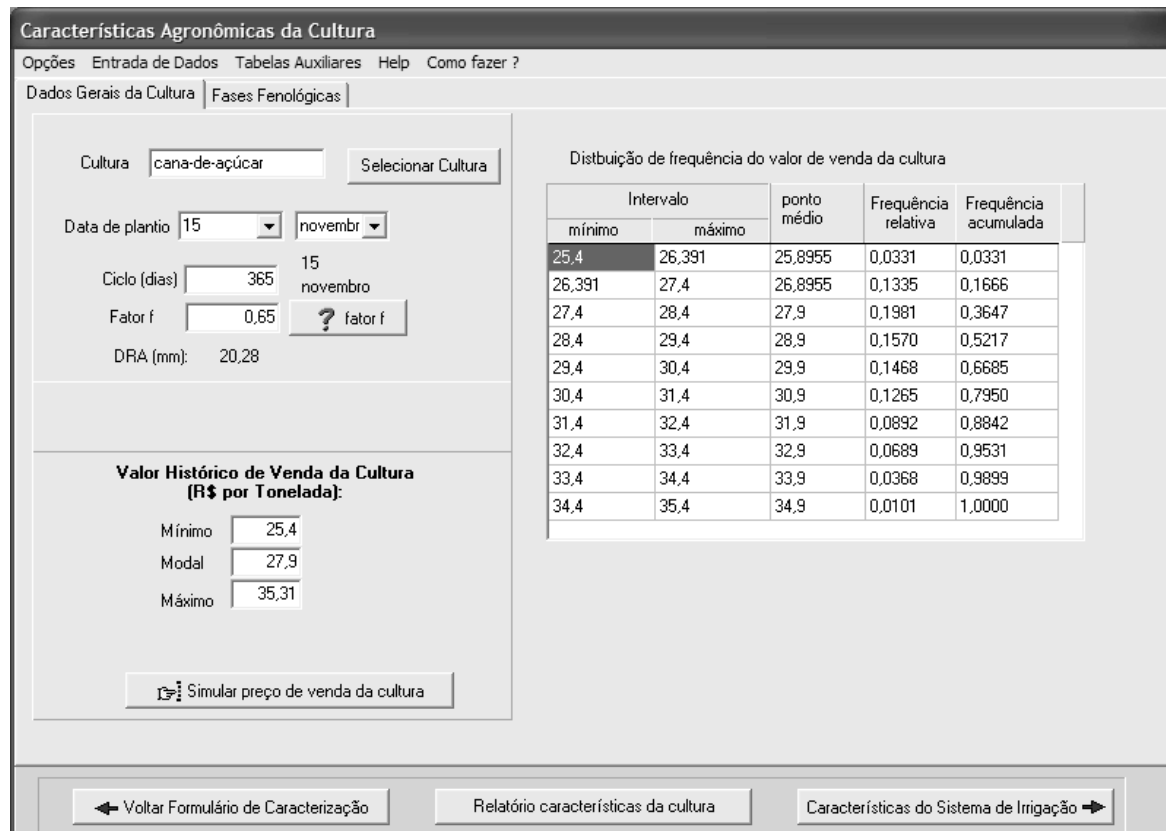

Figura 20 - Tela de características agronômicas da cultura: dados da cultura

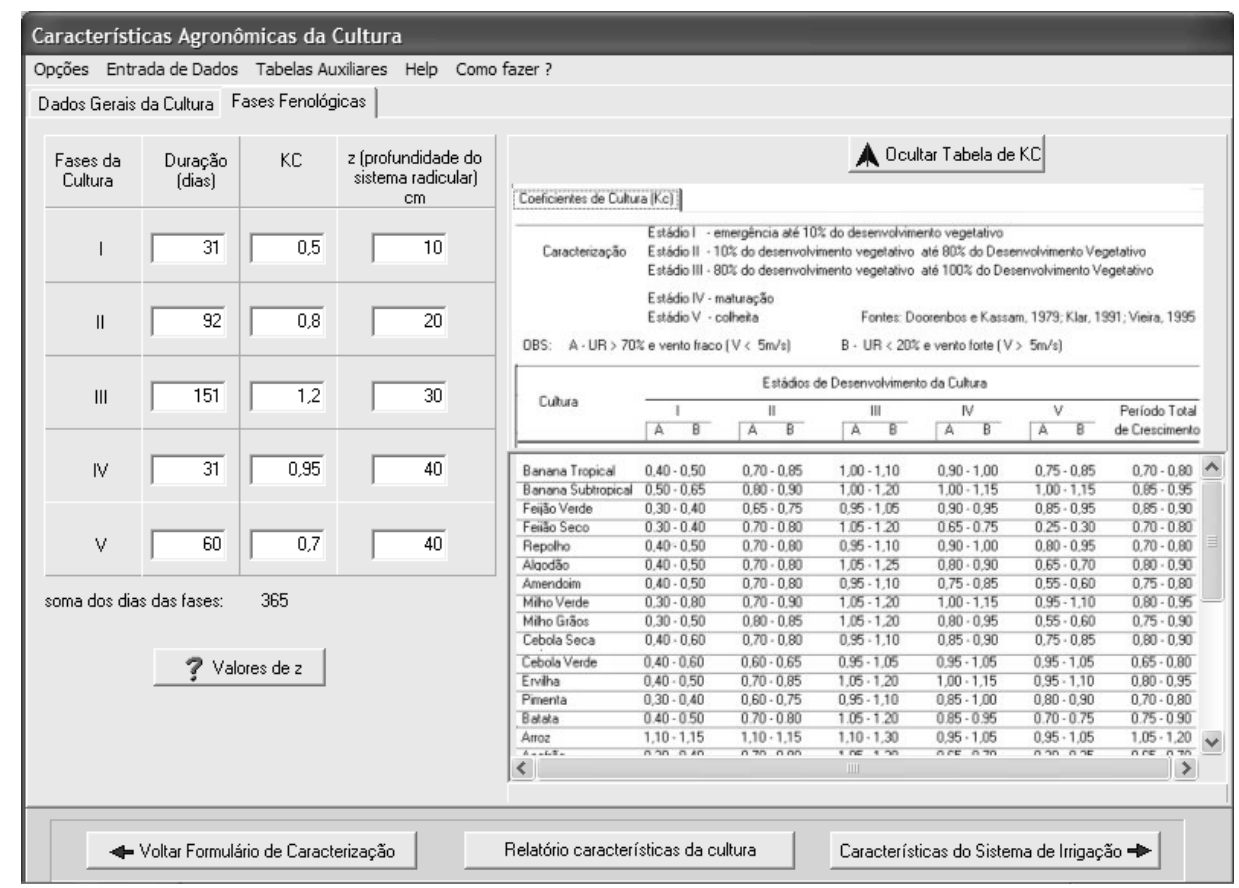

Figura 21 - Tela de características agronômicas da cultura: valores de kc, período em dias e profundidade efetiva do sistema radicular 


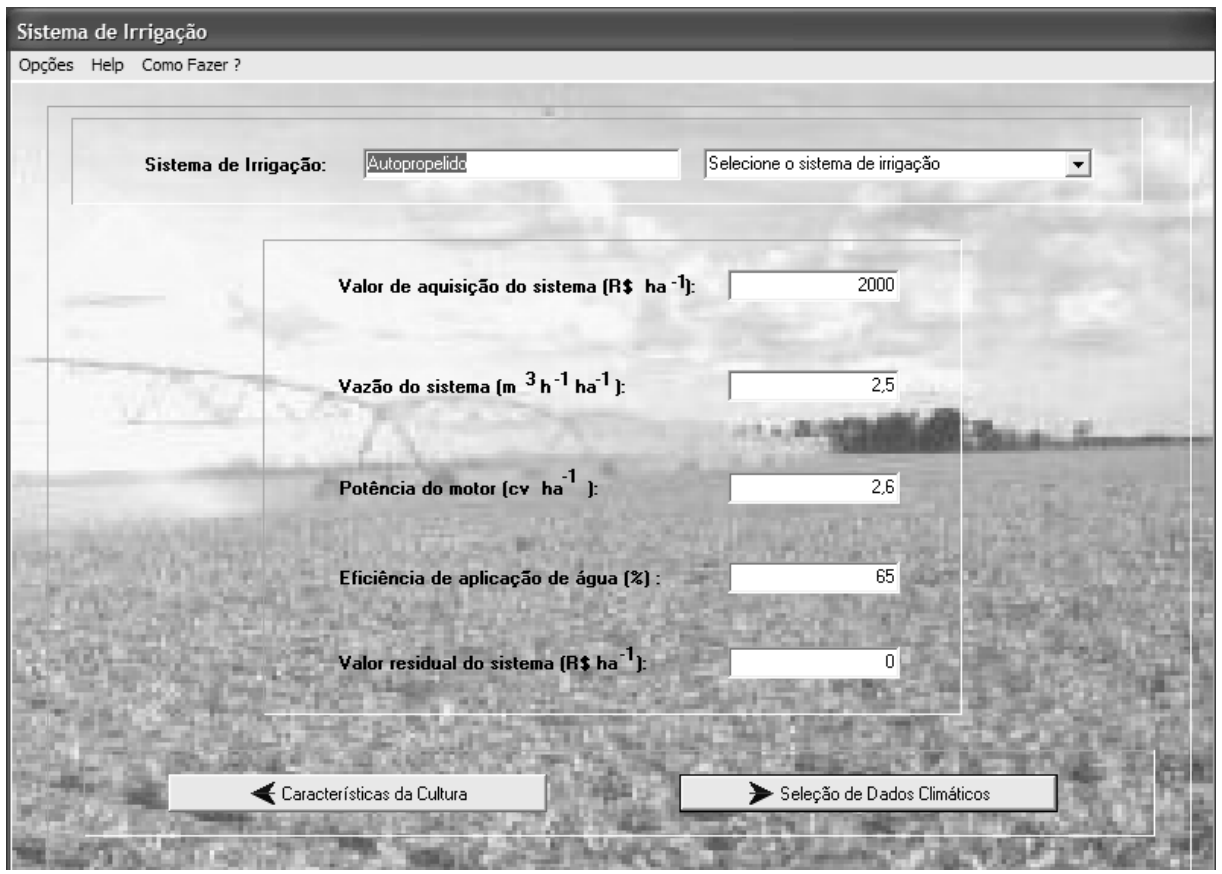

Figura 22 - Tela de características do sistema de irrigação

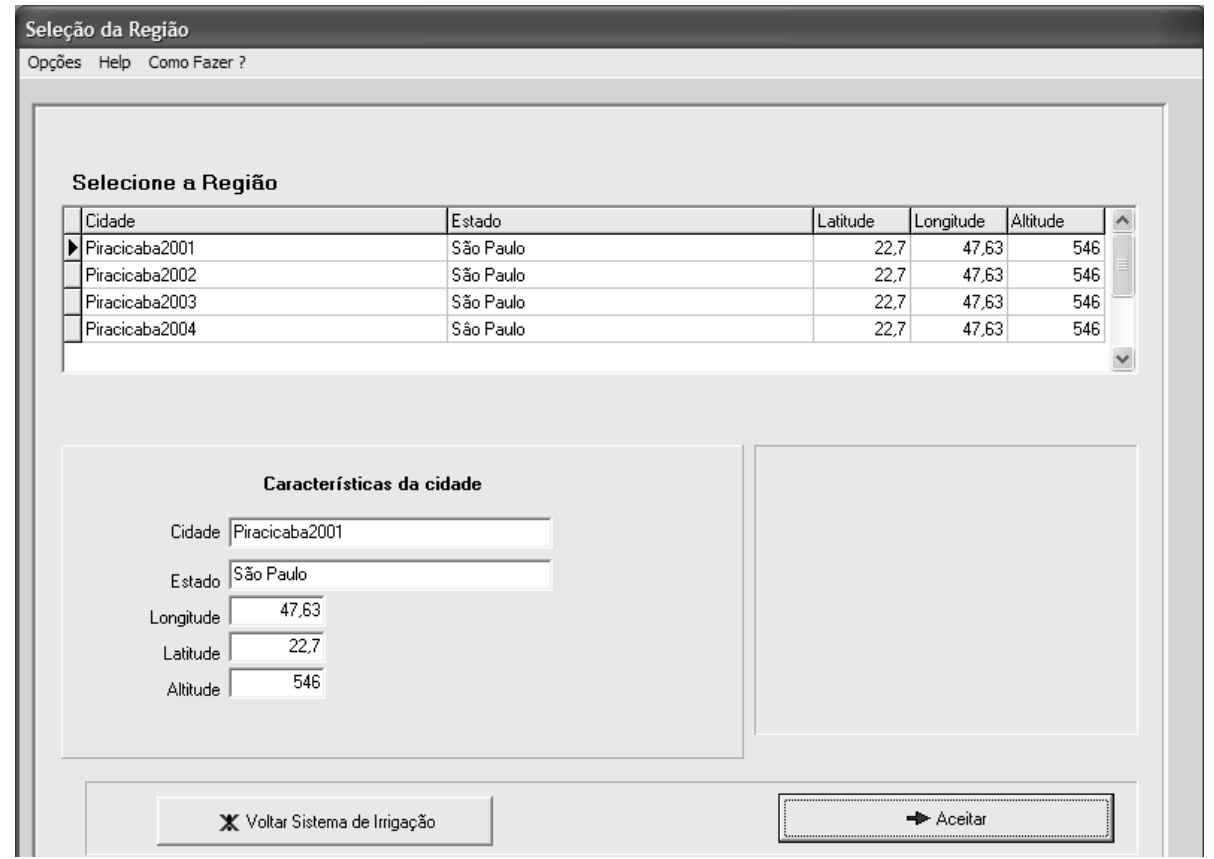

Figura 23 - Tela de seleção de dados climáticos por região 
A tela seguinte refere-se ao cálculo do balanço hídrico (Figura 24) onde são calculadas as lâminas brutas mensais de irrigação mediante o cálculo diário da irrigação necessária. Esta tela permite selecionar o método de cálculo da estimativa da evapotranspiração de referência (Figura 25) sendo os métodos: Camargo Simplificado, Hargreaves \& Samani, Priestley-Taylor e Penman-Monteith baseados em Doorenbos \& Kassam (2000) e Pereira et al. (2002). Neste momento o projeto inicia os cálculos dos benefícios e custos da irrigação. Na próxima tela (Figura 26) são inseridos os valores pertinentes aos benefícios brutos da irrigação, ou seja, o incremento de renda proveniente do uso da irrigação. Em seqüência aos benefícios brutos da irrigação tem-se a tela dos custos fixos anuais da irrigação (Figura 27) onde se realiza a simulação por Monte Carlo da taxa de juros (Figura 28) e a da vida útil do sistema de irrigação (Figura 29), com estes valores são calculados os 25 valores de custo fixo anual da irrigação e respectivas probabilidades de ocorrência.

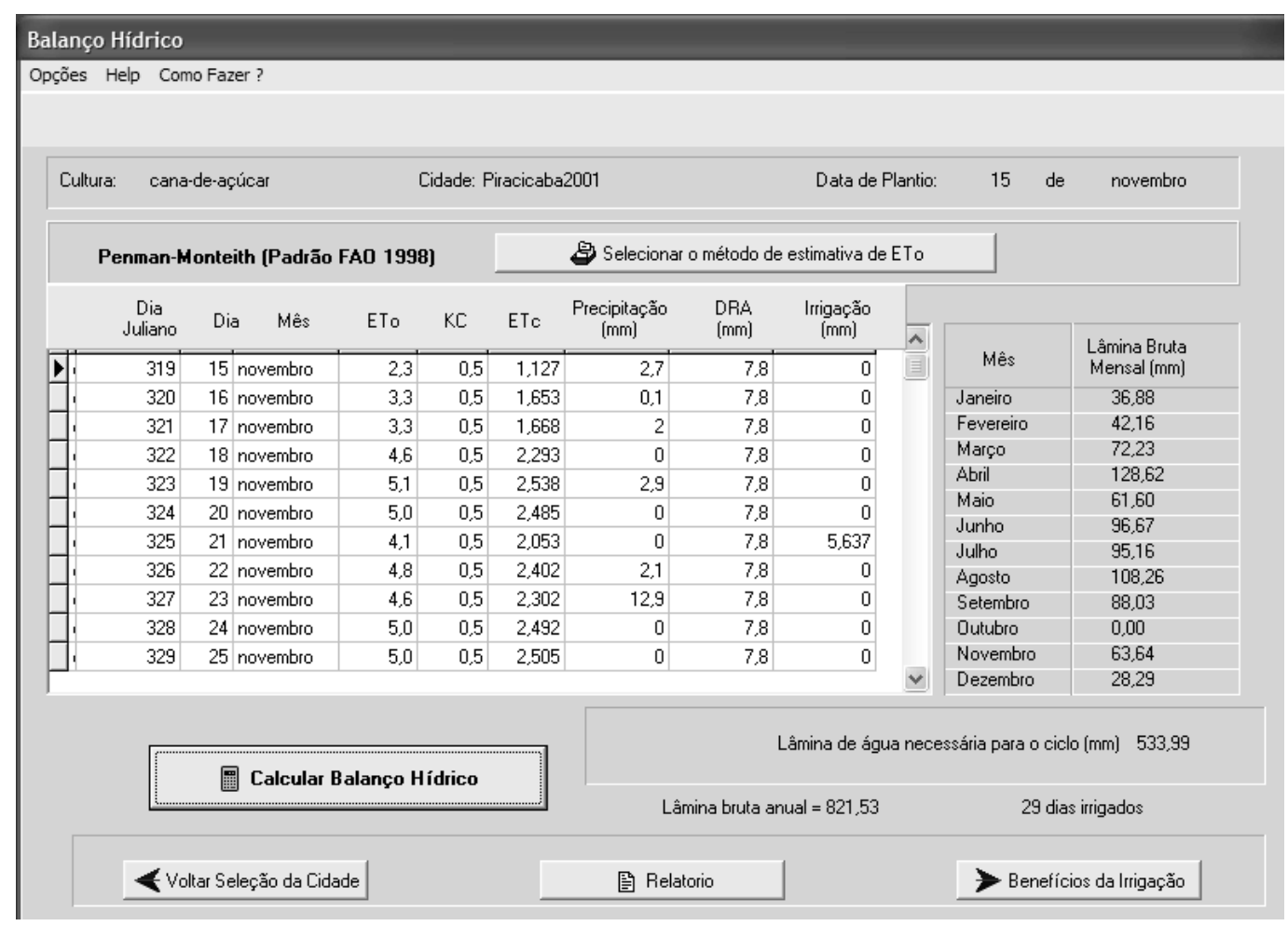

Figura 24 - Tela de cálculo do balanço hídrico diário 


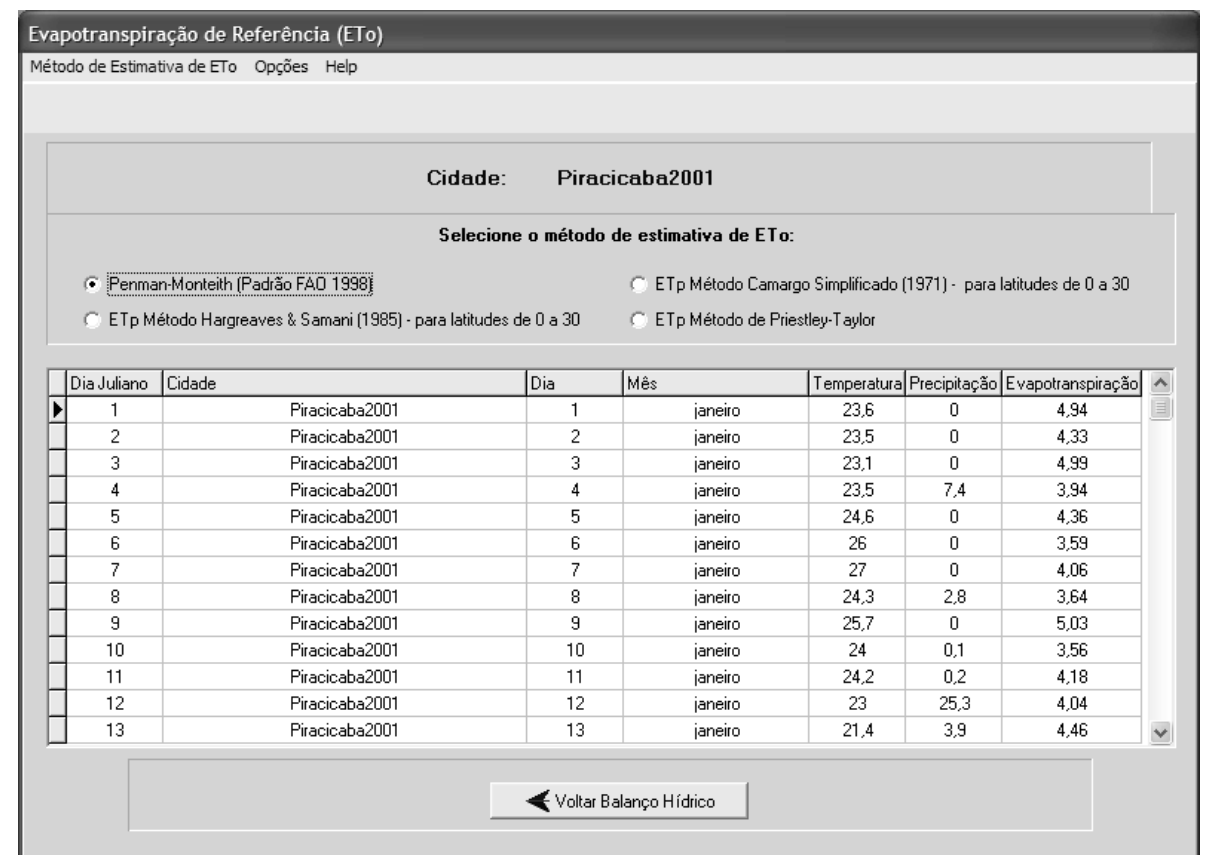

Figura 25 - Tela de cálculo da evapotranspiração de referência

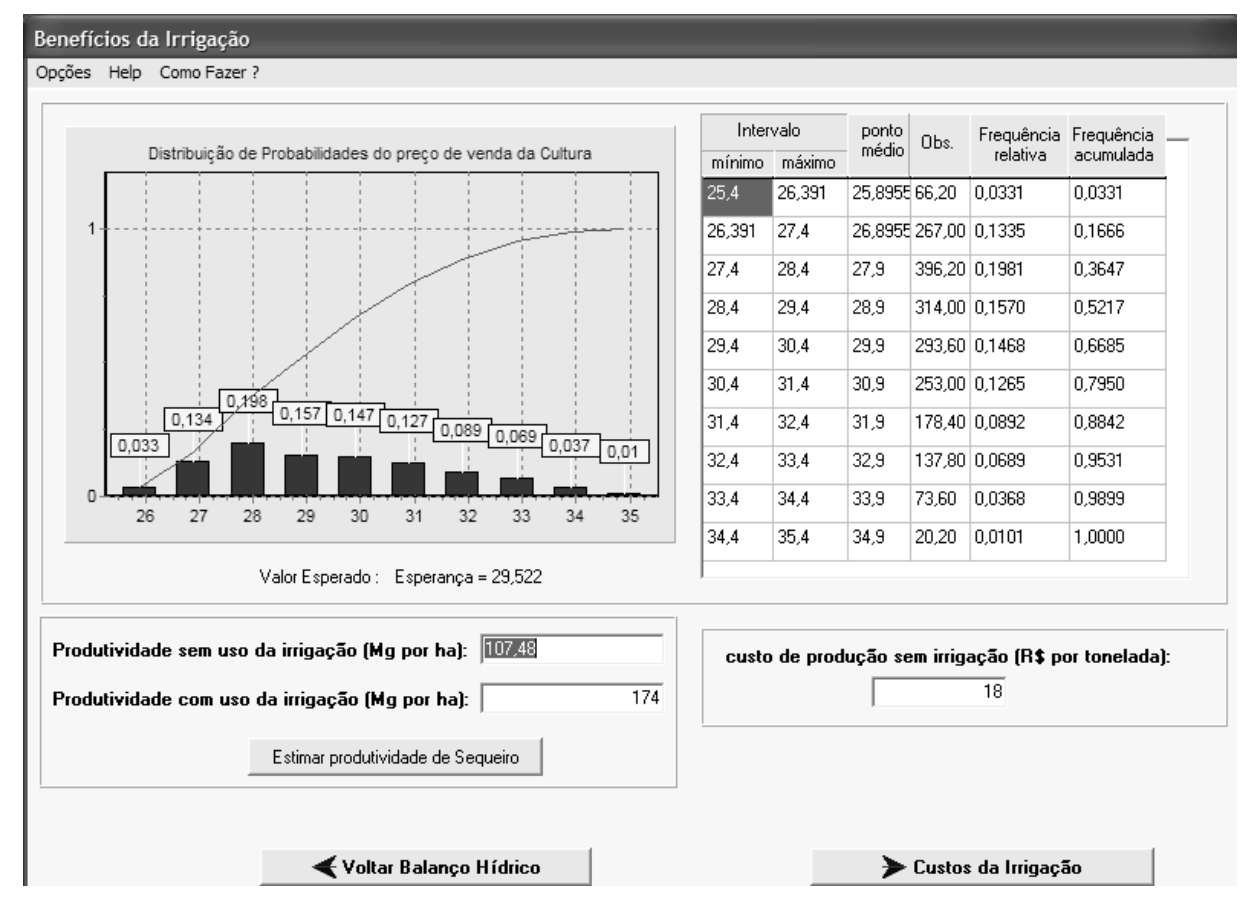

Figura 26 - Tela de benefícios brutos da irrigação 


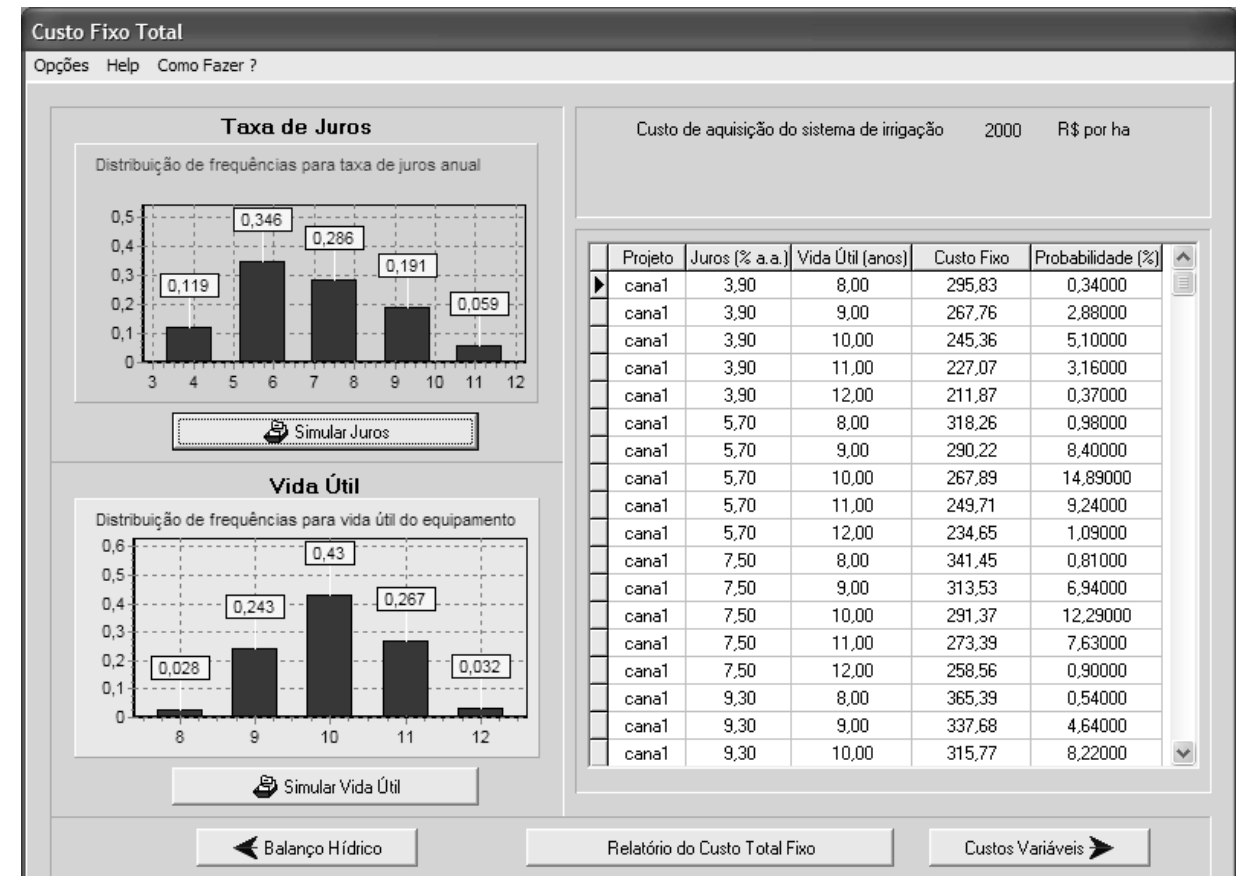

Figura 27 - Tela de custos fixos anuais da irrigação

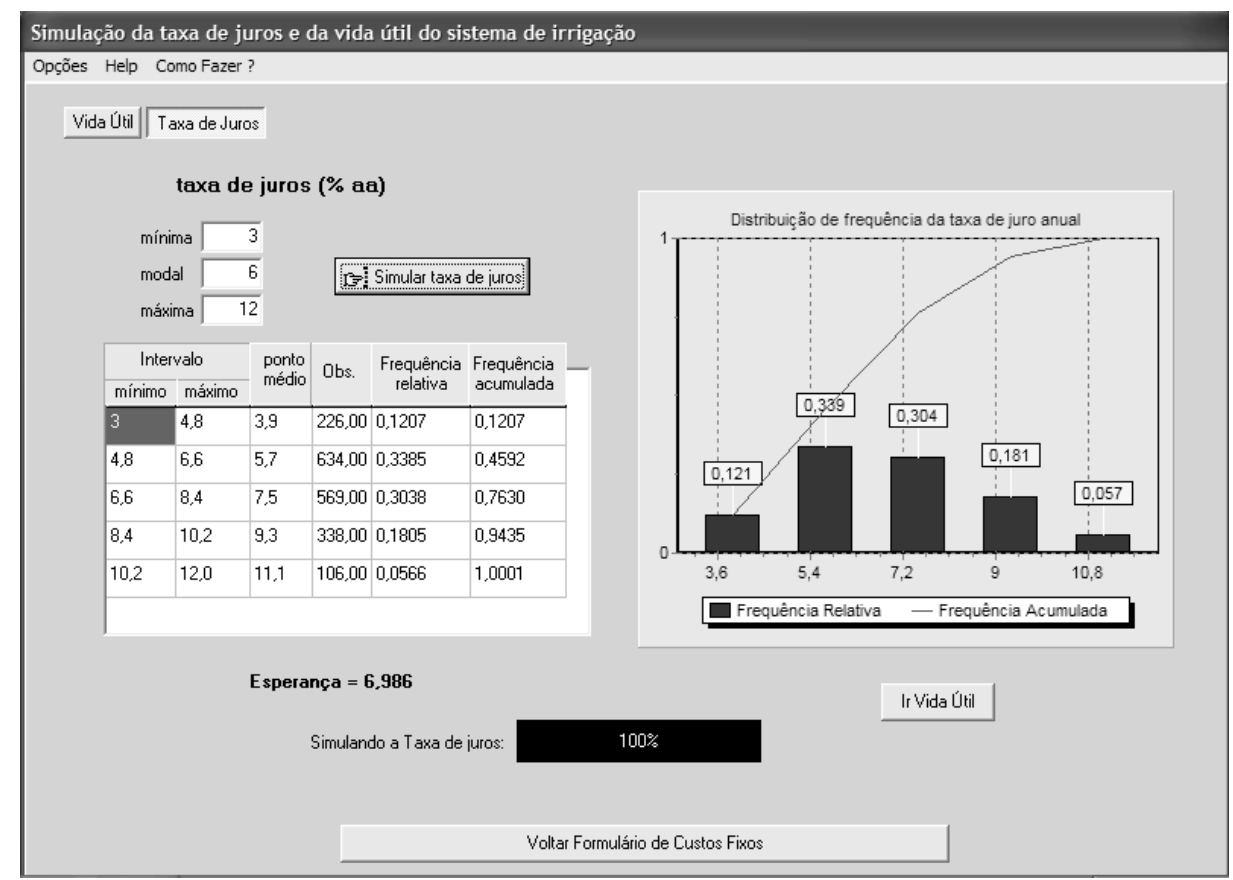

Figura 28 - Tela de simulação da taxa de juros 


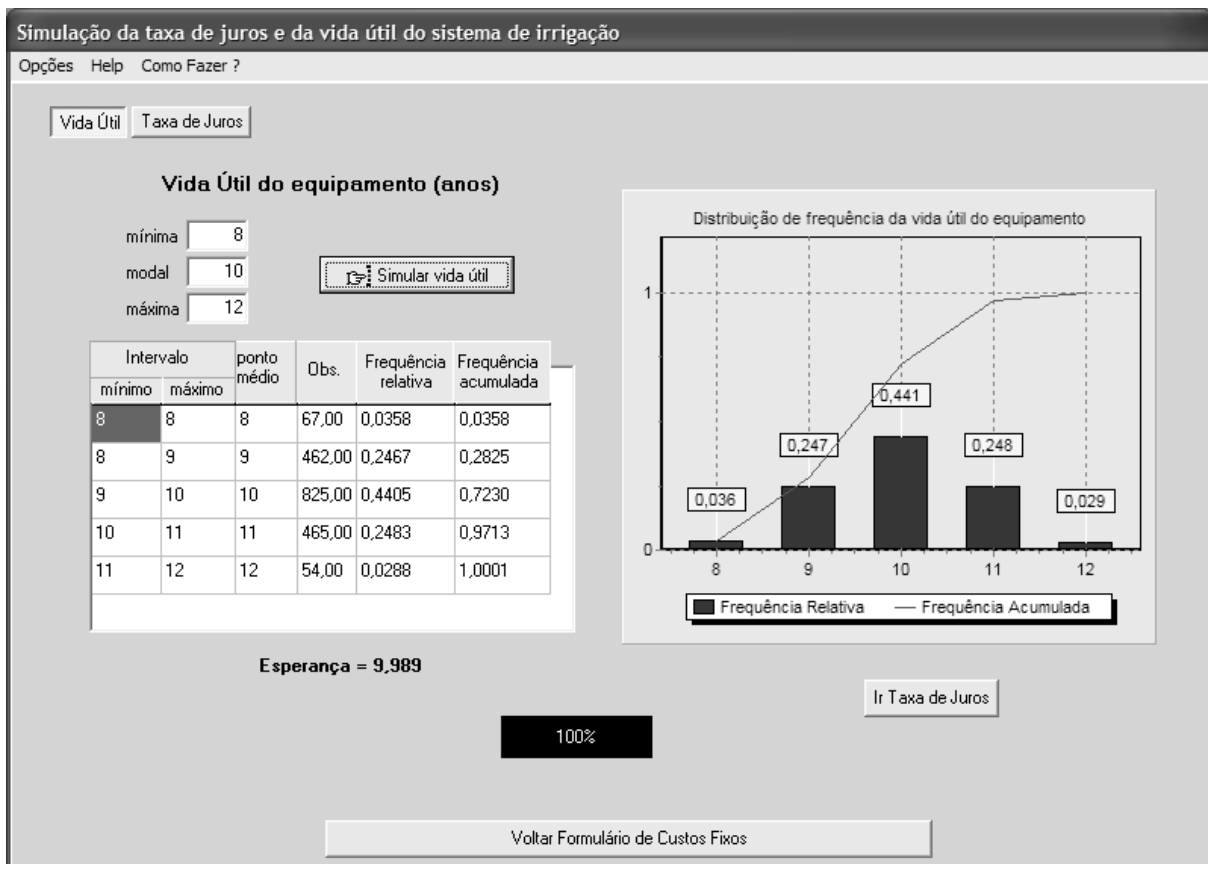

Figura 29 - Tela de simulação da vida útil do sistema de irrigação

Com os custos fixos calculados e armazenados em banco de dados prossegue-se para o cálculo dos custos variáveis anuais da irrigação (Figura 30). Nessa tela é realizada a simulação por Monte Carlo da taxa de manutenção (Figura 31), simulação do preço da água para cálculo do custo da água (Figura 32), simulação do número de horas por irrigação para o cálculo do custo da mão-de-obra (Figura 33) e cálculo do custo do bombeamento (Figura 34). 


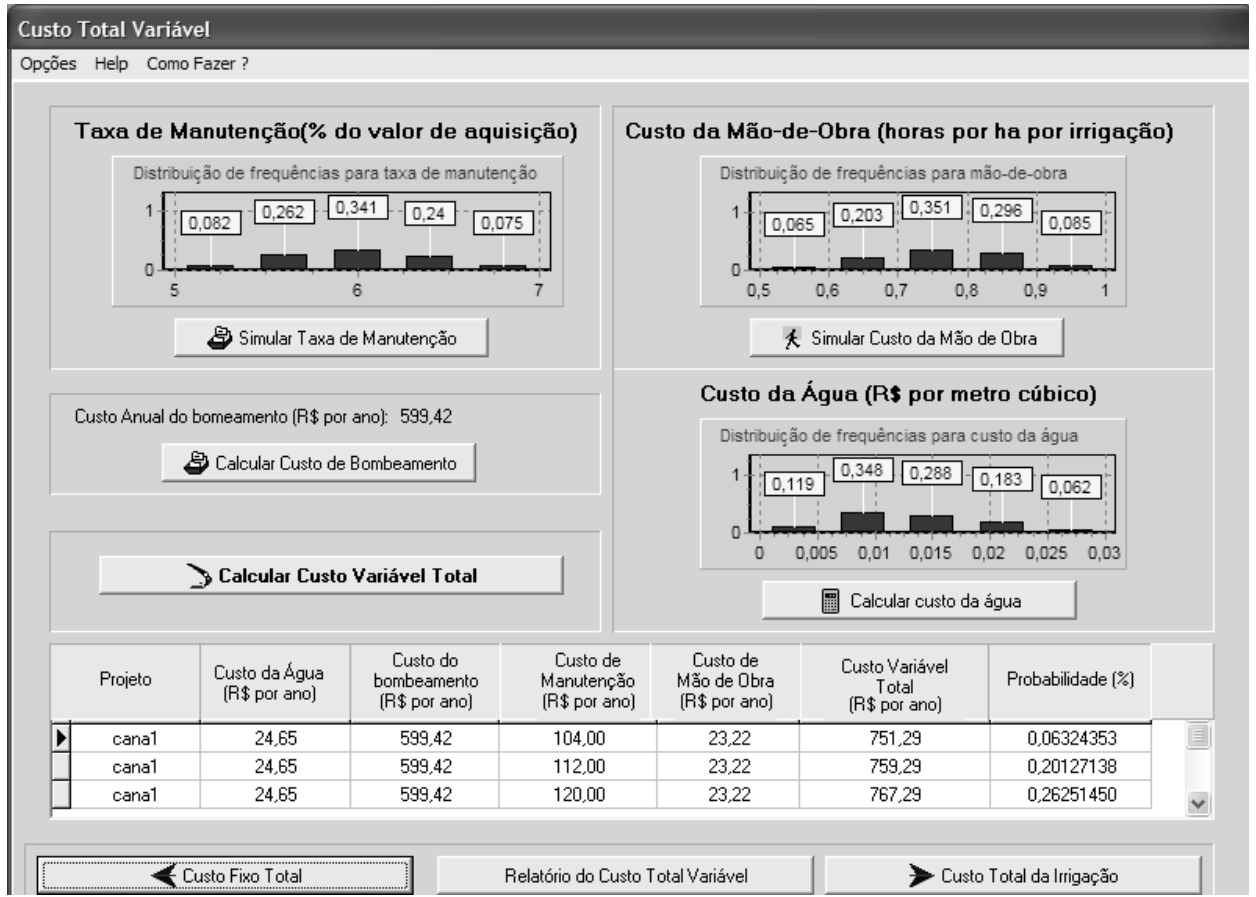

Figura 30 - Tela de custos variáveis anuais da irrigação

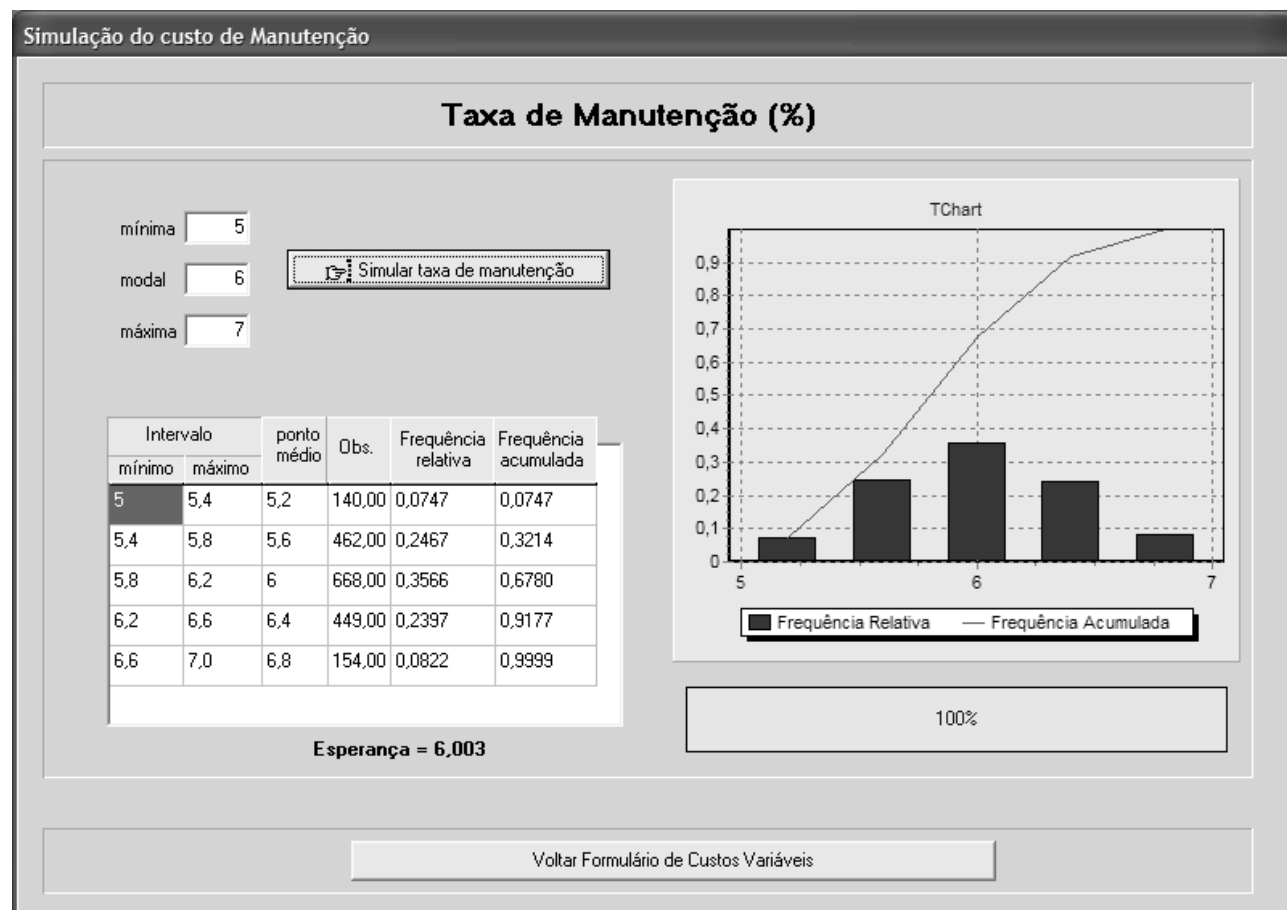

Figura 31 - Tela de simulação da taxa de manutenção 


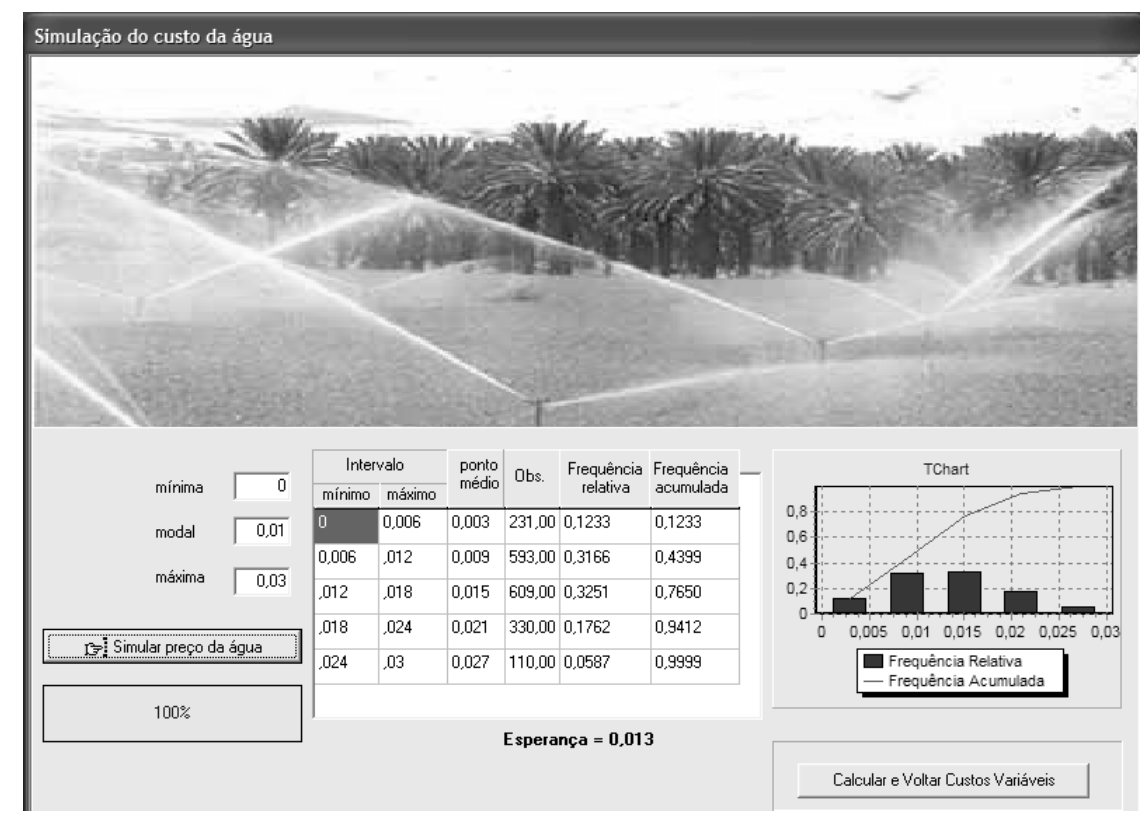

Figura 32 - Tela de simulação do preço da água para o cálculo do custo da água

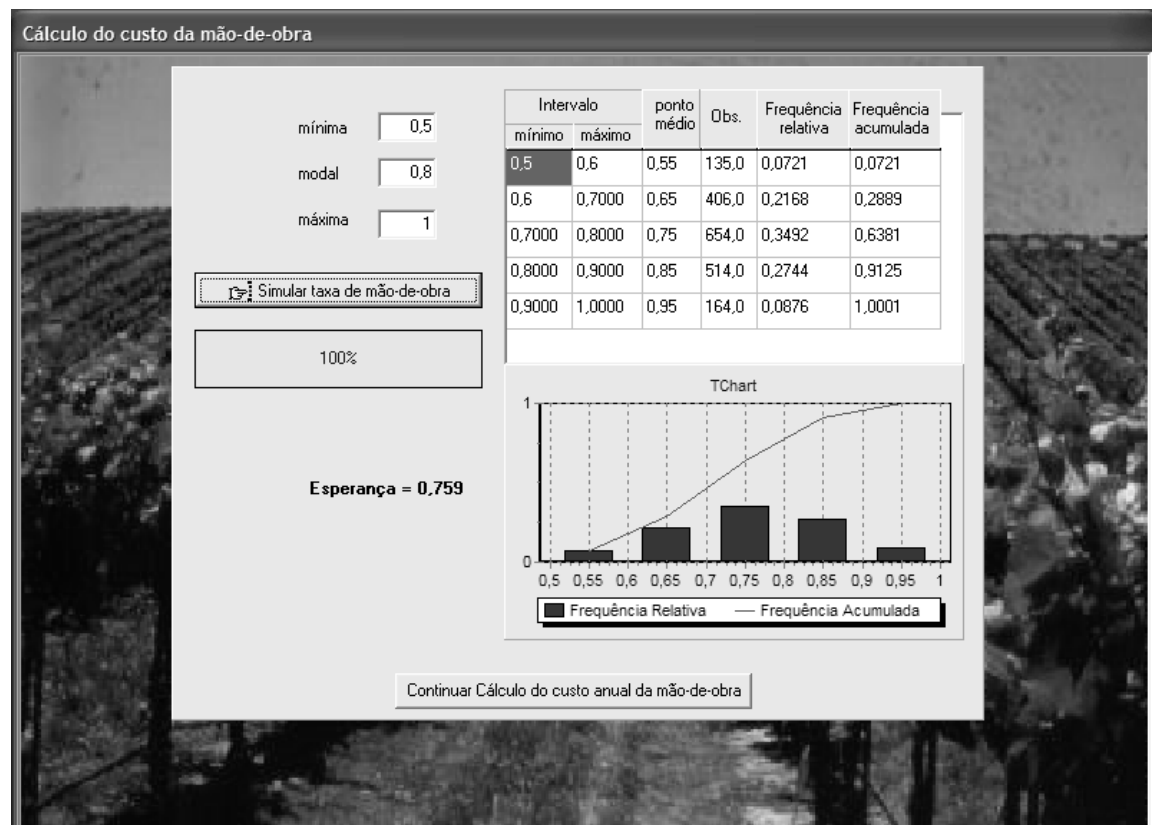

Figura 33 - Tela de simulação do número de horas por hectare e por irrigação para o cálculo do custo da mão-de-obra 


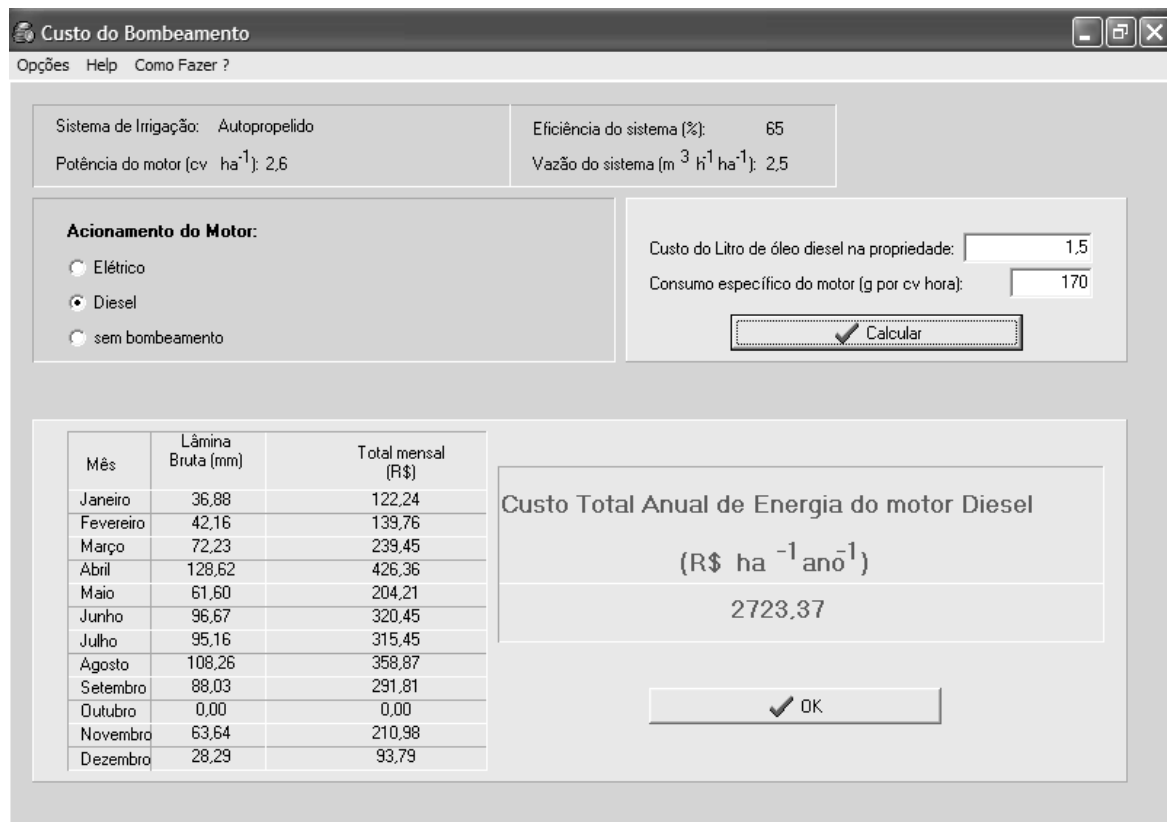

Figura 34 - Tela de cálculo do custo do bombeamento

Com os custos variáveis também calculados e armazenados em banco de dados, o modelo computacional segue para o cálculo do custo total anual da irrigação (Figura 35) pela combinação de 3125 valores. Em seguida têm-se a tela de cálculo dos benefícios líquidos e cálculo dos coeficientes econômicos; nessa tela são realizadas as combinações finais, resultando em 31.250 valores de benefícios líquidos, e realiza-se a distribuição de freqüências para posterior teste de aderência (Figura 36). Na tela seguinte realiza-se o teste de aderência e cálculo da probabilidade de viabilidade, ou seja, benefício líquido anual $>0$ (Figura 37). A última tela consta da análise de sensibilidade para os fatores econômicos (Figura 38), resultando em um gráfico e nos valores de desvio padrão para cada fator variado. 


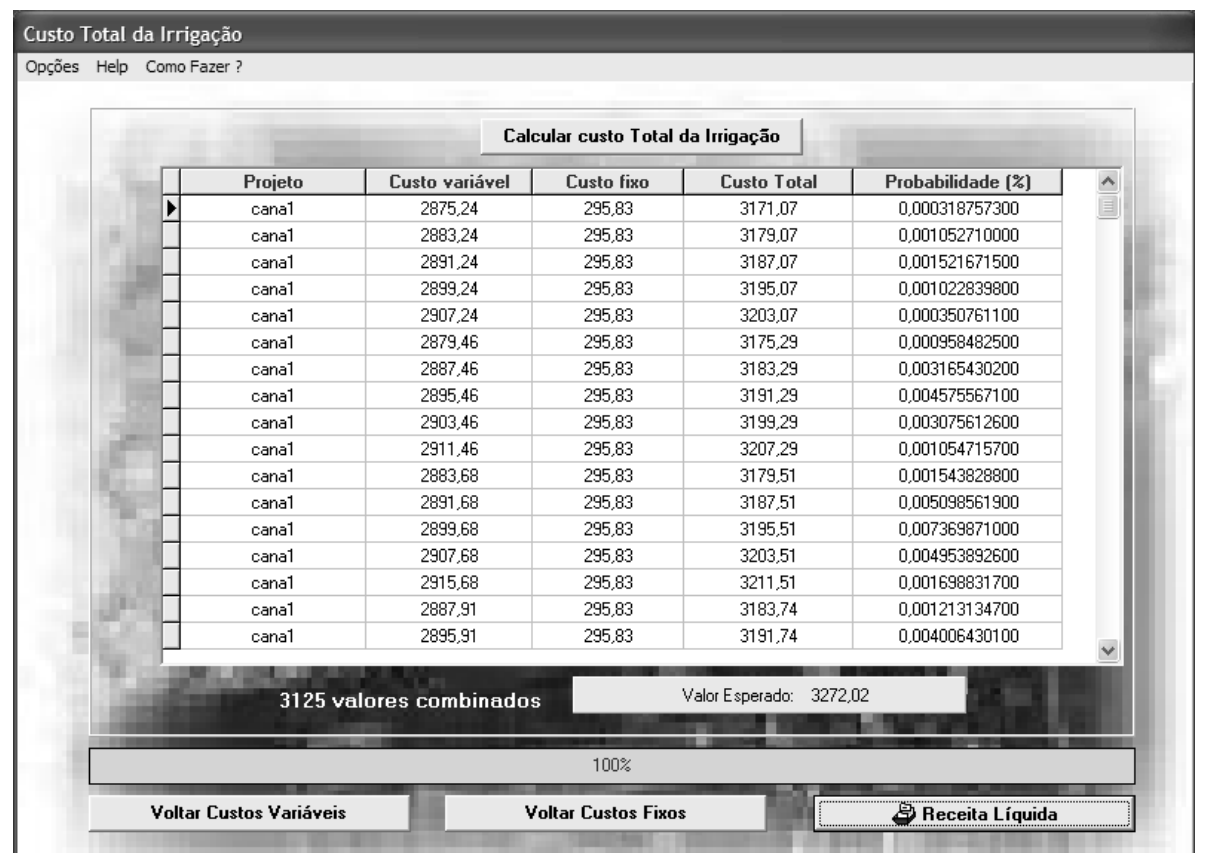

Figura 35 - Tela do custo total da irrigação

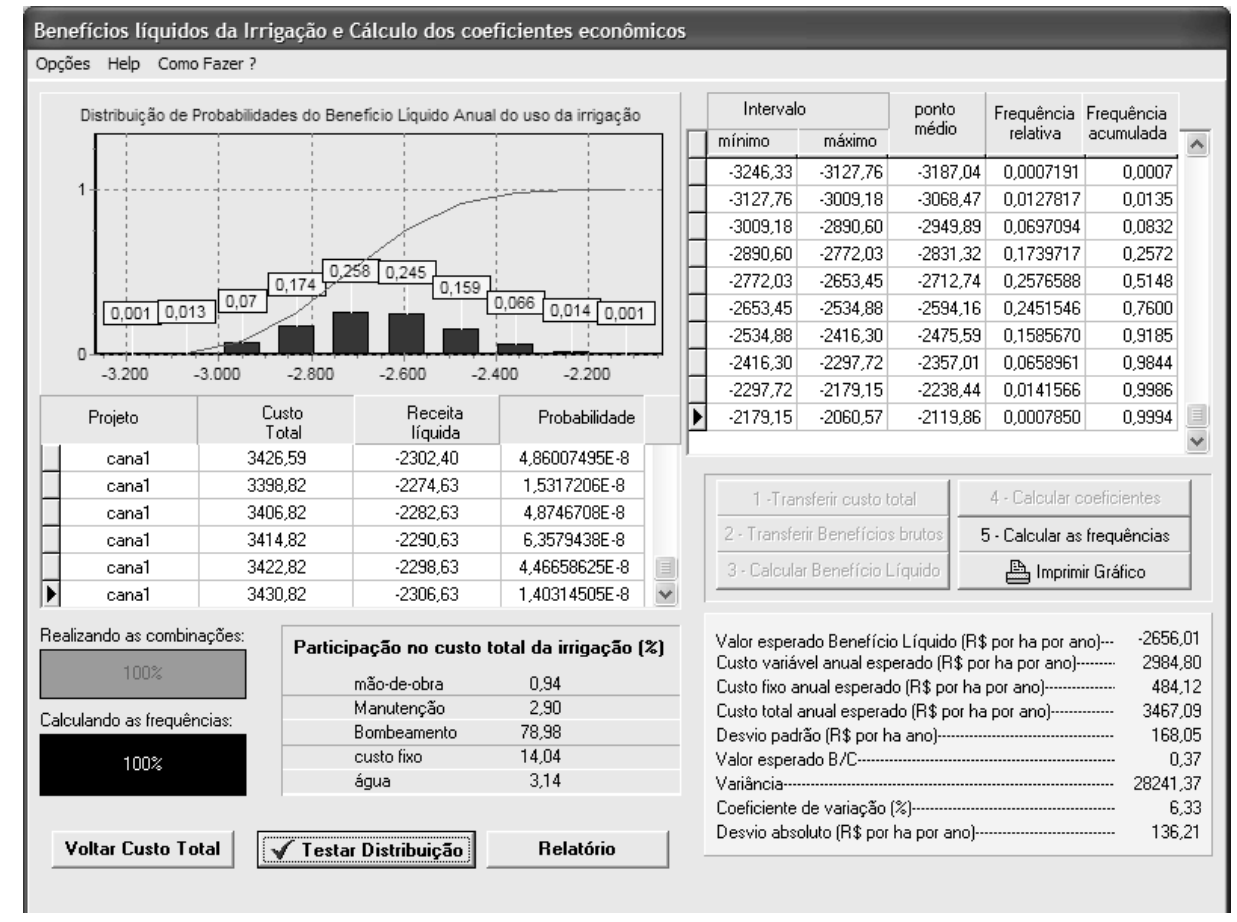

Figura 36 - Tela do cálculo dos benefícios líquidos e dos coeficientes econômicos 


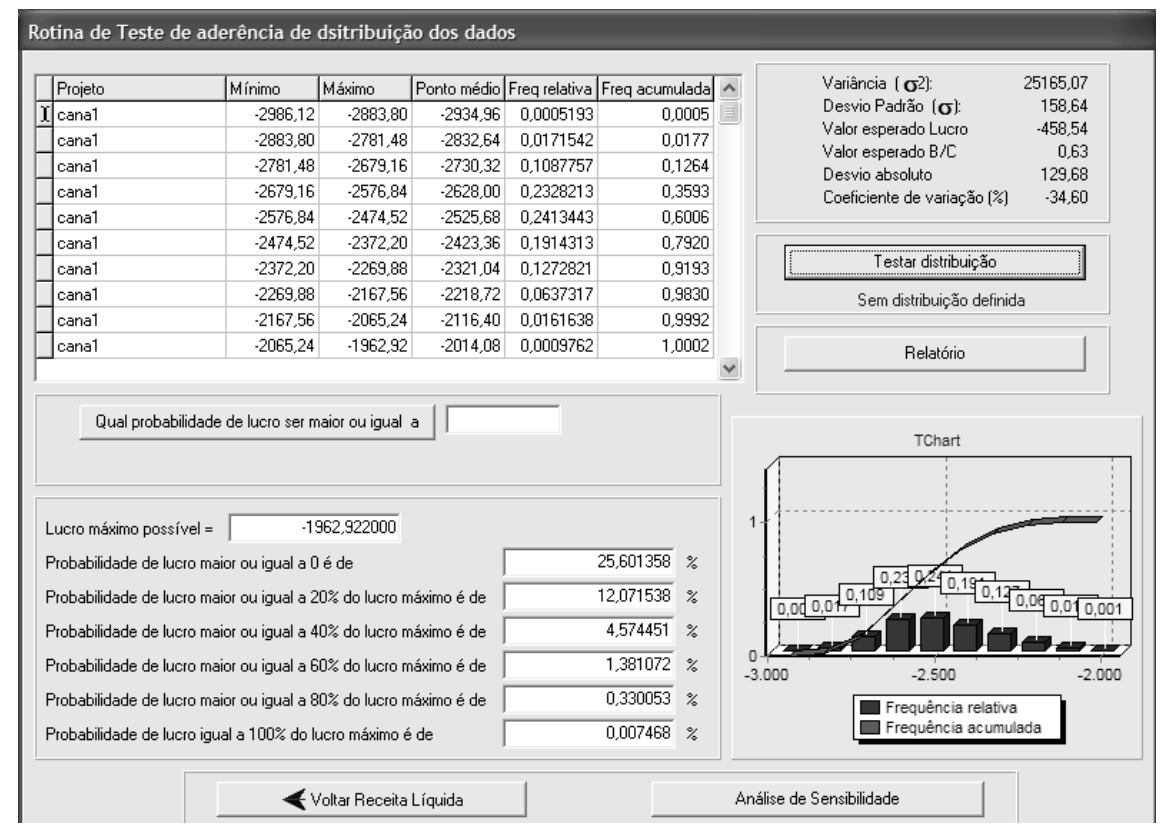

Figura 37 - Tela do teste de aderência da distribuição pelo método de KolmogorovSmirnov

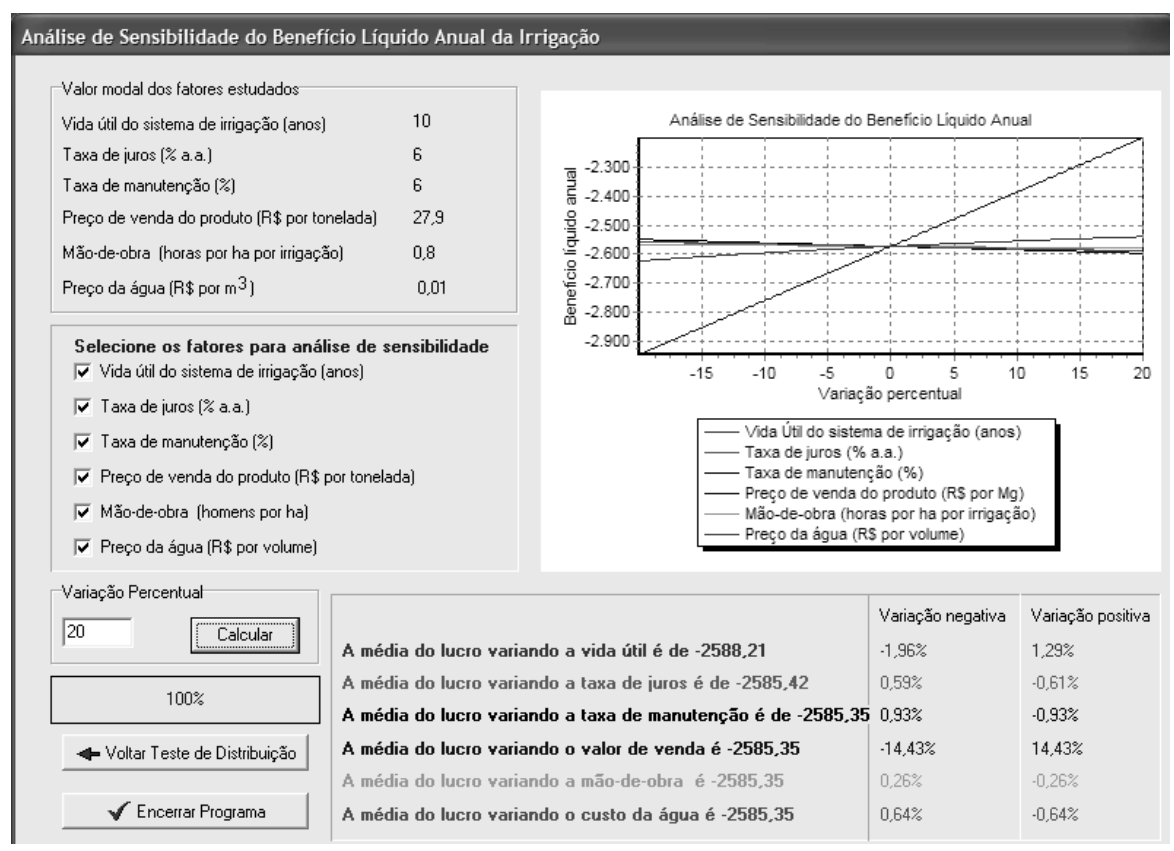

Figura 38 - Tela da análise de sensibilidade do benefício líquido anual com a variação dos fatores econômicos 


\subsection{Análise econômica e análise de sensibilidade utilizando o modelo}

Os resultados são apresentados por meio de uma análise econômica e análise de sensibilidade resultantes de 48 estudos por cultura, sendo quatro anos estudados, três sistemas de irrigação e quatro modalidades de bombeamento (motor elétrico com tarifas verde, azul e convencional e motor diesel). Nos anexos A, B e C são exibidos, respectivamente, os resultados referentes às simulações para cada sistema de irrigação; a análise econômica por sistema e por ano, e a análise de sensibilidade por sistema de irrigação e por ano estudado. As Tabelas 11 e 12 apresentam os valores esperados médios obtidos por ano estudado para as culturas de cana-de-açúcar e tomate industrial na região de Piracicaba.

Tabela 11. Valores esperados obtidos nos estudos para a cultura da cana-de-açúcar na região de Piracicaba

\begin{tabular}{ccccc}
\hline Valores & 2001 & 2002 & 2003 & 2004 \\
\hline Lâmina líquida de irrigação (mm ano $^{-1}$ ) & 533,99 & 586,29 & 407,28 & 436,27 \\
Dias irrigados no ciclo (365 dias) & 29 & 31 & 21 & 25
\end{tabular}

Produtividade esperada sem irrigação

\begin{tabular}{|c|c|c|}
\hline$\left(\mathrm{Mg} \mathrm{ha}^{-1} \mathrm{ano}^{-1}\right)$ & 112,65 & 107,48 \\
\hline
\end{tabular}

Benefício bruto anual esperado de

$$
\text { sequeiro }\left(\mathrm{R} \$ \text { ha }^{-1} \mathrm{ano}^{-1}\right) \quad 3.383,32 \quad 3.130,14 \quad 3.293,23 \quad 3.250,16
$$

Benefício bruto anual esperado com

$$
\text { irrigação ( }\left(\mathrm{R}_{\text {S ha }}{ }^{-1} \text { ano }^{-1}\right) \quad 5.225,90 \quad 5.065,76 \quad 5.169,47 \quad 5.142,96
$$

Benefício bruto anual esperado da

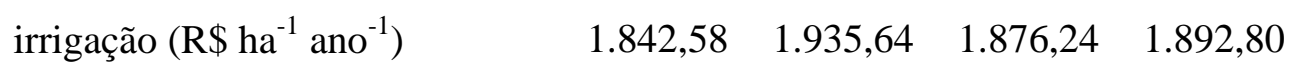

Custo de produção de sequeiro

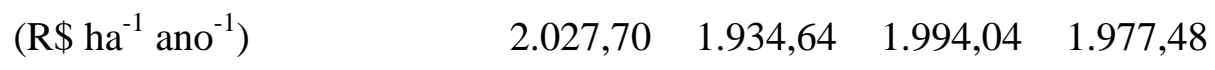

Custo de produção com irrigação

desconsiderando os custos da irrigação

\begin{tabular}{lllll}
$\left(\mathrm{R} \$\right.$ ha $\left.^{-1} \mathrm{ano}^{-1}\right)$ & $3.132,00$ & $3.132,00$ & $3.132,00$ & $3.132,00$ \\
\hline
\end{tabular}


Tabela 12. Valores esperados obtidos nos estudos para a cultura do tomate industrial na região de Piracicaba

\begin{tabular}{|c|c|c|c|c|}
\hline Valores & 2001 & 2002 & 2003 & 2004 \\
\hline $\begin{array}{l}\text { Lâmina líquida de irrigação } \\
\qquad\left(\mathrm{mm} \mathrm{ano}^{-1}\right)\end{array}$ & 156,76 & 149,01 & 126,41 & 152,30 \\
\hline Dias irrigados no ciclo (125 dias) & 7 & 7 & 5 & 6 \\
\hline $\begin{array}{l}\text { Produtividade esperada sem } \\
\text { irrigação }\left(\mathrm{Mg} \mathrm{ha}^{-1} \mathrm{ano}^{-1}\right)\end{array}$ & 44,16 & 45,99 & 42,34 & 47,99 \\
\hline $\begin{array}{l}\text { Benefício bruto anual esperado de } \\
\text { sequeiro }\left(\mathrm{R} \$ \mathrm{ha}^{-1} \mathrm{ano}^{-1}\right)\end{array}$ & $7.141,57$ & $7.577,88$ & $6.731,18$ & $8.866,65$ \\
\hline $\begin{array}{l}\text { Benefício bruto anual esperado com } \\
\text { irrigação }\left(\mathrm{R} \$ \mathrm{ha}^{-1} \mathrm{ano}^{-1}\right)\end{array}$ & $12.937,63$ & $13.181,79$ & $12.718,34$ & $13.480,56$ \\
\hline $\begin{array}{l}\text { Benefício bruto anual esperado da } \\
\text { irrigação }\left(\mathrm{R} \$ \mathrm{ha}^{-1} \mathrm{ano}^{-1}\right)\end{array}$ & $5.796,06$ & $5.603,91$ & $5.987,16$ & $5.393,91$ \\
\hline $\begin{array}{l}\text { Custo de produção de sequeiro } \\
\qquad\left(\mathrm{R} \$ \mathrm{ha}^{-1} \mathrm{ano}^{-1}\right)\end{array}$ & $4.636,80$ & $4.828,95$ & $4.445,70$ & $5.038,95$ \\
\hline $\begin{array}{l}\text { Custo de produção com irrigação } \\
\text { desconsiderando os custos da } \\
\text { irrigação }\left(\mathrm{R} \$ \text { ha }^{-1} \mathrm{ano}^{-1}\right)\end{array}$ & $8.400,00$ & $8.400,00$ & $8.400,00$ & $8.400,00$ \\
\hline
\end{tabular}




\subsubsection{Análise econômica e análise de sensibilidade para a cultura de cana-de-açúcar na região de Piracicaba}

Para a cultura da cana-de-açúcar irrigada na região de Piracicaba observou-se na Tabela 13 que em todas as análises realizadas o uso da irrigação apresentou valores da relação B/C sempre inferiores a 1, ou seja, não ocorreu viabilidade econômica, pois um projeto deve apresentar B/C maior que a unidade para que seja viável (Clark et al., 1993; Frizzone \& Silveira, 2000). As maiores relações B/C foram encontradas para a média do sistema pivô central (Tabela 13) utilizando motor elétrico nas tarifas verde e azul (0,82), com o maior valor de 0,85 obtido com o sistema pivô central, bombeamento utilizando motor elétrico e tarifas verde e azul (Tabela 31 Anexo B). As menores relações de B/C foram para a média do sistema autopropelido (Tabela 13) utilizando motor diesel $(0,24)$, sendo o menor valor encontrado no estudo de 0,22 para o sistema autopropelido com bombeamento utilizando diesel (Tabela 36 Anexo B).

Tabela 13. Valores médios da relação B/C para os sistemas de irrigação em função do tipo de motor e de tarifa, para a cultura da cana-de-açúcar na região de Piracicaba

\begin{tabular}{lccc}
\hline Valores $\left(\mathrm{R} \mathrm{ha}^{-1} \mathrm{ano}^{-1}\right)$ & Pivô Central & $\begin{array}{c}\text { Deslocamento } \\
\text { Linear }\end{array}$ & Autopropelido \\
\hline Motor diesel & 0,45 & 0,44 & 0,24 \\
Motor elétrico (média) & 0,79 & 0,70 & 0,63 \\
Tarifa Verde & 0,82 & 0,73 & 0,67 \\
Tarifa Azul & 0,82 & 0,73 & 0,68 \\
Tarifa Convencional & 0,72 & 0,65 & 0,53 \\
\hline
\end{tabular}


Quando observados os coeficientes médios de risco (variância, desvio padrão e desvio absoluto), na Tabela 14, o sistema que apresentou o maior risco foi o deslocamento linear, seguido pelo pivô central e o autopropelido. Os maiores valores de risco (variância de $\mathrm{R} \$^{2}$ 25.487,2 ha $^{-1}$ ano $^{-1}$, desvio padrão de $\mathrm{R} \$ 159,65 \mathrm{ha}^{-1} \mathrm{ano}^{-1} \mathrm{e}$ desvio absoluto de R\$ 130,41 ha ${ }^{-1}$ ano $^{-1}$ ) foram obtidos para o sistema deslocamento linear com os dados climáticos do ano 2002 (Tabelas 32 e 35 Anexo B). Já os menores valores de risco (variância de $\mathrm{R} \${ }^{2} 21.431,8 \mathrm{ha}^{-1} \mathrm{ano}^{-1}$, desvio padrão de $\mathrm{R} \$ 146,40 \mathrm{ha}^{-1}$ $\mathrm{ano}^{-1}$ e desvio absoluto de R\$120,19 $\mathrm{ha}^{-1} \mathrm{ano}^{-1}$ ) foram encontrados para o sistema autopropelido com os dados climáticos do ano 2003 (Tabelas 33 e 36 Anexo B).

Tabela 14. Coeficientes médios de risco para os sistemas de irrigação considerando a cultura da cana-de-açúcar na região de Piracicaba

\begin{tabular}{|c|c|c|c|}
\hline Valores & Pivô Central & $\begin{array}{c}\text { Deslocamento } \\
\text { Linear }\end{array}$ & Autopropelido \\
\hline Variância $\left(\mathrm{R}^{2}\right.$ ha $^{-1}$ ano $\left.^{-1}\right)$ & $22.802,96$ & $23.308,19$ & $22.596,53$ \\
\hline Desvio padrão ( $\left.\mathrm{R} \$ \mathrm{ha}^{-1} \mathrm{ano}^{-1}\right)$ & 150,95 & 152,62 & 150,66 \\
\hline Desvio absoluto ( $\mathrm{R} \$ \mathrm{ha}^{-1} \mathrm{ano}^{-1}$ ) & 123,54 & 124,81 & 124,71 \\
\hline
\end{tabular}

Com relação à probabilidade de ocorrência de benefício líquido anual $>0$ (Tabela 15), para o uso do motor diesel todas as análises indicaram valores nulos, o que elimina a indicação do seu uso para as condições estudadas. Por este motivo, as análises de custo foram separadas em motor elétrico e motor diesel. No estudo do motor elétrico, as maiores médias de probabilidades de obtenção de benefício líquido anual maior que zero foram observadas para o pivô central utilizando motor elétrico, com ênfase para as tarifas azul $(14,70 \%)$ e verde $(14,51 \%)$ e os menores valores foram encontrados para o autopropelido, no qual descarta-se o uso da tarifa convencional (0\%). Dentre os valores obtidos nas análises realizadas, o maior valor de probabilidade de benefício líquido anual > 0 foi de 19,06\% obtido com os dados climáticos do ano 2004 para o sistema pivô central utilizando a tarifa azul (Tabela 31 Anexo B). 
Tabela 15. Valores médios de probabilidade de benefício líquido anual > 0 (\%) para os sistemas de irrigação em função do tipo de motor e de tarifa, para a cultura da cana-de-açúcar na região de Piracicaba

\begin{tabular}{lccc}
\hline \multicolumn{1}{c}{ Tipo de motor } & Pivô Central & $\begin{array}{c}\text { Deslocamento } \\
\text { Linear }\end{array}$ & Autopropelido \\
\hline Motor diesel & 0,00 & 0,00 & 0,00 \\
Motor elétrico (média) & 10,77 & 2,67 & 0,98 \\
Tarifa Verde & 14,51 & 3,70 & 1,45 \\
Tarifa Azul & 14,70 & 3,79 & 1,48 \\
Tarifa Convencional & 3,09 & 0,53 & 0,00 \\
\hline
\end{tabular}

Observando o benefício líquido anual esperado utilizando motor elétrico (Tabela 16), todas as análises indicaram a ocorrência de prejuízo, ou seja, o valor que na média deveríamos esperar que viesse a ocorrer foi sempre inferior a zero. Os menores valores médios estão associados ao sistema autopropelido e os maiores valores ao sistema pivô central como encontrado em Melo (1993). O maior valor de benefício líquido anual obtido na análise foi de $\mathrm{R} \$-130,69 \mathrm{ha}^{-1} \mathrm{ano}^{-1}$ para o pivô central utilizando a tarifa azul (Tabela 31 Anexo B). Em relação aos custos totais da irrigação (Tabela 16), os maiores valores foram encontrados para o sistema autopropelido, seguido do deslocamento linear, e o menor valor é apresentado para o pivô central. 
Tabela 16. Valores médios de benefícios líquidos anuais e custos médios anuais advindos do uso da irrigação, para os sistemas de irrigação utilizando motor elétrico na cultura da cana-de-açúcar para a região de Piracicaba

\begin{tabular}{lccc}
\hline \multicolumn{1}{c}{ Valores $\left(\mathrm{R} \$ \mathrm{ha}^{-1} \mathrm{ano}^{-1}\right)$} & Pivô Central & $\begin{array}{c}\text { Deslocamento } \\
\text { Linear }\end{array}$ & Autopropelido \\
\hline Custo Fixo Anual esperado & 331,39 & 386,67 & 286,86 \\
Custo Variável Anual esperado & 612,07 & 669,38 & 921,53 \\
Custo Total Anual esperado & 943,46 & $1.056,05$ & $1.208,39$ \\
Benefício Líquido Anual esperado & $-205,20$ & $-317,75$ & $-470,12$ \\
\hline
\end{tabular}

Analisando, para o motor elétrico, os custos da irrigação (Tabela 16) e sua participação percentual no custo total da irrigação (Tabela 17), observa-se que os maiores custos fixos estão associados ao sistema deslocamento linear, devido ao seu alto custo de implantação que inclui a construção de canais, e os menores custos fixos referem-se ao sistema autopropelido, devido ao seu baixo custo de aquisição quando comparado aos sistemas estudados. Porém, quando observados os custos variáveis, o autopropelido apresenta os maiores custos, como encontrado em Bonomo et al. (1999), devido ao seu alto consumo de energia, representando 54,73\% do custo total da irrigação. Para os sistemas pivô central e deslocamento linear os gastos com o bombeamento representam, respectivamente, 38,36\% e 33,61\% dos custos totais da irrigação. Para todos os sistemas estudados os custos variáveis representaram a maior participação no custo total da irrigação, e dentre os custos variáveis, como citado em Gohring \& Wallender (1987), Frizzone et al. (1994), Bonomo et al. (1999) e Andrade Júnior et al. (2001) o consumo de energia destacou-se como o fator de maior influência. O custo da mão-de-obra apresentou pouca influência com valores sempre inferiores a 3\% do custo total da irrigação, como obtido nos estudos de Rezende et al. (1992). 
Tabela 17. Participação percentual dos custos advindos da irrigação no custo total da irrigação da cana-de-açúcar utilizando motor elétrico para Piracicaba

Participação no custo total da irrigação (\%)

Pivô Central Deslocamento Linear Autopropelido

\begin{tabular}{cccc}
\hline Custos Fixos esperados & 35,33 & 36,77 & 24,20 \\
Custos Variáveis esperados & 64,67 & 63,23 & 75,80 \\
Mão-de-obra & 1,62 & 2,44 & 2,48 \\
Manutenção & 15,98 & 19,98 & 10,15 \\
Bombeamento & 38,36 & 33,61 & 54,73 \\
Água & 8,71 & 7,20 & 8,44 \\
\hline
\end{tabular}

Para o motor diesel, os componentes dos custos da irrigação e sua participação percentual no custo total são apresentados nas Tabelas 18 e 19. Observou-se o mesmo comportamento dos custos fixos e custos variáveis. Porém, quando observados os custos variáveis os valores são superiores aos obtidos para o motor elétrico, como observado em Frizzone et al. (1994). Isto ocorreu devido ao alto custo do óleo diesel e da não possibilidade de desconto noturno, como oferecido no bombeamento utilizando motor elétrico. Os custos com bombeamento foram sempre superiores a 50\% do custo total da irrigação (Tabela 19) demonstrando que o custo de bombeamento destacou-se sempre como o fator de maior influência. Já o fator de menor influência também foi o custo da mão-de-obra com valores sempre inferiores a $2 \%$ do custo total da irrigação. Em relação aos custos totais, seguiu-se a mesma tendência do bombeamento utilizando motor elétrico, sendo os maiores valores encontrados para o sistema autopropelido seguido do deslocamento linear e o pivô central. 
Tabela 18. Benefícios líquidos anuais e custos médios anuais advindos do uso da irrigação para os sistemas de irrigação utilizando motor diesel para cana-deaçúcar na região de Piracicaba

\begin{tabular}{lccc}
\hline \multicolumn{1}{c}{ Valores $\left(\mathrm{R} \$ \mathrm{ha}^{-1} \mathrm{ano}^{-1}\right)$} & Pivô Central & $\begin{array}{c}\text { Deslocamento } \\
\text { Linear }\end{array}$ & Autopropelido \\
\hline Custo Fixo Anual esperado & 331,39 & 386,67 & 286,86 \\
Custo Variável Anual esperado & $1.272,71$ & $1.265,72$ & $2.754,04$ \\
Custo Total Anual esperado & $1.604,01$ & $1.652,39$ & $3.040,90$ \\
Benefício líquido Anual esperado & $-867,29$ & $-914,02$ & $-2.302,54$ \\
\hline
\end{tabular}

Tabela 19. Participação percentual dos custos advindos da irrigação no custo total da irrigação utilizando motor diesel para cana-de-açúcar na região de Piracicaba

\begin{tabular}{cccc}
\hline & \multicolumn{3}{c}{ Participação no custo total da irrigação (\%) } \\
& Pivô Central & Deslocamento Linear & Autopropelido \\
\hline Custos Fixos esperados & 20,39 & 23,09 & 9,30 \\
Custos Variáveis esperados & 79,61 & 76,91 & 90,70 \\
Mão-de-obra & 0,95 & 1,54 & 0,96 \\
Manutenção & 9,21 & 12,54 & 3,90 \\
Bombeamento & 64,29 & 58,19 & 82,52 \\
Água & 5,16 & 4,64 & 3,32 \\
\hline
\end{tabular}

Observando a análise econômica da irrigação da cana-de-açúcar na região de Piracicaba, os maiores custos totais foram observados para o bombeamento utilizando motor diesel, com os maiores valores encontrados para o sistema autopropelido como observado por Melo (1993). De maneira geral o custo da mão-de-obra foi o que menos influenciou o custo total da irrigação (1,67\%), seguido pelo custo da água (6,25\%) e pelo custo de manutenção (11,96\%). O custo do bombeamento representou a maior participação nos custos totais da irrigação $(55,20 \%)$ estando de acordo com os resultados obtidos em Bonomo et al. (1999); Andrade Junior et al. (2001) e Soares et al. (2003). 
Na Tabela 20, são apresentados os custos anuais de bombeamento em função do tipo de motor e de tarifa. Nota-se que os maiores custos são associados ao motor diesel estando em conformidade com Melo (1993), Frizzone et al. (1994), Alves Júnior et al. (2004). Scaloppi (1985), estudando as exigências de energia para irrigação, observou que o custo da energia requerida no bombeamento para os motores acionados a óleo diesel representou cerca de seis vezes o custo dos motores elétricos. Nestas análises para a cana-de-açúcar, o custo do bombeamento utilizando diesel representou em média 3 vezes o custo de bombeamento dos motores elétricos.

Em relação ao motor elétrico, a tarifa convencional, que não contempla tarifas diferenciadas para a época do ano (período seco e período úmido) e para o horário de funcionamento (ponta e fora de ponta), apresentou os maiores custos. As tarifas verde e azul apresentaram valores semelhantes devido a não utilização do horário de ponta nas análises. Souza \& Frizzone (2003a) encontraram como melhores opções as tarifas verde e azul com desconto noturno, e explicam que a igualdade nas tarifas azul e verde ocorreu devido ao equacionamento da tarifas de seu modelo, que desconsidera a possibilidade de utilização dos sistemas de irrigação no horário de ponta, eliminando a desvantagem da tarifa azul que está em utilizá-la no horário de ponta. Entre os sistemas de irrigação, o autopropelido sempre apresentou os maiores custos de bombeamento, estando de acordo com os resultados obtidos por Scaloppi (1985).

Tabela 20. Custo anual do bombeamento para os sistemas de irrigação em função do tipo de motor e de tarifa para cana-de-açúcar na região de Piracicaba

\begin{tabular}{lccc}
\hline \multirow{2}{*}{ Tipo de motor e tarifa } & \multicolumn{3}{c}{ Custo do bombeamento $\left(\mathrm{R} \$ \mathrm{ha}^{-1} \mathrm{ano}^{-1}\right)$} \\
& Pivô Central & Deslocamento Linear & Autopropelido \\
\hline Motor diesel & $1.025,27$ & 953,74 & $2.503,86$ \\
Motor elétrico (média) & 365,09 & 357,63 & 671,73 \\
Tarifa Verde & 322,54 & 316,06 & 568,43 \\
Tarifa Azul & 322,64 & 316,93 & 568,81 \\
Tarifa Convencional & 450,08 & 439,90 & 877,94 \\
\hline
\end{tabular}


A Tabela 21 apresenta os valores da análise de sensibilidade do benefício líquido anual com a variação dos fatores econômicos. O valor de venda do produto foi o fator econômico que mais alterou o benefício líquido anual onde com uma variação de $\pm 20 \%$ promoveu uma variação média do benefício líquido anual de $\pm 66,81 \%$, concordando com as asserções feitas por Paz et al. (2002). Os fatores que mais influenciaram o benefício líquido anual para a irrigação da cana-de-açúcar na região de Piracicaba, foram em ordem decrescente: o valor de venda do produto, a vida útil do sistema de irrigação, a taxa de manutenção, a taxa de juros, o preço da água e a mão-de-obra. A cobrança pelo uso da água foi o fator que menos influenciou no benefício líquido anual sendo superior somente ao custo da mão-de-obra, como encontrado em Blanco et al. (2004).

Tabela 21. Análise de sensibilidade do benefício líquido anual, com a variação de $\pm 20 \%$, para os sistemas de irrigação para a cana-de-açúcar na região de Piracicaba

\begin{tabular}{|c|c|c|c|c|c|c|}
\hline \multirow{3}{*}{ Fatores econômicos } & \multicolumn{6}{|c|}{ Variação do benefício líquido anual (\%) } \\
\hline & \multicolumn{2}{|c|}{ Pivô Central } & \multicolumn{2}{|c|}{$\begin{array}{l}\text { Deslocamento } \\
\text { Linear }\end{array}$} & \multicolumn{2}{|c|}{ Autopropelido } \\
\hline & $-20 \%$ & $+20 \%$ & $-20 \%$ & $+20 \%$ & $-20 \%$ & $+20 \%$ \\
\hline $\begin{array}{l}\text { Vida útil do sistema de } \\
\text { irrigação (anos) }\end{array}$ & $-12,35$ & 8,03 & $-10,63$ & 6,90 & $-6,25$ & 4,13 \\
\hline $\begin{array}{c}\text { Taxa de juros } \\
\text { (\% а.а.) }\end{array}$ & 6,00 & $-6,23$ & 5,14 & $-7,36$ & 1,89 & $-1,88$ \\
\hline $\begin{array}{l}\text { Taxa de manutenção } \\
\qquad(\%)\end{array}$ & 7,57 & $-7,57$ & 7,82 & $-7,82$ & 2,98 & $-2,98$ \\
\hline $\begin{array}{l}\text { Valor de venda do produto } \\
\qquad\left(\mathrm{R} \$ \mathrm{Mg}^{-1}\right)\end{array}$ & $-89,78$ & 89,78 & $-66,52$ & 66,52 & $-44,14$ & 44,14 \\
\hline $\begin{array}{c}\text { Mão-de-obra } \\
\text { (horas ha }^{-1} \text { irrigação }^{-1} \text { ) }\end{array}$ & 0,77 & $-0,77$ & 1,04 & $-1,04$ & 0,78 & $-0,78$ \\
\hline $\begin{array}{l}\text { Preço da água } \\
\qquad\left(\mathrm{R} \$ \mathrm{~m}^{-3}\right)\end{array}$ & 3,05 & $-3,05$ & 2,13 & $-2,13$ & 1,83 & $-1,83$ \\
\hline
\end{tabular}




\subsubsection{Análise econômica e análise de sensibilidade para a cultura do tomate industrial na região de Piracicaba}

Para a cultura do tomate industrial irrigado na região de Piracicaba em todas as análises realizadas o uso da irrigação apresentou valores da relação B/C sempre superiores a 1, ou seja, ocorreu viabilidade econômica (Tabela 22). Considerando-se que quanto maior esta relação, mais atraente é projeto (Clark et al., 1993; Frizzone \& Silveira, 2000), as maiores relações B/C foram encontradas para a média do sistema aspersão convencional (Tabela 22) utilizando motor elétrico nas tarifas verde e azul (4,74), com o maior valor de 5,20 obtido com os dados climáticos do ano 2003 na aspersão convencional com bombeamento utilizando motor elétrico e tarifa verde (Tabela 38 Anexo B). As menores relações de B/C foram para a média do sistema autopropelido (Tabela 22) utilizando motor diesel (1,72), sendo o menor valor encontrado no estudo de 1,53 obtido com os dados climáticos do ano 2004 para o sistema autopropelido com bombeamento utilizando diesel (Tabela 42 Anexo B).

Tabela 22. Valores médios da relação B/C para os sistemas de irrigação em função do tipo de motor e de tarifa, para a cultura do tomate industrial na região de Piracicaba

\begin{tabular}{lccc}
\hline Valores $\left(\mathrm{R} \$ \mathrm{ha}^{-1} \mathrm{ano}^{-1}\right)$ & Pivô Central & $\begin{array}{c}\text { Aspersão } \\
\text { Convencional }\end{array}$ & Autopropelido \\
\hline Motor diesel & 2,51 & 2,97 & 1,72 \\
Motor elétrico (média) & 3,16 & 4,55 & 3,10 \\
Tarifa Verde & 3,23 & 4,74 & 3,23 \\
Tarifa Azul & 3,23 & 4,74 & 3,23 \\
Tarifa Convencional & 3,03 & 4,18 & 2,85 \\
\hline
\end{tabular}


Quando observados os coeficientes médios de risco (variância, desvio padrão e desvio absoluto), na Tabela 23, o sistema que apresentou o maior risco foi o pivô central, seguido pelo autopropelido e a aspersão convencional. Os maiores valores de risco (variância de $\mathrm{R} \$^{2}$ 155.783,00 ha ${ }^{-1}$ ano $^{-1}$, desvio padrão de $\mathrm{R} \$ 394,69 \mathrm{ha}^{-1}$ ano $^{-1}$ e desvio absoluto de $\mathrm{R} \$ 321,84 \mathrm{ha}^{-1} \mathrm{ano}^{-1}$ ) foram obtidos para o sistema pivô central com os dados climáticos do ano 2003 (Tabelas 37 e 40 Anexo B). Já os menores valores de risco (variância de $\mathrm{R}^{2}$ 111.871,20 ha ${ }^{-1}$ ano $^{-1}$, desvio padrão de $\mathrm{R} \$ 334,47$ ha $^{-1}$ ano $^{-1}$ e desvio absoluto de R\$272,60 ha ${ }^{-1}$ ano $^{-1}$ ) foram encontrados para o sistema aspersão convencional com os dados climáticos do ano 2004 (Tabelas 38 e 41 Anexo B).

Tabela 23. Coeficientes médios de risco para os sistemas de irrigação considerando a cultura do tomate industrial na região de Piracicaba

\begin{tabular}{lccc}
\hline \multicolumn{1}{c}{ Valores } & Pivô Central & $\begin{array}{c}\text { Aspersão } \\
\text { Convencional }\end{array}$ & Autopropelido \\
\hline Variância $\left(\mathrm{R} \$^{2} \mathrm{ha}^{-1} \mathrm{ano}^{-1}\right)$ & $134.345,73$ & $132.960,53$ & $133.426,68$ \\
Desvio padrão $\left(\mathrm{R} \$ \mathrm{ha}^{-1} \mathrm{ano}^{-1}\right)$ & 365,89 & 363,99 & 364,63 \\
Desvio absoluto $\left(\mathrm{R} \$ \mathrm{ha}^{-1} \mathrm{ano}^{-1}\right)$ & 298,51 & 296,61 & 297,26 \\
\hline
\end{tabular}

No estudo do tomate industrial, em relação à probabilidade de ocorrência de benefício líquido anual >0 (Tabela 24), todas as análises indicaram a possibilidade de obtenção de benefício líquido anual maior que zero. As maiores médias de probabilidades de obtenção de benefício líquido anual maior que zero foram observadas para o pivô central utilizando motor elétrico, para as tarifas azul e verde (99,99\%) e os menores valores foram encontrados para a aspersão convencional com o uso das tarifas verde e azul (99,58\%). Para todas as análises realizadas com o motor elétrico o valor de probabilidade de obtenção de benefício líquido anual maior que zero foram superiores a 99\%. Para o motor diesel apenas o sistema autopropelido apresentou valores inferiores, com um valor mínimo de 97,22\% (Tabela 42 Anexo B). Dessa maneira os três sistemas estudados podem ser considerados viáveis para as condições do estudo. 
Tabela 24. Valores médios da probabilidade de benefício líquido anual > 0 (\%) para os sistemas de irrigação em função do tipo de motor e de tarifa, para a cultura do tomate industrial na região de Piracicaba

\begin{tabular}{lccc}
\hline Tipo de motor & Pivô Central & $\begin{array}{c}\text { Aspersão } \\
\text { Convencional }\end{array}$ & Autopropelido \\
\hline Motor diesel & 99,94 & 99,97 & 99,59 \\
Motor elétrico (média) & 99,99 & 99,67 & 99,98 \\
Tarifa Verde & 99,99 & 99,58 & 99,98 \\
Tarifa Azul & 99,99 & 99,58 & 99,98 \\
Tarifa Convencional & 99,98 & 99,84 & 99,97 \\
\hline
\end{tabular}

Observando o benefício líquido anual esperado (Tabela 25), todas as análises indicaram a ocorrência de lucro, ou seja, o valor que na média deveríamos esperar que viesse a ocorrer foi sempre superior a zero. Os menores valores médios estão associados ao sistema autopropelido e os maiores valores ao sistema aspersão convencional. O maior valor de benefício líquido anual foi de $\mathrm{R} \$ 1.772,20 \mathrm{ha}^{-1} \mathrm{ano}^{-1}$ obtido para a aspersão convencional utilizando a tarifa verde (Tabela 38 Anexo B) e o menor valor de benefício líquido anual foi de $\mathrm{R} \$ 644,37 \mathrm{ha}^{-1} \mathrm{ano}^{-1}$ obtido para o autopropelido utilizando a motor diesel (Tabela 42 Anexo B).

Em relação aos custos totais da irrigação (Tabela 25), os maiores valores foram encontrados para o sistema autopropelido seguido do pivô central e o menor valor é apresentado pela aspersão convencional. Analisando, para o motor elétrico, os custos da irrigação, observa-se que os maiores custos fixos estão associados ao sistema pivô central e os menores custos fixos referem-se ao sistema aspersão convencional devido ao seu baixo custo de aquisição quando comparado aos sistemas estudados. Porém, quando observados os custos variáveis o autopropelido apresenta os maiores custos, como encontrado em Scaloppi (1985) e Bonomo et al. (1999). 
Tabela 25. Valores médios de benefícios líquidos anuais e custos médios anuais advindos do uso da irrigação, para os sistemas de irrigação utilizando motor elétrico na cultura do tomate industrial para a região de Piracicaba

\begin{tabular}{lccc}
\hline \multicolumn{1}{c}{ Valores $\left(\mathrm{R} \$ \mathrm{ha}^{-1} \mathrm{ano}^{-1}\right.$ ) } & Pivô Central & $\begin{array}{c}\text { Aspersão } \\
\text { Convencional }\end{array}$ & Autopropelido \\
\hline Custo Fixo Anual esperado & 331,72 & 186,74 & 287,15 \\
Custo Variável Anual esperado & 315,01 & 263,65 & 374,20 \\
Custo Total Anual esperado & 646,73 & 450,39 & 661,35 \\
Benefício líquido Anual esperado & $1.385,96$ & $1.582,60$ & $1.371,53$ \\
\hline
\end{tabular}

Na Tabela 26 são apresentados os percentuais dos custos oriundos da irrigação em relação ao custo total da irrigação utilizando motor elétrico. Para os sistemas aspersão convencional e autopropelido os custos variáveis representaram a maior participação no custo total da irrigação (>50\%), com o bombeamento sendo o fator de maior participação. Para o sistema pivô central os custos fixos foram em média superiores aos custos variáveis por este sistema apresentar o maior valor de aquisição a maior eficiência de aplicação de água entre os sistemas estudados. O custo da mão-deobra apresentou pouca influência com valores sempre inferiores a $2 \%$ do custo total da irrigação para os sistemas pivô central e autopropelido. Porem o sistema aspersão convencional apresentou uma participação de 5,06\%, em média, da mão-de-obra no custo total da irrigação; isto ocorre porque este sistema requer movimentação da tubulação durante o processo de irrigação, o que promove menores custos fixos, mas implica em maiores custos com a mão-de-obra. 
Tabela 26. Participação percentual dos custos advindos da irrigação no custo total da irrigação do tomate industrial utilizando motor elétrico para Piracicaba

Participação no custo total da irrigação (\%)

Pivô Central Aspersão Convencional Autopropelido

\begin{tabular}{cccc}
\hline Custos Fixos esperados & 51,37 & 41,63 & 43,64 \\
Custos Variáveis esperados & 48,63 & 58,37 & 56,36 \\
Mão-de-obra & 0,56 & 5,06 & 1,03 \\
Manutenção & 23,19 & 8,35 & 18,25 \\
Bombeamento & 21,15 & 38,78 & 32,52 \\
Água & 3,73 & 6,18 & 4,56 \\
\hline
\end{tabular}

Para o motor diesel, os custos da irrigação e sua participação percentual no custo total da irrigação são apresentados nas Tabelas 27 e 28 . Observou-se o mesmo comportamento para os custos fixos. Em relação aos custos variáveis os valores são superiores aos obtidos para o motor elétrico, como observado em Frizzone et al. (1994). Isto ocorreu devido ao alto custo do óleo diesel e da não possibilidade de desconto noturno oferecido no bombeamento utilizando motor elétrico. Os custos com bombeamento representaram as maiores participações no custo total da irrigação para todos os sistemas de irrigação estudados (Tabela 28), demonstrando que o custo de bombeamento destaca-se sempre como o fator de maior influência para o motor diesel. Já o fator de menor influência também foi o custo da mão-de-obra, seguindo o mesmo comportamento discutido para o motor elétrico. Em relação aos custos totais da irrigação, seguiu-se a mesma tendência do bombeamento elétrico, sendo os maiores valores encontrados para o sistema autopropelido, seguido do pivô central e da aspersão convencional. 
Tabela 27. Benefícios líquidos anuais e custos médios anuais advindos do uso da irrigação para os sistemas de irrigação utilizando motor diesel para tomate industrial na região de Piracicaba

\begin{tabular}{lccc}
\hline \multicolumn{1}{c}{ Valores $\left(\mathrm{R} \$ \mathrm{ha}^{-1} \mathrm{ano}^{-1}\right)$} & Pivô Central & $\begin{array}{c}\text { Aspersão } \\
\text { Convencional }\end{array}$ & Autopropelido \\
\hline Custo Fixo Anual esperado & 331,72 & 186,74 & 287,15 \\
Custo Variável Anual esperado & 482,82 & 503,53 & 902,23 \\
Custo Total Anual esperado & 814,54 & 690,27 & $1.189,38$ \\
Benefício líquido Anual esperado & $1.218,10$ & $1.342,37$ & 843,47 \\
\hline
\end{tabular}

Tabela 28. Participação percentual dos custos advindos da irrigação no custo total da irrigação utilizando motor diesel para tomate industrial na região de Piracicaba

Participação no custo total da irrigação (\%)

Pivô Central Aspersão Convencional Autopropelido

\begin{tabular}{cccc}
\hline Custos Fixos esperados & 40,78 & 27,13 & 24,22 \\
Custos Variáveis esperados & 59,22 & 72,87 & 75,78 \\
Mão-de-obra & 0,44 & 3,28 & 0,57 \\
Manutenção & 18,42 & 5,44 & 10,13 \\
Bombeamento & 37,41 & 60,13 & 62,56 \\
Água & 2,95 & 4,02 & 2,52 \\
\hline
\end{tabular}

Observando a análise econômica da irrigação do tomate industrial na região de Piracicaba os maiores custos totais foram observados para o bombeamento utilizando motor diesel, com os maiores valores encontrado para o sistema autopropelido como observado por Scaloppi (1985); Melo (1993) e Bonomo et al. (1999). De maneira geral o custo da mão-de-obra foi o que menos influenciou o custo total da irrigação (1,82\%), seguido pelo custo da água (3,99\%) e o custo da manutenção (13,96\%). O custo do bombeamento representou, em média, a maior participação (42,10\%) nos custos totais da irrigação em conformidade com os resultados obtidos em Bonomo et al. (1999); 
Andrade Junior et al. (2001) e Soares et al. (2003). Na Tabela 29, são analisados os custos de bombeamento em função do tipo de motor e de tarifa. Nota-se que os maiores custos são associados ao motor diesel (Melo, 1993; Frizzone et al. 1994; Alves Júnior et al., 2004). Nestas análises o custo do bombeamento utilizando diesel representou em média 2,6 vezes o custo de bombeamento dos motores elétricos.

Tabela 29. Custo do bombeamento para os sistemas de irrigação em função do tipo de motor e de tarifa para tomate industrial na região de Piracicaba

\begin{tabular}{lccc}
\hline \multirow{2}{*}{ Tipo de motor e tarifa } & \multicolumn{3}{c}{ Custo do bombeamento $\left(\mathrm{R} \$ \mathrm{ha}^{-1} \mathrm{ano}^{-1}\right)$} \\
& Pivô Central & Aspersão Convencional & Autopropelido \\
\hline Motor diesel & 305,15 & 415,86 & 745,22 \\
Motor elétrico (média) & 137,33 & 175,78 & 217,20 \\
Tarifa Verde & 122,84 & 156,93 & 188,60 \\
Tarifa Azul & 122,86 & 156,98 & 188,71 \\
Tarifa Convencional & 166,30 & 213,42 & 274,28 \\
\hline
\end{tabular}

Em relação ao motor elétrico, a tarifa convencional, que não contempla tarifas diferenciadas para a época do ano (período seco e período úmido) e para o horário de funcionamento (ponta e fora de ponta), apresentou os maiores custos. As tarifas verde e azul apresentaram valores semelhantes devido a não utilização do horário de ponta nas análises, como discutido para a análise da irrigação da cana-de-açúcar, eliminando a desvantagem da tarifa azul. Entre os sistemas de irrigação o autopropelido sempre apresentou os maiores custos de bombeamento de acordo com os resultados obtidos por Scaloppi (1985) que observou o maior consumo energético no autopropelido superando o pivô central e a aspersão convencional.

A Tabela 30 apresenta os valores da análise de sensibilidade do benefício líquido anual com a variação dos fatores econômicos utilizados na simulação. Nota-se que o valor de venda do produto também foi, nesta análise, o fator econômico que mais alterou o benefício líquido anual; onde com uma variação de $\pm 20 \%$ promoveu uma variação média do benefício líquido anual de $\pm 68,60 \%$, concordando com as asserções feitas por 
Paz et al. (2002), seguido pela vida útil do sistema de irrigação com variações médias do benefício líquido anual de $-2,91 \%$ e 1,89\% para variações respectivas de $-20 \%$ e $+20 \%$ da vida útil.

Tabela 30. Análise de sensibilidade do benefício líquido anual, com a variação de $\pm 20 \%$, para os sistemas de irrigação para o tomate industrial na região de Piracicaba Variação do benefício líquido anual (\%)

\begin{tabular}{|c|c|c|c|c|c|c|}
\hline \multirow[t]{2}{*}{ Fatores econômicos } & \multicolumn{2}{|c|}{ Pivô Central } & \multicolumn{2}{|c|}{$\begin{array}{c}\text { Aspersão } \\
\text { convencional }\end{array}$} & \multicolumn{2}{|c|}{ Autopropelido } \\
\hline & $-20 \%$ & $+20 \%$ & $-20 \%$ & $+20 \%$ & $-20 \%$ & $+20 \%$ \\
\hline $\begin{array}{l}\text { Vida útil do sistema de } \\
\text { irrigação (anos) }\end{array}$ & $-3,10$ & 2,03 & $-1,82$ & 1,20 & $-3,81$ & 2,45 \\
\hline $\begin{array}{c}\text { Taxa de juros } \\
\text { (\% a.a.) }\end{array}$ & 1,52 & $-1,55$ & 0,67 & $-0,70$ & 1,17 & $-0,93$ \\
\hline $\begin{array}{l}\text { Taxa de manutenção } \\
\text { (\%) }\end{array}$ & 1,92 & $-1,92$ & 0,43 & $-0,43$ & 1,84 & $-1,84$ \\
\hline $\begin{array}{l}\text { Valor de venda do produto } \\
\qquad\left(\mathrm{R} \$ \mathrm{Mg}^{-1}\right)\end{array}$ & $-66,20$ & 66,20 & $-60,73$ & 60,73 & $-78,88$ & 78,88 \\
\hline $\begin{array}{c}\text { Mão-de-obra } \\
\text { (horas ha }^{-1} \text { irrigação }^{-1} \text { ) }\end{array}$ & 0,10 & $-0,10$ & 0,26 & $-0,26$ & 0,13 & $-0,13$ \\
\hline $\begin{array}{l}\text { Preço da água } \\
\qquad\left(\mathrm{R} \$ \mathrm{~m}^{-3}\right)\end{array}$ & 0,24 & $-0,24$ & 0,24 & $-0,24$ & 0,35 & $-0,35$ \\
\hline
\end{tabular}




\section{CONCLUSÕES}

O modelo computacional para a determinação do risco econômico em culturas irrigadas mostrou-se eficiente no seu objetivo de fornecer a probabilidade de benefício líquido anual maior que zero, índices de viabilidade (relação benefício/custo, valor esperado de beneficio líquido) e incluir o risco econômico presente no projeto (desvio absoluto, desvio padrão, variância e coeficiente de variação). Permitindo assim, a tomada de decisão e o estudo de diferentes projetos baseados em valores probabilísticos que representem as possíveis conseqüências dessa decisão.

O modelo permite o estudo da influência dos fatores econômicos (custo fixo, custo da mão-de-obra, custo da água, custo do bombeamento e custo de manutenção) no custo total da irrigação, bem como a possibilidade de testar o efeito do tipo de energia utilizada no bombeamento.

De acordo com as análises das aplicações realizadas, utilizando o modelo para o estudo do uso da irrigação em culturas irrigadas na região de Piracicaba, concluiu-se que: 
Para a cana-de-açúcar:

- os valores da relação benefício/custo média para todos os sistemas testados apresentaram valores inferiores a 1, indicando inviabilidade da irrigação;

- para o benefício líquido anual esperado, todos os sistemas apresentaram valores negativos, indicam prejuízo e reforçando a inviabilidade do investimento;

- com relação à probabilidade de benefício líquido anual maior que zero, o uso do motor diesel foi descartado por apresentar resultados nulos para todos os sistemas testados;

- a tarifa convencional apresentou valores nulos de probabilidade de benefício líquido anual maior que zero somente para o sistema autopropelido;

- o sistema de irrigação que apresentou os melhores resultados foi o pivô central utilizando energia elétrica com tarifas azul e verde;

- o sistema que apresentou maior risco foi o deslocamento linear com um desvio padrão de $\mathrm{R} \$ 152,62 \mathrm{ha}^{-1} \mathrm{ano}^{-1}$;

- o bombeamento foi o fator de maior influência no custo total da irrigação representando em média 55,20\% do custo total.

Para o tomate industrial:

- todos os sistemas analisados apresentaram viabilidade, ou seja, todos apresentaram relação benefício/custo superior a 1 e benefício líquido anual esperado superior a zero;

- o sistema de aspersão convencional utilizando energia elétrica foi o que apresentou a maior relação benefício/custo média $(4,74)$, o maior benefício líquido anual esperado ( R\$ 1.582,60 ha ano $^{-1}$ ) e o menor risco com desvio padrão de $\mathrm{R} \$ 363,99 \mathrm{ha}^{-1} \mathrm{ano}^{-1}$;

- o sistema que apresentou maior risco foi o pivô central com um desvio padrão de R\$ 365,89 ha $^{-1}$ ano $^{-1}$,

- O custo do bombeamento representou, em média, a maior participação (42,10\%) nos custos totais da irrigação. 
De maneira geral, considerando as análises:

- os maiores custos totais anuais da irrigação estão associados ao uso do motor diesel;

- o sistema autopropelido apresentou os maiores custos totais da irrigação devido ao seu alto consumo de energia para o bombeamento;

- não houve diferença entre as tarifas azul e verde pela não utilização do bombeamento no horário de ponta;

- o fator econômico que menos influência teve sobre o custo total anual da irrigação foi a mão-de-obra (1,75\%), seguido pelo custo da água (5,12\%) e custo de manutenção (12,96\%). O custo do bombeamento apresentou a maior influência sobre o custo total anual da irrigação com uma participação média de 48,91\%. 
ANEXOS 
Anexo A

Distribuição de freqüências de simulações 


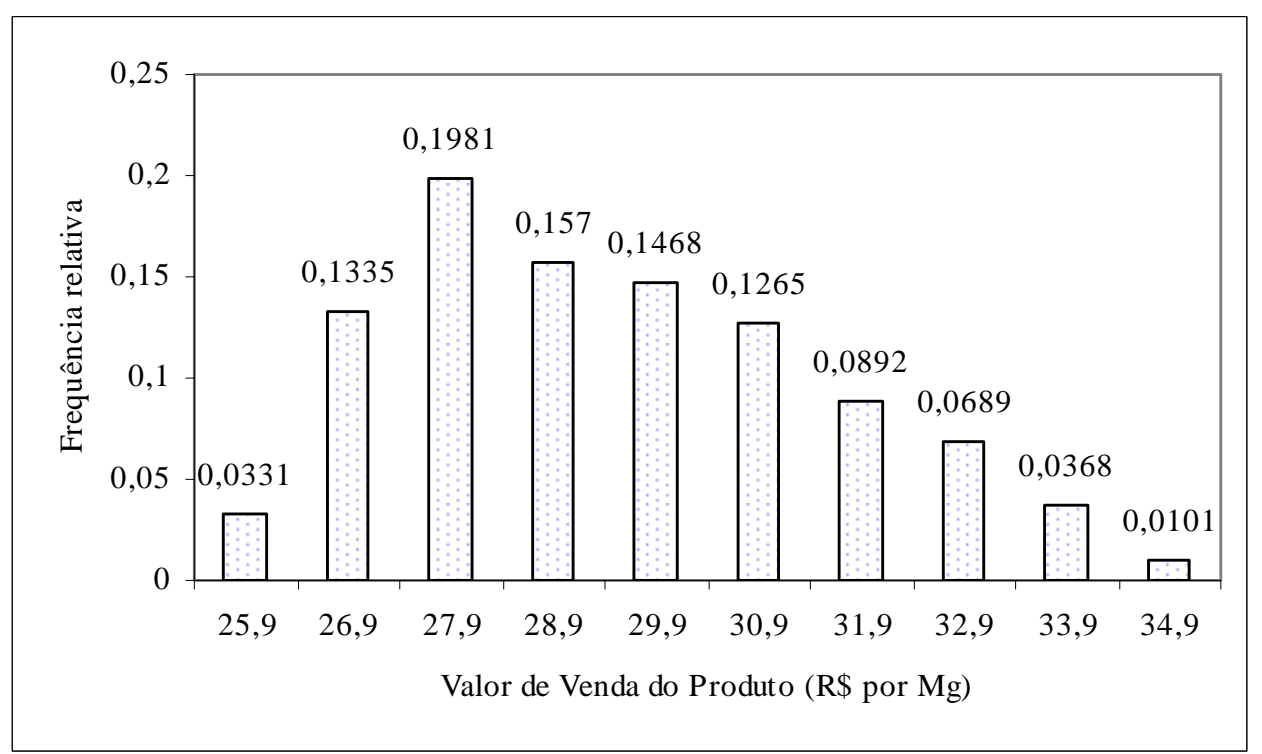

Figura 39 - Distribuição de freqüência obtida por uma simulação do valor de venda do produto para cana-de-açúcar

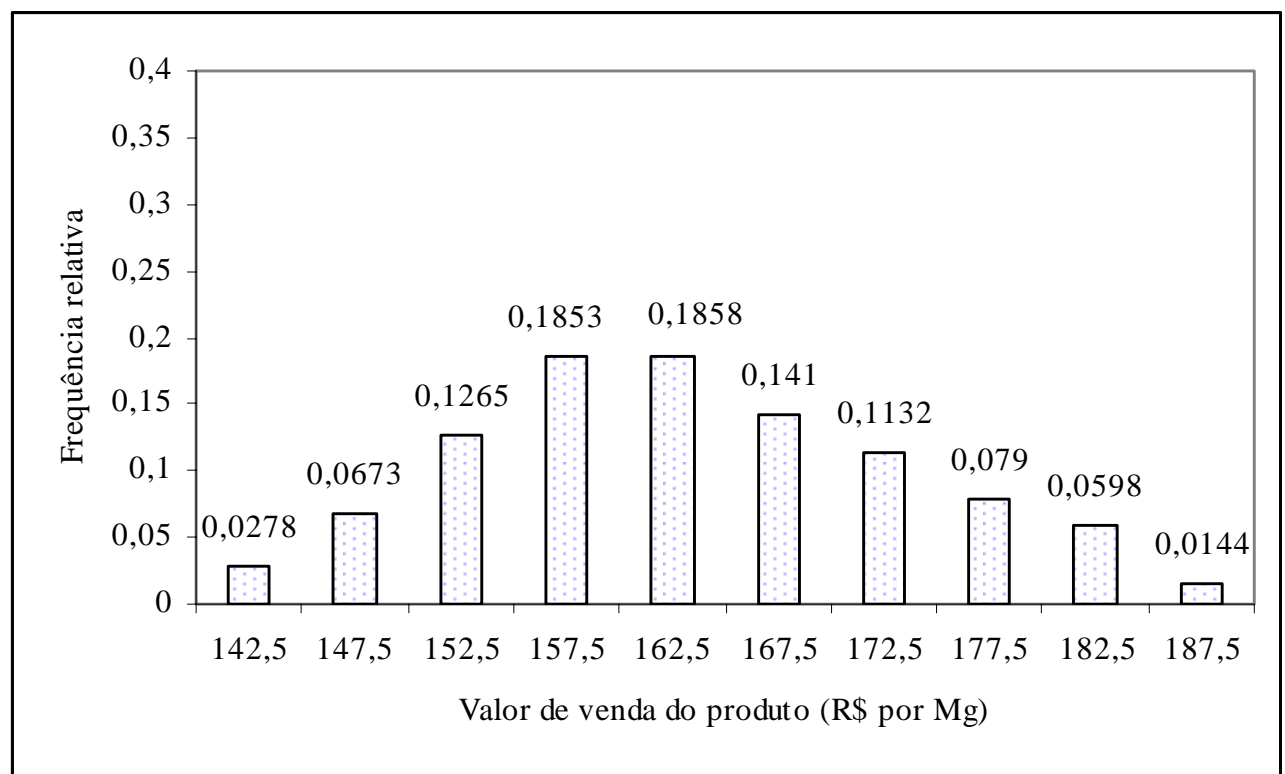

Figura 40 - Distribuição de freqüência obtida por uma simulação do valor de venda do produto para tomate industrial 


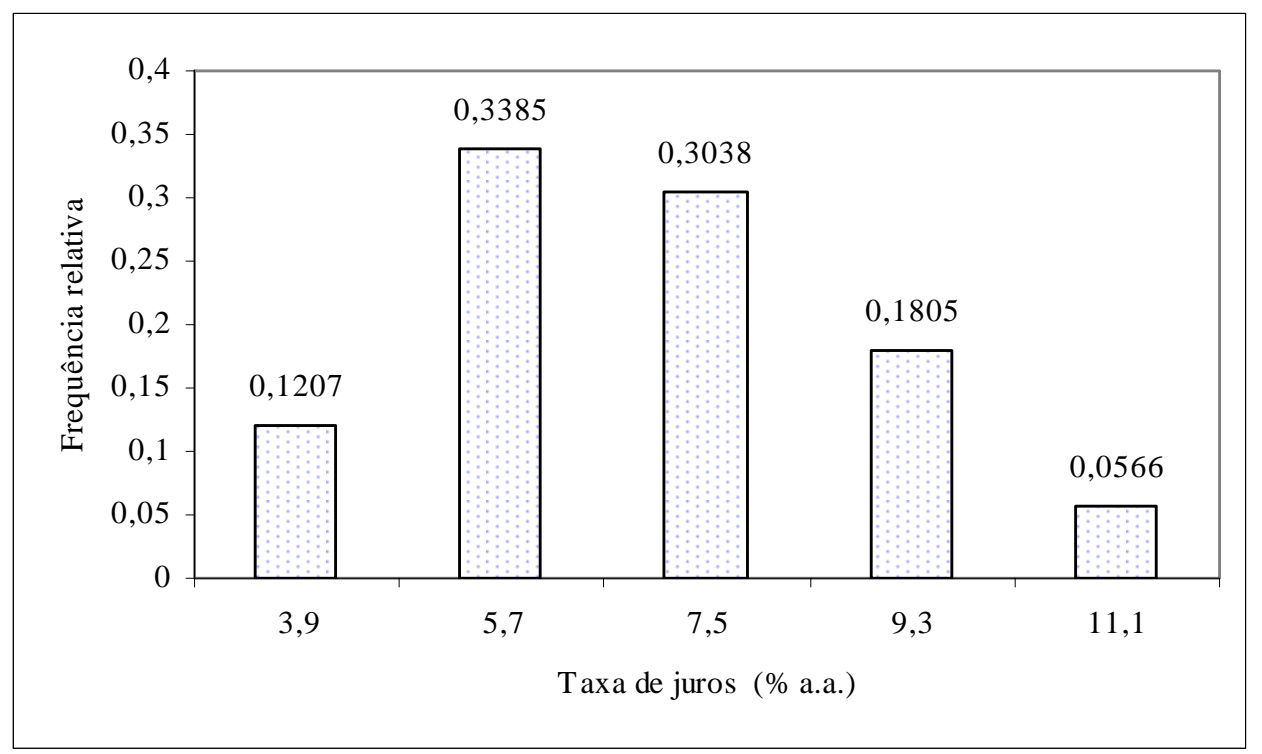

Figura 41 - Distribuição de freqüência obtida por uma simulação da taxa de juros anual

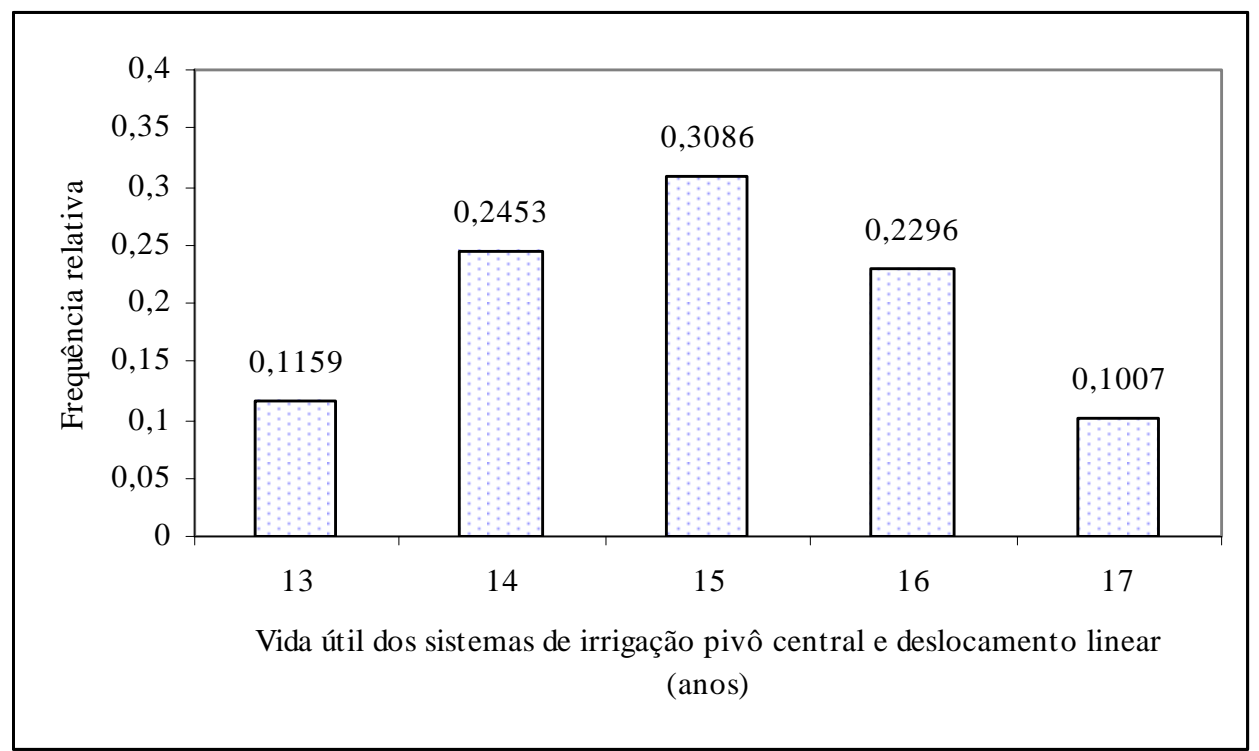

Figura 42 - Distribuição de freqüência obtida por uma simulação da vida útil dos sistemas de irrigação pivô central e deslocamento linear 


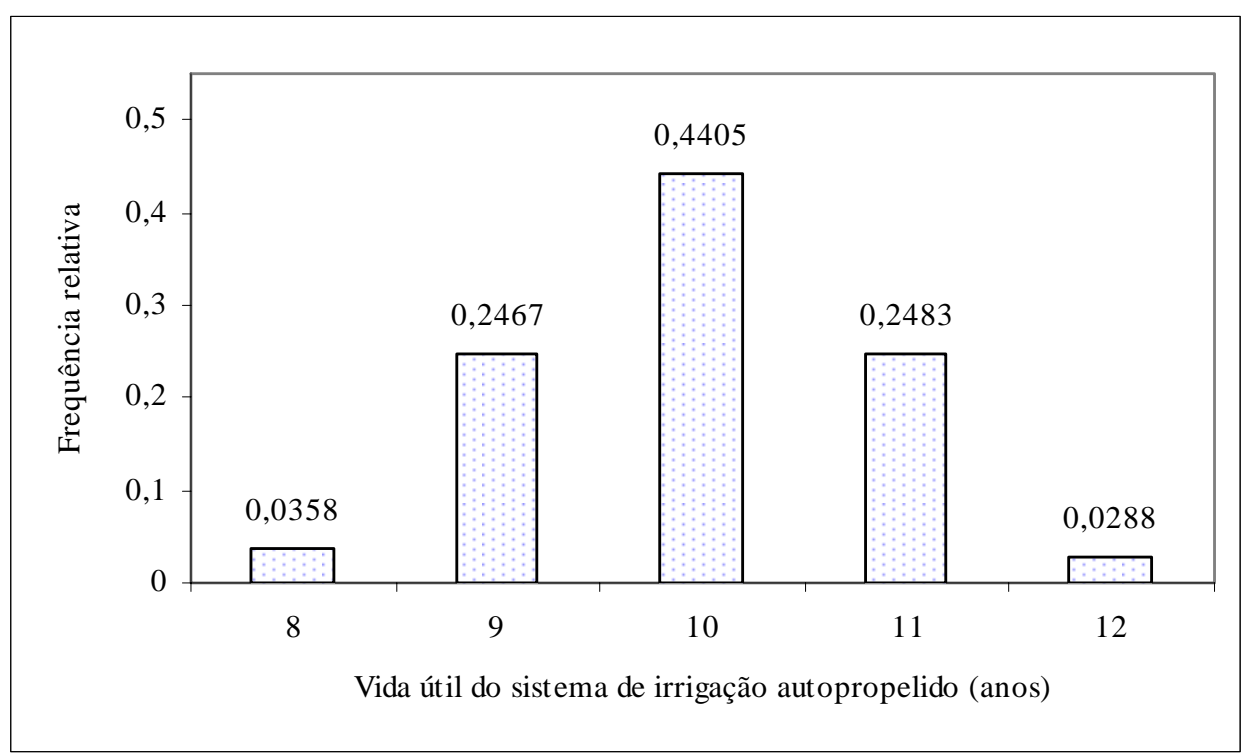

Figura 43 - Distribuição de freqüência obtida por uma simulação da vida útil do sistema de irrigação autopropelido

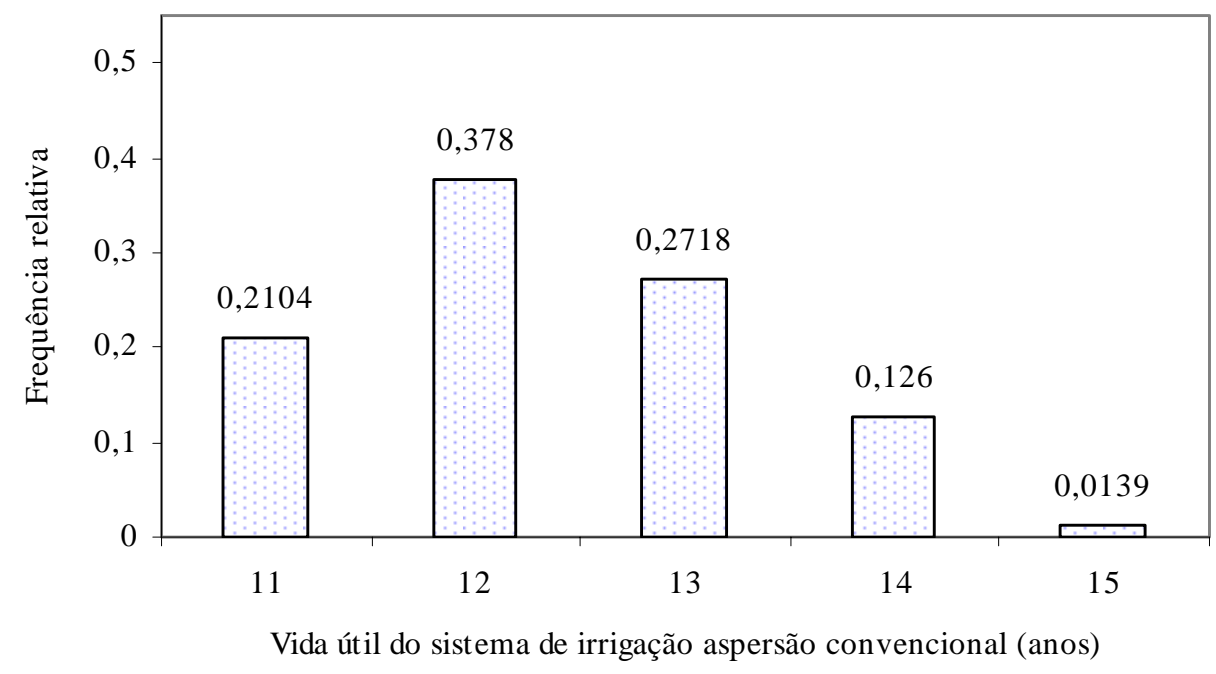

Figura 44 - Distribuição de freqüência obtida por uma simulação da vida útil do sistema de irrigação aspersão convencional 


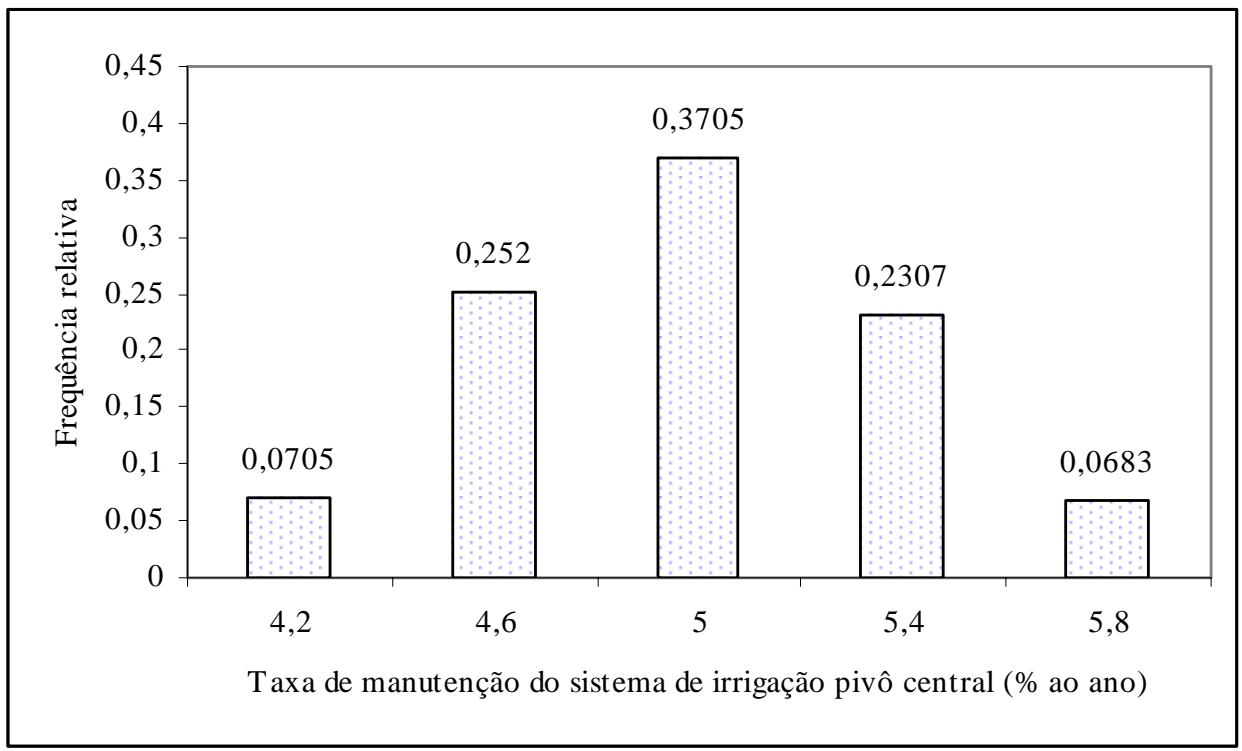

Figura 45 - Distribuição de freqüência obtida por uma simulação da taxa de manutenção do sistema de irrigação pivô central

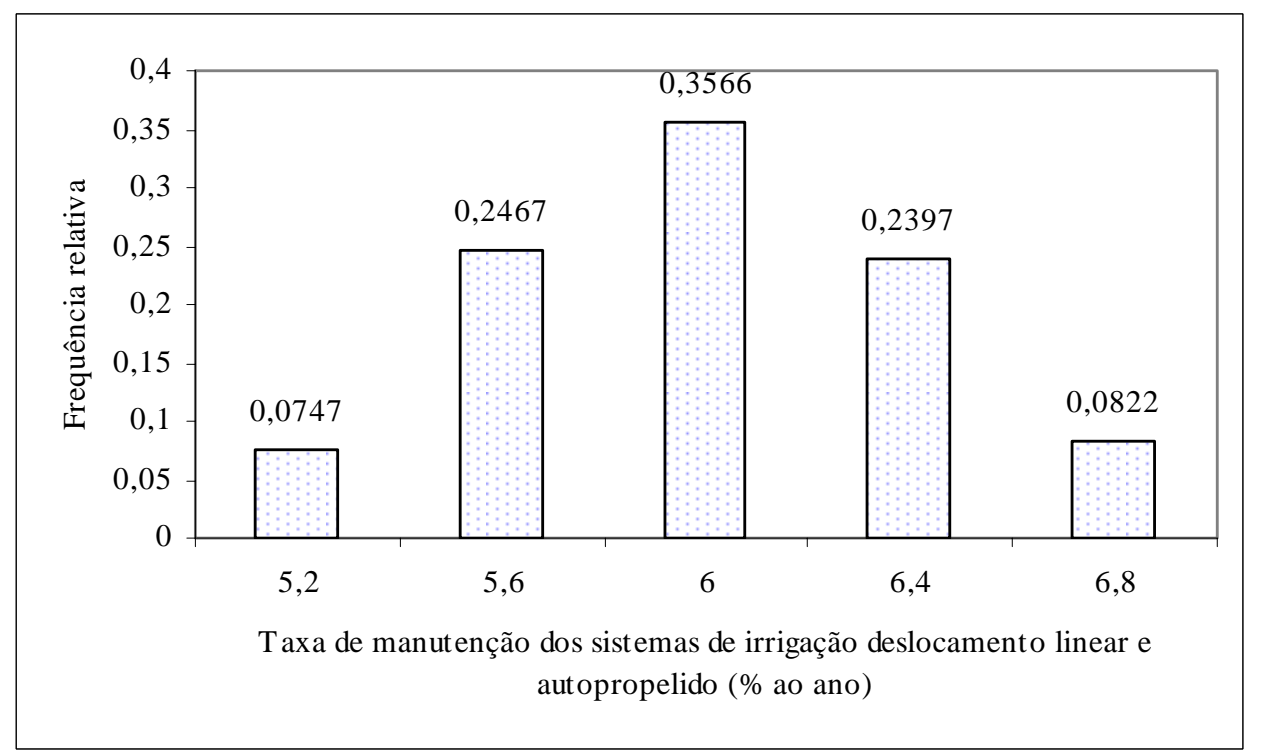

Figura 46 - Distribuição de freqüência obtida por uma simulação da taxa de manutenção dos sistemas de irrigação deslocamento linear e autopropelido 


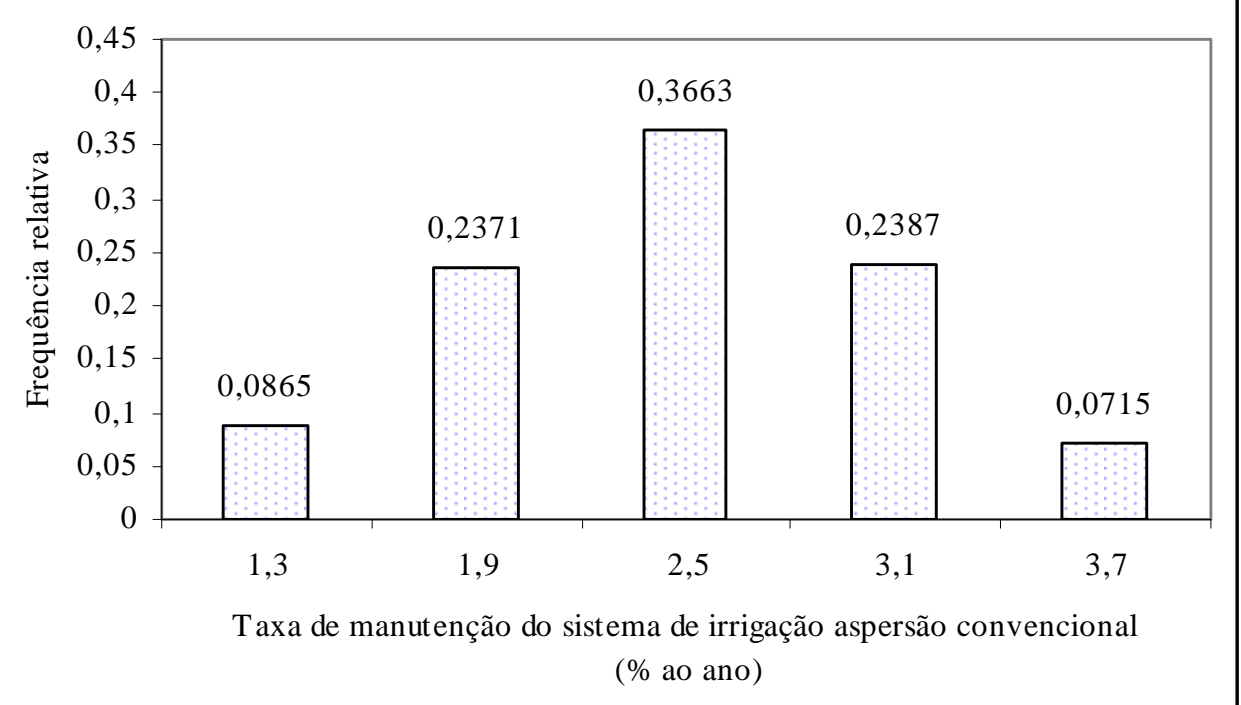

Figura 47 - Distribuição de freqüência obtida por uma simulação da taxa de manutenção do sistema de irrigação aspersão convencional

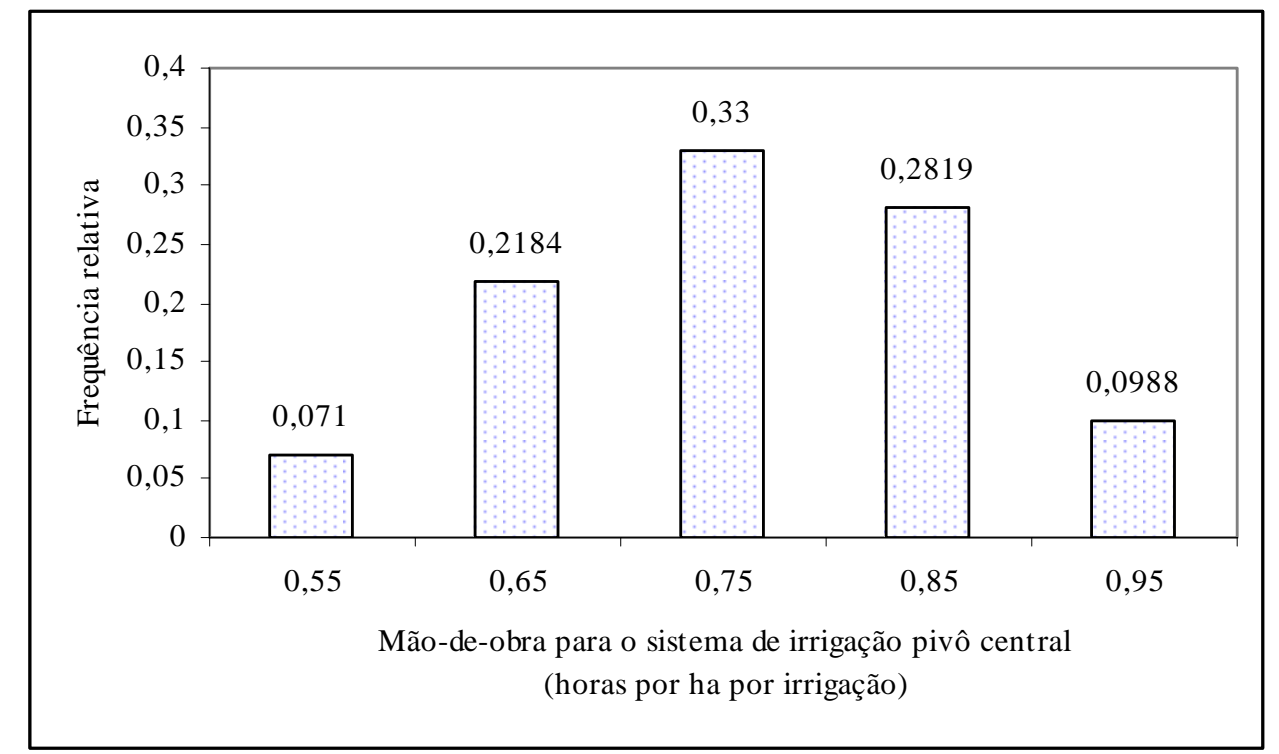

Figura 48 - Distribuição de freqüência obtida por uma simulação da mão-de-obra para o sistema de irrigação pivô central 


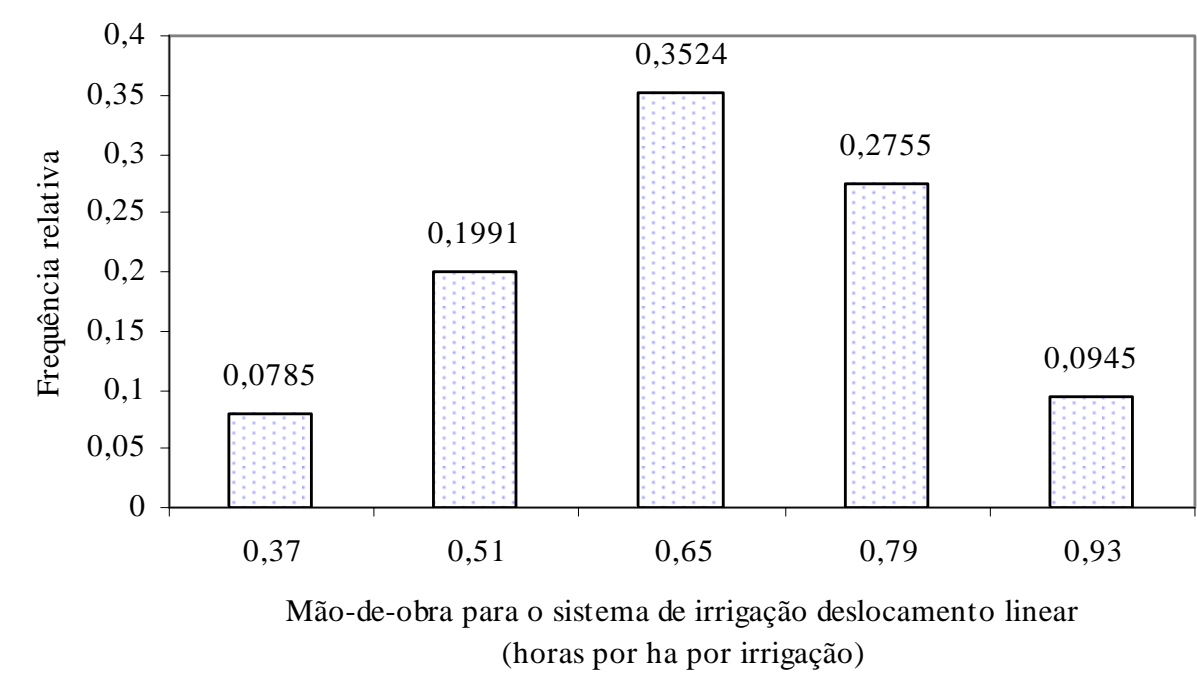

Figura 49 - Distribuição de freqüência obtida por uma simulação da mão-de-obra para o sistema de irrigação deslocamento linear

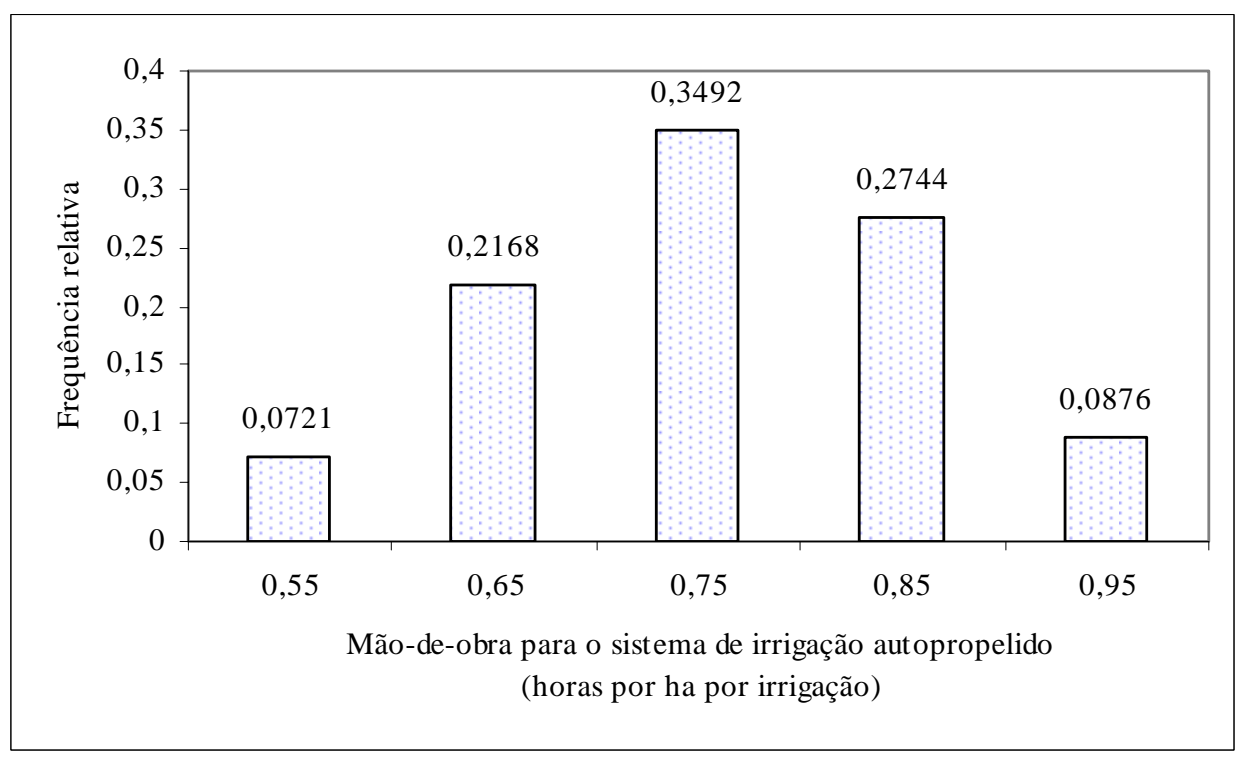

Figura 50 - Distribuição de freqüência obtida por uma simulação da mão-de-obra para o sistema de irrigação autopropelido 


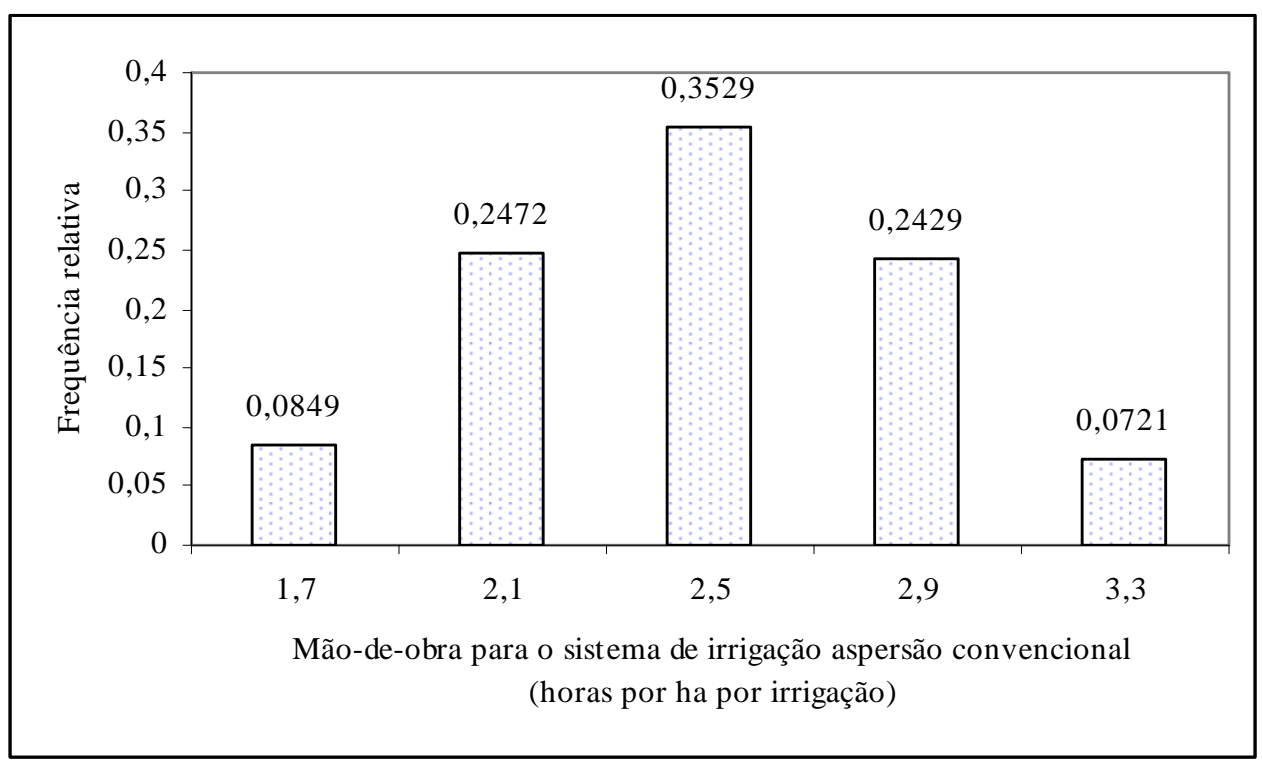

Figura 51 - Distribuição de freqüência obtida por uma simulação da mão-de-obra para o sistema de irrigação aspersão convencional

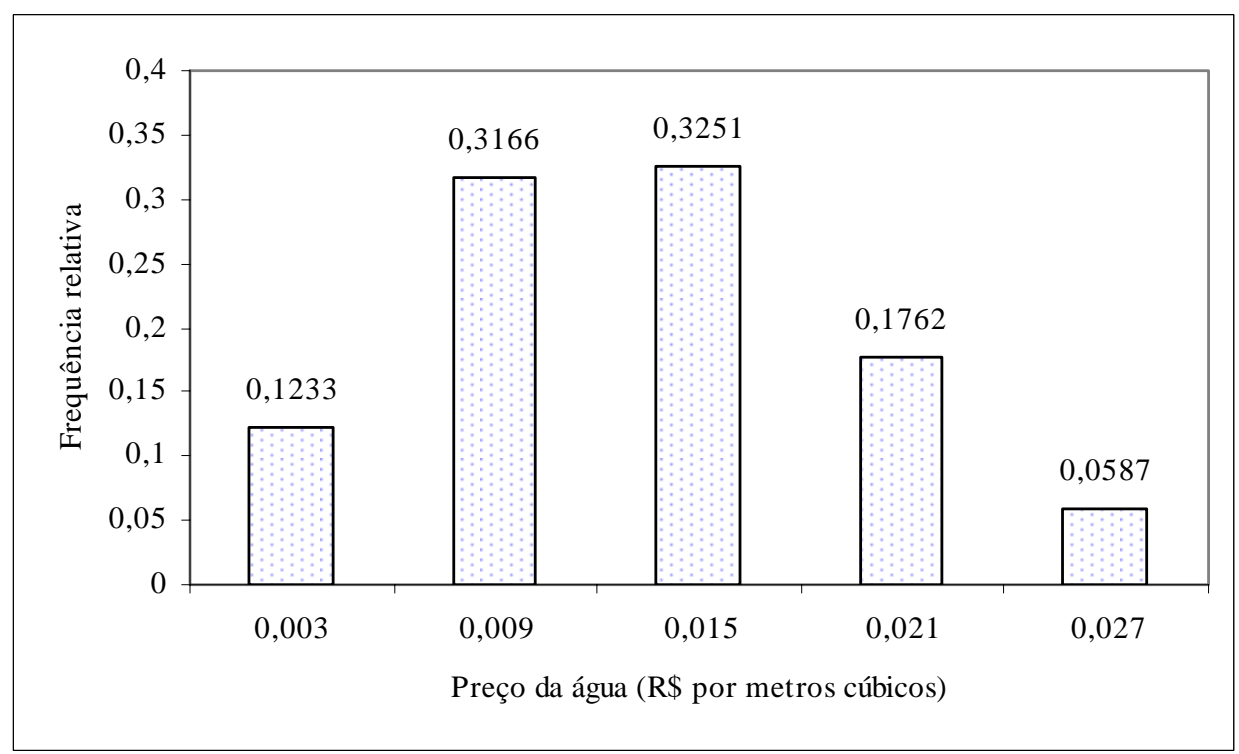

Figura 52 - Distribuição de freqüência obtida por uma simulação do preço da água 
Anexo B

Índices econômicos obtidos no estudo classificados por sistema de irrigação, por cultura e por ano estudado. 
Tabela 31. Índices econômicos obtidos para irrigação da cana-de-açúcar para o pivô central utilizando energia elétrica para os anos estudados

\begin{tabular}{|c|c|c|c|c|}
\hline Índices econômicos & 2001 & 2002 & 2003 & 2004 \\
\hline \multicolumn{5}{|l|}{ Tarifa Verde } \\
\hline Probabilidade de BLA >0 (\%) & 8,49 & 12,38 & 18,49 & 18,69 \\
\hline Relação B/C & 0,78 & 0,81 & 0,85 & 0,85 \\
\hline Valor esperado de BLA $\left(\mathrm{R} \$\right.$ ha $\left.^{-1} \mathrm{ano}^{-1}\right)$ & $-202,22$ & $-182,83$ & $-132,73$ & $-133,74$ \\
\hline Desvio padrão (R\$ ha ${ }^{-1}$ ano $\left.^{-1}\right)$ & 147,25 & 158,13 & 148,02 & 150,38 \\
\hline Variância $\left(\mathrm{R} \$^{2}\right.$ ha $\left.^{-1} \mathrm{ano}^{-1}\right)$ & $21.683,9$ & $25.004,2$ & 21.909,6 & $22.614,2$ \\
\hline Desvio absoluto ( $\mathrm{R} \$ \mathrm{ha}^{-1} \mathrm{ano}^{-1}$ ) & 120,26 & 129,36 & 121,33 & 123,20 \\
\hline Coeficiente de variação (\%) & 72,82 & 86,49 & 111,52 & 112,45 \\
\hline \multicolumn{5}{|l|}{ Tarifa Azul } \\
\hline Probabilidade de BLA >0 (\%) & 8,51 & 12,37 & 18,86 & 19,06 \\
\hline Relação B/C & 0,78 & 0,81 & 0,85 & 0,85 \\
\hline Valor esperado de BLA $\left(\mathrm{R} \$\right.$ ha $\left.^{-1} \mathrm{ano}^{-1}\right)$ & $-201,33$ & $-182,95$ & $-130,69$ & $-131,70$ \\
\hline Desvio padrão ( $\mathrm{R} \$$ ha $^{-1} \mathrm{ano}^{-1}$ ) & 147,25 & 158,13 & 148,02 & 150,38 \\
\hline Variância $\left(\mathrm{R} \$^{2} \mathrm{ha}^{-1} \mathrm{ano}^{-1}\right)$ & $21.683,9$ & $25.004,2$ & 21.909,6 & $22.614,2$ \\
\hline Desvio absoluto ( $\mathrm{R} \$ \mathrm{ha}^{-1} \mathrm{ano}^{-1}$ ) & 120,26 & 129,36 & 121,33 & 123,20 \\
\hline Coeficiente de variação (\%) & 72,92 & 86,43 & 113,28 & 114,81 \\
\hline \multicolumn{5}{|l|}{ Tarifa Convencional } \\
\hline Probabilidade de BLA >0 (\%) & 1,13 & 1,95 & 4,67 & 4,61 \\
\hline Relação B/C & 0,68 & 0,7 & 0,75 & 0,75 \\
\hline Valor esperado de BLA $\left(\mathrm{R} \$\right.$ ha $\left.^{-1} \mathrm{ano}^{-1}\right)$ & $-334,75$ & $-326,47$ & $-248,3$ & $-253,28$ \\
\hline Desvio padrão ( $\mathrm{R} \$$ ha $^{-1} \mathrm{ano}^{-1}$ ) & 147,25 & 158,13 & 148,02 & 150,38 \\
\hline Variância $\left(\mathrm{R} \$^{2} \mathrm{ha}^{-1} \mathrm{ano}^{-1}\right)$ & $21.683,9$ & $25.004,2$ & $21.909,6$ & $22.614,2$ \\
\hline Desvio absoluto ( $\mathrm{R} \$ \mathrm{ha}^{-1} \mathrm{ano}^{-1}$ ) & 120,26 & 129,36 & 121,33 & 123,20 \\
\hline Coeficiente de variação (\%) & 43,85 & 48,44 & 59,67 & 59,37 \\
\hline
\end{tabular}


Tabela 32. Índices econômicos obtidos para irrigação da cana-de-açúcar para o deslocamento linear utilizando energia elétrica, para os anos estudados

\begin{tabular}{|c|c|c|c|c|}
\hline Índices econômicos & 2001 & 2002 & 2003 & 2004 \\
\hline \multicolumn{5}{|l|}{ Tarifa Verde } \\
\hline Probabilidade de BLA >0 (\%) & 1,73 & 3,19 & 4,89 & 4,98 \\
\hline Relação B/C & 0,70 & 0,73 & 0,75 & 0,75 \\
\hline Valor esperado de BLA $\left(\mathrm{R} \$\right.$ ha $\left.^{-1} \mathrm{ano}^{-1}\right)$ & $-314,62$ & $-295,79$ & $-248,09$ & $-250,44$ \\
\hline Desvio padrão (R\$ ha ${ }^{-1}$ ano $\left.^{-1}\right)$ & 148,91 & 159,65 & 149,82 & 152,08 \\
\hline Variância $\left(\mathrm{R} \$^{2}\right.$ ha $\left.^{-1} \mathrm{ano}^{-1}\right)$ & $22.173,3$ & $25.487,2$ & $22.445,4$ & $23.126,9$ \\
\hline Desvio absoluto ( $\mathrm{R} \$ \mathrm{ha}^{-1} \mathrm{ano}^{-1}$ ) & 121,45 & 130,41 & 122,57 & 124,41 \\
\hline Coeficiente de variação (\%) & 47,33 & 53,97 & 60,39 & 60,72 \\
\hline \multicolumn{5}{|l|}{ Tarifa Azul } \\
\hline Probabilidade de BLA >0 (\%) & 1,79 & 3,19 & 5,03 & 5,12 \\
\hline Relação B/C & 0,70 & 0,73 & 0,75 & 0,75 \\
\hline Valor esperado de BLA $\left(\mathrm{R} \$\right.$ ha $\left.^{-1} \mathrm{ano}^{-1}\right)$ & $-312,60$ & $-295,90$ & $-246,05$ & $-248,38$ \\
\hline Desvio padrão ( $\mathrm{R} \$$ ha $^{-1} \mathrm{ano}^{-1}$ ) & 148,91 & 159,65 & 149,82 & 152,08 \\
\hline Variância $\left(\mathrm{R} \$^{2} \mathrm{ha}^{-1} \mathrm{ano}^{-1}\right)$ & $22.173,3$ & $25.487,2$ & $22.445,4$ & $23.126,9$ \\
\hline Desvio absoluto ( $\mathrm{R} \$ \mathrm{ha}^{-1} \mathrm{ano}^{-1}$ ) & 121,45 & 130,41 & 122,57 & 124,41 \\
\hline Coeficiente de variação (\%) & 47,64 & 53,95 & 60,39 & 61,22 \\
\hline \multicolumn{5}{|l|}{ Tarifa Convencional } \\
\hline Probabilidade de BLA >0 (\%) & 0,15 & 0,33 & 0,82 & 0,81 \\
\hline Relação B/C & 0,62 & 0,64 & 0,67 & 0,67 \\
\hline Valor esperado de BLA $\left(\mathrm{R} \$\right.$ ha $\left.^{-1} \mathrm{ano}^{-1}\right)$ & $-441,20$ & $-434,04$ & $-359,89$ & $-365,99$ \\
\hline Desvio padrão ( $\mathrm{R} \$$ ha $^{-1} \mathrm{ano}^{-1}$ ) & 148,91 & 159,65 & 149,82 & 152,08 \\
\hline Variância $\left(\mathrm{R} \$^{2} \mathrm{ha}^{-1} \mathrm{ano}^{-1}\right)$ & $22.173,3$ & $25.487,2$ & $22.445,4$ & 23.126,9 \\
\hline Desvio absoluto ( $\mathrm{R} \$ \mathrm{ha}^{-1} \mathrm{ano}^{-1}$ ) & 121,45 & 130,41 & 122,57 & 124,41 \\
\hline Coeficiente de variação (\%) & 33,75 & 36,78 & 41,63 & 41,55 \\
\hline
\end{tabular}


Tabela 33. Índices econômicos obtidos para irrigação da cana-de-açúcar para o autopropelido utilizando energia elétrica, para os anos estudados

\begin{tabular}{|c|c|c|c|c|}
\hline Índices econômicos & 2001 & 2002 & 2003 & 2004 \\
\hline \multicolumn{5}{|l|}{ Tarifa Verde } \\
\hline Probabilidade de BLA >0 (\%) & 0,14 & 0,19 & 3,38 & 2,08 \\
\hline Relação B/C & 0,62 & 0,63 & 0,73 & 0,71 \\
\hline Valor esperado de BLA $\left(\mathrm{R} \$\right.$ ha $\left.^{-1} \mathrm{ano}^{-1}\right)$ & $-439,59$ & $-459,08$ & $-267,48$ & $-303,52$ \\
\hline Desvio padrão ( $\left.\mathrm{R} \$ \mathrm{ha}^{-1} \mathrm{ano}^{-1}\right)$ & 146,79 & 158,80 & 146,40 & 148,96 \\
\hline Variância $\left(\mathrm{R} \$^{2} \mathrm{ha}^{-1} \mathrm{ano}^{-1}\right)$ & $21.547,5$ & $25.218,7$ & $21.431,8$ & $22.188,2$ \\
\hline Desvio absoluto ( $\left.\mathrm{R} \$ \mathrm{ha}^{-1} \mathrm{ano}^{-1}\right)$ & 119,95 & 129,76 & 120,19 & 122,20 \\
\hline Coeficiente de variação (\%) & 33,39 & 34,59 & 54,73 & 49,08 \\
\hline \multicolumn{5}{|l|}{ Tarifa Azul } \\
\hline Probabilidade de BLA >0 (\%) & 0,15 & 0,19 & 3,43 & 2,15 \\
\hline Relação B/C & 0,62 & 0,63 & 0,74 & 0,71 \\
\hline Valor esperado de BLA $\left(\mathrm{R} \$\right.$ ha $\left.^{-1} \mathrm{ano}^{-1}\right)$ & $-437,70$ & $-459,56$ & $-265,45$ & $-301,54$ \\
\hline Desvio padrão $\left(\mathrm{R} \$ \mathrm{ha}^{-1} \mathrm{ano}^{-1}\right)$ & 146,79 & 158,80 & 146,40 & 148,96 \\
\hline Variância $\left(\mathrm{R} \$^{2} \mathrm{ha}^{-1} \mathrm{ano}^{-1}\right)$ & $21.547,5$ & $25.218,7$ & $21.431,8$ & $22.188,2$ \\
\hline Desvio absoluto ( $\left.\mathrm{R} \$ \mathrm{ha}^{-1} \mathrm{ano}^{-1}\right)$ & 119,95 & 34,56 & 120,19 & 122,20 \\
\hline Coeficiente de variação (\%) & 33,54 & & 55,15 & 49,40 \\
\hline \multicolumn{5}{|l|}{ Tarifa Convencional } \\
\hline Probabilidade de BLA >0 (\%) & 0,00 & 0,00 & 0,00 & 0,00 \\
\hline Relação B/C & 0,48 & 0,48 & 0,59 & 0,56 \\
\hline Valor esperado de BLA $\left(\mathrm{R} \$\right.$ ha $\left.^{-1} \mathrm{ano}^{-1}\right)$ & $-772,29$ & $-837,80$ & $-516,45$ & $-580,98$ \\
\hline Desvio padrão $\left(\mathrm{R} \$\right.$ ha $\left.^{-1} \mathrm{ano}^{-1}\right)$ & 146,79 & 158,80 & 146,40 & 148,96 \\
\hline Variância $\left(\mathrm{R} \$^{2} \mathrm{ha}^{-1} \mathrm{ano}^{-1}\right)$ & $21.547,5$ & $25.218,7$ & $21.431,8$ & $22.188,2$ \\
\hline Desvio absoluto ( $\mathrm{R} \$ \mathrm{ha}^{-1} \mathrm{ano}^{-1}$ ) & 119,95 & 129,76 & 120,19 & 122,20 \\
\hline Coeficiente de variação (\%) & 19,01 & 18,95 & 28,35 & 25,64 \\
\hline
\end{tabular}


Tabela 34. Índices econômicos obtidos para irrigação da cana-de-açúcar para o pivô central utilizando óleo diesel, para os anos estudados

\begin{tabular}{|c|c|c|c|c|}
\hline Índices econômicos & 2001 & 2002 & 2003 & 2004 \\
\hline Probabilidade de BLA >0 (\%) & 0,00 & 0,00 & 0,00 & 0,00 \\
\hline Relação B/C & 0,42 & 0,42 & 0,52 & 0,50 \\
\hline Valor esperado de BLA $\left(\mathrm{R} \$ \mathrm{ha}^{-1} \mathrm{ano}^{-1}\right)$ & $-992,93$ & $-1.054,43$ & $-679,79$ & $-736,42$ \\
\hline Desvio padrão ( $\left.\mathrm{R} \$ \mathrm{ha}^{-1} \mathrm{ano}^{-1}\right)$ & 147,25 & 158,13 & 148,02 & 150,38 \\
\hline Variância $\left(\mathrm{R} \$^{2} \mathrm{ha}^{-1} \mathrm{ano}^{-1}\right)$ & 21.683,9 & $25.004,2$ & $21.909,6$ & $22.614,2$ \\
\hline Desvio absoluto ( $\mathrm{R} \$ \mathrm{ha}^{-1} \mathrm{ano}^{-1}$ ) & 120,26 & 129,36 & 121,33 & 123,20 \\
\hline Coeficiente de variação (\%) & 14,78 & 15,00 & 21,77 & 20,42 \\
\hline
\end{tabular}

Tabela 35. Índices econômicos obtidos para irrigação da cana-de-açúcar para o deslocamento linear utilizando óleo diesel, para os anos estudados

\begin{tabular}{|c|c|c|c|c|}
\hline Índices econômicos & 2001 & 2002 & 2003 & 2004 \\
\hline Probabilidade de BLA >0 (\%) & 0,00 & 0,00 & 0,00 & 0,00 \\
\hline Relação B/C & 0,41 & 0,41 & 0,50 & 0,48 \\
\hline Valor esperado de BLA ( $\left.\mathrm{R} \$ \mathrm{ha}^{-1} \mathrm{ano}^{-1}\right)$ & $-1.032,27$ & $-1.088,46$ & $-740,27$ & $-794,66$ \\
\hline Desvio padrão ( $\left.\mathrm{R} \$ \mathrm{ha}^{-1} \mathrm{ano}^{-1}\right)$ & 148,91 & 159,65 & 149,82 & 152,08 \\
\hline Variância $\left(\mathrm{R} \$^{2} \mathrm{ha}^{-1} \mathrm{ano}^{-1}\right)$ & $22.173,3$ & $25.487,2$ & $22.445,4$ & 23.126,9 \\
\hline Desvio absoluto ( $\mathrm{R} \$ \mathrm{ha}^{-1} \mathrm{ano}^{-1}$ ) & 121,45 & 130,41 & 122,57 & 124,41 \\
\hline Coeficiente de variação (\%) & 14,42 & 14,67 & 20,24 & 19,14 \\
\hline
\end{tabular}


Tabela 36. Índices econômicos obtidos para irrigação da cana-de-açúcar, para o autopropelido utilizando óleo diesel, para os anos estudados

\begin{tabular}{|c|c|c|c|c|}
\hline Índices econômicos & 2001 & 2002 & 2003 & 2004 \\
\hline Probabilidade de BLA >0 (\%) & 0,00 & 0,00 & 0,00 & 0,00 \\
\hline Relação B/C & 0,22 & 0,22 & 0,28 & 0,27 \\
\hline Valor esperado de BLA $\left(\mathrm{R} \$ \mathrm{ha}^{-1} \mathrm{ano}^{-1}\right)$ & $-2.563,54$ & $-2.780,46$ & $-1.859,42$ & $-2.006,71$ \\
\hline Desvio padrão $\left(\mathrm{R} \$\right.$ ha $\left.^{-1} \mathrm{ano}^{-1}\right)$ & 146,79 & 158,80 & 146,40 & 148,96 \\
\hline Variância $\left(\mathrm{R} \$^{2} \mathrm{ha}^{-1} \mathrm{ano}^{-1}\right)$ & $21.547,5$ & $25.218,7$ & $21.431,8$ & $22.188,2$ \\
\hline Desvio absoluto ( $\mathrm{R} \$ \mathrm{ha}^{-1} \mathrm{ano}^{-1}$ ) & 119,95 & 129,76 & 120,19 & 122,20 \\
\hline Coeficiente de variação (\%) & 5,73 & 5,71 & 7,87 & 7,42 \\
\hline
\end{tabular}


Tabela 37. Índices econômicos obtidos para irrigação do tomate industrial para o pivô central utilizando energia elétrica para os anos estudados

\begin{tabular}{|c|c|c|c|c|}
\hline Índices econômicos & 2001 & 2002 & 2003 & 2004 \\
\hline \multicolumn{5}{|l|}{ Tarifa Verde } \\
\hline Probabilidade de BLA >0 (\%) & 99,99 & 99,99 & 99,98 & 99,98 \\
\hline Relação B/C & 3,26 & 3,22 & 3,50 & 2,95 \\
\hline Valor esperado de BLA $\left(\mathrm{R} \$\right.$ ha $^{-1}$ ano $\left.^{-1}\right)$ & $1.442,74$ & $1.363,46$ & $1.565,76$ & $1.229,87$ \\
\hline Desvio padrão ( $\mathrm{R} \$$ ha $\left.^{-1} \mathrm{ano}^{-1}\right)$ & 375,16 & 357,22 & 394,69 & 336,50 \\
\hline Variância $\left(\mathrm{R} \$^{2} \mathrm{ha}^{-1} \mathrm{ano}^{-1}\right)$ & $140.747,9$ & $127.604,1$ & $155.783,0$ & $113.247,9$ \\
\hline Desvio absoluto ( $\mathrm{R} \$ \mathrm{ha}^{-1} \mathrm{ano}^{-1}$ ) & 306,11 & 291,39 & 321,84 & 274,68 \\
\hline Coeficiente de variação (\%) & 26,00 & 26,20 & 25,21 & 27,36 \\
\hline \multicolumn{5}{|l|}{ Tarifa Azul } \\
\hline Probabilidade de BLA >0 (\%) & 99,99 & 99,99 & 99,98 & 99,98 \\
\hline Relação B/C & 3,27 & 3,22 & 3,50 & 2,95 \\
\hline Valor esperado de BLA $\left(\mathrm{R} \$\right.$ ha $\left.^{-1} \mathrm{ano}^{-1}\right)$ & $1.442,9$ & $1.363,07$ & $1.565,73$ & $1.229,83$ \\
\hline Desvio padrão ( $\left.\mathrm{R} \$ \mathrm{ha}^{-1} \mathrm{ano}^{-1}\right)$ & 375,16 & 357,22 & 394,69 & 336,50 \\
\hline Variância $\left(\mathrm{R} \$^{2} \mathrm{ha}^{-1} \mathrm{ano}^{-1}\right)$ & $140.747,9$ & $127.604,1$ & $155.783,0$ & $113.247,9$ \\
\hline Desvio absoluto ( $\mathrm{R} \$ \mathrm{ha}^{-1} \mathrm{ano}^{-1}$ ) & 306,11 & 291,39 & 321,84 & 274,68 \\
\hline Coeficiente de variação (\%) & 25,98 & 26,20 & 25,21 & 27,36 \\
\hline \multicolumn{5}{|l|}{ Tarifa Convencional } \\
\hline Probabilidade de BLA >0 (\%) & 99,98 & 99,98 & 99,99 & 99,97 \\
\hline Relação B/C & 3,05 & 3,02 & 3,28 & 2,75 \\
\hline Valor esperado de BLA $\left(\mathrm{R} \$\right.$ ha $\left.^{-1} \mathrm{ano}^{-1}\right)$ & $1.396,9$ & $1.323,42$ & $1.523,44$ & $1.184,38$ \\
\hline Desvio padrão ( $\mathrm{R} \$$ ha $^{-1} \mathrm{ano}^{-1}$ ) & 375,16 & 357,22 & 394,69 & 336,50 \\
\hline Variância $\left(\mathrm{R} \$^{2} \mathrm{ha}^{-1} \mathrm{ano}^{-1}\right)$ & $140.747,9$ & $127.604,1$ & $155.783,0$ & $113.247,9$ \\
\hline Desvio absoluto ( $\mathrm{R} \$$ ha $^{-1} \mathrm{ano}^{-1}$ ) & 306,11 & 291,39 & 321,84 & 274,68 \\
\hline Coeficiente de variação (\%) & 26,86 & 26,99 & 25,91 & 28,41 \\
\hline
\end{tabular}


Tabela 38. Índices econômicos obtidos para irrigação do tomate industrial para aspersão convencional utilizando energia elétrica, para os anos estudados

\begin{tabular}{|c|c|c|c|c|}
\hline Índices econômicos & 2001 & 2002 & 2003 & 2004 \\
\hline \multicolumn{5}{|l|}{ Tarifa Verde } \\
\hline Probabilidade de BLA >0 (\%) & 99,63 & 99,59 & 99,24 & 99,85 \\
\hline Relação B/C & 4,71 & 4,77 & 5,20 & 4,26 \\
\hline Valor esperado de BLA ( $\left.\mathrm{R} \$ \mathrm{ha}^{-1} \mathrm{ano}^{-1}\right)$ & $1.639,59$ & $1.566,27$ & $1.772,28$ & $1.427,22$ \\
\hline Desvio padrão ( $\mathrm{R} \$$ ha $\left.^{-1} \mathrm{ano}^{-1}\right)$ & 373,18 & 355,24 & 393,09 & 334,47 \\
\hline Variância $\left(\mathrm{R} \$^{2} \mathrm{ha}^{-1} \mathrm{ano}^{-1}\right)$ & $139.261,0$ & 126.192,1 & $154.517,8$ & $111.871,2$ \\
\hline Desvio absoluto ( $\left.\mathrm{R} \$ \mathrm{ha}^{-1} \mathrm{ano}^{-1}\right)$ & 304,03 & 289,48 & 320,31 & 272,6 \\
\hline Coeficiente de variação (\%) & 22,76 & 22,68 & 22,18 & 23,40 \\
\hline \multicolumn{5}{|l|}{ Tarifa Azul } \\
\hline Probabilidade de BLA >0 (\%) & 99,61 & 99,59 & 99,25 & 99,85 \\
\hline Relação B/C & 4,72 & 4,77 & 5,19 & 4,26 \\
\hline Valor esperado de BLA ( $\left.\mathrm{R} \$ \mathrm{ha}^{-1} \mathrm{ano}^{-1}\right)$ & $1.640,8$ & $1.566,23$ & $1.772,25$ & $1.427,17$ \\
\hline Desvio padrão ( $\left.\mathrm{R} \$ \mathrm{ha}^{-1} \mathrm{ano}^{-1}\right)$ & 373,18 & 355,24 & 393,09 & 334,47 \\
\hline Variância $\left(\mathrm{R} \$^{2} \mathrm{ha}^{-1} \mathrm{ano}^{-1}\right)$ & $139.261,0$ & $126.192,1$ & $154.517,8$ & $111.871,2$ \\
\hline Desvio absoluto ( $\left.\mathrm{R} \$ \mathrm{ha}^{-1} \mathrm{ano}^{-1}\right)$ & 304,03 & 289,48 & 320,31 & 272,60 \\
\hline Coeficiente de variação (\%) & 22,74 & 22,68 & 22,18 & 23,44 \\
\hline \multicolumn{5}{|l|}{ Tarifa Convencional } \\
\hline Probabilidade de BLA >0 (\%) & 99,88 & 99,85 & 99,68 & 99,96 \\
\hline Relação B/C & 4,14 & 4,24 & 4,60 & 3,75 \\
\hline Valor esperado de BLA ( $\left.\mathrm{R} \$ \mathrm{ha}^{-1} \mathrm{ano}^{-1}\right)$ & $1.579,75$ & $1.514,04$ & $1.717,48$ & $1.368,11$ \\
\hline Desvio padrão ( $\mathrm{R} \$ \mathrm{ha}^{-1} \mathrm{ano}^{-1}$ ) & 373,18 & 355,24 & 393,09 & 334,47 \\
\hline Variância $\left(\mathrm{R} \$^{2} \mathrm{ha}^{-1} \mathrm{ano}^{-1}\right)$ & $139.261,1$ & $126.192,1$ & $154.517,8$ & $111.871,2$ \\
\hline Desvio absoluto ( $\left.\mathrm{R} \$ \mathrm{ha}^{-1} \mathrm{ano}^{-1}\right)$ & 304,03 & 289,48 & 320,31 & 272,60 \\
\hline Coeficiente de variação (\%) & 23,62 & 23,43 & 22,89 & 24,45 \\
\hline
\end{tabular}


Tabela 39. Índices econômicos obtidos para irrigação do tomate industrial para o autopropelido utilizando energia elétrica, para os anos estudados

\begin{tabular}{|c|c|c|c|c|}
\hline Índices econômicos & 2001 & 2002 & 2003 & 2004 \\
\hline \multicolumn{5}{|l|}{ Tarifa Verde } \\
\hline Probabilidade de BLA >0 (\%) & 99,99 & 99,99 & 99,98 & 99,97 \\
\hline Relação B/C & 3,27 & 3,21 & 3,63 & 2,82 \\
\hline Valor esperado de BLA $\left(\mathrm{R} \$\right.$ ha $^{-1}$ ano $\left.^{-1}\right)$ & $1.444,93$ & $1.363,85$ & $1.589,22$ & $1.202,43$ \\
\hline Desvio padrão ( $\mathrm{R} \$$ ha $\left.^{-1} \mathrm{ano}^{-1}\right)$ & 373,76 & 355,93 & 393,70 & 335,13 \\
\hline Variância $\left(\mathrm{R} \$^{2} \mathrm{ha}^{-1} \mathrm{ano}^{-1}\right)$ & $139.699,4$ & $126.688,5$ & $155.003,6$ & $112.315,2$ \\
\hline Desvio absoluto ( $\mathrm{R} \$ \mathrm{ha}^{-1} \mathrm{ano}^{-1}$ ) & 304,61 & 290,24 & 320,89 & 273,31 \\
\hline Coeficiente de variação (\%) & 25,87 & 26,10 & 24,77 & 27,87 \\
\hline \multicolumn{5}{|l|}{ Tarifa Azul } \\
\hline Probabilidade de BLA >0 (\%) & 99,99 & 99,99 & 99,98 & 99,97 \\
\hline Relação B/C & 3,27 & 3,21 & 3,63 & 2,82 \\
\hline Valor esperado de BLA $\left(\mathrm{R} \$\right.$ ha $\left.^{-1} \mathrm{ano}^{-1}\right)$ & $1.444,99$ & $1.363,75$ & $1.589,14$ & $1.202,3$ \\
\hline Desvio padrão ( $\left.\mathrm{R} \$ \mathrm{ha}^{-1} \mathrm{ano}^{-1}\right)$ & 373,76 & 355,93 & 393,70 & 335,13 \\
\hline Variância $\left(\mathrm{R} \$^{2} \mathrm{ha}^{-1} \mathrm{ano}^{-1}\right)$ & $139.699,4$ & $126.688,5$ & $155.003,6$ & $112.315,2$ \\
\hline Desvio absoluto ( $\mathrm{R} \$ \mathrm{ha}^{-1} \mathrm{ano}^{-1}$ ) & 304,61 & 290,24 & 320,89 & 273,31 \\
\hline Coeficiente de variação (\%) & 25,88 & 26,10 & 24,77 & 27,87 \\
\hline \multicolumn{5}{|l|}{ Tarifa Convencional } \\
\hline Probabilidade de BLA >0 (\%) & 99,97 & 99,97 & 99,99 & 99,94 \\
\hline Relação B/C & 2,88 & 2,83 & 3,26 & 2,43 \\
\hline Valor esperado de BLA $\left(\mathrm{R} \$\right.$ ha $\left.^{-1} \mathrm{ano}^{-1}\right)$ & $1.359,18$ & $1.280,34$ & $1.520,2$ & $1.097,96$ \\
\hline Desvio padrão ( $\mathrm{R} \$$ ha $^{-1} \mathrm{ano}^{-1}$ ) & 373,76 & 355,93 & 393,70 & 335,13 \\
\hline Variância $\left(\mathrm{R} \$^{2} \mathrm{ha}^{-1} \mathrm{ano}^{-1}\right)$ & $139.699,4$ & $126.688,5$ & $155.003,6$ & $112.315,2$ \\
\hline Desvio absoluto ( $\mathrm{R} \$$ ha $^{-1} \mathrm{ano}^{-1}$ ) & 304,61 & 290,24 & 320,89 & 273,31 \\
\hline Coeficiente de variação (\%) & 27,50 & 27,80 & 25,90 & 30,52 \\
\hline
\end{tabular}


Tabela 40. Índices econômicos obtidos para irrigação do tomate industrial para o pivô central utilizando óleo diesel, para os anos estudados

\begin{tabular}{|c|c|c|c|c|}
\hline Índices econômicos & 2001 & 2002 & 2003 & 2004 \\
\hline Probabilidade de BLA >0 (\%) & 99,95 & 99,94 & 99,97 & 99,90 \\
\hline Relação B/C & 2,49 & 2,42 & 2,86 & 2,27 \\
\hline Valor esperado de BLA $\left(\mathrm{R} \$\right.$ ha $\left.^{-1} \mathrm{ano}^{-1}\right)$ & $1.245,03$ & $1.160,92$ & $1.425,96$ & $1.040,48$ \\
\hline Desvio padrão ( $\mathrm{R} \$$ ha $\left.^{-1} \mathrm{ano}^{-1}\right)$ & 375,16 & 357,22 & 394,69 & 336,5 \\
\hline Variância $\left(\mathrm{R} \$^{2} \mathrm{ha}^{-1} \mathrm{ano}^{-1}\right)$ & $140.747,9$ & $127.604,1$ & $155.783,0$ & $113.247,9$ \\
\hline Desvio absoluto ( $\mathrm{R} \$$ ha $^{-1} \mathrm{ano}^{-1}$ ) & 306,11 & 291,39 & 321,84 & 274,68 \\
\hline Coeficiente de variação (\%) & 30,13 & 30,77 & 27,61 & 32,34 \\
\hline
\end{tabular}

Tabela 41. Índices econômicos obtidos para irrigação do tomate industrial para aspersão convencional utilizando óleo diesel, para os anos estudados

\begin{tabular}{|c|c|c|c|c|}
\hline Índices econômicos & 2001 & 2002 & 2003 & 2004 \\
\hline Probabilidade de BLA >0 (\%) & 99,98 & 99,97 & 99,98 & 99,96 \\
\hline Relação B/C & 2,88 & 2,83 & 3,52 & 2,64 \\
\hline Valor esperado de BLA ( $\left.\mathrm{R} \$ \mathrm{ha}^{-1} \mathrm{ano}^{-1}\right)$ & $1.358,94$ & $1.281,78$ & $1.570,69$ & $1.158,15$ \\
\hline Desvio padrão ( $\left.\mathrm{R} \$ \mathrm{ha}^{-1} \mathrm{ano}^{-1}\right)$ & 373,18 & 355,24 & 393,09 & 334,47 \\
\hline Variância $\left(\mathrm{R} \$^{2} \mathrm{ha}^{-1} \mathrm{ano}^{-1}\right)$ & $139.261,0$ & $126.192,1$ & $154.517,8$ & $111.871,2$ \\
\hline Desvio absoluto ( $\mathrm{R} \$ \mathrm{ha}^{-1} \mathrm{ano}^{-1}$ ) & 304,03 & 289,48 & 320,31 & 272,6 \\
\hline Coeficiente de variação (\%) & 27,46 & 27,71 & 25,03 & 28,88 \\
\hline
\end{tabular}


Tabela 42. Índices econômicos obtidos para irrigação do tomate industrial, para o autopropelido utilizando óleo diesel, para os anos estudados

\begin{tabular}{|c|c|c|c|c|}
\hline Índices econômicos & 2001 & 2002 & 2003 & 2004 \\
\hline Probabilidade de BLA >0 (\%) & 98,75 & 98,57 & 99,76 & 97,28 \\
\hline Relação B/C & 1,67 & 1,65 & 2,03 & 1,53 \\
\hline Valor esperado de BLA $\left(\mathrm{R} \$ \mathrm{ha}^{-1} \mathrm{ano}^{-1}\right)$ & 873,53 & 779,54 & $1.112,43$ & 644,37 \\
\hline Desvio padrão ( $\left.\mathrm{R} \$ \mathrm{ha}^{-1} \mathrm{ano}^{-1}\right)$ & 373,76 & 355,93 & 393,70 & 335,13 \\
\hline Variância $\left(\mathrm{R} \$^{2} \mathrm{ha}^{-1} \mathrm{ano}^{-1}\right)$ & 139.699,3 & $126.688,5$ & $155.003,6$ & $112.315,2$ \\
\hline Desvio absoluto ( $\left.\mathrm{R} \$ \mathrm{ha}^{-1} \mathrm{ano}^{-1}\right)$ & 304,61 & 290,24 & 320,89 & 273,31 \\
\hline Coeficiente de variação (\%) & 44,63 & 45,66 & 35,39 & 52,01 \\
\hline
\end{tabular}


Anexo C

Análise de sensibilidade para os sistemas de irrigação por ano e por cultura 
Tabela 43. Análise de sensibilidade do benefício líquido, com variação de $-20 \%$ e $+20 \%$, para pivô central em cana-de-açúcar, anos de 2001, 2002, 2003 e 2004

\begin{tabular}{|c|c|c|c|c|c|c|c|c|}
\hline \multirow{2}{*}{ Fatores econômicos } & \multicolumn{2}{|c|}{2001} & \multicolumn{2}{|c|}{2002} & \multicolumn{2}{|c|}{2003} & \multicolumn{2}{|c|}{2004} \\
\hline & $-20 \%$ & $+20 \%$ & $-20 \%$ & $+20 \%$ & $-20 \%$ & $+20 \%$ & $-20 \%$ & $+20 \%$ \\
\hline $\begin{array}{l}\text { Vida útil do sistema de } \\
\text { irrigação (anos) }\end{array}$ & $-10,70$ & 6,92 & $-10,97$ & 7,15 & $-14,05$ & 9,13 & $-13,70$ & 8,92 \\
\hline Taxa de juros (\% a.a.) & 5,20 & $-5,42$ & 5,30 & $-5,53$ & 6,82 & $-7,05$ & 6,67 & $-6,93$ \\
\hline $\begin{array}{c}\text { Taxa de manutenção } \\
\text { (\%) }\end{array}$ & 6,57 & $-6,57$ & 6,73 & $-6,73$ & 8,59 & $-8,59$ & 8,38 & $-8,38$ \\
\hline $\begin{array}{l}\text { Valor de venda do } \\
\left.\text { produto ( } \mathrm{R} \$ \mathrm{Mg}^{-1}\right)\end{array}$ & $-74,65$ & 74,65 & $-83,18$ & 83,18 & $-101,1$ & 101,1 & $-100,2$ & 100,2 \\
\hline $\begin{array}{c}\text { Mão-de-obra } \\
\text { (horas ha }^{-1} \text { irrigação }^{-1} \text { ) }\end{array}$ & 0,73 & $-0,73$ & 0,80 & $-0,80$ & 0,69 & $-0,69$ & 0,85 & $-0,85$ \\
\hline Preço da água ( $\left.\mathrm{R} \$ \mathrm{~m}^{-3}\right)$ & 2,92 & $-2,92$ & 3,28 & $-3,28$ & 2,93 & $-2,93$ & 3,07 & $-3,07$ \\
\hline
\end{tabular}

Tabela 44. Análise de sensibilidade do benefício líquido, com variação de $-20 \%$ e $+20 \%$, para autopropelido em cana-de-açúcar, anos de 2001, 2002, 2003 e 2004

\begin{tabular}{|c|c|c|c|c|c|c|c|c|}
\hline \multirow{2}{*}{ Fatores econômicos } & \multicolumn{2}{|c|}{2001} & \multicolumn{2}{|c|}{2002} & \multicolumn{2}{|c|}{2003} & \multicolumn{2}{|c|}{2004} \\
\hline & $-20 \%$ & $+20 \%$ & $-20 \%$ & $+20 \%$ & $-20 \%$ & $+20 \%$ & $-20 \%$ & $+20 \%$ \\
\hline $\begin{array}{l}\text { Vida útil do sistema de } \\
\text { irrigação (anos) }\end{array}$ & $-5,33$ & 3,52 & $-5,00$ & 3,32 & $-7,70$ & 5,07 & $-6,98$ & 4,62 \\
\hline Taxa de juros (\% а.а.) & 1,63 & $-1,7$ & 1,50 & $-1,25$ & 2,33 & $-2,42$ & 2,10 & $-2,20$ \\
\hline $\begin{array}{c}\text { Taxa de manutenção } \\
\text { (\%) }\end{array}$ & 2,53 & $-2,53$ & 2,38 & $-2,38$ & 3,65 & $-3,65$ & 3,35 & $-3,35$ \\
\hline $\begin{array}{l}\text { Valor de venda do } \\
\text { produto }\left(\mathrm{R} \$ \mathrm{Mg}^{-1}\right)\end{array}$ & $-36,20$ & 36,20 & $-36,75$ & 36,75 & $-53,97$ & 53,97 & $-49,65$ & 49,65 \\
\hline $\begin{array}{c}\text { Mão-de-obra } \\
\text { (horas ha }^{-1} \text { irrigação }^{-1} \text { ) }\end{array}$ & 0,75 & $-0,75$ & 0,75 & $-0,75$ & 0,78 & $-0,78$ & 0,83 & $-0,83$ \\
\hline Preço da água ( $\left.\mathrm{R} \$ \mathrm{~m}^{-3}\right)$ & 1,73 & $-1,73$ & 1,77 & $-1,77$ & 1,93 & $-1,93$ & 1,90 & $-1,90$ \\
\hline
\end{tabular}


Tabela 45. Análise de sensibilidade do benefício líquido, com variação de $-20 \%$ e $+20 \%$, para deslocamento linear em cana-de-açúcar, anos de 2001, 2002, 2003 e 2004

\begin{tabular}{|c|c|c|c|c|c|c|c|c|}
\hline \multirow{2}{*}{ Fatores econômicos } & \multicolumn{2}{|c|}{2001} & \multicolumn{2}{|c|}{2002} & \multicolumn{2}{|c|}{2003} & \multicolumn{2}{|c|}{2004} \\
\hline & $-20 \%$ & $+20 \%$ & $-20 \%$ & $+20 \%$ & $-20 \%$ & $+20 \%$ & $-20 \%$ & $+20 \%$ \\
\hline $\begin{array}{l}\text { Vida útil do sistema de } \\
\text { irrigação (anos) }\end{array}$ & $-9,60$ & 6,23 & $-9,72$ & 6,32 & $-11,60$ & 7,52 & $-11,60$ & 7,52 \\
\hline Taxa de juros (\% а.a.) & 4,63 & $-12,83$ & 4,73 & $-4,92$ & 5,60 & $-5,85$ & 5,60 & $-5,85$ \\
\hline $\begin{array}{l}\text { Taxa de manutenção } \\
\text { (\%) }\end{array}$ & 7,08 & $-7,08$ & 7,17 & $-7,17$ & 8,52 & $-8,52$ & 8,52 & $-8,52$ \\
\hline $\begin{array}{l}\text { Valor de venda do } \\
\text { produto }\left(\mathrm{R} \$ \mathrm{Mg}^{-1}\right)\end{array}$ & $-57,63$ & 57,63 & $-63,22$ & 63,22 & $-72,62$ & 72,62 & $-72,62$ & 72,62 \\
\hline $\begin{array}{c}\text { Mão-de-obra } \\
\text { (horas ha }^{-1} \text { irrigação }^{-1} \text { ) }\end{array}$ & 0,98 & $-0,98$ & 1,12 & $-1,12$ & 1,03 & $-1,03$ & 1,03 & $-1,03$ \\
\hline Preço da água ( $\left.\mathrm{R} \$ \mathrm{~m}^{-3}\right)$ & 2,07 & $-2,07$ & 2,33 & $-2,33$ & 2,07 & $-2,07$ & 2,07 & $-2,07$ \\
\hline
\end{tabular}

Tabela 46. Análise de sensibilidade do benefício líquido, com variação de $-20 \%$ e $+20 \%$, para pivô central em tomate industrial, anos de 2001, 2002, 2003 e 2004

\begin{tabular}{|c|c|c|c|c|c|c|c|c|}
\hline \multirow{2}{*}{ Fatores econômicos } & \multicolumn{2}{|c|}{2001} & \multicolumn{2}{|c|}{2002} & \multicolumn{2}{|c|}{2003} & \multicolumn{2}{|c|}{2004} \\
\hline & $-20 \%$ & $+20 \%$ & $-20 \%$ & $+20 \%$ & $-20 \%$ & $+20 \%$ & $-20 \%$ & $+20 \%$ \\
\hline $\begin{array}{l}\text { Vida útil do sistema de } \\
\text { irrigação (anos) }\end{array}$ & $-2,60$ & 1,70 & $-3,27$ & 2,13 & $-2,92$ & 1,92 & $-3,62$ & 2,37 \\
\hline Taxa de juros (\% а.а.) & 1,25 & $-1,32$ & 1,60 & $-1,63$ & 1,45 & $-1,45$ & 1,77 & $-1,80$ \\
\hline $\begin{array}{c}\text { Taxa de manutenção } \\
(\%)\end{array}$ & 1,60 & $-1,60$ & 2,00 & $-2,00$ & 1,82 & $-1,82$ & 2,25 & $-2,25$ \\
\hline $\begin{array}{l}\text { Valor de venda do } \\
\text { produto }\left(\mathrm{R} \$ \mathrm{Mg}^{-1}\right)\end{array}$ & $-63,28$ & 63,28 & $-67,22$ & 67,22 & $-64,35$ & 64,35 & $-69,95$ & 69,95 \\
\hline $\begin{array}{c}\text { Mão-de-obra } \\
\text { (horas ha }^{-1} \text { irrigação }^{-1} \text { ) }\end{array}$ & 0,10 & $-0,10$ & 0,10 & $-0,10$ & 0,10 & $-0,10$ & 0,10 & $-0,10$ \\
\hline Preço da água ( $\left.\mathrm{R} \$ \mathrm{~m}^{-3}\right)$ & 0,20 & $-0,20$ & 0,25 & $-0,25$ & 0,20 & $-0,20$ & 0,30 & $-0,30$ \\
\hline
\end{tabular}


Tabela 47. Análise de sensibilidade do benefício líquido, com variação de $-20 \%$ e $+20 \%$, para aspersão convencional em tomate industrial, anos de 2001, 2002, 2003 e 2004

\begin{tabular}{|c|c|c|c|c|c|c|c|c|}
\hline \multirow{2}{*}{ Fatores econômicos } & \multicolumn{2}{|c|}{2001} & \multicolumn{2}{|c|}{2002} & \multicolumn{2}{|c|}{2003} & \multicolumn{2}{|c|}{2004} \\
\hline & $-20 \%$ & $+20 \%$ & $-20 \%$ & $+20 \%$ & $-20 \%$ & $+20 \%$ & $-20 \%$ & $+20 \%$ \\
\hline $\begin{array}{l}\text { Vida útil do sistema de } \\
\text { irrigação (anos) }\end{array}$ & $-1,52$ & 1,02 & $-1,92$ & 1,27 & $-1,72$ & 1,15 & $-2,12$ & 1,37 \\
\hline Taxa de juros (\% а.а.) & 0,57 & $-0,60$ & 0,72 & $-0,75$ & 0,65 & $-0,65$ & 0,75 & $-0,82$ \\
\hline $\begin{array}{c}\text { Taxa de manutenção } \\
\text { (\%) }\end{array}$ & 0,37 & $-0,37$ & 0,45 & $-0,45$ & 0,40 & $-0,40$ & 0,48 & $-0,48$ \\
\hline $\begin{array}{l}\text { Valor de venda do } \\
\text { produto }\left(\mathrm{R} \$ \mathrm{Mg}^{-1}\right)\end{array}$ & $-59,10$ & 59,10 & $-61,48$ & 61,48 & $-58,87$ & 58,87 & $-63,45$ & 63,45 \\
\hline $\begin{array}{c}\text { Mão-de-obra } \\
\text { (horas ha }^{-1} \text { irrigação }^{-1} \text { ) }\end{array}$ & 0,25 & $-0,25$ & 0,30 & $-0,30$ & 0,20 & $-0,20$ & 0,30 & $-0,30$ \\
\hline Preço da água ( $\left.\mathrm{R} \$ \mathrm{~m}^{-3}\right)$ & 0,20 & $-0,20$ & 0,25 & $-0,25$ & 0,20 & $-0,20$ & 0,30 & $-0,30$ \\
\hline
\end{tabular}

Tabela 48. Análise de sensibilidade do benefício líquido, com variação de $-20 \%$ e $+20 \%$, para autopropelido em tomate industrial, anos de 2001, 2002, 2003 e 2004

\begin{tabular}{|c|c|c|c|c|c|c|c|c|}
\hline \multirow{2}{*}{ Fatores econômicos } & \multicolumn{2}{|c|}{2001} & \multicolumn{2}{|c|}{2002} & \multicolumn{2}{|c|}{2003} & \multicolumn{2}{|c|}{2004} \\
\hline & $-20 \%$ & $+20 \%$ & $-20 \%$ & $+20 \%$ & $-20 \%$ & $+20 \%$ & $-20 \%$ & $+20 \%$ \\
\hline $\begin{array}{l}\text { Vida útil do sistema de } \\
\text { irrigação (anos) }\end{array}$ & $-3,08$ & 2,07 & $-4,03$ & 2,37 & $-3,42$ & 2,27 & $-4,70$ & 3,08 \\
\hline Taxa de juros (\% а.а.) & 0,95 & $-0,42$ & 1,25 & $-1,10$ & 1,05 & $-0,75$ & 1,42 & $-1,47$ \\
\hline $\begin{array}{c}\text { Taxa de manutenção } \\
\text { (\%) }\end{array}$ & 1,47 & $-1,47$ & 1,97 & $-1,97$ & 1,65 & $-1,65$ & 2,27 & $-2,27$ \\
\hline $\begin{array}{l}\text { Valor de venda do } \\
\text { produto }\left(\mathrm{R} \$ \mathrm{Mg}^{-1}\right)\end{array}$ & $-73,50$ & 73,50 & $-81,37$ & 81,37 & $-72,50$ & 72,50 & $-88,17$ & 88,17 \\
\hline $\begin{array}{c}\text { Mão-de-obra } \\
\text { (horas ha-1 }^{-1} \text { irrigação }^{-1} \text { ) }\end{array}$ & 0,10 & $-0,10$ & 0,15 & $-0,15$ & 0,10 & $-0,10$ & 0,15 & $-0,15$ \\
\hline Preço da água ( $\left.\mathrm{R} \$ \mathrm{~m}^{-3}\right)$ & 0,32 & $-0,32$ & 0,40 & $-0,40$ & 0,25 & $-0,25$ & 0,42 & $-0,42$ \\
\hline
\end{tabular}




\section{REFERÊNCIAS BIBLIOGRÁFICAS}

AGÊNCIA NACIONAL DE ENERGIA ELÉTRICA. htpp://aneel.gov.br (08 jun. 2004).

ALBERTON, A. Uma metodologia para auxiliar no gerenciamento de riscos e na seleção de alternativas de investimentos em segurança. Florianópolis, 1996. Dissertação (Mestrado) - Universidade Federal de Santa Catarina. http://www.eps.ufsc.br/disserta96/anete/index/indx_ane.htm (20 mar. 2004).

ALFONSI, R.R.; BRUNINI, O.; CAMARGO, M.B.P.; PEZZOPANE, J.R.M. Disponibilidade hídrica no solo para a cultura do milho no estado de São Paulo, em função de épocas de semeadura e cultivares. Bragantia, v.57, n.1, p.127-133, 1998.

ALVES JÚNIOR, J.; FIGUEREDO JÚNIOR, L.G.M.; COELHO, R.D.; ZOCOLER, J.L. Quanto custa a energia na irrigação. In: FNP CONSULTORIA \& COMÉRCIO. AGRIANUAL 2004: anuário estatístico da agricultura brasileira. São Paulo, 2004. p.19-22.

ANDRADE JÚNIOR, A.S.; FRIZZONE, J.A.; BASTOS, E.A.; CARDOSO, M.J.; RODRIGUES, B.H.N. Estratégias ótimas de irrigação para a cultura da melancia. Pesquisa Agropecuária Brasileira, v.36, n.2, p.301-305, fev. 2001. 
ARAÚJO, L.A. Fronteira eficiente econômica sob condições de risco: uma análise da convergência econômica entre empresas agrícolas do Sul de Santa Catarina. Piracicaba, 1997. 150p. Dissertação (Mestrado) - Escola Superior de Agricultura “Luiz de Queiroz” ESALQ/Universidade de São Paulo.

ARRUDA, F.B.; GRANDE, M.A. Fator de resposta da produção do cafeeiro ao déficit hídrico em Campinas. Bragantia, v.62, n.1, p.139-145, 2003.

ASCOUGH II, J.C.; HOAG, D.L.; FRASIER, W.M.; McMASTER, G.S. Computer use in agriculture: an analysis of great plains producers. Computers and Eletronics in Agriculture, v.23, p.189-204, 1999.

ASSIS, F.N.; ARRUDA, H.V.; PEREIRA, A.R. Aplicações de estatística à climatologia: teoria e prática. Pelotas: Editora Universitária/UFPel, 1996. 161p.

AZEVEDO FILHO, A.J.B.V. Análise econômica de projetos: “software” para situações deterministas e de risco envolvendo simulação. Piracicaba, 1988. 127p. Dissertação (Mestrado) - Escola Superior de Agricultura “Luiz de Queiroz”, Universidade de São Paulo.

BALSALOBRE, M.A.A.; SANTOS, P.M.; MAYA, F.L.A.; PENATI, M.A.; CORSI, M. Pastagens irrigadas. In: SIMPÓSIO SOBRE MANEJO DE PASTAGEM,20., Piracicaba, 2003. Produção animal em pastagens: situação atual e perspectivas. Piracicaba: FEALQ, 2003. p.265-296.

BALTRA, A.O.C. Utilização da informática na irrigação. ITEM: Irrigação e Tecnologia Moderna, n.28, p.13-15, mar. 1987. 
BASTOS, E.A.; FOLEGATTI, M.V.; ANDRADE JUNIOR, A.S.; CARDOSO, M.J.; FARIA, R.T. Manejo econômico da irrigação de feijão-caupi via modelo de simulação. IRRIGA, v.5, n.2, p.84-98, 2000.

BAUTISTA, E.A.L. A distribuição generalizada de valores extremos no estudo da velocidade máxima do vento em Piracicaba, SP. Piracicaba, 2002. 47p. Dissertação (Mestrado) - Escola Superior de Agricultura “Luiz de Queiroz”, Universidade de São Paulo.

BLANCO, F.F.; MACHADO, C.C; COELHO, R.D.; FOLEGATTI, M.V. Viabilidade econômica da irrigação da manga para o Estado de São Paulo. Revista Brasileira de Engenharia Agrícola e Ambiental, v.8, n.1, p.153-159, 2004.

BISSERA, J.V. Rentabilidade da irrigação publica no nordeste, sob condições de risco o caso do perímetro Morada Nova. Revista de Economia e Sociologia Rural, v.32, n.3, p.289-303, jul./set. 1994.

BONOMO, R.; MANTOVANI, E.C.; CAIXETA, G.Z.T. Comparação de custos para diferentes sistemas de irrigação empregados na cafeicultura irrigada em áreas de cerrado de Minas Gerais. (compact disc). In: CONGRESSO BRASILEIRO DE ENGENHARIA AGRÍCOLA, 28., Pelotas, 1999. Anais Pelotas: UFPel, 1999.

BRUNELLI, G.M. Simulação do custo de produção de laranja no Estado de São Paulo. Piracicaba, 1990. 99p. Dissertação (Mestrado) - Escola Superior de Agricultura “Luiz de Queiroz”, Universidade de São Paulo.

CAMPANA, S. Racionalização do uso de energia elétrica em sistemas de irrigação tipos pivô central e aspersão convencional. Viçosa, 2000. 108p. Dissertação (Mestrado) - Universidade Federal de Viçosa. 
CAMPOS, H. Estatística experimental não-paramétrica. 4.ed. Piracicaba: FEALQ, 1983. 349p.

CASTRO, M.C.; FARAI, M.A.; SILVA, A.M. Sistema computacional para a determinação da lâmina ótima econômica em irrigação pressurizada. Revista Brasileira de Engenharia Agrícola e Ambiental, v.6, n.2, p.372-378, 2002.

CHRISTOFIDIS, D. Irrigação, a fronteira hídrica na produção de alimentos. ITEM: Irrigação e Tecnologia Moderna, n.54, p.46-55, 2002.

CLARK, E.; JACOBSON, K.; OLSON, D.C. Avaliação econômica e financeira de projetos de irrigação. Brasília: Ministério da Integração Nacional/Secretaria da Irrigação, 1993. (Manual de irrigação, 3).

COMPANHIA DE ABASTECIMENTO E ARMAZÉNS GERAIS DO ESTADO DE PERNAMBUCO. Comparativo de preços (mais comum) em nível de atacado registrado na Ceasa. http://www.ceagepe.com.br/compara.htm (23 ago. 2004).

COMPANHIA PAULISTA DE FORÇA E LUZ. Tarifas para o fornecimento de energia elétrica. http://www.cplfl.com.br/piratininga/tarifa_27102003.htm (16 nov. 2004).

DIÁRIO OFICIAL Resolução $n^{0} 540$ de $1^{0}$ de outubro de 2002. Diário Oficial, seção 1, p.81, v.139, n.191, 02 de outubro de 2002.

DIAS, C.T.S. Planejamento de uma fazenda em condições de risco: programação linear e simulação multidimensional. Piracicaba, 1996. 100p. Tese (Doutorado) - Escola Superior de Agricultura “Luiz de Queiroz” Universidade de São Paulo. 
DOORENBOS, J.; KASSAM, A.H. Efeito da água no rendimento das culturas. 2.ed. Trad. de H.R. Gheyi; A.A. Sousa; F.A.V. Damasceno e J.F. Medeiros. Campina Grande: UFPB, 2000. 221p. (Estudos FAO: Irrigação e Drenagem, 33).

DOORENBOS, J.; PRUITT, W.O. Guidelines for predicting crop water requirements. Rome: FAO, 1984. (FAO Irrigation and Drainage Paper, 24).

FAVETA, G.M. Estudo econômico do sistema de adução em equipamentos de irrigação do tipo pivô central. Piracicaba, 1998. 110p. Tese (Doutorado) - Escola Superior de Agricultura “Luiz de Queiroz”, Universidade de São Paulo.

FARIA, R.A.; SOARES, A.A.; SEDIYAMA, G.C.; RIBEIRO, C.A.A.S. Economia de água e energia em projetos de irrigação suplementar no Estado de Minas Gerais. Revista Brasileira de Engenharia Agrícola e Ambiental, v.6, n.2, p.189-194, 2002.

FARIA, R.T.; CARAMORI, P.H.; CHIBANA, E.Y.; SOUZA BRITO, L.R. Clima: programa computacional para organização e análise de dados meteorológicos. Engenharia Agrícola, v.23, n.2, p.372-387, maio/ago. 2003.

FNP CONSULTORIA \& COMÉRCIO. AGRIANUAL 2005: Anuário da agricultura brasileira. São Paulo, 2005. 521p.

FRANKE, A.E.; DORFMAN, R. Viabilidade econômica da irrigação, sob condições de risco, em regiões de clima subtropical. I. cultura do milho. Pesquisa Agropecuária Brasileira, v.33, n.12, p.2003-2013, dez. 1998.

FRANKE, A.E.; DORFMAN, R. Necessidades de irrigação suplementar em soja nas condições edafoclimáticas do Planalto Médio e Missões, RS. Pesquisa Agropecuária Brasileira, v.35, n.8, p.1675-1683, ago. 2000. 
FREITAS, A.J. Gestão de recursos hídricos. In: SILVA, D.D.; PRUSKI, F.F.(Ed.) Gestão de recursos hídricos: aspectos legais, econômicos, administrativos e sociais. Brasília: Secretaria de Recursos hídricos; Viçosa: Universidade Federal de Viçosa; Porto Alegre: Associação Brasileira de Recursos Hídricos, 2000. cap.1 p.1-120.

FREITAS, P.S.L.; MANTOVANI, E.C.; REZENDE, R.; GONÇALVES, A.C.A.; BERTONHA, A. Análise econômica de lâminas de água e de doses de nitrogênio, na cultura do milho, Zea mays L., utilizando o modelo CERES-Maize. Acta Scientiarum, v.23, n.5, p.1139-1147, 2001.

FRIZZONE, J.A. Planejamento da irrigação uma abordagem às decisões de investimento. Piracicaba: ESALQ, 1999. 110p.

FRIZZONE, J.A. Análise de decisão econômica em irrigação. Piracicaba: ESALQ, 2005. 371p.

FRIZZONE, J.A.; SILVEIRA, S.F.R. Análise econômica de projetos hidroagrícolas. In: SILVA, D.D.; PRUSKI, F.F. (Ed.). Gestão de recursos hídricos: aspectos legais, econômicos, administrativos e sociais. Brasília: Secretaria de Recursos hídricos; Viçosa: Universidade Federal de Viçosa; Porto Alegre: Associação Brasileira de Recursos Hídricos, 2000. cap.5 p. 449-617.

FRIZZONE, J.A.; BOTREL, T.A.; FREITAS, H.A.C. Análise comparativa dos custos de irrigação por pivô-central, em culturas de feijão, utilizando energia elétrica e óleo diesel. Engenharia Rural, v.5, n.1, p.34-53, jul. 1994.

FRIZZONE, J.A.; COELHO, R.D.; DOURADO-NETO, D.; SOLIANI, R. Linear programming model to optimize the water resource use in irrigation projects: an application to the Senator Nilo Coelho project. Scientia Agricola, v.54, n. especial, p.136-148, jun. 1997. 
FRIZZONE, J.A.; MATIOLI, C.S.; REZENDE, R.; GONÇALVES, A.C.A. Viabilidade econômica da irrigação suplementar da cana-de-açúcar, Saccharum spp., para a região Norte do Estado de São Paulo. Acta Scientiarum, v.23, n.5, p.1131-1137, 2001.

GARCIA, J.C.; RUAS, D.G.G. Seleção de sistemas de produção para milho em condições de risco. Revista de Economia Rural, v.19, n.4, p.585-595, out./dez. 1981.

GENTIL, L.V. Pivot central para empresários agrícolas. Brasília: Universidade de Brasília, 2000. 81p.

GOHRING, T.R.; WALLENDER, W.W. Economics of sprinkler irrigation systems. Transaction of ASAE, v.30, n.4, p.1083-1089, Jul./Aug. 1987.

GÓMEZ-LIMÓN, J.A.; ARRIAZA, M.; RIESGO, L. An MCDM analysis of agricultural risk aversion. European Journal of Operational Research, v.151, n.3, p.569-585, Dec. 2003.

GOMIDE, R.L. Determinação e análise da uniformidade de distribuição da água no sistema de irrigação por aspersão. Viçosa, 1979. 87p. Dissertação (Mestrado) Universidade Federal de Viçosa.

HATCH, L.; HARDY JUNIOR, W.E.; ROCHESTER, E.W; JOHNSON, G.C. Optimal irrigation pivot location on irregularly shaped fields. Southern Journal of Agricultural economics, p163-170, Dec. 1985.

HERNANDEZ, F.B.T.; LEMOS FILHO, M.A.F.; BUZETTI, S. Software hidrisa e o balanço hídrico de Ilha Solteira. Ilha Solteira: UNESP, 1995. 45p. (Série Irrigação, 1) 
HILLIER, F.S; LIEBERMAN, G.J. Introdução à pesquisa operacional. São Paulo: EDUSP, 1988. 805p.

INSTITUTO DE ECONOMIA AGRÍCOLA. Preços médios recebidos pelo produtor http://www.iea.sp.gov.br/out/ibcoiea.htm (23 ago. 2004a).

INSTITUTO DE ECONOMIA AGRÍCOLA. Variações dos preços diários recebidos pelos produtores. http://www.iea.sp.gov.br/out/ivarpre.htm (23 ago. 2004b).

IGLESIAS, E.; GARRIDO, A.; GÓMEZ-RAMOS, A. Evaluation of drought management in irrigated areas. Agricultural Economics, v.29, n.2, p.211-229, Oct. 2003.

JUST, R.E.; POPE, R.D. Agricultural risk analysis adequacy of models, data and issues. American Journal of Agricultural Economics, v.85, n.5, p.1249-1256, Dec. 2003.

KELLER, J.; BLIESNER, I.D. Sprinkler and trickle irrigation. New York: Van Nostrand Reinhold, 1990. 652p.

KIM, K.; CHAVAS, J.P. Technological change and risk management: an application to the economics of corn production. Agricultural Economics, v.29, n.2, p.125-142, 2003.

KROLL, A.C.P.S. Análise estatística de preços agrícolas do boi gordo. Piracicaba, 2001. 63p. Dissertação (Mestrado) - Escola Superior de Agricultura "Luiz de Queiroz”, Universidade de São Paulo.

LEMOS, J.J.S. Sustentabilidade e risco da agricultura do nordeste. Revista de Economia e Sociologia Rural, v.33, n.1, p.73-87, jan./mar. 1995. 
MANNOCCHI, F.; MECARELLI, P. Optimization analysis of deficit irrigation systems. Journal of Irrigation and Drainage Engineering, v.120, n.3, p.484-503, May/Jun. 1994.

MANZAN, R.J. Irrigação do tomate industrial. Informe Agropecuário, v.6, n.66, p.20-21, 1980.

MAROUELLI, W.A.; SILVA, W.L.C. Seleção de sistemas de irrigação para hortaliças. Brasília: EMBRAPA, 1998. 16p. (Circular Técnica da Embrapa Hortaliças, 11).

MARQUES, P.A.A.; COELHO, R.D. Estudo da viabilidade econômica da pupunha (Bactris Gasipaes H.B.K) para Ilha Solteira - SP, Brasil. Ciência Rural, v.33, n.2, p.291-297, 2003.

MARQUES, P.A.A.; MARQUES, T.A.; COELHO, R.D. Programa pupunha: software para avaliação econômica da irrigação da pupunha. Revista Brasileira de Engenharia Agrícola, v.6, n.2, p.379-384, 2002.

MATIOLI, C.S.; FRIZZONE, J.A.; PERES, F.C. Irrigação suplementar de cana-deaçúcar: modelo de análise de decisão para a região Norte do Estado de São Paulo. STAB, v.17, n.2, p.42-45, nov./dez. 1998.

MATTOS, Z.P.B. Lucratividade e risco na produção de alimentos no Estado de São Paulo. Revista de Economia Rural, v.22, n.3, p.282-295, jul./set. 1984.

MAYA, F.L.A. Produtividade e viabilidade econômica da recria e engorda de bovinos em pastagens adubadas intensivamente com e sem o uso da irrigação. Piracicaba, 2003. 83p. Dissertação (Mestrado) - Escola Superior de Agricultura "Luiz de Queiroz”, Universidade de São Paulo. 
MEDEIROS, A.T. Estimativa de evapotranspiração a partir da equação de PenmanMonteith, de medidas lisimétricas e de equações empíricas, em Panaipaba, CE. Piracicaba, 2002. 103p. Tese (Doutorado) - Escola Superior de Agricultura "Luiz de Queiroz”, Universidade de São Paulo.

MEDEIROS, H.R. de. Avaliação de modelos matemáticos desenvolvidos para auxiliar a tomada de decisão em sistemas de produção de ruminantes em pastagens. Piracicaba, 2003. 98p. Tese (Doutorado) - Escola Superior de Agricultura “Luiz de Queiroz”, Universidade de São Paulo.

MELO, J.F. Custos da irrigação por aspersão em Minas Gerais. Viçosa, 1993. 147p. Dissertação (Mestrado) - Universidade Federal de Viçosa.

MENDES, J.T.G.; LARSON, D.W. Análise econômica de estratégias de comercialização da soja sob condições de risco. Revista de Economia Rural, v.20, n.2, p.175-192, abr./jun. 1982.

MOREIRA, H.J.C.; TORRES FILHO, D.R. S.A.A.C.I. sistema agroclimático para o acompanhamento das culturas irrigadas: manual prático para manejo de irrigação. Brasília: Secretaria Nacional de Irrigação, 1993. 90p.

MOREIRA, H.M. Combinação ótima de atividades e efeito de risco de preços nos planos de produção para as pequenas empresas rurais. Informe Agropecuário, v.7, n.83, p.79-86, 1981.

MOTA, F.S. da; VERONA, L.A.F.; MOTA, J.F.A.S.; NOVAES, L.E.S.M. microcomputador na meteorologia agrícola. São Paulo: Nobel, 1989. 137p. 
MOTA, R.S.; OLIVEIRA, R.A.; VASCONCELOS, C.F.; RAMOS, M.M.; BASTOS, L.N. Sistema multimídia para ensino e aprendizado de irrigação. (compact disc). In: CONGRESSO BRASILEIRO DE ENGENHARIA AGRÍCOLA, 30., Foz do Iguaçu, 2001. Anais Foz do Iguaçu: SBEA, 2001.

NAGAOKA, M.P.T.; MARTINS, C.M.; ESPERANCINI, M.T.S.; LEMOS, L.B. Avaliação econômica da cobrança da água para feijão irrigado por aspersão no município de Paranapanema - Estado de São Paulo. (compact disc). In: CONGRESSO BRASILEIRO DE ENGENHARIA AGRÍCOLA, 30., Foz do Iguaçu, 2001. Anais Foz do Iguaçu: SBEA, 2001.

NEVES, E.M. Análise econômica do investimento em condições de risco na cultura da borracha. Piracicaba, 1984. 171p. Tese (Livre docência) - Escola Superior de Agricultura “Luiz de Queiroz”, Universidade de São Paulo.

NORONHA, J.F. Eficiência econômica envolvendo risco: maximização de lucro versus maximização de utilidade na agricultura. Revista de Economia Rural, v.21, n.3, p.323-339, jul./set. 1983.

NORONHA, J.F.; LATAPIA, M.X.I.C. Custos de produção sob condições de risco no estado de São Paulo. Revista de Economia e Sociologia Rural, v.26, n.3, p.275287, jul./set. 1988.

OLIVEIRA, M.M. Informática na agricultura: a tecnologia a serviço do capital. Revista Brasileira de Tecnologia, v.16, n.5, p.37-40, set./out. 1985.

PARETON, K.A.; CUMMING, R.J. An application of Target-MOTAD programming to the analysis of downside business and financial risk on farms. Review of Marketing and Agricultural Economics, v.58, n.1, p.76-88, 1990. 
PAUDYAL, G.N.; GUPTA, A.D. Irrigation planning by multilevel optimization. Journal of Irrigation and Drainage Engineering, v.116, n.2, p.273-289, Mar./Apr. 1990.

PAZ, V.P.S; FRIZZONE, J.A.; BOTREL, T.A.; FOLEGATTI, M.V. Otimização do uso da água em sistemas de irrigação por aspersão. Revista Brasileira de Engenharia Agrícola e Ambiental, v.6, n.3, p.404-408, 2002.

PEREIRA, A.R.; ANGELOCCI, L.R.; SENTELHAS, P.C. Agrometeorologia: fundamentos e aplicações práticas. Guairá: Agropecuária, 2002. 478p.

PICKREN, R.L. A MOTAD of risk return relationships for farm planning decisions using center pivot irrigation. Auburn, 1986. 110p. Thesis (Master of Science) Faculty of Auburn University.

PINHEIRO, V.D.; COELHO, R.D. Análise econômica da irrigação de pastagens na região Centro-Oeste do Brasil. (compact disc). In: CONGRESSO BRASILEIRO DE ENGENHARIA AGRÍCOLA, 32., Goiânia, 2003. Anais Goiânia: SBEA, 2003.

PINHEIRO, V.D.; COELHO, R.D.; LOURENÇO, L.F. Viabilidade econômica da irrigação de pastagem de capim Tanzânia em diferentes regiões do Brasil. In: SIMPÓSIO SOBRE MANEJO DA PASTAGEM, 19., Piracicaba, 2002. Inovações tecnológicas no manejo de pastagens. Piracicaba: FEALQ, 2002. p.159-188.

PIZZOL, S.J.S. de. Comportamento dos cafeicultores perante o risco: uma análise de três sistemas de produção na região de Marilia, SP. Piracicaba, 2002. 150p. Dissertação (Mestrado) - Escola Superior de Agricultura "Luiz de Queiroz" Universidade de São Paulo. 
PORTO, V.H.F.; CRUZ, E.R.; INFELD, J.A. Metodologia para incorporação de risco em modelos de decisão usados na análise comparativa entre alternativas: o caso da cultura de arroz irrigado. Revista de Economia Rural, v.20, n.2, p.193-211, abr./jun. 1982.

PORTO, V.H.F.; CORDEIRO, D.S.; KICHEL, A.N.; VERNETTI, H.M. Análise econômica de sistemas de produção de sorgo sacarino sob condições de risco. Pesquisa Agropecuária Brasileira, v.20, n.4, p.395-401, 1985.

PORTUGUAL, A.D. A relação entre o consumo de energia e a prática da agricultura irrigada. ITEM: Irrigação e Tecnologia Moderna, n.50, p.10-11, 2001.

RAJU, K.S.; KUMAR, D.N. Multicriterion decision making in irrigation planning. Agricultural Systems, v.62, p. 117-129, 1999.

REILLY, F.K. Investment analysis and portfolio management. Orlando: Dryden Press, 1994. 792p.

REIS, J.N.P.; PONGIBOVE, A.P. Planejamento agropecuário em condições de risco: um estudo de caso por meio de um modelo de programação linear, em Minas Gerais. Revista de Economia e Sociologia Rural, v.35, n.2, p.74-94, abr.jun. 1997.

REZENDE, F.C.; FRIZZONE, J.A.; BOTREL, T.A. Otimização dos parâmetros de projeto de um sistema de irrigação por sulcos: II - análise da sensibilidade ao custo da água, da mão-de-obra e das estruturas hidráulicas. Engenharia Rural, v.3, n.2, p.32-49, dez. 1992. 
REZENDE, R.; CARDOSO, C.O.; GONÇALVES, A.C.A.; PERES, F.C.; FRIZZONE, J.A.; FOLEGATTI, M.V. Viabilidade econômica da irrigação complementar na cultura de citros na região noroeste do estado do Paraná. Acta Scientiarum, v.21, n.3, p.591-598, 1999.

RODRIGUEZ, F. Custos e benefícios da irrigação no Brasil. ITEM: Irrigação e Tecnologia Moderna, n.41, p.6-11, 1990.

SCALOPPI, E.J. Exigências de energia para irrigação. ITEM: Irrigação e Tecnologia Moderna, n.21, p.13-17, 1985.

SETTI, A.A. Legislação para o uso dos recursos hídricos. In: SILVA, D.D.; PRUSKI, F.F. Gestão de recursos hídricos: aspectos legais, econômicos, administrativos e sociais. Brasília: Secretaria de Recursos hídricos; Viçosa: Universidade Federal de Viçosa; Porto Alegre: Associação Brasileira de Recursos Hídricos, 2000. cap. 2 p.121-412.

SIEGEL, S. Estatística não-paramétrica. São Paulo: Mc-Graw Hill do Brasil, 1975. 350p.

SILVA, A.L.; FARIA, M.A.; REIS, R.P. Viabilidade técnico econômica do uso do sistema de irrigação por gotejamento na cultura do cafeeiro. Revista Brasileira de Engenharia Agrícola e Ambiental, v.7, n.1, p.34-74, 2003.

SILVA NETO, B.; STULP, V.J. A consideração de tendências na otimização de sistemas de produção agropecuária sob condições de risco. Revista de Economia e Sociologia Rural, v.38, n.3, p. 61-80, 2000. 
SOARES, J.M.; VIEIRA, V.J.S.; GOMES JÚNIOR, W.F.; ARAÚJO FILHO, A.A. Agrovale, uma experiência de 25 anos em irrigação da cana-de-açúcar na região do Submédio São Francisco. ITEM: Irrigação e Tecnologia Moderna, n.60, p.55-64, 2003.

SOCIEDADE DE OLERICULTURA BRASILEIRA. Cotação de preços. http://www.horticiencia.com.br/cotacoes/default.asp (23 ago. 2004)

SOUSA, S.A.V. Programa computacional para simulação da ocorrência de veranicos e queda de produção. Piracicaba, 1999. 124p. Tese (Doutorado) - Escola Superior de Agricultura “Luiz de Queiroz”, Universidade de São Paulo.

SOUZA, J.L.M Modelo para análise de risco econômico aplicado ao planejamento de projetos de irrigação para cultura do cafeeiro. Piracicaba, 2001. 253p. Tese (Doutorado) - Escola Superior de Agricultura “Luiz de Queiroz”, Universidade de São Paulo.

SOUZA, J.L.M.; FRIZZONE, J.A. Modelo aplicado ao planejamento da cafeicultura irrigada. I. simulação do balanço hídrico e do custo com água. Acta Scientiarum: Agronomy, v.25, n.1, p.103-112, 2003a.

SOUZA, J.L.M.; FRIZZONE, J.A. Modelo aplicado ao planejamento da cafeicultura irrigada. II. Preço e opção de venda da saca de café beneficiado. Acta Scientiarum: Agronomy, v.25, n.1, p.113-118, 2003b.

SRIVASTAVA, R.C.; VERMA, H.C.; MOHANTY, S.; PATTANAIK, S.K. Investment decision model for drip irrigation system. Irrigation Science, v.22, n.2, p.79-5, Set. 2003. 
STONE, L.F.; SILVEIRA, P.M.S. Determinação da evapotranspiração para fins de irrigação. Brasília: Ministério da Agricultura, do Abastecimento e da Reforma Agrária; Goiânia: EMBRAPA, Centro Nacional de Pesquisa de Arroz e Feijão (CNPAF), 1995. 49p.

TURCO, J.E.P.; FERNANDES, E.J. Determinação da acurácia de instrumentos de medidas para obter a evapotranspiração de referência pelo método de PenmanMonteith. Engenharia Agrícola, v.23, n.2, p.243-249, maio/ago. 2003.

TURRA, F.E. Análise de diferentes métodos de cálculo de custos de produção na agricultura brasileira. Piracicaba, 1990. 134p. Dissertação (Mestrado) - Escola Superior de Agricultura “Luiz de Queiroz” Universidade de São Paulo.

VAN LIER, Q.J.; DOURADO NETO, D. Balanço hídrico para culturas anuais e perenes: software aplicativo. Piracicaba: ESALQ, 1991. 190p.

WREGE, M.S.; GONÇALVES, S.L.; CARAMORI, P.H.; VASCONCELLOS, M.E.C.; OLIVEIRA, D.; ABUCARUB NETO, M. BORROZZINO, E.; CAVIGLIONE, J.H. Risco de deficiência hídrica na cultura do milho no Estado do Paraná. Pesquisa Agropecuária Brasileira, v.34, n.7, p.1119-1124, jul. 1999.

ZOCOLER, J.L. Análise econômica de sistemas de irrigação. In: MIRANDA, J.H.; PIRES, R.C.M. Irrigação. Jaboticabal: Funep, 2003. p.653-703 (Série Engenharia Agrícola, 2). 